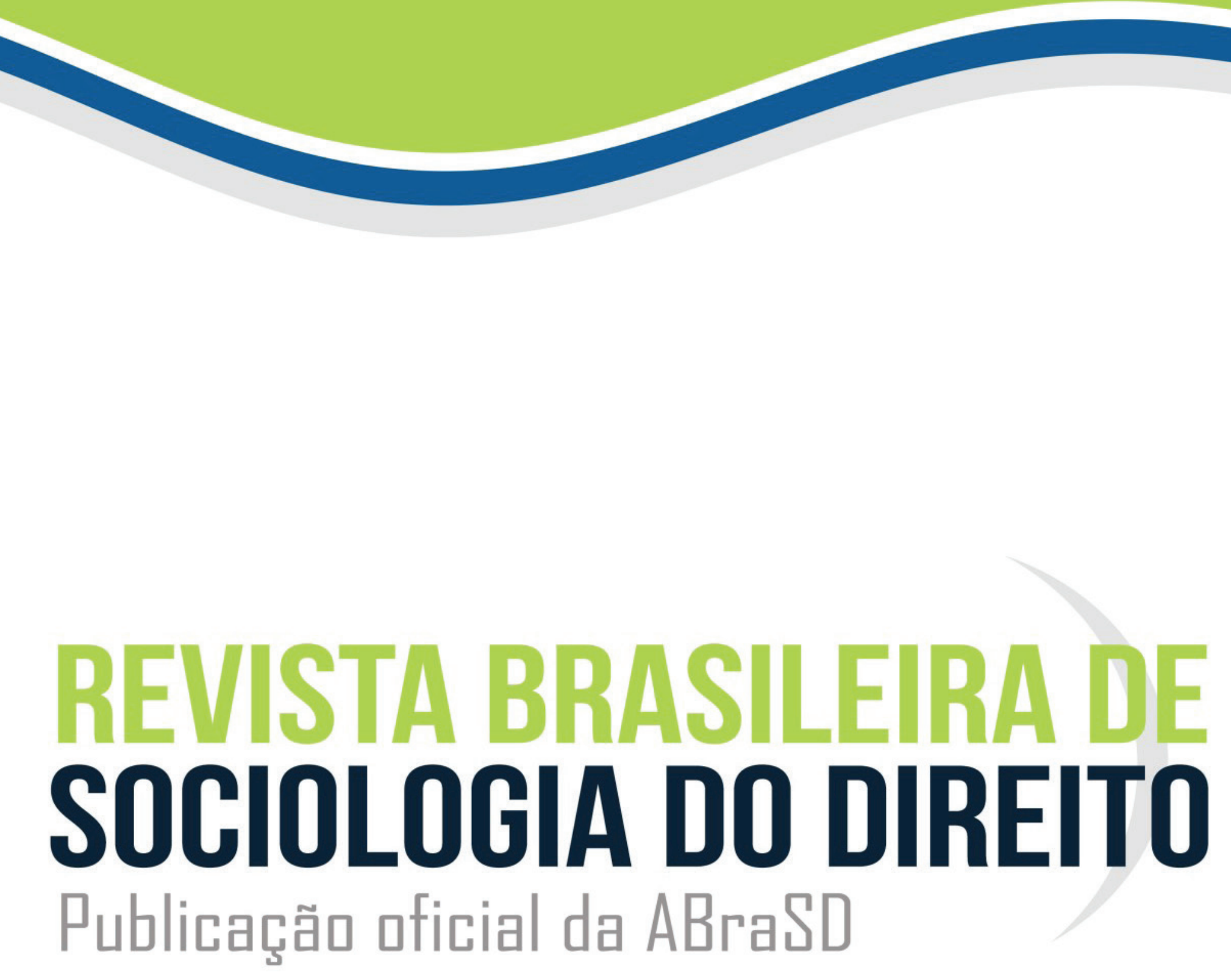


(ISSN 2359-5582)

VOLUME 2, NÚMERO 2

\section{DIRETORIA DA ABraSD}

Presidente:

Artur Stamford da Silva (UFPE-PE)

Primeiro Vice-Presidente:

Marcelo Pereira de Mello (UFF-RJ)

Segundo Vice-Presidente:

Fernando Rister de Sousa Lima (UNITOLEDO-SP)

\section{CONSELHO DELIBERATIVO}

Antônio Brasil (UFRJ-RJ)

Juliana Neuenschwander Magalhães (IFRJ-RJ)

Leonel Severo Rocha (UNISINOS-RS)

Olga Jubert Krell (UFAL-AL)

Quenya Correa de Paula (FDV)

\section{CONSELHO FISCAL}

Germano Schwartz (UNILASSALE-RS)

José Antônio Callegari (UFF-RJ)

João Paulo Allain Teixeira (UFPE/UNICAP-PE) 


\section{CORPO EDITORIAL}

REVISTA BRASILEIRA DE SOCIOLOGIA DO DIREITO

Adelia Miglievich-Ribeiro (UFES)

Alberto Febbrajo (University of Macerata)

Andreas Philippoulos-Mihalopoulos (University of Westminster)

André-Jean Arnaud (CNRS-França)

Artur Stamford da Silva (UFPE)

Arvind Agrawal (University of Rajasthan)

Carlos Lista (Universidad Nacional de Córdoba)

Celso Fernandes Campilongo (PUC-SP, USP)

Clarice von Oertzen de Araújo (PUC-SP)

Cláudio Souto (UFPE)

Dalmir Lopes Junior (UFF)

Dani Rudnick (UniRitter)

Daniel Barile da Silveira (UNITOLEDO, Araçatuba)

Darío Rodrigues Mansilla (Pontificia Universidad Catolica del Chile)

David Nelken (University of Macerata/Cardiff Law School)

Delton Soares Meirelles (UFF)

Ferdinando Spina (UNISALENTO)

Fernanda Busanello Ferreira (UFGO)

Fernanda Fonseca Rosenblatt (UNICAP)

Fernanda Frizzo Bragato (UNISINOS)

Fernando Rister de Sousa Lima (UNITOLEDO, Araçatuba)

Francisco Ilídio Ferreira Rocha (Uniaraxá)

Guilherme Azevedo (UNISINOS)

Guilherme Leite Gonçalves (FGV-RJ)

Gustavo Ferreira Santos (UNICAP e UFPE)

Henrique Garbellini Carnio (FADISP)

Igor Suzano Machado (UFV)

João Paulo Allain Teixeira (UNICAP e UFPE)

José Antonio Callegari (UFF)

José Roberto Xavier (UFRJ)

José Ribas Vieira (PUC-RJ)

Joxerramon Bengoetxea (Universidad del País Vasco)

Juliana Neuenschwander Magalhães (UFRJ)

Leonel Severo Rocha (UNISINOS)

Lucca Pantaleo (University of Luxembourg)

Luigi Cominelli (University of Milan)

Mara Regina de Oliveira (USP, PUC-SP)

Marcelo Galuppo (PUC-MG)

Marcelo Neves (UNB)

Márcio Pugliesi (PUC-SP)

Marco Aurélio Florêncio Filho (Mackenzie)

Marilia Montenegro Pessoa de Mello (UNICAP,UFPE)

Mauro Gaglietti (IMED)

Michael King (University of Reading) 
Olga Jubert Gouveia Krell (UFAL)

Orlando Villas Boas Filho (USP, Mackenzie)

Pierre Guibentif (ISCTE/Portugal)

Raquel Fabiana Lopes Sparemberger (UFRGS)

Renata Almeida da Costa (UNILASALLE)

Ricardo Tinôco de Góes (UFRN)

Rodrigo Azevedo (PUC-RS)

Ronaldo Porto Macedo Junior (USP, FGV-SP)

Salo de Carvalho (UFRGS)

Sandra Regina Vial (Unisinos)

Sol Picciotto (Instituto Internacional de Sociologia Jurídica Oñati)

Susana Henriques da Costa (USP)

Virgínia Leal (UFPE)

Vittorio Olgiati (University of Macerata)

Wanda Capeller (Université de Toulouse)

Willis Santiago Guerra Filho (PUC-SP, UNIRIO)

COMISSÃO EDITORIAL-EXECUTIVA

\section{EDITOR-CHEFE}

Fernando Rister de Sousa Lima (UNITOLEDO, Araçatuba-SP)

\section{EDITORES-ADJUNTOS}

Fernanda Busanelo Ferreira (GO)

José Antônio Callegari (RJ)

Marcelo Pereira Mello (RJ) 


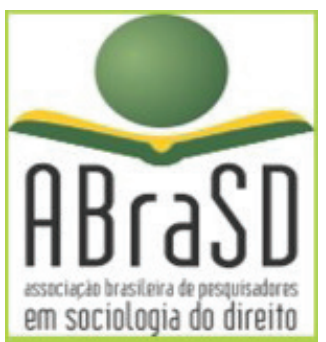

\section{NORMAS PARA PUBLICAÇÃO DE ARTIGOS}

Disciplina as normas para publicação de artigos na Revista Brasileira de Sociologia do Direito - publicação oficial da Associação Brasileira de Pesquisadores em Sociologia do Direito - ABraSD

\section{SUBMISSÃO DE ARTIGOS}

Os artigos deverão ser enviados para o seguinte endereço eletrônico: revista@ abrasd.com.br

\section{REGRAS BÁSICAS}

- Os artigos enviados deverão: (i) ser inéditos no Brasil, (ii) representar, obrigatoriamente, pesquisa desenvolvida pelo autor e (iii) apresentar problema de pesquisa devidamente definido.

- Não serão aceitos textos meramente descritivos sem pretensão de cientificidade.

- Os artigos serão submetidos a pareceres peer double blind review.

- A aceitação final dos artigos dependerá de recomendação de aprovação dos pareceristas.

- Em caso de aprovação condicionada à recomendação de ajustes, o artigo será enviado ao autor para reformulação no prazo indicado. A devolução em prazo superior ao indicado implicará publicação em edição futura. Não será publicado o artigo devolvido com erros substanciais que impossibilitem a aceitação.

- Os membros do conselho editorial poderão indicar professores de relevância na Sociologia do Direito para publicarem como convidados. Essas indicações não poderão ultrapassar o percentual de $20 \%$ da publicação anual da revista.

- Os artigos deverão ser entregues preferencialmente em português, admitido o envio em espanhol, francês, inglês ou italiano.

- O conteúdo dos artigos é de responsabilidade exclusiva de seus autores.

- Não se aceitará mais de um artigo por candidato para a mesma edição da revista.

\section{FORMATAÇÃO}

\subsection{Geral}

- Arquivo com extensão “.doc” ou outra compatível com o editor de textos Microsoft Word.

- Número de páginas: de 15 a 20 páginas, incluída a lista de referências.

- Folhas de formato A4.

- Redação do texto principal em fonte Arial, tamanho 12, com espaçamento 1,5 entre as linhas.

- Margens: superior e esquerda de $3 \mathrm{~cm}$; inferior e direita de $2 \mathrm{~cm}$. 


\subsection{Conteúdo}

- Título e subtítulo (quando houver) - fonte Arial, tamanho 12, em caixa alta, negrito e alinhamento à esquerda. Importante: Agradecimentos e referências à agência de fomento devem ser mencionados em nota de rodapé, inserida no fim do título do artigo.

- Nome(s) do(s) autor(es) - fonte Arial, tamanho 12, dois espaços abaixo do título, alinhado(s) à margem direita. Importante: A qualificação e a instituição do(s) autor(es) devem ser apresentadas, igualmente, em nota de rodapé, logo após o nome do(s) respectivo(s) autor(es).

- Resumo em português - texto contínuo de até 200 palavras. Especificações: fonte Arial, tamanho 12, dois espaços após o(s) nome(s) do(s) autor(es), espaçamento simples entre as linhas. $\mathrm{O}$ alinhamento deve ser justificado em ambas as margens.

- Palavras-chaves (entre 3 e 5) - fonte Arial, tamanho 12, logo abaixo do Resumo. Alinhamento justificado em ambas as margens.

- Abstract e keywords - seguem a mesma formatação do Resumo em português.

- O texto do artigo deve compreender: introdução, desenvolvimento, discussão e resultados, e as referências. Importante: Citações deverão ser feitas em sistema de nota de rodapé (citação numérica).

- INTRODUÇÃO ou título e subtítulo (se houver): fonte Arial, tamanho 12. Especificações: caixa alta, alinhamento justificado, fonte Arial, tamanho 12, espaçamento 1,5 entre as linhas. Importante: a Introdução recebe a numeração "1" (Exemplo: 1 INTRODUÇÃO)

- Desenvolvimento: Sequência dos capítulos e respectivos títulos. Especificações: negrito, caixa alta, alinhamento justificado, fonte Arial, tamanho 12, espaçamento 1,5 entre as linhas.

- Discussão e Resultados: é o último capítulo - a conclusão do artigo

- Referências - lista (em ordem alfabética) das obras efetivamente citadas no artigo. As referências seguem as regras da Norma ABNT NBR 6023 - "Informação e Documentação - Referências - Elaboração".

3.3 Referências (citação numérica): alguns exemplos

Livro $=$ SOBRENOME, Nome(s) do(s) autor(es). Título do livro (em itálico). Cidade: editora, ano, página(s) consultada(s).

Ex.: SOUTO, Cláudio. Sociologia do direito: teoria substantiva. Recife: ABraSD, 2014.

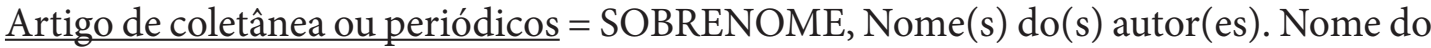
artigo. Nome do organizador (Org.), Título do livro ou periódico (em itálico). Cidade: editora, ano, página(s) do artigo consultado.

Ex.: SILVA, Armindo Costa. Direito na sociedade brasileira: leituras nacionais. MIRANDA, Rosa (Org.). Sociologia do direito. Rio de Janeiro: UFIXD, 2000, p. 13-27. Texto de internet $=$ SOBRENOME, Nome(s) do(s) autor(es). Título do artigo (em itálico). Disponível em: <http://www.abrasd.com.br/revista1>. Acesso em: 08 mar. 2015, p. 1-14.

Ex.: BERTRIL, Cláudio Augusto. Direito e sociedade na atualidade. Disponível em: $<$ http://www.abrasd.com.br/revista1>. Acesso em: 20 jan. 2015, p. 1-14. 


\section{SUMÁRIO}

FERNANDO RISTER DE SOUSA LIMA

APRESENTAÇÃO

1 DOUTRINA SOCIOJURÍDICA

1.1 Teoria sociojurídica internacional

DARÍO RODRÍGUEZ M. e ARTUR STAMFORD DA SILVA

Como sociólogo se puede hacer de todo,

sin quedar encasillado en un ámbito temático

MARIO S. GERLERO

Inclusión del "modelo complejo" en la Sociología Jurídica reflexiva

1.2 Teoria sociojurídica nacional 50

JONATHAN HERNANDES MARCANTONIO

O desenvolvimento do Estado moderno:

conflito entre garantias inovadoras e formas tradicionais

ORLANDO VILLAS BÔAS FILHO

A juridicização e a judiciarização enfocadas

a partir da "Sociologia Política do Direito". de Jacques Commaille 56

2 PESQUISAS SOCIOJURÍDICAS

2.1 Sociologia constitucional.

DANIEL BARILE DA SILVEIRA

Entre políticos, bacharéis, coronéis e juízes da República Velha: as práticas

jurídicas e a tradição patrimonialista na formação do Estado brasileiro.

LUÍS FELIPE PERDIGÃO DE CASTRO

Agricultura familiar, habitus e acesso à terra

2.2 Poder Judiciário

ANA CAROLINA CINOCA PIOVAN

Acesso à justiça e direito à moradia: uma crítica à atuação do Judiciário nos

processos de reintegração de posse no centro da cidade de São Paulo 106

PAULA DECONTO

A judicialização e a crise de autoridade nas demandas que versam sobre

o aborto preventivo no Tribunal de Justiça do Rio Grande do Sul 
2.3 Teoria dos Sistemas

DOUGLAS ELMAUER

Direito global e responsividade: uma abordagem crítico-sistêmica do direito

em face dos novos desafios da sociedade mundial

LUCAS FUCCI AMATO

Direitos humanos e sistema econômico:

estrutura e semântica de um fragmento constitucional global 


\section{APRESENTAÇÃO}

Apresenta-se o Volume 2 - Número 2 da Revista Brasileira de Sociologia do Direito (RBSD). Ao todo, são quatro exemplares que materializam as aspirações da comunidade sociojurídica em sistematizar, em um periódico, parte da pesquisa produzida no Brasil e, além disso, travar o necessário e profícuo diálogo com pesquisadores estrangeiros por meio da publicação de suas respectivas pesquisas, as quais, desde a primeira edição, têm sido amplamente divulgadas no periódico - vale registrar.

Com a publicação deste exemplar, nota-se, claramente, que é possível identificar uma agenda contemporânea da Sociologia do Direito. Neste sentido, apresenta-se a presente edição, que se encontra dividida em duas partes.

A primeira parte, tradicionalmente, aloca a teoria internacional sociojurídica, representada pelos trabalhos de Darío Rodríguez Mansilla, professor titular da Universidad Diego Portales (Chile), em coautoria com o professor doutor Artur Stanford da Silva, da Faculdade de Direito da Universidade Federal de Pernambuco (UFPE), cujo artigo, intitulado "Como sociólogo se puede hacer de todo, sin quedar encasillado en un ámbito temático", reconstrói o percurso intelectual de Niklas Luhmann para forjar a sua teoria dos sistemas como sistema comunicacional. Como parte da metodologia de pesquisa, apontam textos que Luhmann publicou nas décadas de 1960 e 1970, a fim de ilustrar a sua utilização de aportes teóricos oriundos de outros ramos do saber, como a teoria biológica dos chilenos Maturama e Varela, a lógica de Spencer Brown e, claro, agora na Sociologia, a teoria dos sistemas de Talcolt Parsons, seu professor em Havard. O texto do professor argentino, Mario Gerlero, complementa o espaço destinado aos pesquisadores estrangeiros no periódico, com a apresentação da sua proposta de uma sociologia jurídica reflexiva, centrada na recapacitação da referida disciplina, com base nos movimentos sociais e culturais sob um plano de estudo em processos de investigação de casos práticos. Dessa forma, com esteio em aportes teóricos e fenômenos sociais, poder-se-á proporcionar autonomia à sociologia reflexiva, o que permitiria resgatar o direito como (i) instrumento; (ii) legitimação; (iii) estruturação dos direitos, em especial dos direitos humanos.

A seção destinada à teoria sociojurídica nacional publica dois trabalhos de docentes da Universidade de São Paulo (USP). O primeiro, de autoria do professor doutor Jonathan Hernandes Marcantonio da Faculdade de Ribeirão Preto (SP), discute os valores que consagraram o Estado moderno, como as ideias iluministas, direitos subjetivos e objetivos, a resultar em premissas tipicamente individualistas, para defender a necessidade de sua revisão conceitual com as lentes de parâmetros mais ligados à sociedade atual. No segundo texto, o professor doutor Orlando Villas Bôas Filho do Largo de São Francisco, com propriedade, apresenta à comunidade sociojurídica brasileira a sociologia política do Direito de Jaques Commaille, de modo a destacar que o Direito não pode ser compreendido independentemente do exercício do Poder Público e de todo o contexto específico de atos e relações sociais em interlocução com as demais teorias sociais. Seu ideário denota, por esse contexto, um forte aceno interdisciplinar à pesquisa jurídica. Antes, porém, Villas Bôas, de forma muito clara, explicita as diferenças entre a Dogmática Jurídica, a Teoria do Direito e a Sociologia Jurídica com o mote de contextualizar nesse debate a teoria sociológica apresentada no 
seu estudo.

A segunda parte da edição é focada na divulgação de pesquisas desenvolvidas por jovens pesquisadores da Sociologia Jurídica, seja de natureza institucional, seja de natureza individual, com destaque para as financiadas por agências de fomento. O total de seis pesquisas jurídicas aqui publicadas bem demonstra a força da Revista - como braço da $\mathrm{ABraSD}$ - em aglutinar pesquisas jurídicas e, sobretudo, fomentar a pesquisa sociojurídica brasileira, dando espaço e visibilidade à produção científica.

As pesquisas sociojurídicas foram divididas em três subpartes, com a primeira destinada a publicar dois textos com enfoque na Sociologia da Constituição, sendo o primeiro do doutor em Direito pela Universidade de Brasília (UNB) Daniel Barile da Silveira e o segundo de autoria do mestre em Agronegócio radicado em Luziânia (GO), Luis Felipe Perdigão de Castro. A segunda subparte traz artigos com objetos de pesquisa voltados ao Poder Judiciário, precisamente os trabalhos de Ana Carolina Cinoca Piovan (SP) e Paula Deconto (RS). Por fim, a terceira subparte (2.3) apresenta uma seção especial sobre teoria dos sistemas, com os textos de Douglas Elmauer, doutorando na Universität Bremen, Alemanha, bolsista DAAD (Deutsher Akademischer Austauschdienst), e de Luccas Fucci Amato, atualmente visiting researcher na Harvard Law School, que contou com apoio da Fundação de Apoio à Pesquisa do Estado de São Paulo (Fadesp) na pesquisa, num texto com enfoque nos direitos humanos.

Agradece-se à Presidência da Associação Brasileira de Pesquisadores em Sociologia do Direito (ABraSD) pela indicação para a função de Editor-chefe, nominalmente ao então Presidente, o professor doutor Marcelo Pereira Mello e ao atual Presidente, o professor doutor Artur Stamford da Silva, função esta que encerro com este número, mas, não sem consignar os meus efusivos votos de que os próximos editores possam levar adiante este auspicioso projeto de publicar a Revista Brasileira de Sociologia do Direito (RBSD) com zelo e, sobretudo, preocupação com o papel histórico que poderá ou não ser outorgado ao periódico.

Ademais, a Revista não teria vindo à luz com a qualidade apresentada sem a participação da professora Sueli Aragão e do jornalista Caio Carvalho, cuja capacidade e comprometimento com o projeto foram decisivos na revisão e na formatação de todos os exemplares até então publicados. Agradece-se, por fim, aos professores José Antônio Callegari (RJ), Fernanda Busanelo Ferreira (GO) e Marcelo Pereira Mello (RJ), pelo importante auxílio que prestaram na editoração deste volume na condição de editoresadjuntos.

Obrigado! Saudações acadêmicas!

\author{
Fernando Rister de Sousa Lima \\ Editor-chefe (2013-2016)
}




\section{DOUTRINA SOCIOJURÍDICA}




\title{
COMO SOCIÓLOGO SE PUEDE HACER DE TODO, SIN QUEDAR ENCASILLADO EN UN ÁMBITO TEMÁTICO
}

\author{
AS A SOCIOLOGIST YOU CAN DO EVERYTHING \\ WITHOUT BEING CLASSIFIED IN A SUBJECT AREA
}

Darío Rodríguez M. ${ }^{\mathrm{i}}$ Artur Stamford da Silva ${ }^{\text {ii }}$

Resumen: Introducción. I Ilustración sociológica. II Sistemas sociales. III La sociedad de la sociedad. IV Conclusión. Referencias.

\begin{abstract}
Resumen
Escribir la trayectoria intelectual de Niklas Luhmann es aclarar puntos centrales de una teoría de la sociedad que no tiene clasificación en términos de los modelos teóricos da sociología actual. Así es porque Luhmann no transfiere ideas de autores y teorías a su teoría de la sociedad, pero sí las reformula y revisita para darles lugar en su teoría de la sociedad como sistema de comunicación. Con esto objetivo, presentamos cómo ha sido posible a Luhmann producir la teoría de la sociedad pautada por las novedades de la teoría de sistemas de los años 60.Escribir la trayectoria intelectual de Niklas Luhmann es aclarar puntos centrales de una teoría de la so-
\end{abstract}




\subsection{TEORIA SOCIOJURÍDICA INTERNACIONAL}

ciedad que no tiene clasificación en términos de los modelos teóricos da sociología actual. Así es porque Luhmann no transfiere ideas de autores y teorías a su teoría de la sociedad, pero sí las reformula y revisita para darles lugar en su teoría de la sociedad como sistema de comunicación. Con esto objetivo, presentamos cómo ha sido posible a Luhmann producir la teoría de la sociedad pautada por las novedades de la teoría de sistemas de los años 60.

Palabras claves: Teoría de la sociedad. Niklas Luhmann. Sociedad de la sociedad. Teoría de sistemas.

\begin{abstract}
Write the intellectual history of Niklas Luhmann is to clarify key points of a theory of society that has no classification in terms of current sociological theoretic models. Is was possible because Luhmann does not transferred the authors ideas and theories to his theory of society, but Luhmann reformulates and revisits this ideas for give place in his theory of society as a communication system. With this aim, we present how it has been possible to produce Luhmann's theory of society grounded in developments of the theory of systems of the 60s.
\end{abstract}

Keywords: Theory of society. Niklas Luhmann. Systems theory.

\section{INTRODUCTION}

A comienzos de la década de los 1960s, la sociología parecía haber perdido creatividad. El trabajo académico se reducía casi exclusivamente al análisis exegético de los clásicos, cuando no era simple y pura ideología. El desarrollo teórico de Talcott Parsons era duramente criticado tanto por los exégetas, que lo acusaban de haber mal interpretado a los fundadores, como por los ideólogos, que lo tachaban de conservador. La teoría crítica era una opción ideológicamente más atractiva para la sensibilidad intelectual de la época. Este aburrido escenario iba a ser remecido por una polémica que marcó la segunda mitad del siglo veinte. El año 1971 es publicado el libro que inaugura la discusión más importante que haya tenido la disciplina, cuyos interlocutores, Jürgen Habermas y Niklas Luhmann, al polemizar generan las bases de la sociología del siglo veintiuno.

Pocos años antes, en 1968, Niklas Luhmann había sido convocado a formar parte de la recientemente creada Universidad de Bielefeld, eligiendo asumir la cátedra de sociología porque pensaba que "como sociólogo se puede hacer de todo, sin quedar encasillado en ningún ámbito determinado" ${ }^{\text {. }}$.

La frase revela una amplia variedad de intereses que, en el curso del tiempo, se expresó en más de cuarenta libros sobre economía, derecho, Estado, arte, amor, pedagogía, familia, religión, ciencia, diferenciación social, riesgo, etc. El propósito que une esta diversidad es desarrollar una teoría universal, un sistema de pensamiento capaz de comprender la complejidad de la moderna sociedad mundial. Luhmann construye un sistema conceptual nuevo, porque su objeto también lo es: Nunca hubo una sociedad como ésta y por eso no es posible entenderla con conceptos heredados de otras épocas. Los conceptos necesarios para este ambicioso proyecto fueron siendo cuidadosamente escogidos desde muchas vertientes de la ciencia contemporánea. La teoría del sistema social de Talcott Parsons, la teoría biológica de los sistemas autopoiéticos 


\subsection{TEORIA SOCIOJURÍDICA INTERNACIONAL}

desarrollada en Chile por Humberto Maturana y Francisco Varela, la lógica de la forma de George Spencer Brown, la psicología de la percepción de Fritz Heider, la cibernética de W.R. Ashby, la teoría de la información de Gregory Bateson, etc. aportaron distinciones que debieron ser redefinidas para integrarlas a la arquitectura de una teoría sociológica que ve la luz el año 1984, con la publicación de "Sistemas sociales", libro que presenta un marco teórico adecuado para observar toda clase de fenómenos sociales, desde un corto diálogo entre desconocidos hasta la sociedad mundial. Pero Luhmann no se dio por satisfecho con haber generado una teoría de los sistemas sociales; la aplicó al estudio de la sociedad moderna, y a cada uno de los sistemas funcionales que la componen, en los textos mencionados más arriba. En 1997 publica "La sociedad de la sociedad" obra en que expone su teoría de la sociedad. El año 2000 aparece "Organización y Decisión”, con una inédita teoría de las organizaciones que revolucionará ese campo de estudios interdisciplinarios y durante mucho tiempo, después de la muerte de Luhmann acaecida en 1998, continuaron siendo editados otros volúmenes con textos que quedaron en distintos grados de elaboración.

El esfuerzo de Luhmann ha sido plenamente reconocido. Robert Spaemann, para únicamente citar un ilustre ejemplo, sostiene que la teoría de sistemas de Luhmann solo es comparable a la filosofía de Hegel. ${ }^{2}$ Su vasta obra ha sido traducida, entre otros idiomas, al italiano, español, inglés, francés, portugués, japonés, chino, ruso, croata y eslovaco. La absoluta falta de dogmatismo que la caracteriza ha permitido que surjan de ella diversos enfoques teóricos, tales como los de Helmut Willke, Rudolf Stichweh, Dirk Baecker, Elena Esposito, Raffaele Di Georgi, Giancarlo Corsi, Marcelo Neves, Gunther Teubner, Alberto Febbrajo, Andrea Pitasi y Aldo Mascareño, por mencionar solo algunos de los numerosos programas de investigación académica que reconocen haberse nutrido de esa fuente, aunque sigan derivas diferentes, dando así testimonio de la vi- gencia, en el siglo veintiuno, del pensamiento del gran teórico del siglo veinte.

En las páginas que siguen se intenta describir, de la manera más simple posible, el desarrollo del edificio conceptual con el que Luhmann abordó las diversas expresiones del fenómeno social en la modernidad. En este largo proceso de construcción teórica, llama la atención la coherencia con que se fueron agregando nuevos conceptos y que, pese a que muchos de ellos no provienen de la tradición sociológica, su paulatina incorporación no significó cambiar el esquema inicial ni tampoco modificó el programa de investigación anunciado en los primeros trabajos. El proyecto académico que había de ocupar la vida de Niklas Luhmann parece haber definido su meta muy temprano ya que, en la primera página de Die Gesellschaft der Gesellschaft, obra aparecida en 1997, el autor recuerda que, al iniciar su trabajo académico en la Universidad de Bielefeld, debió indicar el proyecto de investigación que realizaría y que su respuesta fue: Teoría de la sociedad; tiempo estimado, 30 años; costos, ninguno. ${ }^{3}$ Es probable que esta temprana decisión haya sido determinante para la coherencia de la obra, así como también es posible entender toda la enorme producción de libros y artículos en términos de una sola gran obra: el desarrollo de la teoría de la sociedad moderna. Desde esta perspectiva, numerosos artículos se orientan a consideraciones metodológicas y teóricas, otros estudian aspectos centrales de subsistemas de la sociedad, otros refieren investigaciones históricas sobre la evolución de algunos de estos subsistemas, otros exploran el modo de operar de ciertos mecanismos de la sociedad. La variedad temática es inmensa porque su unidad de análisis también lo es. La sociedad es el sistema social que comprende todas las comunicaciones posibles y, por consecuencia, no hay elemento social alguno fuera de ella.

Dada la extensión y coherencia de la obra, hemos optado por seguir un orden histórico en la presentación de su desarrollo. Solo para facilitar la lectura, hemos dividido esta exposición

${ }^{2}$ SPAEMANN, R. Laudatio anlässlich der Verleihung des Hegel-Preises 1989: Niklas Luhmanns Herausforderung der Philosophie. In: LUHMANN, N. Luhmann. Paradigm lost: Über die ethische reflexion der moral. Frankfurt am Main: Suhrkamp, 1990. p. 62.

${ }^{3}$ LUHMANN, N. Die gesellschaft der gesellschaft. Frankfurt am Main: Suhrkamp, 1997. p. 11. 


\subsection{TEORIA SOCIOJURÍDICA INTERNACIONAL}

bajo tres encabezados que corresponden a libros significativos en la obra del pensador alemán: "Ilustración sociológica", "Sistemas sociales" y "La sociedad de la sociedad". Podríamos decir que representan etapas de un proceso acumulativo, pero no constituyen puntos de quiebre en el pensamiento ni momentos de bifurcación en su desarrollo.

\section{ILUSTRACIÓN SOCIOLÓGICA}

El año 1970, Niklas Luhmann publica una colección de ensayos que habían venido apareciendo desde 1962 en distintas revistas. El título de esta compilación fue "Ilustración sociológica" y dio origen a una serie de seis libros con el mismo nombre. Los trabajos contenidos en ese primer volumen de "Ilustración sociológica" demuestran estar inspirados por la idea de elaborar una teoría capaz de comprender una realidad social nueva sin recurrir a explicaciones hechas para dar cuenta de realidades sociales ya pasadas. Esto significa que el proyecto académico que habría de orientar toda la vida de Luhmann comienza a desarrollarse a su vuelta de Harvard, años antes de darlo a conocer de manera explícita en su respuesta a la solicitud de la Universidad de Bielefeld a la que nos referimos antes.

En el primero de esos ensayos, "Función y causalidad", que data de 1962, Luhmann se pregunta qué es lo que hace fascinante una explicación funcionalista como la que propone $\mathrm{Ma}-$ linowski al demostrar que los ritos ofrecen una solución social a situaciones aflictivas de supervivencia de una colectividad. Dice Luhmann que lo interesante de este modo de análisis reside en que hace comparables, desde una perspectiva abstracta, sistemas de explicación ideológicos, reacciones emocionales particulares colectivas o individuales y un sinnúmero de otras posibles salidas a una situación crítica. La abstracción de la perspectiva funcionalista permite abrir el ámbito de comparación, elevarlo sobre sus límites, para encontrar soluciones funcionalmente equivalentes. Aunque ya existe el concepto de equivalencia funcional, agrega, no se le ha dado el carácter de principio del método funcionalista y por eso se ha desaprovechado su enorme potencialidad. ${ }^{4}$

El segundo ensayo, "Método funcional y teoría de sistemas" (1964), insiste en que el sentido propio del método funcional consiste en racionalizar el planteamiento del problema a través de la construcción abstracta de posibilidades de comparación. ${ }^{5}$ Las perspectivas de comparación pueden ser elegidas de manera puramente lógica, pero esto podría conducir a seleccionarlas arbitrariamente, sin un adecuado fundamento teórico. Por eso, el método funcional ha de ser complementado con una teoría que defina con claridad dichas perspectivas de comparación. La teoría de los sistemas sociales concentra la clase de alternativas funcionalmente equivalentes disponibles como soluciones a los problemas, haciendo así posible la explicación y la predicción. La clase de posibilidades funcionalmente equivalentes se reduce al considerar que un sistema debe solucionar numerosos problemas y que lo hace construyendo estructuras. ${ }^{6}$

El 25 de enero de 1967, Niklas Luhmann dicta su clase inaugural en la Facultad de Derecho y Ciencias de la Administración Pública de la Universidad de Münster. Publicado como tercer artículo del libro, el tema de esa lección sirve como título para la compilación de ensayos: "Ilustración sociológica". Señala Luhmann que esta formulación es osada porque la ilustración y la sociología corresponden a distintas épocas históricas, la ilustración no se ocupó de los temas que luego habrían de ser tratados por la sociología y esta tampoco puede ser concebida como directa continuación del impulso ilustrado. Al disminuir el optimismo de la ilustración, la sociología se declara una ciencia escéptica que lleva adelante sus investigaciones según reglas metodológicas, las cuales no pueden hacerse totalmente responsables, sin embargo, de las consecuencias de su propio quehacer.

Pese a todo, el fundamento ilustrado de la sociología se hace notar con claridad en cuatro aspectos:

i. en el intento de explicar el comportamiento 


\subsection{TEORIA SOCIOJURÍDICA INTERNACIONAL}

humano mediante perspectivas incongruentes,

ii. en el problema de la latencia,

iii. en el paso de teorías de factores a teorías de sistemas, $y$

iv. en las peculiares dificultades del método funcional.

Todos estos son aspectos del enfrentamiento de la complejidad y aluden al problema oculto de la ilustración: cómo se pueden tratar cantidades excesivamente complejas de información. El mundo es extremadamente complejo y es muy poca la capacidad efectiva de atención del vivenciar y el actuar intencionales. La ilustración es el proceso histórico que se esfuerza por hacer accesibles al experimentar y al actuar, en términos de sentido, las posibilidades del mundo. La sociología asume una actitud crítica, husmea tras las fachadas oficiales y las desacredita. Se hace entonces visible la contingencia social del mundo. La latencia oculta aspectos relevantes de la acción para no perder capacidad motivadora. La represión de ciertas informaciones sería una autoprotección de los sistemas personales y sociales, necesaria para mantener constantes su propia identidad y estructura integradora en un mundo altamente complejo. La sociología no considera propio de sí mantener ocultos los aspectos latentes, sino denunciarlos como problemas sociales, comportamientos desviados $\mathrm{u}$ organización informal. Al pasar de teorías de factores a teorías de sistemas, la sociología adquiere mayor capacidad para tratar la complejidad; ya no descubre solo causas latentes, sino también funciones y estructuras latentes. No desenmascara representaciones como simple fachada embellecida de motivos oscuros, sino como selección incompleta y sobre-simplificadora de una realidad social mucho más compleja. El método funcional considera al mundo como horizonte extremadamente complejo de otras posibilidades y los sistemas sociales deben ser capaces de generar su propia complejidad, para comprender y reducir la complejidad del mundo y poder mantenerse en él. ${ }^{7}$

En esta clase inaugural, Luhmann da a conocer el programa de investigación cuyo desarrollo ocupará el resto de su vida. ${ }^{8}$ Consiste en elaborar una teoría capaz de comprender y reducir la complejidad. Para ello, será necesario hacer uso de las posibilidades comparativas del método funcional y rediseñar la teoría estructural-funcionalista como funcionalismo-estructural. De esta manera, la teoría se podrá referir al problema de la complejidad, desde la perspectiva de la función de estructuras y sistemas. El concepto ontológico de sistema definía a los sistemas como todos formados por partes, dirigiendo la atención hacia el interior del sistema cuya existencia se daba por supuesta; también consideraba dado el ordenamiento de las partes. Era preciso reemplazar el concepto de sistema de todo/partes por el concepto de sistema/entorno, que concibe a los sistemas como identidades complejas capaces de mantener su orden en un entorno extremadamente complejo, inabarcable y fluctuante. Al completar este cambio en la teoría de sistemas, se hace posible dejar de lado el supuesto del orden interno preexistente y reconocer la función que cumple la construcción de un sistema: esta es la comprensión y reducción de la complejidad del mundo. ${ }^{9}$

Los sistemas operan como intermediarios entre la complejidad indeterminada del mundo y el estrecho potencial de sentido de todo vivenciar y actuar. Según la "requisite variety law"10, todo sistema es menos complejo que su entorno y se relaciona con él reduciendo complejidad. La construcción de sistema define un límite respecto al entorno que permite que el sistema mantenga invariable su ordenamiento de complejidad reducida. Este orden interno y sus condiciones de mantención sirven como fundamento para desarrollar un bosquejo selectivo y simplificado del entorno que permite al sistema comportarse

\footnotetext{
${ }^{7}$ LUHMANN, N. Soziologische Aufklärung 1, p. 66-75.

${ }^{8}$ En su intervención en el coloquio en memoria de Luhmann que tuvo lugar en la Universidad de Bielefeld el 8 de diciembre de 1998, a dos días de la muerte de este, el profesor Franz-Xaver Kaufmann recuerda que, al escuchar esta clase inaugural, pensó que anunciaba un programa científico que, luego del desencantamiento del mundo por el pensamiento científico diagnosticado por Max Weber, ahora se proponía desencantar el pensamiento humano. KAUFMANN, F. X. Ein Wittgenstein'sches Schweigen. In: STICHWEH, R. Wirkungen eines theoretikers. Bielefeld: Transcript Verlag, 1998. p. 9-17.

${ }^{9}$ LUHMANN, N. Soziologische Aufklärung 1, p. 75.

${ }^{10}$ ASHBY, W. R. An introduction to cybernetics. New York: John Wiley \& Sons, 1958. p. 206-209.
} 


\subsection{TEORIA SOCIOJURÍDICA INTERNACIONAL}

significativamente en él.

De este modo, la complejidad indeterminada del mundo es convertida en problemas más exactamente especificables de automantenimiento. La problemática del mundo se traslada parcialmente desde afuera hacia adentro donde se puede resolver mejor, con métodos más rigurosos de procesamiento de la información. Este logro en complejidad reducida se alcanza al incrementar, mediante la construcción de sistema, la selectividad del actuar humano. A través de sistemas se coordinan actividades simultáneas o sucesivas de procesamiento de información, de manera que la selección de una de estas actividades refuerza la de otra. Se puede elegir entre pocas alternativas, dando por supuesto que en otras partes también se ha elegido o se elegirá, justificando así esta limitación de alternativas. Una elección presidencial, por ejemplo, se hace entre pocos candidatos que han sido seleccionados al interior de sus propios partidos. Esto demuestra que solo los sistemas, no el público que discute libremente, pueden servir como medios de la ilustración. El punto es importante, además, porque subraya la diferencia entre la Ilustración basada en la razón (siglo XVIII) y la ilustración sociológica. La ilustración sociológica no puede suponer que la reducción de complejidad se deba a una capacidad innata, a la razón. Tampoco puede estimar que esa capacidad se distribuya por igual entre todos los seres humanos. Finalmente tampoco basta con la libertad de discusión para ilustrar sociológicamente. Únicamente el aumento de la capacidad de comprensión y reducción de la complejidad sirve a la ilustración sociológica y ésta consiste en la capacidad de considerar muchas posibilidades desde el sentido - en relaciones que han de ser optimizadas entre la variedad social, la objetual y la escasez de tiempo - y, pese a ello, actuar rápidamente. También se trata de la presión temporal que genera el incremento de dichas interdependencias. Dado que no es posible modificar el reducido espacio de atención del vivenciar humano, el aumento de capacidad de comprensión y reducción de complejidad solo se puede realizar mediante la construcción de sistemas que aseguren que los procesos de elaboración de informaciones se produzcan en una coherencia de sentido que refuerce su selectividad. ${ }^{11}$

Las decisiones de usar esta nueva versión de la teoría de sistemas, entender el método funcional como esquema de comparación y redefinir al estructural-funcionalismo como funcional-estructuralismo permiten que Luhmann conecte su desarrollo teórico futuro con la teoría de sistemas de Talcott Parsons (Parsons 1964), el estructural funcionalismo de Merton $^{12} \mathrm{y}$ otros sociólogos estadounidenses de mediados del siglo XX. Una conexión teórica como ésta implica continuidad y ruptura. Continuidad, porque reconoce el trabajo adelantado previamente y se plantea interrogantes que acaso no habrían surgido sin aquél. Ruptura, porque propone una forma diferente de observación que supera las limitaciones del enfoque parsoniano.

El método funcional había sido utilizado en las ciencias sociales, pero no lograba dar una respuesta convincente a la antigua crítica de confundir función con causa y, por lo tanto, del riesgo de acudir a explicaciones teleológicas. Comte había percibido la dificultad y por eso había rechazado las explicaciones por causas finales. ${ }^{13}$ Durkheim también intentó hacer una diferencia tajante entre las causas y la función de un fenómeno social, proponiendo recurrir al análisis histórico para encontrar las causas y luego al método funcional para reconocer las funciones. ${ }^{14}$ Pese a todo, la crítica persiste, debido a la dificultad de distinguir entre las causas que originan un fenómeno y la función que lo hace necesario y que, por lo tanto, puede ser vista como causa de su permanencia. ${ }^{15}$ Luhmann considera que la equivalencia funcional es el principio mismo del método funcional con lo cual la función no es un efecto a producir, sino un esquema de sentido que organiza un ámbito de comparación en-

\footnotetext{
${ }^{11}$ LUHMANN, N. Soziologische Aufklärung 1, p. 76-77.

${ }^{12}$ MERTON, R. K. Teoría y estructura sociales. México: Fondo de Cultura Económica, 1965.

${ }^{13}$ COMTE, A. La física social. Madrid, Aguilar, 1981.

${ }^{14}$ DURKHEIM, E. De la división del trabajo social. Buenos Aires: Shapire, 1967.

${ }^{15}$ TURNER, J. H.; BEEGHLEY, L. The emergence of sociological theory. Homewood, Ill: Dorsey Press, 1981. p. 41.
} 


\subsection{TEORIA SOCIOJURÍDICA INTERNACIONAL}

tre variadas posibles causas equivalentes, desde la perspectiva de un cierto efecto problemático. ${ }^{16}$

De acuerdo a Luhmann, la teoría del sistema general de la acción de Parsons presenta dificultades al definir los sistemas por su mantenimiento de límites considerando, al mismo tiempo, que la sociedad es el sistema social continente. El estructural-funcionalismo de Parsons sostiene que todo sistema debe satisfacer cuatro funciones básicas que son sus prerrequisitos. La sola existencia de un sistema cualquiera implica haber satisfecho estos prerrequisitos. No hay cabida, entonces, para preguntar por la función que cumple la formación de sistema. Luhmann propone que la función de la construcción de sistemas es la reducción de complejidad y que la sociedad es el sistema social que, con sus límites, excluye la complejidad indeterminada, pre- estructurando con ello las posibilidades que puedan ser aprehendidas y realizadas en la sociedad. ${ }^{17}$

Si bien Luhmann asume la tarea teórica en discusión con la obra de Parsons, su perspectiva es muy diferente de la de éste. Radicalizar el método funcional y precisarlo como método de comparación deja fuera toda consideración ontológica. La teoría luhmanniana comienza desde la diferencia, no desde la identidad y, de manera consistente, cada nueva decisión conceptual agrega alguna distinción que permite observar un fenómeno en términos de su contraste con otras posibilidades. Aunque en el largo proceso de elaboración teórica se van incluyendo nuevos conceptos e incluso conglomerados conceptuales, la rigurosa observación de este principio hace que, pese a hacerse más compleja, la teoría mantenga su orientación sin desviarse. De esta manera, en el curso del tiempo, acoge conceptos de la teoría de Parsons, de la cibernética ${ }^{18}$, de la lógica formal ${ }^{19}$, de la biología ${ }^{20}$, etc., pero dándoles una definición coherente con su propia arquitectura teórica. Las nuevas distinciones son adecuadas para observar un fenómeno social también nuevo, la sociedad moderna, evitando que conceptos desarrollados en el pasado para observar antiguas realidades sociales obscurezcan en lugar de iluminar. También ésta es la misión de la ilustración sociológica.

Un concepto tomado de Parsons es el de doble contingencia. $\mathrm{Al}$ apropiarse de este concepto, Luhmann recurre a su sentido escolástico original y desde allí lo reconstruye, para que se ajuste a su teoría con exactitud. Algo es contingente cuando puede suceder o no. Es como es, pero podría haber sido de otra forma. Todo comportamiento humano es contingente y es preciso entenderlo como la selección de una alternativa entre otras posibilidades de acción. La consecuencia es que cuando se encuentran dos seres humanos, cada uno de ellos desconoce el modo en que va a actuar el otro y, al mismo tiempo, sabe que su respectivo otro tampoco sabe cómo va a actuar él. La doble contingencia, por lo tanto, es tanto un problema como una oportunidad para la generación de sistemas sociales. Un problema, porque plantea una situación abierta por ambos lados. La contingencia de cada uno es experimentada por este como libertad y disponibilidad de alternativas y la contingencia del respectivo otro es experimentada por cada cual como parte de la complejidad de su entorno que es necesario reducir. El otro se presenta como una caja negra con la cual hay que interactuar ajustando expectativas hasta lograr construir expectativas mutuamente referidas.

En esta misma época, se produce su famosa polémica con Jürgen Habermas que habría de sacudir el aletargado ambiente sociológico, proponiendo alternativas teóricas relevantes y modernas. El libro que contiene esa discusión académica se tituló: “ ¿Teoría de la sociedad o tecnología social?". ${ }^{21}$ Este título fue sugerido

\footnotetext{
${ }^{16}$ LUHMANN, N. Soziologische Aufklärung 1, p. 14.

${ }^{17}$ LUHMANN, N. Moderne systemtheorien als form gesamtgesellschaftlicher analyse. In: nologie - Was leistet die systemforschung? Frankfurt am Main: Suhrkamp, 1975. p. 7-24.

${ }^{18}$ FOERSTER, H. Las semillas de la cibernética. Barcelona: Gedisa, 2006.

${ }^{19}$ SPENCER-BROWN, G. Laws of form. New York: Dutton, 1979.

${ }^{20}$ MATURANA, H.; VARELA, F. El árbol del conocimiento. Santiago: OEA/Editorial Universitaria, 1984.

${ }^{21}$ HABERMAS, J.; LUHMANN, N. Theorie der gesellschaft oder sozialtechnologie. Was leistet die Systemforschung? Frankfurt am Main: Suhrkamp, 1971. p. 25-100.
} 


\subsection{TEORIA SOCIOJURÍDICA INTERNACIONAL}

por Habermas y Luhmann lo aceptó sin reparos. Dirk Baecker hace ver que el sentido de ese título sugería que la "teoría de la sociedad" le correspondía a Habermas y la "tecnología social" a Luhmann. De acuerdo a Baecker, no carece de ironía que, después de "La sociedad de la sociedad", Luhmann es sin duda alguna uno de los más significativos teóricos de la sociedad del siglo veinte, en tanto Habermas, gracias al enorme éxito logrado entre políticos, pedagogos, consultores y terapeutas, ha hecho un aporte de indudable relevancia a la "tecnología social". ${ }^{22}$

En el primer capítulo de este libro, denominado: "Modernas teorías de sistemas como forma de análisis de la sociedad global", Luhmann hace algunas críticas al trabajo de Parsons que le servirán de punto de partida para su propia teoría. Lo hace mediante tres frases construidas según el esquema de: "Si bien...., no..." Dicho esquema le permite señalar continuidades y rupturas con Parsons porque, junto con reconocer la validez de lo avanzado por éste, muestra que ese avance no es suficiente. La primera de estas afirmaciones dice que si bien Parsons, conectándose con Weber, superó el behaviorismo al definir la acción a través del sentido mentado, no desarrolla adecuadamente el concepto de sentido, porque lo ve como una propiedad de la acción y no como selección entre posibilidades. Luego afirma que si bien Parsons no plantea ya el problema del orden en términos de la autoridad política, sino desde la contingencia del sentido subjetivamente mentado y de la complementariedad de expectativas que superan dicha contingencia, no construye el concepto de sentido funcionalmente. Finalmente, aduce que si bien Parsons puede aplicar el análisis funcional al interior de estructuras sistémicas dadas, no llega a plantearse la pregunta fundamental respecto a qué función cumple la construcción de un sistema ni la función satisfecha por la elaboración de sus estructuras. ${ }^{23}$

Las críticas mencionadas se refieren al concepto de sentido, dando pie a Luhmann para desarrollarlo como "concepto fundamental de la sociología". Lo define, separando su pensamiento de Max Weber y Talcott Parsons, sin recurrir al concepto de sujeto. Desde su perspectiva, dicho concepto presupone al de sentido, porque el sujeto es concebido como una identidad constituida significativamente. Prefiere evitar el concepto de sujeto y hablar, más bien, de sistemas, los cuales no son entendidos como fuente de energía, causas, substrato orgánico-psíquico ni mucho menos como seres humanos concretos, sino como complejos de sentido. ${ }^{24}$ Esta decisión teórica evita implicar una interpretación psicológica que luego obligue a decidir si se opta por una atribución psicológica o sociológica. La misma decisión se trasluce en otros conceptos, tales como acción, vivencia, expectativa o desilusión, perfilando una posición definidamente sociológica.

Basándose en la fenomenología de Edmund Husserl, Luhmann considera que el sentido designa la forma de ordenamiento del vivenciar humano; se presenta como excedente de referencias de lo que ha sido experimentado, a otras posibles vivencias. El vivenciar se vivencia a sí mismo como flexible. No se encuentra ensimismado, encerrado en sí mismo, sino siempre referido a algo que en ese momento no es su contenido. Integra, inevitablemente, la actualidad de la experiencia con la trascendencia de sus otras posibilidades. La problemática de sobrecargar el vivenciar con otras posibilidades tiene la estructura doble de complejidad y contingencia. La complejidad hace referencia a que siempre hay más posibilidades de acción y experiencia que las que pueden ser actualizadas y la contingencia hace notar que las otras posibilidades de experiencia y acción, que se destacan en el horizonte de la experiencia actual, solo son posibilidades y, por ello, también podrían suceder de manera diferente a la esperada. La complejidad, por lo tanto, significa prácticamente compulsión a seleccionar y la contingencia implica el peligro

\footnotetext{
${ }^{22}$ BAECKER, D. Wozu soziologie? Berlin: Kulturverlag Kadmos, 2004. p. 85-86.

${ }^{23}$ LUHMANN, N. Moderne systemtheorien als form gesamtgesellschaftlicher analyse. In: nologie - Was leistet die systemforschung? Frankfurt am Main: Suhrkamp, 1975. p. 13-14.

${ }^{24}$ LUHMANN, N. Sinn als grundbegriff der soziologie. In: forschung? Frankfurt am Main: Suhrkamp, 1971. p. 28-29. HABERMAS, J. Theorie der gesellschaft oder sozialtechHABERMAS, J. Theorie der gesellschaft oder sozialtechnologie - Was leistet die System-
} 


\subsection{TEORIA SOCIOJURÍDICA INTERNACIONAL}

de la desilusión y la necesidad de aventurarse al riesgo. ${ }^{25}$

El sentido opera como premisa de la elaboración de la experiencia, la cual hace posible, por una parte, la elección de estados de conciencia sin eliminar lo no elegido, sino dejándolo accesible en el mundo. Por eso es que Luhmann afirma que, con su forma de elaborar la experiencia, el sentido garantiza la reducción y el mantenimiento de la complejidad al mismo tiempo. ${ }^{26} \mathrm{El}$ sentido se basa en la capacidad propiamente humana de negar. La negación es el símbolo lingüístico más universalmente aplicable y permite reducir la complejidad al negar posibilidades sin dejarlas definitivamente excluidas, sino accesibles: "Solo el tiempo, no la negación, elimina definitivamente posibilidades" 27 .

Apoyado en la negación, el sentido cumple con su función de mantener y reducir posibilidades de vivenciar y actuar. Este proceso, sin embargo, no consiste en la simple y poco fructífera negación de todo lo que no sea idéntico, sino que constituye, mediante la negación diferenciada, tres dimensiones de la experiencia del mundo. Estas dimensiones son: objetual, social y temporal. La dimensión objetual aparece en el ser distinto, en que un perro no es un gato, una letra no es un placer, ni el viento una esperanza. La dimensión social se constituye en conjunto con identificaciones objetuales en que un alter es reconocido como alter ego, vale decir es vivenciado como portador de sus propias experiencias y perspectivas del mundo que son diferentes a las mías. La dimensión temporal se ocupa de establecer un distanciamiento temporal entre el sentido que es hecho presente en la actualidad y el sentido pasado o futuro que es posible representar en el presente. Por ejemplo, se pueden elegir en el presente los pasos apropiados para alcanzar una meta futura. ${ }^{28}$
Tanto el sistema social como el sistema psíquico son sistemas constituidos por el sentido. Esto significa que surgen con el sentido y mediante el sentido se constituyen a sí mismos. Una conversación y el fluir del pensamiento son posibles porque tienen sentido. El sentido hace posible las conexiones que atan una comunicación con la que la sigue o un pensamiento con el que lo precediera y el que vendrá después. La historia del sistema social o del fluir del pensamiento puede ser reconstruida mediante su sentido. Ambos tipos de sistemas - psíquico y social - constituyen, además, el sentido. Este no emerge en el vacío, sino que es un sistema psíquico o social el que lo va elaborando al momento en que se va construyendo también a sí mismo. Por eso, los sistemas psíquicos y sociales son constituyentes de sentido y constituidos por el sentido.

Los mismos límites de un sistema psíquico o social no son físicos, como sí lo son los límites de los sistemas materiales (una mesa, una piedra, el sistema solar, un perro), sino de sentido: ¿Dónde comienza y dónde termina un sistema social? ¿Cuáles son los límites de mi propia psiquis? Incluso, dice Luhmann, cuando los límites de un determinado sistema social se definen físicamente (los mojones que señalan la frontera entre dos países), siguen siendo de sentido, porque son simbólicos. Para los sistemas de sentido - psíquicos y sociales - todo es en el sentido y todo tiene sentido. Incluso el sinsentido (teatro del absurdo de Ionesco) tiene sentido como sinsentido.

Otro concepto clave de esta primera época es, precisamente, el de límite. Los sistemas surgen como distinción respecto al entorno. Siguiendo las leyes de la forma de George Spencer-Brown, cada vez que se traza una distinción aparece un sistema y su entorno. ${ }^{29}$ Esto significa que sistema y entorno se suponen mutuamente y que el siste-

\footnotetext{
${ }^{25}$ LUHMANN, N. Sinn als grundbegriff der soziologie. In: forschung? p. 32-33.

${ }^{26}$ LUHMANN, N. Sinn als grundbegriff der soziologie. In: forschung?. p. 34.

${ }^{27}$ LUHMANN, N. Sinn als grundbegriff der soziologie. In: forschung?. p. 36

${ }^{28}$ LUHMANN, N. Sinn als grundbegriff der soziologie. In: forschung?. p. 48-61. ${ }^{29}$ SPENCER-BROWN, G. Laws of form.

HABERMAS, J. Theorie der gesellschaft oder sozialtechnologie - Was leistet die System; HABERMAS, J. Theorie der gesellschaft oder sozialtechnologie - Was leistet die System; HABERMAS, J. Theorie der gesellschaft oder sozialtechnologie - Was leistet die System; HABERMAS, J. Theorie der gesellschaft oder sozialtechnologie - Was leistet die System-
} 
ma se define por sus límites. Por eso, en una formulación que enfatiza el carácter no ontológico de su teoría, Luhmann afirma que un sistema es su diferencia respecto al entorno. Toda distinción es, al mismo tiempo, una indicación. Desde uno de sus lados indica al otro, que es visto como un estado no marcado. La distinción hace posible observar desde el estado marcado al estado no marcado, pero no es posible observar la distinción en uso. Dicha distinción es el punto ciego inherente a toda observación. Es lo que, en palabras de Maturana, el observador no ve que no ve. ${ }^{30} \mathrm{El}$ observador tampoco puede observarse a sí mismo, tal como nadie puede ver sus propios ojos. Para observar la distinción utilizada y pasar a la auto-observación, el sistema puede reintroducir (re-entry) la distinción sistema/entorno en el lado del sistema, en el espacio marcado. Al hacerlo, puede observar la distinción sistema/ entorno que hiende el mundo en dos partes y puede, por lo tanto, observar al sistema y a su entorno. No puede, sin embargo, observar la distinción que usa para observar sistema y entorno, y auto-observarse como sistema-en-un-entorno. Todo sistema se define por sus límites respecto al entorno, en tanto el entorno carece de límites. Un sistema puede, por lo tanto, expandir sus límites haciéndose más complejo, pero no puede llegar jamás a comprender todo su entorno porque el entorno carece de límites y solo posee horizontes que se amplían conforme se expande el sistema. La gradiente de complejidad entre el sistema y el entorno no desaparece al incrementarse la complejidad del sistema porque el entorno aumenta su complejidad del mismo modo en que el sistema incrementa la suya.

Esto significa que el entorno no es un sistema porque no tiene límites que lo distingan de un entorno. Tampoco es sistema el mundo porque el mundo es un concepto sin límites dentro del cual se puede hacer toda suerte de distinciones que separan sistemas y entornos, de tal modo que cada vez que un sistema emerge, emerge en el mundo como distinción respecto a un entorno que también está en el mundo. Por lo mismo también, cada vez que un sistema desaparece, desaparece en el mundo. Podríamos decir, entonces, que el entorno es aquella parte del mundo respecto a la cual se distingue un sistema.

\section{SISTEMAS SOCIALES}

En 1982, dos años antes de la publicación de "Sistemas sociales" (Luhmann 1984), sale a luz en Zeitschrift für Soziologie un ensayo de Niklas Luhmann denominado "Autopoiesis, acción y entendimiento comunicativo". ${ }^{31}$ Es la primera vez que el autor utiliza el complejo conceptual que caracterizará toda su obra posterior. Dicho complejo conceptual proviene de la biología y Luhmann lo incorpora a su teoría porque le permite exponer con mayor claridad sus observaciones sobre los sistemas sociales de la sociedad contemporánea. A partir de este momento se incrementa notablemente el bagaje conceptual de la teoría de sistemas con una terminología totalmente nueva, cuyo origen y desarrollo no pueden ser rastreados examinando la historia de la disciplina sociológica. Aunque algunos sociólogos conservadores resintieron esta importación de neologismos sin conexiones evidentes con sus clásicos preferidos, ella permitió a Luhmann separar definitivamente sus observaciones de las propias del pensamiento ontológico vétero-europeo. Necesitaba, además, como hemos dicho, contar con un instrumental de observación que fuera tan nuevo como su objeto de estudio y construir una teoría sociológica capaz de observar una sociedad que incluye todo lo social, también la sociología y esta misma teoría. Pese a la masiva incorporación terminológica y a pesar de la importancia que adquiere dentro de la obra de Luhmann, no implica un cambio conceptual en el sentido que la teoría evidencie un quiebre sustantivo. Si bien es posible hacer una nítida clasificación de los escritos de Luhmann anteriores y posteriores a 1982, no es igualmente posible establecer diferencias en la teoría. Los conceptos recién adoptados y adaptados contribuyeron a la elegancia de las explicaciones sin modificar su espíritu. Para solo mencionar un ejemplo, en

\footnotetext{
${ }^{30}$ MATURANA, H.; VARELA, F. El árbol del conocimiento.

${ }^{31}$ LUHMANN, N. Die gesellschaft der gesellschaft. Frankfurt am Main: Suhrkamp, 1997.
} 


\subsection{TEORIA SOCIOJURÍDICA INTERNACIONAL}

1978 Luhmann escribe que existe una clase de sistemas que son capaces de generar su propio nivel de emergencia ${ }^{32}$; después de 1982, le basta decir que hay sistemas autopoiéticos. ${ }^{33}$

La misma coherencia teórica del desarrollo conceptual permite explicar que en 1984 se publique "Sistemas sociales", libro que presenta una plenamente elaborada teoría de los sistemas sociales, apropiada para comprender la sociedad moderna y los sistemas sociales de la actualidad. Sería muy difícil explicar la madurez y coherencia teórica lograda por todo este andamio conceptual, si se pensara que sus distinciones claves habían sido incorporadas solo dos años atrás por el autor y se creyera ver en ellas un divorcio con su elaboración teórica anterior.

Hemos visto que, desde su comienzo, toda la carrera académica de Luhmann estuvo orientada a elaborar una teoría apropiada para entender la sociedad moderna. Para cumplir con su objetivo, necesitaba desarrollar un marco conceptual tan moderno como la sociedad a la que iba a ser aplicado. Requería, además, establecer los fundamentos epistemológicos que lo hacían alejarse de la ontología vétero-europea subyacente al pensamiento social y la sociología desde sus inicios hasta los años sesenta del siglo pasado. También era preciso que investigara la evolución de los distintos subsistemas de la sociedad a objeto de determinar los pasos evolutivos por los que había transitado la sociedad occidental en su camino a convertirse en la sociedad moderna. Todas estas líneas de trabajo las fue desenvolviendo en paralelo y publicando sus resultados parciales en decenas de libros y cientos de artículos. "Sistemas sociales" presenta una gran teoría de los sistemas sociales con pretensiones de universalidad, lo que no significa que sea la única teoría sociológica posible, sino que debe ser aplicable a cualquier tipo de sistema social, desde una corta interacción entre dos personas que se saludan al pasar, hasta la moderna sociedad mundial. Es, por decirlo así, el marco teórico con que Luhmann estaba construyendo su teoría de la sociedad contemporánea.

En la introducción a "Sistemas sociales", el sociólogo alemán establece con total claridad la perspectiva en que se inscribe su gran teoría. La teoría general de sistemas constituye un fructífero terreno de investigación que se desarrolla con gran rapidez y experimenta cambios de envergadura lo que contrasta notablemente con la sequedad de la teoría sociológica que retorna a sus clásicos, una y otra vez, sin poder crecer. En efecto, la teoría general de sistemas ha experimentado dos cambios de paradigmas de importancia semejante a las revoluciones científicas de Kuhn. ${ }^{34}$ Ninguno de estos cambios de paradigmas tuvo su origen en la sociología, sino que provienen de la biología, termodinámica, neurofisiología, ciencia de computación, teoría de la información o la cibernética. La sociología no solo se mantuvo excluida de este esfuerzo cooperativo de investigación, sino que además fue incapaz de aprender dentro de este contexto interdisciplinario. ${ }^{35}$ No obstante, estos cambios, especialmente los que configuran la segunda transformación ocurrida en las últimas décadas del siglo XX, hacen que la teoría general de sistemas pueda ser acogida sociológicamente para desarrollar una teoría de los sistemas sociales.

Ambos cambios paradigmáticos tienen lugar al interior de la teoría de sistemas y no declaran equivocados los conceptos del paradigma anterior, sino que más bien los redefinen para incorporarlos a un nuevo paradigma más complejo. El primer cambio pasa de la antigua concepción de "todos" que son "más que la suma de sus partes" a la diferencia entre sistema y entorno. El antiguo paradigma todo/partes es incorporado al nuevo de sistema/entorno como diferenciación, como la repetición al interior del sistema de nuevas diferencias sistema/entorno que dan origen a las partes. De esta manera, el sistema admite convertirse en el ambiente para que sus subsistemas se diferencien en su interior, adquiriendo de este modo mayor complejidad. La teoría general de sistemas de Ludwig von Bertalanffy

\footnotetext{
${ }^{32}$ LUHMANN, N. Organisation und Entscheidung. Opladen: Westdeutscher Verlag, 1978.

${ }^{33}$ LUHMANN, N. The autopoiesis of social systems. Autopoiesis in law and society. Florence: Badia Fiesolana, European University Institute, 1985.

${ }^{34}$ KUHN, T. La estructura de las revoluciones científicas. México: Fondo de Cultura Económica, 1971.

${ }^{35}$ LUHMANN, N. Social systems. Stanford, California: Stanford University Press, 1995. p. 11.
} 


\subsection{TEORIA SOCIOJURÍDICA INTERNACIONAL}

es el mejor ejemplo de este primer cambio de paradigmas que inaugura la teoría moderna de sistemas, con el concepto de sistemas abiertos a su entorno. ${ }^{36}$ El segundo cambio de paradigmas reemplaza el concepto de sistema/entorno por el de autorreferencia, afirmando que los sistemas solo se pueden diferenciar de manera autorreferente, vale decir que, al constituir sus elementos y sus operaciones elementales, los sistemas se diferencian refiriéndose a sí mismos, a sus elementos, a sus operaciones o a su unidad como sistema. ${ }^{37}$ Una vez más, el cambio implica que el paradigma sistema/entorno sea incorporado por la mayor complejidad del paradigma de la autorreferencia. De esta forma, la diferencia sistema/ entorno puede ser vista desde la perspectiva de un observador o ser hecha desde el mismo sistema como auto descripción, como auto observación, para diferenciarse de su entorno. De hecho, el propio observador solo es concebible como sistema autorreferente. ${ }^{38}$

$\mathrm{Al}$ reproducirse, los sistemas autorreferentes operan con la diferencia entre identidad y diferencia. Un sistema autopoiético, por ejemplo, produce sus propios elementos y es capaz de reconocer cualquier elemento que no sea de su propia factura. La teoría de los sistemas autopoiéticos proviene de la biología y fue desarrollada como un modo de comprender la vida. Los seres vivos se caracterizan por ser sistemas autopoiéticos en el espacio molecular; su operación recursiva constituye una red de producción de componentes que se produce y reproduce constantemente a sí misma a través de un proceso permanente de generación de componentes. Las células de todo organismo vivo han sido producidas por el mismo organismo y la vida permanece mientras ese proceso de producción no se detenga. ${ }^{39}$

Para aplicar la teoría de la autopoiesis a los sistemas sociales, es preciso determinar cuáles son los elementos que conforman estos sistemas o, dicho de otro modo, cuál es el nivel de emergencia de lo social. Únicamente así se podrá comprobar si efectivamente todo sistema social se produce a sí mismo en una operación recursiva de producción de componentes. La comunicación cumple con esta condición de ser la unidad elemental de los sistemas sociales, producida por los mismos sistemas sociales que, a través de ella, se producen a sí mismos como redes de comunicaciones. Esto implica que estos elementos son efímeros y deben ser constantemente reproducidos por el sistema que ellos constituyen. La consecuencia de esta temporalidad propia de las comunicaciones es que cada comunicación tiene la capacidad de conectarse con otras comunicaciones que se van generando inmediatamente tras ella. La conectividad de las comunicaciones sociales es el sentido de ellas. Todo lo dicho en un sistema social tiene el sentido que le otorga ese sistema social y gracias a ese sentido puede ser relatado como una historia.

El elemento de un sistema opera, para ese sistema, como unidad indisoluble. Considerar la comunicación como elemento de los sistemas sociales implica una ruptura con la tradición que había caracterizado al pensamiento sociológico y pre-sociológico, el cual siempre había pensado a la acción como elemento básico de la vida en sociedad. ${ }^{40}$ Luhmann estima que las acciones no son necesariamente sociales $y$, por consiguiente, que es necesario calificar la acción cada vez que se quiera entenderla como formando parte esencial de un sistema social. Habría que hablar de acción "social", como hace Weber ${ }^{41} \mathrm{o}$ de acción "comunicativa", como prefiere Habermas. ${ }^{42}$ La comunicación, en cambio, es eminentemente social y, tal como la define Luhmann, no puede existir ninguna comunicación "no social". En efecto, para Luhmann, la comunicación es una síntesis de tres selecciones ${ }^{43}$ :

\footnotetext{
${ }^{36}$ BERTALANFFY, L. v. Perspectivas en la teoría general de sistemas. Madrid: Alianza Editorial, 1979.

${ }^{37}$ MATURANA, H.; VARELA, F. El árbol del conocimiento.

${ }^{38}$ FOESTER, H. v. Observing Systems. California: Seaside, 1981.

${ }^{39}$ MATURANA, H.; VARELA, F. De máquinas y seres vivos. Santiago: Editorial Universitaria, 1973; MATURANA, H.; VARELA, F. El árbol del conocimiento.

${ }^{40}$ PARSONS, T. La estructura de la acción social. Madrid: Ediciones Guadarrama, 1968.

${ }^{41}$ WEBER, M. Economía y sociedad. México: Fondo de Cultura Económica, 1964.

${ }^{42}$ HABERMAS, J. Teoría de la acción comunicativa. Madrid: Taurus, 1998.
} 
i. Selección de una información. Alter selecciona la información que desea dar a conocer a Ego. Cada vez que alguien habla, debe seleccionar, entre todas las informaciones que podría dar a conocer, una que le parezca que es realmente una información para su eventual interlocutor. Información es entendida por Luhmann, según la definición de Bateson, como "la diferencia que hace una diferencia". ${ }^{44}$ ii. Selección de una forma de darla-a-conocer. Alter tiene que seleccionar, además, las palabras con que va a expresar la información que ha seleccionado, también tiene que decidir si la dará a conocer a viva voz, por teléfono, carta, email, inserto en el periódico, etc.

iii. Selección de una comprensión: Ego debe seleccionar su propia interpretación de lo que ha escuchado. Esto significa volver a separar la información de la forma en que le ha sido dada a conocer por Alter. La comprensión necesariamente comprende la incomprensión, esto es que Ego crea que la información portada por las palabras que le fueron dichas es diferente a la que Alter quiso darle a conocer. Al ser la comunicación el elemento de los sistemas sociales, para ellos opera como una unidad indisoluble. En otras palabras, que sea posible separar analíticamente las tres selecciones no quiere decir que dichas selecciones se separen en la operación normal de un sistema social. Los sistemas se constituyen y cambian relacionando y volviendo a relacionar sus elementos, pero no disolviendo dichos elementos en sus partes constitutivas para volver a combinarlas de una nueva forma. Esto lleva a discutir si la unidad de un elemento ha de ser explicada como "nivel de emergencia", vale decir, emerge desde abajo al relacionarse sus componentes de una manera particular, o si, más bien, su explicación es que dicha unidad es constituida desde arriba, al reproducirse el sistema en su operación autopoiética. Luhmann se inclina decididamente por esta segunda opción explicativa. ${ }^{45} \mathrm{Al}$ respecto, se podría entonces decir que los sistemas autopoiéticos generan su propio nivel de emergencia.

Volviendo al concepto de sentido, en "Sistemas sociales", Luhmann explica que el sentido es un logro co-evolutivo de los sistemas psíquicos y sociales. Ambos tipos de sistemas emergen al mismo tiempo, co-evolutivamente, de tal forma que cada uno de ellos es el entorno necesario del otro: las personas no pueden surgir ni existir sin un sistema social y este tampoco puede surgir ni existir sin personas. ${ }^{46}$ La vieja pregunta, acerca de si al comienzo hubo seres humanos que luego se unieron formando un sistema social o si, más bien ocurrió el proceso inverso en que primero hubo un sistema social y luego sus integrantes tomaron conciencia de sí mismos como personas individuales, es respondida en los términos de la simultaneidad evolutiva de ambos tipos de sistemas. Al mismo tiempo que cada individuo tomó conciencia de sí, pudo percibir que estaba rodeado de otros individuos semejantes con quienes establecía contactos comunicativos que daban forma a sistemas sociales. El lenguaje permite tanto la autorreferencia individual como la autorreferencia social. Ambos sistemas hacen uso, por consiguiente, del sentido. Fenomenológicamente, el sentido aparece bajo la forma de un exceso de posibilidades de experiencia y acción: Algo se encuentra en el centro de atención, en el centro de una intención y remite marginalmente a todo lo demás, como un horizonte de remisiones de experiencias y acciones. La referencia se actualiza como punto de partida de la realidad, pero no solo relaciona lo real (o presuntivamente real), sino también lo posible (condicionalmente real) y lo negativo (negativamente real). El conjunto de referencias significativas presenta más de lo que podrá ser actualizado en el paso siguiente y por eso la forma del sentido, con su estructura de referencias, obliga que el próximo paso sea una selección. ${ }^{47}$

Con el sentido (cualquiera que sea) se hace comprensible la complejidad del mundo, que-

\footnotetext{
${ }^{43}$ LUHMANN, N. Soziale systeme. Frankfurt am Main: Suhrkamp, 1984. p. 193-201

${ }^{44}$ BATESON, G. Steps to an ecology of mind. San Francisco: Chandler, 1972. p. 315.

${ }^{45}$ LUHMANN, N. Soziale systeme, p. 43.

${ }^{46}$ LUHMANN, N. Soziale systeme, p. 92.

${ }^{47}$ LUHMANN, N. Soziale systeme, p. 93-94.
} 


\subsection{TEORIA SOCIOJURÍDICA INTERNACIONAL}

dando disponible para las operaciones de los sistemas psíquicos y sociales. La información es un suceso que selecciona estados del sistema. La información presupone estructuras, aunque no es una estructura, sino únicamente el acontecimiento que actualiza el uso de la estructura. Si una información es repetida, no pierde su sentido aunque sí pierde su valor informativo. ${ }^{48}$

Al principio, afirma Luhmann, no se encuentra la identidad, sino la diferencia. Únicamente así se puede hacer que los acontecimientos casuales tengan valor informativo. La información, por consiguiente, no es más que un suceso que opera conectando diferencias, lo que refiere al concepto de información de Bateson: "la diferencia que hace una diferencia". Por su parte, el sentido también se descompone en diferencias. Esto nos conduce a las tres dimensiones del sentido las cuales, dado que todo sistema psíquico y social comprende al mundo y su complejidad desde el sentido, pueden ser también comprendidas como dimensiones de la complejidad y del mundo. Las tres dimensiones del sentido son: objetual, social y temporal. Cada una de estas dimensiones se actualiza como la diferencia entre dos horizontes, vale decir, es una diferencia que se diferencia de otras diferencias y la autorreferencia opera dentro de cada una de las dimensiones sin poder ser reemplazada por la diferencia de los otros horizontes. En otras palabras, el futuro no puede ser reemplazado por el consenso y el consenso no puede ser reemplazado por los horizontes objetuales. ${ }^{49}$

La dimensión objetual se refiere a todos los objetos de intención significativa para los sistemas psíquicos o todos los temas de comunicación significativa de los sistemas sociales. La dimensión objetual se constituye al distinguir entre "esto" y "lo otro". Las diferencias se descomponen en los horizontes de "afuera" y "adentro". Los horizontes no son límites que puedan ser sobrepasados, sino que siempre su persecución parece acercarlos, aunque sin alejarse del horizonte contrario. ${ }^{50}$ En esta dimensión objetual tiene lugar la atribución interna o externa, a partir de la cual se puede observar la diferencia entre acción, en el caso de atribución interna, y experiencia, en el caso de atribución externa. Si la selección del sentido es atribuida internamente, vale decir, al propio sistema, se entiende como una acción del sistema. Cuando la selección del sentido es externamente atribuida, esto es, al entorno del sistema, se comprende como una experiencia del sistema.

La dimensión temporal se constituye al experimentar directamente, en todo acontecimiento, la diferencia entre "antes" y "después". Sus horizontes inalcanzables son: pasado y futuro. Por eso, para los sistemas de sentido (psíquico y social), el tiempo es la interpretación de la realidad desde la perspectiva de una diferencia entre pasado y futuro. Dado que se trata de horizontes y no de límites, en ninguno de ellos se puede encontrar el principio ni el fin del tiempo. Tampoco es posible tener experiencias ni actuar en el pasado o el futuro. Es posible proyectar intenciones en ellos o hacerlos tema de una comunicación, pero no se puede tener vivencias ni realizar acciones dentro de ellos. El lapso entre pasado y futuro en el cual ocurre el hacerse irreversible es experimentado como presente y este dura tanto como dure el tornarse irreversible. ${ }^{51}$

La dimensión social corresponde al que ego considera semejante, como "alter ego" y articula, de este modo la experiencia y la determinación de sentido. Esta dimensión social también tiene, como las otras dos dimensiones, relevancia universal porque, aunque haya un solo alter ego y un solo ego, ambos son relevantes para todas las situaciones y todos los temas. ${ }^{52}$

La diferencia entre la dimensión social y la objetual no debe ser mal entendida en los términos de la vieja diferencia entre naturaleza y ser humano. Lo central es que frente a toda articulación objetual del sentido, se ofrece la dimensión social con su propia peculiaridad, la que consiste

\footnotetext{
${ }^{48}$ LUHMANN, N. Soziale systeme, p. 102.

${ }^{49}$ LUHMANN, N. Soziale systeme, p. 112-113.

${ }^{50}$ LUHMANN, N. Soziale systeme, p. 114.

${ }^{51}$ LUHMANN, N. Soziale systeme, p. 116-118.

${ }^{52}$ LUHMANN, N. Soziale systeme, p. 119.
} 


\subsection{TEORIA SOCIOJURÍDICA INTERNACIONAL}

en que junto a la perspectiva de ego, también se debe considerar una (o varias) perspectivas de alter ego. Esto significa que, ante cada sentido, uno se debe preguntar si otra persona lo experimenta exactamente del mismo modo o de otra manera.

Las tres dimensiones del sentido no aparecen aisladas, sino que en todo sentido se encuentran las tres. El sentido es referencia necesaria de la operación de los sistemas psíquicos y sociales porque ambos sistemas surgen en el curso de la coevolución y, por lo mismo, no son posibles por separado. Se han diferenciado en el sentido, lo que significa que el sentido es la substancia propia de este nivel emergente de la evolución. Por esta razón, es equivocado atribuir al sistema psíquico una precedencia respecto al social. También es erróneo atribuir el sentido a un portador, porque el sentido se porta a sí mismo al hacer posible su propia reproducción autorreferente $y$, recién entonces, las formas de esta reproducción diferencian estructuras psíquicas y sociales. ${ }^{53}$

Las tres dimensiones del sentido se expresan en los temas de comunicación que, para estar en condiciones de coordinar los distintos aportes hechos por los interlocutores, tienen un contenido objetual: se trata del valor de las acciones, del campeonato mundial de fútbol, de los problemas del gobierno o del estado de salud de un conocido común. También tienen un aspecto temporal: se trata de algo nuevo, es posible recordar un acontecimiento similar, ya es un tema aburrido o que interesa solo a algunos o es tan nuevo que pocos lo comprenden. El aspecto social de los temas se hace notar en que los interlocutores también expresan algo acerca de ellos mismos, sus opiniones, actitudes, experiencias, expectativas, etc. y la comunicación también sirve para la presentación de sí mismos de los interlocutores. ${ }^{54}$

Para producirse, la comunicación debe enfrentar y superar tres improbabilidades ${ }^{55}$ :

i. Es improbable que Ego comprenda lo que quiere decir Alter, dada la separación e individualización de sus cuerpos y conciencias.
El sentido refiere al contexto y para cada una de las personas involucradas (Alter y Ego) el contexto remite a lo que pueda percibir y recordar. Esta separación de perspectivas hace improbable la comprensión.

ii. Es improbable que la comunicación alcance a personas que no están presentes en la interacción y esta improbabilidad aumenta si se desea que la comunicación llegue a los ausentes sin haber cambiado. La interacción permite captar la atención de los presentes, pero esa atención no se puede garantizar de parte de los ausentes. Aunque se pueda transmitir la comunicación por medio de un portador resistente al tiempo, no se puede dar por seguro que encontrará la atención requerida más allá de los límites de la interacción.

iii. Aunque la comunicación sea entendida por los que sean alcanzados por ella, no es seguro que será aceptada y sus indicaciones seguidas.

Las improbabilidades de la comunicación y el modo en que son superadas y transformadas en probabilidades también regulan la construcción de sistemas sociales. Luhmann denomina medios a los logros evolutivos que se usan para hace probables estas improbabilidades. El medio que se ha utilizado para superar la primera improbabilidad, la de hacerse entender por otro, es el lenguaje. Este ha permitido ampliar enormemente el repertorio de comunicaciones comprensibles, al punto que prácticamente cualquier suceso puede ser presentado como información y procesado comunicativamente. Para superar la improbabilidad de llegar a los ausentes, se han desarrollado diferentes medios de difusión: la escritura, la imprenta, la radio, la televisión y las innumerables tecnologías de la información. Estos medios de difusión han aumentado de tal modo las comunicaciones que se hace más problemático conseguir que una comunicación dada logre su objetivo: ser aceptada. Para hacer más probable la aceptación, se han desarrollado los medios simbólicamente generalizados de co-

\footnotetext{
${ }^{53}$ LUHMANN, N. Soziale systeme, p. 141.

${ }^{54}$ GOFFMAN, E. La presentación de la persona en la vida cotidiana. Buenos Aires: Amorrortu, 2006.

${ }^{55}$ LUHMANN, N. Soziale systeme, p. 216-225.
} 


\subsection{TEORIA SOCIOJURÍDICA INTERNACIONAL}

municación, los que apoyan al lenguaje motivando la aceptación de lo comunicado. Ejemplos de estos medios simbólicamente generalizados de comunicación son la verdad, el dinero, el amor, el poder, entre otros.

La teoría de sistemas parte de la diferencia entre sistema y entorno. El entorno, en cuanto momento constitutivo de esta diferencia, no es menos importante que el propio sistema. No podría hablarse de un sistema carente de entorno. La teoría de sistemas sociales considera que los seres humanos constituyen parte del entorno de los sistemas sociales. Este modo de verlos permite concebirlos de manera más compleja y libre de lo que podrían ser entendidos si se vieran como parte del sistema social. ${ }^{56}$

La relación entre el sistema social y el sistema psíquico tiene el carácter de interpenetración, con este término se hace referencia a una relación entre sistemas que mutuamente pertenecen al entorno del correspondiente otro. Esto quiere decir que se ofrecen mutuamente su complejidad, para que el respectivo otro la reduzca de acuerdo a sus propios criterios de selección. En otras palabras, la complejidad de los sistemas psíquicos es la complejidad de los pensamientos y su reproducción autopoiética. Esta complejidad es ofrecida al sistema social que no procesa pensamientos, sino comunicaciones $y$, por lo mismo, reduce esa complejidad en términos de comunicación, que son los suyos. Por eso, los pensamientos de los sistemas psíquicos gatillan comunicaciones en el sistema social con que están interpenetrados. A su vez, el sistema social presenta la complejidad de sus comunicaciones a los sistemas psíquicos interpenetrados con él y estos seleccionan pensamientos.

Cada uno de los sistemas que se interpenetran realiza en sí mismo al otro como su diferencia entre sistema y entorno, sin descomponerse él mismo. De este modo cada sistema, en su relación con el respectivo otro, puede realizar su propia mayor complejidad, sus propios modos de descripción y sus propias reducciones y, sobre esta base, puede poner su propia complejidad a disposición del otro. ${ }^{57}$

En la teoría de Luhmann, la sociedad y la interacción corresponden a dos tipos diferentes de sistemas sociales. La sociedad es el sistema social comprensivo que incluye en sí todo lo social y, en consecuencia, carece de entorno social. Si sucede algo social, si aparecen nuevos interlocutores o nuevos temas de comunicación, la sociedad crece con ellos porque ellos se desarrollan en la sociedad. La sociedad es el sistema social autopoiético por excelencia porque todo lo que sea comunicación es parte de la sociedad. De esta manera, la unidad del sistema de la sociedad es la clausura autorreferencial. También se puede describir la sociedad como orden autosustitutivo porque todo lo que deba ser transformado o reemplazado en ella, debe ser transformado o reemplazado dentro de ella. ${ }^{58}$

Al comprender todas las comunicaciones posibles, la sociedad hoy en día es un sistema mundial único. Se comunica sobre algo que puede pertenecer al entorno, pero la comunicación sigue siendo parte componente del sistema de la sociedad. Esto significa que la sociedad requiere contar con sensores que puedan ser estimulados por factores no comunicativos, externos al sistema social. Estos son los seres humanos que son capaces de percibir y que, mediante su interpenetración con el sistema social, permiten que este establezca conexiones con otros niveles de la realidad. ${ }^{59}$

Los sistemas de interacción son sistemas sociales de comunicaciones cuyos límites se determinan por la presencia. Las personas que están presentes en un momento dado pueden percibir la presencia de otros y también ser percibidas como presentes. Si bien la percepción es un proceso psíquico de obtención de información, pasa a ser un fenómeno social que articula la doble contingencia cuando se puede percibir que se percibe. En situaciones sociales, Ego puede ver que Alter ve y también puede ver lo que Alter ve. La interacción carece de suficiente comple-

\footnotetext{
${ }^{56}$ LUHMANN, N. Soziale systeme, p. 291

${ }^{57}$ LUHMANN, N. Soziale systeme, p. 295.

${ }^{58}$ LUHMANN, N. Soziale systeme, p. 556.

${ }^{59}$ LUHMANN, N. Soziale systeme, p. 558.
} 
jidad para permitir la coexistencia del conflicto con comunicaciones no conflictivas. Por eso, una conversación amistosa puede convertirse en un conflicto y continuar de ese modo la comunicación entre los presentes. Las interacciones pueden iniciarse y finalizar porque la sociedad les ofrece los vínculos necesarios. La sociedad pre-existe a una interacción y su existencia continuará cuando la interacción haya terminado. Sin embargo, la sociedad es, a su vez, resultado de interacciones. En cierta medida, la sociedad es el ecosistema de las interacciones que cambia en la medida en que canaliza posibilidades de interacción.

La diferencia entre sociedad e interacción es la condición de posibilidad de la evolución sociocultural. Ideas de interacción innovadoras pueden ser constantemente puestas en práctica. La evolución sociocultural sucede sin planificación, construyendo complejidad altamente improbable. La diferenciación de sistemas autopoiéticos es el presupuesto que, a su vez, también resulta de esto. La unidad de la autopoiesis no es otra cosa que su permanente renovación. Para ello, en toda situación, hay un espacio más o menos amplio de posibilidades de conexión. Este espacio puede ser también concebido como potencial de evolución. Es probable que alguna vez en él se seleccione lo improbable si la cantidad de posibilidades es suficientemente grande. Parece que de vez en cuando el sistema también alcanza posiciones extremas, cuyo surgimiento nadie habría considerado probable y que, por lo mismo, desencadenan consecuencias significativas. ${ }^{60}$

Dejaremos aquí la presentación de "Sistemas sociales", porque esta última observación de Luhmann permite comprender la relevancia que pueden tener los movimientos ciudadanos que, como los "Indignados" de España, han ocupado los primeros lugares de la atención mundial.

\section{LA SOCIEDAD DE LA SOCIEDAD}

El año 1997 es publicada la obra a la que Luhmann dedicó su vida académica. "La sociedad de la sociedad" presenta una teoría de la sociedad contemporánea que ha sido desarrollada utilizando como marco teórico la teoría de los sistemas sociales.

La complejidad de la tarea de elaborar una teoría sociológica de la sociedad radica en que no es posible observar la sociedad ni comunicar esa observación desde fuera de la sociedad. Cualquier descripción de la sociedad es, por consiguiente, una operación de la sociedad y, por lo mismo, dicha descripción también es una descripción de sí misma. La tarea se hace, además, difícil porque requiere superar ciertas ideas acerca de la sociedad que han sido instaladas por la tradición y que constituyen verdaderos "obstáculos epistemológicos” para el avance teórico. Los obstáculos aludidos pueden ser resumidos en cuatro supuestos relacionados entre $\mathrm{si}^{61}$ :

i. La sociedad está constituida por seres humanos concretos y sus relaciones.

ii. La sociedad se establece e integra a través del consenso entre los seres humanos.

iii. Las sociedades son unidades regionales, limitadas territorialmente.

iv. Las sociedades pueden ser observadas desde el exterior, como grupos de seres humanos o como territorios.

El primero de estos obstáculos cae en contradicción tan pronto como se intenta establecer si los seres humanos con toda su realidad biológica constituyen la sociedad, si ésta es un fenómeno viviente cuyo peso aumenta o disminuye cuando nacen o mueren seres humanos, si los procesos mentales de seres humanos concretos pueden ser concebidos como fenómenos sociales, si por ejemplo, las percepciones, sueños o alucinaciones forman parte integrante de la sociedad. Por otra parte, todos los problemas estructurales de la sociedad deberían ser considerados conductas individuales desviadas. Además de esto, si la sociedad fuera un agregado de seres humanos individuales, la diferenciación social necesariamente consistiría en la diferenciación de grupos, razas o clases de seres humanos, esto sería algo tan reñido con el concepto de derechos humanos que la idea se hace insostenible.

\footnotetext{
${ }^{60}$ LUHMANN, N. Soziale systeme, p. 590.

${ }^{61}$ LUHMANN, N. La sociedad de la sociedad. México: Herder, 2007. p. 11-20.
} 


\subsection{TEORIA SOCIOJURÍDICA INTERNACIONAL}

La idea del consenso deja sin explicación los muchos conflictos que siempre han caracterizado la historia de la sociedad. Tampoco tiene cabida en ella la resistencia a consensos políticamente impuestos o se acepta la legitimidad de las instituciones destinadas a imponer el orden y dominar la resistencia.

Comprender que las sociedades son entidades territoriales tiene dificultades crecientes derivadas de la evidente globalización de los distintos aspectos de la vida en sociedad. Apuntar, por otra parte, que la sociedad mundial contiene demasiada heterogeneidad no parece un argumento concluyente si se piensa que cada ciudad, cada barrio e incluso cada calle de nuestros días admiten toda clase de diferencias, sin que éstas lleven a pensar que ciudad, barrio y calle no constituyen unidades sociales.

Apunta Luhmann que asociar el concepto de sociedad a premisas centralistas, como los valores o la dominación, subestima la variabilidad y complejidad de las relaciones regionales, ignorando, además, también la forma descentralizada y conexionista de las redes complejas por las que se comunica por todo el mundo. ${ }^{62}$

La sociedad mundial es un sistema social omniabarcador. Es posible que el descubrimiento del globo terráqueo como esfera cerrada de comunicación haya concluido por establecer la pauta. Desde el siglo XIX, se establece un tiempo único del mundo. Con esto también se hace cada vez más difícil definir la unidad de la sociedad a partir de límites territoriales o dividiendo sus habitantes por características culturales entre pertenecientes y no pertenecientes. Los sistemas funcionales - economía, ciencia, política, educación, derecho, etc. - comienzan a definir límites que trascienden el espacio regional y las barreras de razas y culturas. "En la medida que comunican todos los sistemas parciales participan de la sociedad; en la medida que comunican de modo distinto, se distinguen entre sí. ${ }^{63}$

En "La sociedad de la sociedad", Luhmann incorpora una distinción que había estado utilizando en sus escritos sobre los distintos sistemas funcionales que constituyen la moderna sociedad mundial, aunque no se presenta todavía en "Sistemas sociales". Esta distinción es apropiada por Luhmann desde la psicología de percepción a distancia de Fritz Heider. El hecho que, en diversos momentos de su elaboración conceptual, Luhmann incorpore distinciones que serán relevantes para su desarrollo teórico demuestra la vitalidad de su reflexión que permanentemente busca mejores y más claras formas de expresar sus observaciones.

Fritz Heider construye la distinción medium/ thing, para explicar la percepción a distancia. Podemos ver un objeto con el cual no tengamos contacto físico directo porque la luz opera como un médium cuyos elementos se encuentran acoplados de manera más o menos suelta entre sí. Debido a este acoplamiento flojo (loose coupling) de los elementos del médium, se hace posible imprimir una cosa que los acoplará momentáneamente de manera firme (tight coupling). Como los granos de arena, que se acoplan flojamente entre sí, permiten que se imprima en ellos la huella de una pisada que, con su presión, los hace acoplarse de manera más firme, los sustratos mediales admiten múltiples acoplamientos firmes pasajeros. Las cosas que nos rodean reflejan la luz y podemos verlas. La luz (médium) no es directamente visible, solo la vemos en las cosas que la reflejan. Gracias al aire podemos escuchar los ruidos de nuestro alrededor, que imprimen un acoplamiento firme pasajero a los elementos flojamente acoplados del aire. Escuchamos sonidos, no al aire porque este es silencioso. El sonido del viento no es el sonido del aire, sino del aire en movimiento que también implica el acoplamiento firme de los elementos del aire. Dado que las cosas imprimen un acoplamiento pasajero de elementos del médium respectivo, este no se agota ni va siendo acoplado acumulativamente de manera firme. La misma luz que nos permite ver un árbol nos permitirá ver el prado que lo rodea y el cervatillo que pasta junto a él. El mismo aire que nos permite escuchar una bella melodía, nos hará oír también el

\footnotetext{
${ }^{62}$ LUHMANN, N. La sociedad de la sociedad, p. 17.

${ }^{63}$ LUHMANN, N. La sociedad de la sociedad, p. 112.
} 


\subsection{TEORIA SOCIOJURÍDICA INTERNACIONAL}

ruido de un auto que pasa y las desentonaciones del violinista aprendiz.

Luhmann acoge la distinción de Heider, pero la hace más abstracta al configurarla como la distinción médium/forma. Puede entonces explicar que los sistemas de comunicación se constituyen a sí mismos mediante la distinción médium/ forma, con la cual se ingresa una distinción dependiente del observador y por eso, cada vez que se hable de "medios de comunicación" se estará haciendo referencia al empleo operativo de la diferencia entre sustrato medial y forma.

En el médium del lenguaje hay numerosas palabras acopladas flojamente y cada frase dicha acopla firme y pasajeramente algunas de ellas, sin que con ello queden inutilizables para futuras sentencias. La evolución de la sociedad desarrolla diferentes medios/formas según cuál sea el problema a resolver. Así, por ejemplo, los medios de difusión determinan y amplían el círculo de receptores de una comunicación. En la medida que se difunde la misma información, la información se transforma en redundancia. La redundancia social generada de este modo hace más rápido el tiempo y se hace cada vez más incierto si la información dada a conocer de este modo es aceptada como premisa para una conducta posterior o es simplemente rechazada. Son demasiadas las personas que participan y ya no es posible averiguar lo que produjo la comunicación. Dadas estas condiciones, la evolución puede descubrir soluciones para los nuevos problemas. Una de estas soluciones consiste en el desarrollo de un nuevo tipo de medios, que Luhmann denomina medios de comunicación simbólicamente generalizados. ${ }^{64}$

El lenguaje es el médium fundamental de la comunicación, el que garantiza la autopoiesis de la sociedad. Hablar es un comportamiento tan especializado para la comunicación, que si se usa no puede quedar en duda la intención de comunicar y, al mismo tiempo, se pueden dar por supuestas las percepciones de otros. De este modo, ni el que habla ni el que escucha pueden negar el hecho de la comunicación. ${ }^{65}$

El lenguaje surge como médium de comunicación oral, ligada a la interacción entre presentes. Cuando la sociedad se hace más extensa, se hace preciso idear formas para alcanzar comunicativamente a los ausentes. La comunicación oral siempre va acompañada de metacomunicación. No es posible hablar sin dar a conocer que se está hablando y se desea ser escuchado y entendido. En la comunicación oral, además, los presentes se perciben mutuamente y están en condiciones de percibir lo que perciben los demás; de este modo se puede hacer uso de un lenguaje relativamente reducido, cuyas expresiones pueden ser ambiguas, porque se refieren a lo que todos perciben. Advertencias como ¡fuego!, ¡peligro!, ¡alimento!, etc. son suficientes porque todos los presentes pueden percibir cuál es el objeto concreto al que aluden. La comunicación oral contribuye al consenso porque todo comparten el mismo espacio-tiempo, perciben lo que los rodea y resulta demasiado agresivo el rechazo a algo que parece haber encontrado pleno acuerdo. La comunicación oral depende de la memoria individual y vuelve a repetir, cada vez, parte importante de lo dicho con anterioridad. La comunicación lingüística encuentra su unidad en la codificación sí/no.

Si esto se toma en serio, queda excluido que del mismo lenguaje se pueda derivar una norma ideal que lleve al esfuerzo por entenderse. Solo es necesaria la autopoiesis de la comunicación, y esta autopoiesis no se garantiza por el télos el entendimiento sino por un código binario. Para la comunicación codificada no existe un fin, sino únicamente la opción - reproducida en toda operación de entendimiento - de continuar o por aceptación o por rechazo. ${ }^{66}$

La comunicación oral utiliza el médium del aire y es percibida acústicamente. La escritura se apropia de otro médium, el de la luz, y su percepción es visual. La escritura rompe con la interacción; no necesita que los interlocutores compartan el mismo espacio-tiempo y se perciban mutuamente, además de ser testigos de

\footnotetext{
${ }^{64}$ LUHMANN, N. La sociedad de la sociedad, p. 155-156.

${ }^{65}$ LUHMANN, N. La sociedad de la sociedad, p. 162-163.

${ }^{66}$ LUHMANN, N. La sociedad de la sociedad, p. 177.
} 


\subsection{TEORIA SOCIOJURÍDICA INTERNACIONAL}

los mismos sucesos. Esta separación espacial y temporal de los interlocutores obliga a que la comunicación escrita aporte mayor información de la requerida por la comunicación oral: palabras como ¡peligro!, ¡fuego! o ¡alimento! resultan completamente insuficientes si no son contextualizadas por escrito, para que lo eventuales lectores logren entender a qué se refieren. También se hace necesario considerar eventuales diferencias temporales entre quien selecciona la información y el modo de darla a conocer y quien selecciona la comprensión. Quien escribe debe tener presente que su texto será leído en el futuro y por eso requiere hacerlo interesante para esa posible lectura posterior. El lector, por su parte, sabe que lo escrito sucedió en su pasado. Para ello, los textos escritos mantienen su estabilidad y pueden ser releídos. Las palabras de la conversación oral, en cambio, "se las lleva el viento" y han de ser reinventadas cada vez que se desee hacer alusión a ellas. Se apoyan en la memoria y ésta siempre recrea, en el presente, lo que atribuye al pasado.

La escritura prescinde del permanente intercambio de roles entre quien habla y quien escucha, propio de la comunicación oral. Puede desarrollar una idea completa sin interrupciones, aunque debe procurar tener presentes las posibles dudas e interrogantes que se podrán producir en los lectores futuros. La oralidad depende de la sociabilidad, de la co-presencia de los interlocutores. Escribir y leer, por su parte, son actividades asociales; deben ser llevadas a cabo en solitario y la presencia de otras personas puede provocar molestia. En la escritura adquiere importancia central la información, mientras en la oralidad es posible hablar y hablar por el simple placer de la sociabilidad. Con escasa o ninguna información, los corrillos de gente repiten una y otra vez lo que todos saben, y disfrutan haciéndolo.

La escritura hace posible expandir enormemente las comunicaciones. Trascienden los límites espaciales y temporales y se hacen posibles las traducciones para trascender también las barreras idiomáticas. Dado que la comunicación se produce con la comprensión, es posible comunicarse con personas muertas y dejarse impresionar por su pensamiento que estimula, de este modo, el pensamiento y la creatividad de generaciones futuras. La escritura aumenta el potencial de rechazo a la comunicación. No existen en ella las presiones del círculo de los presentes ni es preciso enfrentar cara a cara al interlocutor rechazado. Ni siquiera es necesario comunicarle la propia disconformidad con lo que ha escrito. Todo esto incrementa notablemente las posibilidades de innovación y cambio de la sociedad.

La imprenta presenta un nuevo hito en este proceso evolutivo, provocando una enorme difusión de lo escrito. El volumen de lo publicado es tal, que la difusión de los textos ya no puede ser controlada en términos de los contenidos ni, menos, por la autoridad. La impresión de textos obliga que la lengua se uniforme lo que lleva a la estandarización de las lenguas nacionales convirtiéndolas, así, en poderosos instrumentos de nacionalización política. ${ }^{67}$ Las normas jurídicas se ponen por escrito para la imprenta y se independizan así de la jurisdicción local de los señores feudales. La multiplicación del conocimiento y su mejora se hacen accesibles a zonas muy distantes del lugar en que se producen los avances y pueden generar allí nuevas ideas e innovaciones. Todo esto produce temores e intentos de control. Se habla de los efectos negativos de la lectura y se intenta prohibir la reproducción de textos "impropios", pero las imprentas se dejan guiar por el mercado y la prohibición aumenta su demanda. A mediados del siglo XIX hay ya un grado de alfabetización suficiente como para que se produzca una prensa de masas diaria y barata. ${ }^{68}$

Los medios electrónicos vuelven a multiplicar de manera exponencial las oportunidades de comunicación, haciendo que sus limitaciones espaciales y temporales tiendan a cero. Se desarrollan máquinas de procesamiento de la información y surgen redes de interconexión que operan mundialmente coleccionando, evaluando y distribuyendo datos.

\footnotetext{
${ }^{67}$ LUHMANN, N. La sociedad de la sociedad, p. 229

${ }^{68}$ LUHMANN, N. La sociedad de la sociedad, p. 233.
} 


\subsection{TEORIA SOCIOJURÍDICA INTERNACIONAL}

Ya no se parte de figuras definidas que pueden ser juzgadas como verídicas o falsas, útiles o inútiles, según sean los códigos de los sistemas funcionales, sino que cada fijación produce un espacio sin marca $\mathrm{y}$, dentro de él, otro lado que únicamente se puede determinar mediante otras operaciones, con la mismas consecuencias. ${ }^{69}$

La comunicación a través de computadores separa la introducción de datos de la información requerida, lo cual conduce a que se abandone la identidad entre dar a conocer y entender. "Quien ingresa algún dato no sabe [...] lo que será extraído por el otro lado. En el entretanto los datos se 'procesan'. El receptor ni siquiera debe saber si se le tiene que dar a conocer algo ni qué será".70

Los medios de difusión indicados multiplican significativamente el número de destinatarios a los que pueden llegar las comunicaciones, pero, por lo mismo, también aumentan considerablemente la improbabilidad de que estas comunicaciones sean aceptadas. Por eso en el curso de la evolución se ha desarrollado otro tipo de medios que Luhmann denomina "Medios de Comunicación Simbólicamente Generalizados". Estos medios sirven para aumentar la probabilidad de aceptación de las comunicaciones y tienen como modelo de operación al dinero. El dinero se convierte en el medio de comunicación propio del sistema económico y también opera con la distinción médium/forma. El dinero como médium está constituido por elementos flojamente acoplados los cuales aceptan formas de acoplamiento firme que son las sumas específicas de dinero que se ha de pagar por los bienes correspondientes. Una vez hecha la transacción, el dinero vuelve a acoplar flojamente sus elementos, de tal modo que puedan adoptar nuevos acoplamientos firmes, nuevas formas, al momento de ser usados en otras transacciones. Tal como el aire o la luz, el dinero como tal permanece sin ser visto, solo se ven cantidades mayores o menores de dinero, esto es, formas impresas en el médium. En el sistema económico, el dinero aumenta la probabilidad de aceptación de las demandas que pueden pagar y las ofertas que pueden ser pagadas. En el sistema científico, el medio de comunicación simbólicamente generalizado válido para aumentar la probabilidad de aceptación de las comunicaciones científicas es la verdad empíricamente demostrable según el método científico. En el sistema de las relaciones íntimas el medio correspondiente es el amor, así como el poder opera en el sistema político.

Otro gran tema desarrollado en "La sociedad de la sociedad" es el de la diferenciación. Señala Luhmann que, prescindiendo del hecho que las primeras sociedades humanas posiblemente se encontraban diferenciadas tan solo por las naturales diferencias entre sexos y edades, en el curso de la evolución se han desarrollado cuatro formas de diferenciación ${ }^{71}$ :

i. Segmentaria: Se caracteriza porque los subsistemas en que la sociedad se diferencia se consideran iguales entre sí. Estos sistemas parciales se diferencian unos de otros porque cada uno de ellos se considera emparentado internamente por constituir la descendencia biológica o simbólica de un ancestro común o provenir de alguna región específica. Cualquiera sea el caso, no hay un orden de preferencia que indique que alguno de los segmentos es superior a los demás. No es poco frecuente, por ejemplo, que se afirme que los ancestros de cada uno de los segmentos hayan sido hermanos entre sí.

ii. Centro y periferia: Considera una forma de dos lados, la cual instaura un caso de desigualdad que se impone a la segmentación, dejando segmentos en cada uno de los lados de la forma. El centro puede ser destacado por contener el templo, la fortaleza o los lugares sagrados donde solo pueden habitar ciertos segmentos.

iii. Estamental: En ella existe una desigualdad de rango entre los sistemas parciales. Se distinguen los pares de los pertenecientes al estamento inferior. Una estructura diferenciada estamentalmente que constara de solo dos estamentos sería sumamente inestable y 


\subsection{TEORIA SOCIOJURÍDICA INTERNACIONAL}

se podría fácilmente invertir. Por esta razón, pronto se establecen nuevos estamentos - al menos tres - que hacen más difícil el cambio y ofrecen mayor estabilidad.

iv. Funcional: Consiste en una estructura en la cual los sistemas parciales son diferentes entre sí, por cuanto cada uno de ellos se especializa en una función particular, e iguales, porque todas las funciones son igualmente importantes para la supervivencia del sistema social global.

Estas cuatro formas de diferenciación han resultado de la experimentación que ha venido haciendo la evolución de la sociedad. Esto significa que no hay razón alguna para pensar que no puedan producirse otros modos de diferenciación de la sociedad como resultado de la evolución posterior. Tampoco se puede afirmar que la evolución deba seguir un curso definido. Podría, naturalmente, producirse la vuelta a formas previas de diferenciación o a desarrollos regresivos.

No podemos aquí referirnos a las características de la diferenciación en las sociedades pre-modernas. Por eso nos concentraremos en la diferenciación funcional que se ha impuesto en la moderna sociedad mundial. Acaso lo más distintivo de esta forma de diferenciación es que no distribuye seres humanos completos entre sus diferentes sistemas parciales. Tanto la diferenciación estamental como la diferenciación en centro y periferia y la estratificación consideraban diferencias de agrupamientos sociales, los cuales estaban conformados por personas que podían pertenecer a uno y solo uno de estos grupos diferenciados. Quien pertenecía a un clan quedaba definido por su pertenencia total a dicho clan; allí encontraba su identidad y el comportamiento que debía caracterizar toda su vida. Lo mismo sucedía con un noble, un siervo o un burgués de la sociedad estratificada; aunque sus condiciones económicas le permitieran aspirar a un ascenso en la escala, todo lo que constituía su identidad como integrante de una clase se oponía a que sus aspiraciones se cumplieran, como lo demuestra Molière en "El burgués gentilhombre".

La diferenciación funcional enfatiza la desigualdad de sus sistemas parciales. Cada uno de ellos se encarga del cabal cumplimiento de una de las funciones que requiere la sociedad mundial para su mantención. Por la misma razón, la sociedad no puede establecer un orden de prioridad que destaque a algunos sistemas funcionales y deje a otros en posiciones secundarias. Los sistemas funcionales de la sociedad moderna son igualmente importantes para ésta: si bien es cierto que una sociedad funcionalmente diferenciada no podría operar sin contar con un sistema especializado en la función económica, tampoco sería pensable sin otros sistemas dedicados a la educación, la política, la ciencia, el derecho, etc. Por eso, es posible afirmar que en la sociedad diferenciada funcionalmente los sistemas parciales son completamente desiguales entre sí y que porque son desiguales, son igualmente importantes.

Si bien no existe un orden de relevancia entre las funciones de la sociedad, para cada uno de los sistemas funcionales la función en que se ha especializado es indudablemente más importante que todas las demás. Para el subsistema económico, nada puede ser más importante que la economía, así como para el subsistema político lo más relevante es la política y para el subsistema científico no es concebible que otra función sea prioritaria a la ciencia. Por esta misma razón, ningún sistema funcional puede ser reemplazado por otro. Cada uno de ellos necesita que los demás cumplan cabalmente su función $y$, en ese sentido, son interdependientes. La economía necesita que la política dicte y haga respetar las leyes que le permitan funcionar, que el sistema educacional forme los profesionales que necesita en su proceso de producción, que la ciencia continúe su tarea de investigación para desprender de ella nuevas tecnologías económicamente atractivas, etc.

Cada sistema funcional puede desempeñar solo una función. Ninguno de ellos puede intervenir en lugar de otro en caso de emergencia. Si hay una crisis de gobierno, la ciencia no puede prestar ayuda alguna con sus verdades científicamente demostradas. La economía puede - y debe - financiar las investigaciones científicas, pero no puede comprar sus resultados y la ciencia agradecerá este financiamiento con "acknowledgements", pero no con la demostración científica de la utilidad de cierto producto económico 
de su sponsor (Rodríguez and Torres Nafarrate 2008).

Así entendida la diferenciación funcional, es evidente que no puede asignar individuos completos a ninguno de los subsistemas funcionales que la constituyen. Nadie puede ser solo un homo economicus; de hecho éste no existe de manera concreta, sino únicamente como una abstracción metodológica hecha para entender el comportamiento humano en el ámbito de la función económica.

Los seres humanos, con toda su complejidad, pertenecen al entorno de la sociedad y participan en las diversas comunicaciones que caracterizan los sistemas funcionales - trabajan y compran en el sistema económico, eligen sus representantes en el sistema político, se rigen por las leyes del derecho y se educan en el sistema educativo, etc. - sin que ninguno de los subsistemas acapare toda su vida social ni, mucho menos, les otorgue su identidad global. Los individuos concretos no pueden ser ubicados concretamente en ninguno de los sistemas funcionales de la sociedad moderna, pero ellos deben poder participar en todos los sistemas funcionales haciendo uso del código de comunicación correspondiente a cada uno de estos sistemas funcionales. La comunicación es adjudicada a distintos sistemas funcionales de acuerdo a su sentido, porque se trata de un pago, la solicitud de auxilio legal, una proclama política, un examen de conocimiento, una demostración científica, un concierto de música, etc.

En la sociedad funcionalmente diferenciada, toda persona debería tener sus derechos, disponer de un ingreso suficiente para tener acceso a bienes económicos y reaccionar como electora a sus experiencias políticas. Todos deberían contar con acceso a la educación escolar, poder exigir un cierto mínimo de servicios sociales, salud y previsión. Todos deberían poderse casar sin requerir permisos especiales, etc. En breve, todos los seres humanos deberían estar incluidos en la sociedad. De hecho, cuando alguien no hace uso de alguno de sus derechos: no se inscribe para votar, no trabaja, no compra en los supermercados, no se educa, no se casa legalmente, no acude a los servicios de salud, etc., se atribuye su ausencia, su no participación, a una decisión propia y libre. De esta forma, la sociedad moderna evita percibir el otro lado de la forma: la exclusión como fenómeno socioestructural..$^{72}$

Al diferenciarse funcionalmente, la sociedad ha traspasado a sus subsistemas funcionales la tarea de regular la relación entre inclusión y exclusión y no existe una instancia central que vigile el cumplimiento de esta tarea. De cuánto dinero dispone un individuo es algo que se decide en el sistema económico. Que los derechos legales de una persona sean debidamente cautelados en un juicio depende del sistema del derecho. Que alguien pueda aprovechar los avances científicos bajo la forma de tabletas depende de los programas de investigación del sistema científico. En suma, al definirse como posible participar en los diversos sistemas funcionales, según las condiciones indicadas por esos mismos sistemas funcionales, se genera la ilusión de que la sociedad incluye a todos los seres humanos, sin hacer excepciones. Lo que efectivamente ocurre, sin embargo, es bastante menos satisfactorio. La exclusión fáctica de un sistema funcional contribuye a aumentar la probabilidad de ser excluido también de otros: personas sin trabajo, sin ingreso, sin cédula de identidad, sin relaciones íntimas estables, sin acceso a contratos ni protección legal, sin alfabetización, sin derechos políticos, en condiciones de salubridad insuficiente y sufriendo desnutrición. En la sociedad moderna hay enormes grupos de personas excluidas las que frecuentemente son aisladas habitacionalmente, lo que las hace invisibles. ${ }^{73}$

En el ámbito de la exclusión surgen redes de clientelismo que se construyen en torno a posiciones dentro de las organizaciones propias de la sociedad funcionalmente diferenciada. Estas redes ofrecen favores y ventajas, mediante contactos directos o intermediados por el amigo del amigo del amigo. Siempre se conoce a alguien que conoce a alguien y la concesión de favores

\footnotetext{
${ }^{72}$ LUHMANN, N. La sociedad de la sociedad, p. 495-496

${ }^{73}$ LUHMANN, N. La sociedad de la sociedad, p. 500.
} 


\subsection{TEORIA SOCIOJURÍDICA INTERNACIONAL}

se encuentra tan extendida que no es posible denegar una ayuda cuando es posible concederla, porque la red genera su propio mecanismo de exclusión y es posible verse de pronto excluido de ella. Estas redes son relativamente estables y logran perdurar en condiciones cambiantes. Redes de seguridad e inteligencia en regímenes autoritarios se convierten, al volver la democracia, en redes de contrabando, tráfico de blancas $\mathrm{y}$ estupefacientes $\mathrm{o}$, simplemente, de presión $\mathrm{y}$ amedrentamiento.

En el ámbito de la inclusión, los seres humanos cuentan como personas, en tanto en el ámbito de la exclusión solo valen como cuerpos y pueden actuar violentamente contra el cuerpo de turistas, ofrecer su cuerpo en términos de prostitución, turismo sexual y pornografía infantil o mostrar sus llagas y enfermedades para conseguir limosnas. También los Estados enfrentan el problema de la exclusión atendiendo solamente a los cuerpos de los excluidos: se los debe vacunar para evitar que se conviertan en foco de infección, se les reparte leche, se ingresa a las favelas con violencia policial o militar. No hay intención de incluirlos, haciéndolos parte de la comunicación. No hay políticos que hagan su campaña al interior de una villa miseria, porque quienes allí habitan carecen de derecho a voto. Tampoco se les ofrece empleo en industrias o servicios, porque no tienen existencia legal, carecen de formación y se les supone drogadictos. Únicamente las redes delictuales les ofrecen trabajar como sicarios, vale decir, como cuerpos capaces de matar y de morir sin ser identificados.

\section{CONCLUSIÓN}

Así hemos concluido con esta breve reseña del desarrollo teórico llevado a cabo por Niklas Luhmann a lo largo de más de treinta años de fructífero trabajo académico. Hemos dejado de lado numerosos libros dedicados al estudio de diferentes sistemas funcionales, tales como el derecho, la economía, la educación, la religión, la política, el arte, la ciencia. Tampoco consideramos las investigaciones que el autor hizo sobre determinados momentos históricos en que la evolución se expresaba a través de cambios semánticos y estructurales.

La evolución sigue su camino. Contamos ahora con una sólida teoría de la sociedad moderna entendida como un único sistema social hecho de comunicaciones, cuya complejidad se incrementa al aumentar las comunicaciones que lo constituyen. Reduce la complejidad a través de sistemas cuya función es, precisamente, reducir la complejidad. La multiplicación de comunicaciones que han hecho posibles las modernas tecnologías de la información ha generado protestas que no han sido debidamente comprendidas por el sistema político de los estados nacionales. Se han hecho visibles las incertidumbres generadas por las decisiones de organizaciones pertenecientes a diferentes sistemas funcionales. También aumenta la desconfianza ciudadana frente al comportamiento de esas mismas $\mathrm{u}$ otras organizaciones. Los sistemas funcionales se clausuran en sí mismos y prestan escasa atención a sus dificultades de coordinación. La exclusión social se hace visible pese al esfuerzo por dejarla inadvertida. La indignación ciudadana se ha cansado de buscar motivos comunes que le permitan hacerse oír y por eso no se une tras un objetivo compartido, sino por la común indignación derivada de motivos muy diversos. Ello queda adecuadamente comprendido por la teoría de la sociedad, donde se reserva un subcapítulo para comprender los nuevos movimientos de protesta. ${ }^{74}$ Estos movimientos no disminuyen en la sociedad moderna, sino que aumentan, lo que puede tener relación con que la sociedad se ha diferenciado funcionalmente.

Los nuevos movimientos de protesta no guardan ninguna relación con los movimientos socialistas; no se trata de protestas contra la industrialización y sus consecuencias ni tampoco exigen una mejor distribución del bienestar. Sus motivos y temas son más heterogéneos. Necesitan de la interacción y por eso citan a concentraciones, pero el sentido de estar juntos e encuentra fuera del estar juntos. Para quienes participan se encuentra en los problemas individuales de la búsqueda de sentido y la autorrealización. Fre-

${ }^{74}$ LUHMANN, N. La sociedad de la sociedad, p. 672-686. 


\subsection{TEORIA SOCIOJURÍDICA INTERNACIONAL}

cuentemente argumentan como "afectados" por los verdaderos "afectados". Su energía y capacidad para cambiar de temas, siempre que puedan comunicarse como protesta, se explica porque oscilan. También esta flexibilidad les permite reconocer correligionarios detrás de otros temas de protesta, formando las correspondientes simpatías. Todo esto puede ser observado con los conceptos teóricos que hemos presentado. La teoría luhmanniana es una teoría de la observación y sus distinciones permiten observar la observación que estos modernos observadores están haciendo de la complejidad en incremento de esta sociedad de comunicaciones. No es posible ofrecer viejas respuestas a preguntas nuevas. Para eso está la reducción de la complejidad.

\section{REFERENCIAS}

ASHBY, W. R. An introduction to cybernetics. New York: John Wiley \& Sons, 1958.

BAECKER, D. Wozu soziologie? Berlin: Kulturverlag Kadmos, 2004.

BATESON, G. Steps to an ecology of mind. San Francisco: Chandler, 1972.

BERTALANFFY, L. v. Perspectivas en la teoría general de sistemas. Madrid: Alianza Editorial, 1979.

COMTE, A. La física social. Madrid, Aguilar, 1981.

DURKHEIM, E. De la división del trabajo social. Buenos Aires: Shapire, 1967.

FOESTER, H. v. Observing Systems. California: Seaside, 1981.

. Las semillas de la cibernética. Barcelona: Gedisa, 2006.

HABERMAS, J. Teoría de la acción comunicativa. Madrid: Taurus, 1998.

; LUHMANN, N. Theorie der gesellschaft oder sozialtechnologie. Was leistet die Systemfors- chung? Frankfurt am Main: Suhrkamp, 1971.

GOFFMAN, E. La presentación de la persona en la vida cotidiana. Buenos Aires: Amorrortu, 2006.

KAUFMANN, F. X. Ein Wittgenstein'sches Schweigen. In: STICHWEH, R. Wirkungen eines theoretikers. Bielefeld: Transcript Verlag, 1998.

KUHN, T. La estructura de las revoluciones científicas. México: Fondo de Cultura Económica, 1971.

LUHMANN, N. Sinn als grundbegriff der soziologie. In: ; HABERMAS, J. Theorie der gesellschaft oder sozialtechnologie - Was leistet die Systemforschung? Frankfurt am Main: Suhrkamp, 1971.

. Soziologische Aufklärung 1. Opladen: Westdeutscher Verlag, 1974.

Moderne systemtheorien als form gesamtgesellschaftlicher analyse. In: ; HABERMAS, J. Theorie der gesellschaft oder sozialtechnologie - Was leistet die systemforschung? Frankfurt am Main: Suhrkamp, 1975.

Organisation und Entscheidung. Opladen: Westdeutscher Verlag, 1978.

Soziale systeme. Frankfurt am Main: Suhrkamp, 1984.

The autopoiesis of social systems. Autopoiesis in law and society. Florence: Badia Fiesolana, European University Institute, 1985.

. Social systems. Stanford, California: Stanford University Press, 1995.

Archimedes und wir. Interviews. Berlin: Merve Verlag, 1987.

Die gesellschaft der gesellschaft. Frankfurt am Main: Suhrkamp, 1997. 
Organización y decisión. Autopoiesis, acción y entendimiento comunicativo. Barcelona: Universidad Iberoamericana/ISUC/Anthropos, 1997.

. La sociedad de la sociedad. México: Herder, 2007.

MATURANA, H.; VARELA, F. Varela De máquinas y seres vivos. Santiago: Editorial Universitaria, 1973.

El árbol del conocimiento. Santiago: OEA/Editorial Universitaria, 1984.

MERTON, R. K. Teoría y estructura sociales. México: Fondo de Cultura Económica, 1965.

PARSONS, T. The social system. New York: The Free Press of Glencoe, 1964.

. La estructura de la acción social. Madrid: Ediciones Guadarrama, 1968.

RODRÍGUEZ, D.; NAFARRATE, J. Torres. Introducción a la teoría de la sociedad de Niklas Luhmann. México: Herder, 2008.

SPAEMANN, R. Laudatio anlässlich der Verleihung des Hegel-Preises 1989: Niklas Luhmanns Herausforderung der Philosophie. In: ; LUHMANN, N. Luhmann. Paradigm lost: Über die ethische reflexion der moral. Frankfurt am Main: Suhrkamp, 1990.

SPENCER-BROWN, G. Laws of form. New York: Dutton, 1979.

TURNER, J. H.; BEEGHLEY, L. The emergence of sociological theory. Homewood, Ill: Dorsey Press, 1981.

WEBER, M. Economía y sociedad. México: Fondo de Cultura Económica, 1964. 


\title{
INCLUSIÓN DEL “MODELO COMPLEJO” EN LA SOCIOLOGÍA JURÍDICA REFLEXIVAL
}

\author{
Mario S. Gerlero ${ }^{\mathrm{i}}$
}

Resumen: 1 Sociología jurídica y la "complejidad" en la pluralidad de dimensiones. 2 La función de los derechos humanos en el "modelo complejo". 3 Modelos complejos, los campos sociales y la identidad del actor. 4 El modelo complejo: desde el multiculturalismo al pluralismo jurídico. $5 \mathrm{La}$ institucionalización real y la formal. Referencias.

\section{Resumo}

A entrada de novos atores sociais, como fenômeno cultural relevante, transforma o campo legal, ampliando o leque de direitos, dentre os quais se destaca a igualdade plena. Para analisar as múltiplas dimensões dos fenômenos sociais, neste contexto, faz-se necessário trabalhar com diversos modelos, metodologias e variáveis múltiplas, resgatando-se a reflexão crítica no campo legal. Novas concepções metodológicas geram espaços abertos de análise teórica da realidade social, permitindo conclusões mais simples de situações obscuras e complexas. Com isto, é possível refletir sobre o campo legal, especulando novas questões e respostas diferentes, em face das re-

\footnotetext{
${ }^{i}$ Doctor y Pos-Doctor de la Universidad de Buenos Aires en el Área de la Sociología Jurídica; Especialista en Sociología Jurídica; Abogado. Profesor de Grado y Postgrado en la Facultad de Derecho de la Universidad de Buenos Aires y en la Facultad de Ciencias Jurídicas y Sociales de la Universidad Nacional de La Plata (República Argentina) Director del Grupo de Estudios de la Complejidad en la Sociedad de la Informática (UNLP-Argentina). Director de Proyectos de Investigación (UBA y UNLP) en áreas de estudios sistémicos, modelos complejos y construcciones identitarias en la temática de géneros, política legislativa y gestión judicial.mario_gerlero@yahoo.com.ar
} 


\subsection{TEORIA SOCIOJURÍDICA INTERNACIONAL}

lações sociais emergentes. A criação de espaços alternativos de análise acadêmica no campo jurídico possibilita a construção de novos sentidos em face da complexa rede de subjetividades que se apresenta, gerando análises críticas do mundo sócio-legal, para o qual a coesão social era o centro de estudo empírico, limitando a emergente "cidadania-plena". Assim, a partir de um conceito multidimensional de análise, a sociologia reflexiva colocou em crise a ideia de instituições jurídicas uniformes. Abordagens multidimensionais produzem um senso coletivo de como são limitadas as instituições existentes, ineficientes no tratamento de novas questões, esquecidas ou não amparadas pelo campo legal.

Palavras-chave: Modelo complexo. Sociologia jurídica. Multiculturalismo. Cidadania plena.

\section{Abstract}

The transformation of the legal field with the entry of new social actors (as relevant social phenomenon) involves the deepening and expansion of rights among which stand out full equality and ensuring the differences. It is necessary to use a plurality of variables, dimensions, models and methodologies to work the phenomena from multiple dimensions, rescuing course, critical reflection in the legal field. The situation of redefinition of epistemology conceptions of knowledge creation spaces open, allowing aside a simplified theoretical vision of social reality to think and rethink the situations darkened and complex. Allows above all reflect on the relationships that test the legal institution and to speculate on the structures to imagine theoretical questions, contain analysis and studies lead to different answers. Creating alternative spaces in academics in the juridical field and rise to a search for a new sense and a new and complex network of subjectivities, a situation that puts a strain on the socio-legal worldview where social cohesion was the hub of empirical study and limit the "full citizenship". Then Reflexive Sociology of Law, from a multidimensional concept, put into crisis the idea of uniform legal institutions as a (complex) multidimensional approach produces a collective sense of how limited are exis- ting institutions to address new issues, silenced or not covered the legal field.

Keywords: Complex model. Legal sociology. Multiculturalism. Full citizenship.

\section{SOCIOLOGÍA JURÍDICA Y LA “COMPLE- JIDAD” EN LA PLURALIDAD DE DIMEN- SIONES}

a. En la República Argentina se está produciendo un proceso de transformación en el campo jurídico con el ingreso de nuevos actores sociales que hasta hace poco tiempo fueron silenciados. Se trata de un proceso de ampliación y profundización de derechos entre los cuales se destacan la igualdad, el respeto y la garantía de las diferencias. Esta situación lleva, de manera necesaria, a despojarse de los dogmatismos y empecinamientos teóricos en el área de la Sociología que aborda el campo jurídico, ya que resultaría necesario recurrir a una pluralidad de modelos y de metodologías que permitan trabajar los fenómenos desde múltiples dimensiones, rescatando siempre la reflexión critica.

Surge como protagonista, en el campo jurídico, un proceso de aggiornamiento en la teoría y en la investigación como efecto del agenciamiento, a través del derecho y la gestión de diferentes reparticiones de la administración pública, de las construcciones históricas de las subjetividades donde actores en interacción constituyen una compleja red de relaciones que dan un nuevo sentido al campo jurídico y a su saberes. Si se pudiera referir a un modelo estándar a ser utilizado este debería surgir del abordaje de múltiples dimensiones con una orientación crítica y cuestionadota del sistema vigente por razones simples: el alto impacto en la estructura jurídica-judicial y la vocación de la misma a ser un colectivo identificado con la resistencia a cualquier intento de transformación social con notorios ejemplos de intransigencia a la inclusión y emponderamiento de sectores sociales excluidos.

b. Este documento, entonces, intenta introducir la noción de recurrir a la inclusión de un "modelo complejo" conformado por un amplio 


\subsection{TEORIA SOCIOJURÍDICA INTERNACIONAL}

programa teórico que en muchos casos resignifique aportes considerados clásicos y necesarios para el tratamiento de fenómenos que han adquirido una notoria visibilidad en los últimos treinta años y que son producto de los "Nuevos Movimientos Sociales en Latinoamérica” De este modo el texto es un intento por encontrar y sistematizar aportes teóricos y fenómenos sociales que posiciona y dan autonomía a la Sociología Jurídica Reflexiva, como una confluencia y concurrencia de modelos, estudios, escuelas y teorías algunas en debate pero que todas sumadas en una suerte de paradigma con pretensiones de ser "coral" admiten una construcción en donde se cimienten los estudios empírico para confirmar: (i) la consolidación y la expansión socio-jurídica del concepto de ciudadanía plena (desde las teorías subjetivistas a la estructuración concretada en la vigencia de legislación que concrete los principios de los derechos humanos) y (ii) el asegurar la plena existencia socio-cultural-política-económica de diversas subjetividades e identidades garantizadas por la vía jurídica y judicial.

La variedad y diversidad de las experiencias de cada uno de los agentes ponen en claro una precondición indispensable para la transición mencionada y para las transformaciones jurídicas aunque, por otra parte existe una marcada tendencia a ignorar, subvaluar y anular las situaciones mencionadas por medio de procesos de homogeneización forzada de sectores considerados hasta la actualidad como dominantes y hegemónicos.

La idea de la Sociología Jurídica Reflexiva sostenida por el "modelo complejo" implica recapacitar sobre las relaciones sociales y culturales que ponen a prueba a la institución jurídica y especular como imaginar estructuras teóricas que permitan formular preguntas, contener análisis, conducir los estudios a diferentes respuestas y potenciar o consolidar procesos de transformación a partir de la "investigación-acción".

Queda claro que, en el presente contexto social y político, se producen transformaciones en: a) la subjetividad colectiva, b) la producción cultural, c) la vida cotidiana, d) el proyecto de vida, e) las relaciones entre el ser y el otro, f) las condiciones laborales, g) las estructuras estatales h) las relaciones interestatales, y i) el sistema democrático. Estas situaciones generan: la perdida de legitimidad de instituciones consideradas valiosas para el sistema socio-jurídico; la desaparición de las referencias sociales sólidas (numerosas ambivalencias y contradicciones); el ingreso y la búsqueda de consolidación de prácticas socio-jurídicas que fueron consideradas como subalternas; la reducción de las semejanzas entre los actores y el aumenta la distancia social; y la exteriorización de las tensiones sociales y la presencia de los conflictos en un mismo espacio público-político. Todas estas situaciones tratadas a lo largo del presente texto crean un vació en el contenido de las instituciones.

c. Por esta razón resulta importante, en el estudio de la configuración de distintas tradiciones teóricas del pensamiento socio-jurídico, trabajar las experiencias de ruptura social que Robert Castel ${ }^{1}$ llama "desafiliación" o "desconexión social" respecto de las regulaciones institucionales formales a través de las cuales por lo general la vida social se reproduce y se renueva. A partir de tan contundente afirmación es de necesario destacar que una formación social está hecha de la interconexión de posiciones más o menos garantizadas, los individuos y los agrupamientos inscriptos en las redes productoras de la riqueza y el reconocimiento social están "integrados" en cambio se encuentran excluidos o desafiliados aquellos que no participan de ninguna manera en esos intercambios regulares esta situación generan inestabilidad social, cultural, económica, afectiva, política, entre otros ejemplos. Pero entre esos dos tipos de situaciones existe una gama de posiciones intermedias más o menos estables. Caracterizar la marginalidad es situarla en el seno de ese espacio social, alejado del centro de los valores dominantes pero sin embargo ligada a ellos ya que lo marginal lleva el signo invertido de la norma que no cumple; marca distancia. ${ }^{2}$

d. En dicho contexto la Sociología Jurídica

${ }^{1}$ CASTEL, Robert. El ascenso de las incertidumbres: trabajo, protecciones, estatuto del individuo. Buenos Aires: Fondo de Cultura Económica, 2010. p. 229. 


\subsection{TEORIA SOCIOJURÍDICA INTERNACIONAL}

permite rescatar al derecho como un instrumento, una forma de legitimación, una forma de estructuración y a su vez una excusa o un mero enmascaramiento de los intereses y necesidades de los agentes con programas políticos-administrativos explícitos o implícitos referidos a diferentes fenómenos y problemáticas sociales. Permite ver a la normativa formal como un dispositivo de control, muchas veces funcional a sectores y colectivos sociales con espacio de poder en el sistema social.

El derecho es una herramienta de control, de cambio y de legitimación, de acuerdo a la agenda y a la ejecución de las diferentes políticas adoptadas por entidades administrativas públicas y sus protagonistas; es un dispositivo en el complejo andamiaje de las políticas públicas ${ }^{3}$. Esto es: normativa formal emanada de los operadores que depende de manera directa o indirecta del programa o proyecto (sistematizado o no) de una Administración, donde se destaca la presencia de gobernantes especializados (autoridad) y de mecanismos persuasivos o coercitivos de gobierno que buscan, en apariencia, la integración y el desarrollo armonioso en sociedades complejas con el fin de recrear o mantener - supuestamente - la conciencia colectiva, la existencia y el desarrollo armonioso de la sociedad en su conjunto, claro está con la posibilidad que las ordenes sean obedecidas. Sujetos aparentemente garante del interés colectivo, dotado de legitimidad y con reglas propias, y supuestamente disociado de aparatos económicos, políticos y religiosos.

e. Por lo tanto, la Sociología Jurídica, desde el "modelo complejo" pone en crisis, desde el “investigación-acción”, la idea de instituciones jurídicas identificadas con el sentido común y el imaginario acerca de lo que se concibe por normas y organizaciones jurídicas, incluso reflexiona sobre las valoraciones positivas respecto de los sujetos que conforman dichas instituciones y cuestiona el imaginario social sobre la valía de las instituciones referidas. Un enfoque multidimensional produce, en el observador, una sensación colectiva de lo limitada que son las instituciones vigentes para tratar temáticas o situaciones supuestamente novedosas. En la percepción generalizada de académico parecería que los sentidos de algunas de las instituciones llegaron a su fin, de que pueden ser obsoletas en un contexto de pluralismo de dimensiones.

f. Desde una Sociología Jurídica identificada e inserta en un marco complejo (multidimensional y transdisciplinario) y punto de partida de un fenómeno social concreto relevante implica, entonces, trabajar con alternativas al poder teórico hegemónico y entender que el mero hecho de colocarse ahí es ya un principio que socava las encorcetaduras y limitaciones teóricas y metodológicas. Implica trabajar situándose fuera del poder establecido y considerado válido y único como respuesta para conocer, interpretar y explicar fenómenos. Es reparar en un contexto complejo, que no se circunscribe al mero hecho de tener en cuenta dimensiones sociales, culturales, políticas, económicas, históricas y/o geográficas; incluso va mas allá: cada una de estas dimensiones pueden ser profundizadas como por ejemplo "la dimensión social" cuando en estas surgen situaciones de segmentación, ten-

\footnotetext{
${ }^{2}$ La exclusión se da, entonces, en aquello que esta fuera de los circuitos vitales de los intercambios sociales, nombra situaciones que se traducen en una degradación respecto de una posición anterior (situación vulnerable). El excluido poblaría la zona más periférica caracterizada por una relación perdida, de falta de reconocimiento y por el aislamiento social; por lo general es producto de cómo se deshacen las solidaridades y aparecen déficit específicos. La exclusión no es la marginación aunque puede conducir a ella. Se podría destacar tres momentos la vulnerabilidad creada por la degradación de las relaciones, la marginación como un déficit en la integración y la exclusión. Las dos primeras categorías implican una "amenaza de exclusión” La noción de marginal se asocia con la movilidad social, las situaciones sociales inestables y cierto cosmopolitismo. CASTEL, Robert. El ascenso de las incertidumbres: trabajo, protecciones, estatuto del individuo, p. 245.

Lo expuesto es lo que se podría considerar como postura de la "teoría anfitriona" en los estudios socio-jurídicos, es el punto de partida e idea que facilita la síntesis integradora del fenómeno de la diversidad sexual y de la identidad de género.

${ }^{3}$ El derecho es considerado como el conjunto de normas vigentes formales originadas en los intercambios de expectativas de sectores prevalecientes, situados en una comunidad en constante tensión por su fragmentación. Encuentra su legitimación, no sólo en el espacio de poder del sector con ánimo de dominio sino además cuando, supuestamente, se adecuan a las circunstancias históricas de la mencionada comunidad fracturada. Su principal objeto es intentar regular la vida social e institucional desde un buscado y necesario conformismo de los actores, con el objeto de garantizar la competencia y facultad de satisfacer expectativas individuales y/o grupales de acuerdo a los valores institucionalizados de manera hegemónica. Se presenta como una sofisticada técnica (herramienta o instrumento) de organización social que contribuye a la implementación de un orden, a la realización de un modelo organizativo social posible producto de un dudoso consenso.
} 


\subsection{TEORIA SOCIOJURÍDICA INTERNACIONAL}

siones, exclusión, estructura de dominación, por diferentes motivos. La presente tiende a enfrentarse a todo mecanismo de neutralización de los fenómenos sociales que llevan, con el tiempo a hacerlos pasar como naturales; al mostrar a los agentes sociales los resortes del control y la opresión les brindan argumentos susceptibles de poner en juego acciones políticas. Como bien lo afirma Bourdieu ${ }^{4}$ la mencionada disciplina puede ser un contrapoder garante de la democracia ya que suministra instrumentos al ejercicio normal de la crítica de las ilusiones sociales y permite fundar un utopismo realista alejado de los voluntarismos; siguiendo esta línea la Sociología Jurídica lo es al terminar facilitando herramientas para un observatorio del mundo jurídico y judicial, denunciando prácticas que atentes contra: las políticas de las identidades y la política de la diversidad; en último termino develando toda la búsqueda de acallar el multiculturalismo desde sectores hegemónicos en un contexto de "comunidad ilusoria" creada y recreada por diferentes redes, colectivos y organizaciones con espacio de poder en la estructura social.

\section{LA FUNCIÓN DE LOS DERECHOS HUMA- NOS EN EL "MODELO COMPLEJO”}

a. En este contexto la Sociología Jurídica recurre a los derechos humanos como punto de partida para poder integrar las múltiples dimensiones de fenómenos sociales concretos relevantes. Así el concepto de derechos humanos puede predicarse respecto de todo ser humano por el sólo hecho de ser tal y el cualquier sociedad; de allí la universalidad de la noción y su diferencia con los derechos de los hombres libres. ${ }^{5}$ Su universalidad no puede sino conducir a su igualdad que reconoce como corolario la no discriminación como forma de deslegitimar, declarando ilegal, toda diferencia que tenga por objeto cercenar, conculcar, afectar o impedir el goce y ejercicio de derechos humanos. Se trata de las prácticas y medios por los que se abren espacios de emancipación que incorporan a los seres humanos en los procesos de reproducción y mantenimiento de de una vida digna. Aún cuando se encuentran protegidos por la mayoría de las legislaciones internacionales, los derechos humanos suponen una base moral y ética que la sociedad considera necesaria respetar para proteger la dignidad de las personas.

b. Los diferentes derechos humanos ${ }^{6}$ son, entonces, un conjunto de prerrogativas inherentes a la naturaleza de la persona, cuya realización efectiva resulta indispensable para el desarrollo integral del individuo que vive en una sociedad jurídicamente organizada. Tal vez los fundamentos de los derechos humanos más relevantes se encuentre en las transferencias de poder que se producen entre los grupos sociales, así como las instituciones en que se articulan y las lógicas que inspiran las relaciones sociales en un acuerdo racional alcanzado por consenso y que se cimientan en la experiencia socio-cultural y la conciencia morales. Asegura las condiciones que permiten crear una relación integrada entre la persona, los grupos, la estructura social y la estructura formal-estatal.

A partir de los derechos humanos como anclaje de la democratización de la sexualidad y de los estudios de identidad de género - a modo de ejemplo - se han vuelto sinónimo del respeto por las libertades individuales y los valores de tolerancia y aceptación de la diferencia; de manera que se ha conformado uno de los ejes mediante los que un estado puede definirse a si mismo como democrático y moderno. ${ }^{7}$

c. Para lo expuesto es necesario identificar la compleja tejido de actores sociales (sujeto, persona autónoma, individuo e identidad) en relación con la estructura social que construye desde el entramado de interacciones (redes, colectivos

\footnotetext{
${ }^{4}$ BOURDIEU, Pierre; WACQUANT. Löic. Una invitación a la sociología reflexiva. Buenos Aires: Siglo Veintiuno, 2005.

${ }^{5}$ PINTO, Mónica. Temas de derechos humanos. Buenos Aires: Del Puerto, 2009. p. 10.

${ }^{6}$ Los derechos de primera generación son los derechos civiles y políticos, vinculados con el principio de libertad. Generalmente se consideran derechos de defensa o negativos, que exigen de los poderes públicos su inhibición y no injerencia en la esfera privada. Por su parte, los derechos de segunda generación son los derechos económicos, sociales y culturales, que están vinculados con el principio de igualdad donde se exigen para su realización efectiva de la intervención de los poderes públicos, a través de prestaciones y servicios públicos. Por su parte, la tercera generación de derechos, se vinculan a la solidaridad, la paz, la calidad de vida, entre otros ejemplos.

${ }^{7}$ SABSAY, Leticia. Fronteras sexuales: espacios urbanos, cuerpos y ciudadanía. Buenos Aires: Paidós, 2011 . p. 31.
} 


\subsection{TEORIA SOCIOJURÍDICA INTERNACIONAL}

y organizaciones). En este sentido es de importancia destacar el muticulturalismo (emergente de diferentes colectivos y referente de las multidimensiones) su impacto y potencialidad en el campo jurídico y en la gestión de diferentes agencias de la administración. Más derechos aseguran la igualdad desde la diversidad y son percibidos y vividos, por diferentes sectores sociales, en plenitud ya que haciendo realidad los principios de los derechos humanos se desplazan las tensiones y los conflictos que surgen de toda variante de exclusión, pobreza y olvido. Continuar, entonces, por los caminos de la democracia, construyendo una sociedad pluralista, implica reconocer que la diversidad social, cultural, económica y política se ha constituido en el actualizador de las ciencias jurídicas; esto es reconocer realidades que se están institucionalizando y que se encuentran en formación y consolidación dentro del campo jurídico y judicial.

\section{MODELOS COMPLEJOS, LOS CAMPOS SOCIALES Y LA IDENTIDADE DEL ACTOR}

a. El estudio de un fenómeno social concreto relevante en el contexto de una sociedad multidimensional se puede realizar a partir de sus diversas dimensiones con metodologías y enfoques de distintas disciplinas.

Un análisis socio-jurídico enrolado en los estudios de redes o sistemas complejos permitiría abordar un fenómeno social concreto relevante desde una combinación de teorías y métodos ya que seria un detonante para realizar preguntas sobre causas, desarrollos y los posibles nuevos sentidos de dicho fenómeno como sus implicancias en el campo social $y$, de manera destaca en el jurídico.

La idea de "sistema complejo" no sólo facilita describir una estructura social, sino que implica introducir incluir las condiciones dentro del cual los actores/sujetos/individuos adoptan libremente sus decisiones (no siempre racionales y concientes). Permite moldear nexos entre lo micro y lo macro. Con lo expuesto cobra sentido en un análisis de múltiples dimensiones (cuando se recurre a las redes sociales y al estudio de la complejidad) la comprensión del sentido de la acción social en el contexto del mundo de la vida del protagonista participante.

En el proceso de reflexión transnormativa, en un sistema complejo, multidimensional, surgen las siguientes aproximaciones a tener en cuenta en la construcción teórica como empírico del estudio de un fenómeno social concreto relevante: 1) los fenómenos no son lineales, con diferentes matices, posibilidades, con numerosas fases y procesos adaptativos, manifiestan la diversidad $y$ las formas peculiares socio-culturales en relación con la política jurídica y o económico contextualizado por el tiempo y el espacio; y 2) muchas veces las dimensiones a recurrir desafían el sentido común que invitan a tener presente la incertidumbre y lo indecible; la combinación de las descripciones estructurales con la comprensión del sentido de las acciones de los protagonistas, las estructuras sincrónicas mutan, son dinámicas, intervienen sentidos, motivos, intereses, necesidades numerosas.

Resulta destacado, entonces, importante rescatar la relación dialéctica de la "propuesta estructura-constructivista" de Bourdieu sustentada en la relación entre estructuras sociales externas y estructuras sociales internalizadas, lo social hecho cosas y lo social hecho cuerpo. ${ }^{8}$

Es cierto que quedan a la vista limitaciones del constructivismo, el subjetivismo y variantes del posmodernismo. ${ }^{9}$ Parecería que para muchos significó el paso de un sujeto "sujetado" a una estructura por el individuo libre de constricciones. Se desplazó la concepción orgánica y funcional de lo social por otras puramente fragmentadas $y$ fractales; el estudio de la dominación y la reproducción por el de la creatividad del consumidor individual

b. Uno de los problemas de los intentos subjetivistas por rebatir el objetivismo y de las búsquedas de síntesis entre objetivismo y subjetivismo es que generadamente indagan sobre una

\footnotetext{
${ }^{8}$ A Partir del proyecto J-122 "Redes Sociales: el entramado social en entornos digitales" Dirigido por Claudia Tello; Facultad de Ciencias Jurídicas y Sociales; Universidad Nacional de La Plata, Argentina. En la actualidad en autor del presente texto se encuentra analizando el tema aquí referido en el contexto de la Sociología del Derecho a las Sexualidades y a la Identidad de Género (SD-SIG). (2012-2014)

${ }^{9}$ GRIMSON, Alejandro. Los límites de la cultura: crítica de las teorías de la identidad. Buenos Aires: Siglo XXI, 2011. p. $18,19$.
} 


\subsection{TEORIA SOCIOJURÍDICA INTERNACIONAL}

relación determinable entre sujeto y estructura. La noción de contextualidad radical, según Grimson ${ }^{10}$ permite advertir que no hay una relación ahistórica entre sujeto y estructura o mejor dicho entre sujeto y procesos estructurantes y estructurados. Lo que existe son situaciones en las cuales las relaciones entre los seres humanos se hacen, la historia y "las condicionalidades de las circunstancias" que no han elegido varían significativamente no lo suficiente para creer que hay situaciones de sujetos sin estructuras o vice versa pero si lo bastante para saber que hay circunstancias que parecen ser de ese modo. Se está haciendo referencia a lo socialmente construido y a su producción: las normas. Se trata de cosmovisiones, de sistemas de creencias, una suerte de ideología considerada como verdaderas, tomada como verdadera, normal y que le da sentido a cualquier acción (prevención, coacción) de actores que buscan que se mantenga. Está naturalizada y normalizada. Los sujetos aceptan, internalizan dicha cosmovisión social y culturalmente construida sin pensar en el proceso de construcción. Es de afirmar que una posibilidad de superar las formulas subjetivismo/objetivismo es Pierre Bourdieu. Este autor desarrolla un modelo teórico de la práctica social que no es más que la concreción de conocimientos, conscientes o inconscientes, en formas de actuar. Cada sociedad, cada cultura, cada grupo de personas que se reconoce parte de una colectividad, tiene formas de ver al mundo y a su lugar en él; modelos de cómo es este contexto (o mundo), de cómo debe ser, de lo que es la "ser humano". Lo importante es que éstos se aprenden y construyen a través de y como parte de las actividades cotidianas. No tienen sólo funciones cognitivas ya que implica conocer pero, también, hacer. El conocimiento del mundo social es parte integral de la producción y reproducción de ese mundo, a partir de una lógica de la práctica, de del sujeto y su entorno. c. Los diversos caminos que recorrió la teoría social desde los años setentas y especialmente desde la década de 1980 fueron bocanadas de aire fresco. La historicidad, el poder, la subjetividad, la construcción y la reconstrucción abrieron nuevos horizontes o reabrieron perspectivas con extensas tradiciones que hasta entonces habían quedado desplazadas. Posibilitaron así nuevas conceptualizaciones y renovados programas de investigación. ${ }^{11}$ Esta postura resulta de importancia para quitar del centro el análisis objetivista y sus variantes: positivistas, funcionalistas o estructuralistas. Se deja de pensar en los fenómenos es algo que existe como sistemas independientes de los actores y rescatar la idea de que el sujeto es el protagonista que lo crea y recrea.

El protagonista de la descentralización de la retórica homogeneizante es el individuo, aquí es donde se centra la prioridad analítica para reflexiones sobre las normativas formales en un contexto multidimensional. Las certezas se esfuman, se desvanecen el sujeto se apropia de la narración. Es de remarca que esta postura cuestiona de manera radical la idea de que haya aserciones, creencias o conocimientos simplemente verdaderos, pues reconstruye la idea de un mundo dado (las cosas como son) antes y al margen de las interpretaciones de los sujetos. Existen diferentes perspectivas, reflexiones "visionarias del sentido de la sociedad" que terminan en una complejización ${ }^{12}$ de la narración o relato ya que cada actor o agente posee uno. El sujeto, agente o actor, entendido como mirada es una singularidad a partir de la cual se abre un mundo y no una simple mirada sobre el mundo entendido esta singularidad como registro de lo que es. La mirada del otro no es simplemente otra máquina para percibir las imagines, es otro mundo, otra fuente de fenomenalidad, otro punto cero del parecer. Esto es cada una y cada uno tiene su singular manera de mirar la vida en sociedad, su perspectiva del mundo pero este, entonces, se de en

\footnotetext{
${ }^{10}$ GRIMSON, Alejandro. Los límites de la cultura: crítica de las teorías de la identidad.

${ }^{11}$ GRIMSON, Alejandro. Los límites de la cultura: crítica de las teorías de la identidad, p. 21.

${ }^{12}$ Directamente vinculado con los "sistemas complejos" que ponen en crisis la idea de que los fenómenos pueden ser siempre completamente revelados, entendidos y controlados; se trata de todo lo contrario son visiones parciales, inestables y móviles, siempre en una constante redefinición, evolución transformación en confrontación con la idea de cerrado y mono-causal. En los "sistemas complejos" cohabitan interpretaciones múltiples. Los fenómenos, la sociedad, el mundo es indeterminado, abierto, interpretable, plural y menos irrebatible.
} 


\subsection{TEORIA SOCIOJURÍDICA INTERNACIONAL}

el interior de un punto de vista singular. Todas ellas tienen la misma importancia, ninguna es más cierta o más real que otra, sólo puede haber confrontaciones de diferentes visiones o narraciones, ninguna puede ser reducida a una forma. Una de las motivaciones posibles para asumir el subjetivismo o el relativismo es el deseo de evitar la intolerancia y los prejuicios en relación con los demás actores y sus propias perspectivas y esto se puede lograr sólo desde la diversidad. Es así que el sentido que se le asigna a las acciones y a los valores está en cada actor que intenta interpretarlas; esto es la estructura de significados "nunca es segura siempre es compleja", depende siempre de cada práctica interpretativa ya no hay un solo sentido en la acción, en los valores, en los mensajes.

d. El individuo-actor-agente queda cada vez más atravesado por presiones sociales donde existe una mayor incertidumbre frente a la perdida de referentes; los sujetos y de los pequeños colectivos se encuentran solos, con todo para construir pero inmersos en un mar de anomia que originan irresoluciones en su autonomía e inseguridad por su fragilidad. Frente a lo expuesto las diferentes agencias de gobierno se transforman en un mero gestor de la incertidumbre de los individuos. Ahora bien esta situación puede ser provechosa para los agentes, ese contexto le puede permitir cambios y transformaciones no pensadas en diferentes momentos del siglo XX. Si el sujeto se aferra a las viejas instituciones, lo único que conseguirá es erigir monumentos a las propias limitaciones, porque eso es lo que las instituciones representan: la noción de los límites factibles. Tal vez sea el momento de promover diferentes alternativas e innovaciones en las instituciones (tanto normativas como organizacionales).

Por otro lado y en lo que respecta al agente, la fragilidad y la condición por siempre provisional de la identidad ya no se puede ocultar cuando se produce una crisis del vínculo social con el cambio de normas, de modelos y de terminología; esto provoca una desestabilización de los referentes, de las denominaciones y de los sistemas simbólicos anteriores. La dimensión identitaria, aunque sea compleja y oculta, atañe a un proble- ma crucial: el de la subjetividad y el funcionamiento de las formas de individualidad.

e. Es entonces cuando se habla de identidad, esto es debido al desmoronamiento de las instituciones que constituyeron durante muchos años las premisas sobre las que se construyó la sociedad moderna. Con la globalización, la identidad se convierte en un asunto candente. Se borran todos los puntos de referencia que fueron relevantes durantes décadas, tal vez siglos; las biografías de los colectivos y de los agentes se convierten en rompecabezas cuyos intentos de soluciones son difíciles y mudables. No obstante el problema no son las piezas concretas del mosaico, sino cómo encajan entre sí en la transición social, cultural y jurídica. Existe muy poca consistencia identitaria en un contexto de cambios y búsquedas ya que pocos agentes (sujetos o colectivos) están expuestos a una sola comunidad de ideas y principios, así que la mayoría tienen problemas parecidos con la cuestión de la coherencia y el mantenimiento de perfiles, expectativas, intereses y necesidades la que distingue una persona de otra. Todo esto se hace visible con las crisis sociales de las últimas décadas; ya no se puede mantener un mecanismo de ficciones para dar cierta e imposible estabilidad a la sociedad. En este sentido la identidad se presenta como algo que hay que inventar o construir a partir de piezas que se van descubriendo con la crisis de las instituciones; debería considerarse un proceso continuo de redefinición de los sujetos y los colectivos de invención y de reinvención de las historias. Por lo expuesto la identidad no está tallada en la roca, no está protegida por garantías de por vida, son eminentemente negociables y revocables; no es completa, nuca se encuentra culminada.

\section{EL MODELO COMPLEJO: DESDE EL MUL- TICULTURALISMO AL PLURALISMO JU- RÍDICO}

a. El fenómeno del multiculturalismo, sin duda se debe sobre todo a la fragmentación de las sociedades aparentemente homogéneas, por la crisis del consenso interno causada por la fractura social que genera la crisis a su vez del modelo de Estado social, a lo que se une en algunos casos 
la emergencia de las comunidades minoritarias nacionales o culturales hasta ahora en segundo plano, y en otros, la presencia reivindicativa de los grupos alógenos incorporados por el flujo migratorio, que ya no aspiran sin más a una integración en la que se diluyen (entre otras razones de importancia, porque ese objetivo no parece posible: ni el mercado, ni la escuela funcionan ya con esa eficacia universalizante). El muticulturalismo más que un concepto normativo, es un hecho social. Esto es, la presencia de de grupos en una misma sociedad con diferentes códigos culturales (identidades culturales propias) como consecuencia de diferencias étnicas, lingüísticas, religiosas o nacionales, sexuales, de género, de orientación sexual, geográficas o regionales, de estratificación, entre otras. Intercultural se llama a una sociedad civil cuando todos los grupos comunitarios son reconocidos y tomados en cuenta, en tanto que tales, en el funcionamiento político o al menos en algunos ámbitos. Esta afirmación parte de reconocer la presencia de las "identidades simbólicas" en el ámbito de las creencias político-jurídico.

b. Las naciones se convierten en escenarios multideterminados donde diversos sistemas interceptan e "interpenetran", coexistiendo varios códigos simbólicos (identidades de sujetos-agentes-actores diferentes) en un mismo grupo e incluso hasta en un solo sujeto. Frente a la "desterritorialización" se presentan intentos de "reterritorialización" representado por movimientos sociales, culturales y políticos que afirman lo local. En esta situación, los poderes legítimos de los Estados se ejercitan sobre fracciones de la población o directamente sobre "comunidades ilusorias". De allí resulta dificultoso mantener una conexión estable entre el Estado y la Ciudadanía ya que el nexo, entre el orden y el funcionamiento de las instituciones políticas y el status ciudadano, es perturbado o cuestionado debido a los cambios en las estructuras políticas, sociales, económicas y culturales, que adquieren preeminencia en las relaciones, en los procesos y en las estructuras que se desenvuelven en la escala nacional.

Entonces, mejor que nunca, es necesario hacer referencia a la construcción de la ciudadanía en una sociedad moderna, el autor destaca que se ofrece dos dimensiones de análisis: la asignación del goce de derechos y garantías básicas a los individuos por parte del Estado y la capacidad de esos individuos de asegurar su reconocimiento pleno por medio de la participación en el espacio público. Espacio público y ciudadanía son hoy dos conceptos que se necesitan mutuamente en tanto indican la doble dimensión del ciudadano: como sujeto pasivo del goce de derechos y como sujeto activo en la producción de tales derechos. En el mundo actual esta doble dimensión se articula en forma problemática y conflictiva, en tanto los derechos no son necesariamente garantizados de modo universal por todos los estados a todos los ciudadanos y por otra parte, las necesidades y demandas se extienden y transforman al punto de que el espacio público es el lugar de redefinición de derechos y garantías.

Hoy la ciudadanía está puesta en cuestión por un proceso de desigualdad creciente que no sólo ha afectado claramente los derechos sociales, sino también ha puesto en crisis, por insuficientes, los derechos políticos e inclusive los derechos civiles.

c. Cabe destacar que el rol del las diferentes agencias de gobierno se centra en la participación de la elaboración, aplicación e imposición de las reglas. La mencionada participación se refiere a las decisiones y a los actos de gobierno que, por lo tanto, están dirigidos a resolver los conflictos, ejercer un arbitraje, decidir, promulgar reglamentos. Es importante hacer hincapié en que las mencionadas acciones no se ejercen de la misma manera ni con la misma consecuencia con todos los segmentos de una estructura social, por ello es necesario tener en cuenta las relaciones entre los individuos y grupos que conforman la Administración Pública y éstos con los distintos agrupamientos sociales externos al mismo sin olvidar, claro, la posibilidad de influencia. Las diversas pretensiones son puestas en escena (intereses, inquietudes, demandas u obstáculos que son necesarias de ser reconocidas). El resultado es la conformación de una agenda compleja en donde aquellas necesidades de los distintos actores sociales, con diferentes espacios de poder se encuentren presentes. Esto significa que no 
todos los problemas logran captar la atención de la Administración Gubernamental y ubicarse dentro de los temas prioritarios de dicha organización. Algunas cuestiones son aceptadas, otras alteradas o simplemente descartadas todo, claro, resultado de las influencias. La agenda pública permite determinar quienes son los que efectivamente definen y justifican los problemas públicos, cuales grupos y organizaciones tiene la fuerza de transformar cuestiones sociales en publicas y en prioridades de gobierno y revela cual es la estructura de poder que domina efectivamente la política pública. Es por esto que es necesario recurrir al "proyecto o programa administrativo-político"13 o al plan o concepción que el actor social administrativo (diferentes agencias del Estado) tiene sobre los objetivos y estrategias a seguir por las agrupaciones de manera especial en el espacio público-político. Se trata de un esquema o bosquejo flexible, más o menos explícito donde se menciona el diseño y el modo de concretar la administración organizacional que se pretende en el presente, con referencia al pasado y dirigida al futuro en dos vertientes: la interna a la organización y la externa referida al contexto social, cultural y político-judicial. Es decir que el proyecto o programa existe, por un lado una vertiente administrativa y de gestión y por el otro una proyección política dirigida, en especial, a la administración pública.

d. La situación expuesta implica la participación o acción política de los sujetos que tratan de posicionarse reflexivamente mediante la resolución de las tensiones entre los anhelos que se promueven y la realidad. Implica el reconocer la existencia de procesos históricos donde se destaca la transición de la vida subterránea a la visibilidad de la diversidad; de la tolerancia a la lucha por la existencia social, cultural, económica, jurídica, política ya no la simple asimilación al sistema socio-jurídico, esto es: la igualad jurídica-judicial en la diversidad.

En este punto queda claro que el "modelo complejo" no trata sólo de estudiar el impacto de las demandas de actores sociales en lo referente a la exigencias de consolidar la diversidad trata, además, de concentrar el análisis en uno de los supuestos medios más efectivos de la sociedad moderna para lograr cambios, transformaciones, para alcanzar la inclusión socio-jurídica de agrupamientos "desaventajados": las organizaciones o estructuras burocráticas pluralistas que permiten canalizar la energía, los intereses, necesidades y motivaciones de diferentes sujetos sociales promoviendo transformaciones para la efectiva integración -espacio o esfera pública- en una gestión administrativa pluralista.

e. Desde el "empoderamiento" de los colectivos/categorías/agrupamientos permite dar vida a la gobernabilidad y el desarrollo institucional (en este caso jurídico-político) cuando: a) promociona los derechos a la diversidad, b) organiza el sistema que orienta y guía (en la medida de lo posible) la convivencia y el desarrollo de las fuerzas ciudadanas, c) promover un diálogo socio-cultural (un real encuentro entre seres humanos) con alto impacto en la política; y d) tratar de que emerja el potente mundo subterráneo (la silenciada realidad socio-jurídica).

Entonces dudas no existen en lo referido a las necesidades, frente a la realidad socio-cultural, de las transformaciones de las políticas públicas y de las agendas administrativas y de sus referentes "las instituciones jurídicas" con sus dos vertientes: jurídica y judicial.

\section{LA INSTITUCIONALIZACIÓN REAL Y LA FORMAL}

a. La normativa formal es un producto de las significaciones compartidas por algunos sectores sociales, aunque no lo es de otros sectores de la población. No todos los integrantes de la sociedad pueden poner de manifiesto en instrumentos formales sus expectativas. No todos tienen espacio de poder necesario para convertir sus expectativas en instituciones normativas. De todos modos se trata de manifestaciones simbólicas que dan cuenta de imaginarios sociales de sectores sociales y en donde se demonizan a los otros, los excluidos de dicho imaginario o los que se encuentran presente como referente de lo negativo (criminalizados, desviados, prohibidos,

${ }^{13}$ GERLERO, Mario. Introducción a la Sociología Jurídica. Buenos Aires: Grinberg Libros Jurídicos, 2006. 


\subsection{TEORIA SOCIOJURÍDICA INTERNACIONAL}

transgresores, sujetos sancionables).

Al campo jurídico se lo identifica con la existencia de reglas o normas jurídicas: con su sanción, promulgación y aplicación; sería, desde este punto de vista, un sistema o conjunto de normas reguladoras de algunos de los comportamientos humanos en una determinada sociedad, presentándose como una técnica de organización social; técnica y normativa que contribuye a la implementación de un supuesto orden, a la realización de un modelo organizativo social situado en la historia como resultado o producto de la misma. A lo expuesto se agregan como elementos del área jurídica las expectativas, las conductas y las acciones de los operadores del derecho que dan vida a un sin número de normas formales (desde la doctrina, pasando por la jurisprudencia hasta los contratos) varias veces contradictorias, parciales, referidas a intereses específicos de ciertos sectores, agrupamientos y colectivos con visos y pretensiones de ser generales, públicas y objetivas.

b. La formación del derecho es factible de reducirse a un producto de diferentes agencias de la administración pública (operado o gestado de diferentes formas) este es el considerado Derecho Oficial o Estatal. Pero hay otras prácticas institucionalizadas en normas, otros derechos. Ahora bien todos los contextos producen derechos, sin embargo el significado y la relevancia social de estas producciones varía mucho. El Estado moderno al asumir el monopolio de la producción del derecho neutraliza el significado y considerar irrelevante todas las producciones normativas no estatales.

El derecho oficial estatal tiene la prerrogativa de interferir en los derechos nacidos de diferentes contextos. Cada uno de esos contextos es, simultáneamente, sujeto y objeto de saberes jurídicos, autor de decisiones jurídicas y destinatarias de decisiones jurídicas ajenas. Sí planteado el tema es del todo falaz la idea de que basta cambiar el derecho estatal para cambiar la realidad social. Es preciso remarcar que se considera el derecho no sólo como un producto cultural sino también político y económico, como resultado de la interacción de los sujetos e identificado con intereses sociales que controlan la estructu- ra administrativo-política de un sistema. Resulta un hecho evidente y constatable el que las leyes, tanto en su proceso de elaboración como en el de su interpretación y aplicación, son fruto de una determinada opción o supuesto consenso político. Reconocer como derecho lo que el estado (y sus funcionarios) desean que sea visto como tal, quiere decir que lo que el jurista hace es producir un discurso en el cual se dice que eso es "derecho" y debe ser obedecido. Esta tarea social adjudicada al jurista por la enseñanza institucionalizada, es lo que explica que el derecho sea visto como el conjunto de normas que han sido producidas por el estado.

Desde el reconocimiento de la influencia política y económica del derecho positivo cave aceptar la posibilidad de un pluralismo jurídico, ya no se haría referencia a la evasión institucionalizada cuando se toma de manera positiva y funcional sólo el sistema normativo positivo, se estaría rescatando un paradigma donde la existen nuevas normas institucionalizadas a los intereses y necesidades originadas en intereses y necesidades de colectivos o sectores sociales que por lo general quedan al margen de los reconocimientos por parte del derecho positivo.

c. La búsqueda de desplazamiento de "vínculos teóricos de clausura" o únicos relatos que anulan la diferencia es la forma de abordar la "complejidad socio-jurídica", para abordar la multiplicidad y la pluralidad. Esta visión permite un observatorio de estudios de la identidad, las interconexiones y la estructura de red; esto consolida y expande el avance jurídico-judicial plural, en especial el laboratorio en temas de gestión inclusiva de la diversidad en el campo de lo político-administrativo. La clave está en favorecer la ampliación de la teoría y la investigación donde intervengan múltiples dimensiones para reflexionar sobre el campo jurídico y la política pública de transformación y de gestión inclusiva.

En última instancia, tener presente modelos de complejidad contribuye con la consolidación de la política de inclusión social; permite la promoción, consolidación y expansión de una justicia plural (desde la multiplicidad de hechos e intereses) en la defensa y fomento de las particularidades y singularidades pero, también para 


\subsection{TEORIA SOCIOJURÍDICA INTERNACIONAL}

garantizarlas, claro está, en un marco de consenso social, político y jurídico. Es de rescatar que el reconocimiento social, cultural y político es posible en el campo jurídico, no sólo por explicitar la necesidad del sujeto social, el activismo de un colectivo y la efectiva participación de los ciudadanos sino, también, por considerar el proyecto y la gestión de políticas administrativas de las agencias.

\section{REFERENCIAS}

ARFUCHO, Leonor (Comp.). Pensar este tiempo: espacios, afectos y pertenencias.

Buenos Aires: Paidós, 2005.

BOURDIEU, Pierre. Las estrategias de la reproducción social. Buenos Aires: Siglo XXI, 2011.

; Löic WACQUANT. Una invitación a la sociología reflexiva. Buenos Aires: Siglo Veintiuno, 2005.

CASTEL, Robert. El ascenso de las incertidumbres: trabajo, protecciones, estatuto del individuo. Buenos Aires: Fondo de Cultura Económica, 2010 .

DIAZ, Esther. Las grietas del control: vida, vigilancia y caos. Buenos Aires: Biblos, 2010.

DUBAR, Claude. La crisis de las identidades. Barcelona: Bellaterra, 2002.

FOUCUALT, Michel. Nacimiento de la biopolitica. Buenos Aires: Fondo de Cultura Económica, 2007.

GERLERO, Mario. Introducción a la sociología jurídica. Buenos Aires: Grinberg Libros Jurídicos, 2006.

(Coord.). Los silencios del derecho. Buenos Aires: Grinberg Libros Jurídicos, 2008.

. Sociología jurídica y los movimientos sociales. Buenos Aires: Visión Jurídica, 2014.
GRIMSON, Alejandro. Los límites de la cultura: crítica de las teorías de la identidad. Buenos Aires: Siglo XXI, 2011.

PINTO, Mónica. Temas de derechos humanos. Buenos Aires: Del Puerto, 2009.

SABSAY, Leticia. Fronteras sexuales: espacios urbanos, cuerpos y ciudadanía. Buenos Aires: Paidós, 2011.

POLLAK, Michael. Memoria, olvido, silencio: la producción de identidades frente a situaciones límites. La Plata: Al Margen, 2009.

ZAMBRANO, Carlos. Ejes políticos de la diversidad cultural. Bogotá: Siglo del Hombre Editores y Universidad Nacional de Colombia, 2004. 


\title{
O DESENVOLVIMENTO DO ESTADO MODERNO:
}

\author{
CONFLITO ENTRE GARANTIAS \\ INOVADORAS E FORMAS TRADICIONAIS
}

Jonathan Hernandes Marcantonio ${ }^{\mathrm{i}}$

Sumário: Introdução. 1 A Constituição dos direitos e o papel do Estado Moderno. 2 O mau uso do Estado. Conclusão. Referências.

\section{Resumo}

O presente artigo objetiva demonstrar brevemente como a concepção teórica e instrumental de Estado Moderno, a qual supostamente havia propiciado em termos históricos e jurídicos a conquista de direitos materiais rumo à consagração dos direitos humanos, sofre na atualidade por uma necessidade de atualização, especialmente em seus pilares estruturais, graças a in- sistência do Estado em não se desvincular dos primeiros propósitos e princípios jurídicos formais que se consolidaram em sua constituição formal, a partir do século XVII. Nosso propósito aqui é tentar identificar esse lapso de compatibilidade entre o conteúdo material do direito garantido pelo Estado e a própria estrutura do Estado como garantidor de tais direitos, apesar dos esforços históricos para que tal adequação fosse realizada.

Palavras-chave: Estado Moderno. Desenvolvimento. Estrutura formal. Transformação histórica. 


\subsection{TEORIA SOCIOJURÍDICA NACIONAL}

\begin{abstract}
The present paper has as scope show briefly how the Modern State instrumental and theoretical perspective, which had allegedly provided in historical and juridical frames at the Human Rights, claims nowadays a need of structural upgrade and reform thanks its disability to be unattached of its first proposals from its origins, back in 18th century. The effort here is identifying these incompatibility between the development of material and formal perspectives of modern State which has been shown in the contemporary historiography.
\end{abstract}

Keywords: Modern State. Development. Formal structure. Historical perspective.

\section{INTRODUÇÃO}

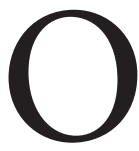
conceito de Estado de Direito foi ideologicamente construído em paralelo ao desenvolvimento teórico que ocorrera nos primeiros séculos que sucederam a Idade Média, precisamente entre os séculos XVII e XX. As principais contribuições teóricas sucederam ao debate europeu contextualizado, marcado pela ascensão da mentalidade burguesa. Toda a preocupação teórica esteve voltada para consolidar o Estado de Direito como o principal projeto político da civilização ocidental. A forma como tal Estado foi teoricamente concebido evidencia duas perspectivas distintas, material e formal, porém coordenadas. A perspectiva material, qual seja, a valorativa, é marcada principalmente pela histórica disputa por direitos vivenciados naqueles séculos. A perspectiva formal, por sua vez, define-se como construção securitária destes direitos materiais, tanto em termos processuais como em termos institucionais.

Pensando nessas distinções e no propósito do presente capítulo, tentaremos identificar esses dois elementos a partir de uma perspectiva histórico-valorativa no âmbito material do Estado e, ao mesmo tempo, demonstrar precisamente a ausência dessa transformação histórica no âmbito formal do Estado de Direito. Para atingir esse desiderato, pretende-se, especificamente: (1) identificar os principais aspectos teóricos da conquista dos direitos fundamentais e como o Estado de Direito providencia a garantia de tais direitos; e (2) demonstrar como as modificações de contexto teórico e histórico possibilitam uma leitura que sugere a necessidade de repensarmos as bases estruturais e formais do Estado de Direito.

\section{A CONSTITUIÇÃO DOS DIREITOS E O PAPEL DO ESTADO MODERNO}

É impossível discutir o desenvolvimento das formas de proteção de direitos disponibilizados pelo Estado de Direito sem abordar, ainda que brevemente, o Direito em si. E aqui repousa uma dúvida: sobre qual perspectiva devemos falar a respeito do Direito? Pela perspectiva 


\subsection{TEORIA SOCIOJURÍDICA NACIONAL}

externa ou interna? Com essas indagações preliminares queremos dizer que os resultados objetivados por este trabalho podem alterar-se se nos focarmos apenas em uma ou em outra das perspectivas aqui mencionadas. Mas o esforço aqui empreendido será, pois, compreender ambas as perspectivas.

A concepção de perspectiva interna pode ser extraída da doutrina de Böckenförde, quando escreve sobre a autocompreensão do sistema de Direito, delineado por toda a tradição acerca da teoria do Direito (Rechtswissenschaft), porém, em uma perspectiva crítica. Aqui, a expressão crítica pode ser compreendida como perspectiva marxista. $\mathrm{O}$ autor considera que essa tradição (de toda a teoria do Direito) tem ignorado as conexões entre Direito e outras teorias sociais compelidas pelo ponto de vista humanista, o qual atribui hodiernamente ao Direito uma posição privilegiada e a situa como definição sistemática e dogmática, lugar onde jaz a impossibilidade de se refletir entre os limites do direito material em si e o sistema de proteção que o possibilita. ${ }^{1}$ Isso significa que o Direito, ao longo dos últimos séculos, desenvolve-se em uma perspectiva particular, por conta da influência dos ideais iluministas que acabaram por gerar essa inclinação da autocompreensão do Direito, que convergiu para a compreensão do sujeito de direito moderno pautado em sua respectiva individualidade.

A proposta explícita dessa individualidade, além de naturalmente se opor às abordagens socialistas e comunitaristas, é supostamente constituir uma unidade coesa entre todos os cidadãos, estabelecendo para tanto um padrão normal de comportamento - o típico comportamento burguês - ancorado na lei. Esse posicionamento claramente exclui a possibilidade de outro tipo de comportamento cultural - ressalvada a flexibilidade possível deste padrão - em privilégio daqueles compatíveis com o citado padrão de comportamento, no intuito de ressalvar os valores culturais, marginalizando automaticamente aqueles que não se adaptem ao padrão formal de conduta, mediante princípios e premissas legais, estabelecidos formalmente pelo Direito, o que é esclarecido por Böckenförde ao utilizar como exemplo a concepção de família presente no sistema de direito da civilização ocidental. ${ }^{2}$ Porém, analisando a questão pelo prisma do pensamento liberal, nem haveria a necessidade de tal salvaguarda na medida em que o Direito tem como alicerce a razão cunhada pelo Iluminismo e que, portanto, assume contornos universais. ${ }^{3}$ Os contornos aqui mencionados denotam um desenho possível, em vias teóricas, do modelo de um homem médio que é capaz de, a partir de uma referência individualizada, orientar suas ações automaticamente para a sociedade, como se tal resultado fosse o único possível. Esta habilidade de escolha do melhor, ou do justo - o chamado juízo - é a pedra de toque do que teoricamente representa o conceito de liberdade nas sociedades modernas. Essa liberdade, não custa lembrar, é respaldada pela lei em seu sentido lato. ${ }^{4}$

Nesse ponto, consegue-se identificar dois distintos processos que, embora se apresentem essencialmente como opostos, em um segundo momento estão intrinsecamente relacionados e dizem respeito ao conteúdo material e formal que o Direito assume em sua sistematização. $\mathrm{O}$ maior e mais importante princípio material de Direito, pelo ângulo das sociedades modernas é a liberdade, compreendida como o poder de escolha que um sujeito detém em determinada sociedade. Por seu turno, os procedimentos previstos em lei, atributo formal do Direito, têm como tarefa desenvolver uma estrutura a partir da qual se possa ser capaz de garantir a liberdade como um princípio de direito material. Para tanto, as regras de Direito (rules of law) podem criar uma rede de direitos materiais que, curiosa e paradoxalmente, só são materializados graças ao texto da lei, ao mesmo tempo em que sua

\footnotetext{
${ }^{1}$ BÖCKENFÖRDE, E. W. Recht, Staat, Freiheit - Studien zur Rechtsphilosophie, Staatstheorie und Verfassungsgeschichte. Frankfurt a.M., Suhrkamp, 1991 p. 58.

${ }^{2}$ BÖCKENFÖRDE, E. W. Recht, Staat, Freiheit - Studien zur Rechtsphilosophie, Staatstheorie und Verfassungsgeschichte, p. 59.

${ }^{3}$ BARRON, Anne. Colonization of the self in the Modern State. In: CARTY, Anthony (Ed.). Post-Modern law - Enlightenment, revolution and the death of the man. Edinburgh: University of Edinburgh Press, 2003. p. 108.

${ }^{4}$ BARRON, Anne. Colonization of the self in the Modern State, p. 109.
} 


\subsection{TEORIA SOCIOJURÍDICA NACIONAL}

materialidade depende do reforço possível do respeito destes direitos materiais em uma dada sociedade, possibilitados graças a um conjunto estrutural de pilares formais que, combinados, resultam no respeito e na consolidação da liberdade como direito. Toda essa dinâmica, entre estruturas e prerrogativas é o próprio Estado. ${ }^{5}$

O Estado, desde sua moderna concepção, tem como finalidade última o resguardo das regras de direito. Nesse sentido, o Estado se mune e se divide em três poderes complementares, os quais possuem, em sua unidade, a soberania. Essa separação de poderes carrega em si a crença de que a racionalidade procedimental representada pela forma do próprio Estado Moderno poderia lidar com a administração da liberdade, entre outros direitos fundamentais, estabelecendo, por sua vez, uma específica forma de racionalidade procedimental em cada um dos poderes do Estado. ${ }^{6}$ Ao mesmo tempo, especialmente durante o século XIX e o início do século XX, a sociedade ocidental também mudou. A acentuação na individualidade e, por consequência, nos direitos individuais estava agora colidindo com outros tipos de direitos que não possuem o mesmo formato daqueles que, como a liberdade, são tidos como atributos puramente racionais. Nesse contexto, o século XIX fez emergir o embate entre classes sociais que, muito embora configuraram um horizonte social completamente distinto, bastante conhecido, a atitude do Estado Moderno, em uma perspectiva simbólica, era tentar adaptar essa nova categoria de direitos materiais em uma mesma formatação que também abrigava direitos de natureza individual, terminando por diferenciar direitos individuais daqueles sociais e políticos de uma forma material, mas não procedimental. $^{7}$

O conflito social em si, bem sabemos, delineia a possibilidade de uma toda nova categorização de direitos. O Estado, por sua vez, apresenta como suporte para essas mudanças o mesmo ferramental apresentado lá atrás, no século XVII, quais sejam: o poder e o uso da força para assegurar as regras de direito, consolidado a partir de políticas que se desenvolveram pautadas em interesses econômicos, tanto na esfera nacional como na internacional. Em termos jurídicos e sociais, isso não poderia acabar bem e, de fato, os movimentos sociais tentaram mostrar esse descompasso entre a perspectiva social dos direitos sociais e a estrutura estatal propiciadora de tais direitos. A título de exemplo, o movimento democrático que a Europa experimentou entre a Primeira e a Segunda Guerras Mundiais, tentou estabelecer-se como uma proposta de mudança de paradigma. De acordo com Dahrendorf, ao revés, o que se viu foi um aumento da importância do poder burocrático ${ }^{8}$ no sentido explicitado por Max Weber, o que institui problemas para a consolidação do real projeto democrático, uma vez que a forma do Estado, em sua perspectiva procedimental, ainda se pauta em interesses econômicos. ${ }^{9}$

Por outra perspectiva, a individualidade como marco central do Estado de Direito estava associada, acertadamente, a todo o moderno processo social presente na obra de Stefan Huf, que concentrou sua pesquisa nos efeitos que o desenvolvimento tecnológico traz para a civilização ocidental, especialmente a partir do séculoXIX. ${ }^{10} \mathrm{~A}$ combinação desses dois elementos produz uma incerteza que demandaria, ao mesmo tempo, uma transformação social acerca da perspectiva relacional entre direitos materiais e uma possível estrutura estável (procedimental) de poder, mantida pelo Direito em si e, consequentemente, pelo Estado de Direito.

Nesse sentido, todo o processor de diferenciação (diferenzierungsprozess) da modernidade é mantido a partir de um padrão de incerteza que contrasta o período denominado de Pré-Moderno e o Período Moderno, isso porque a ideia de tradição, mantida

\footnotetext{
${ }^{5}$ BARRON, Anne. Colonization of the self in the Modern State, p. 110.

${ }^{6}$ BARRON, Anne. Colonization of the self in the Modern State, p. 112.

${ }^{7}$ DAHRENDORF, Ralf. Der moderne soziale Konflikt - Essay zur Politik der Freiheit. Munique: Deutscher Taschenbuch, 1994. p. 80-81.

${ }^{8}$ DAHRENDORF, Ralf. Der moderne soziale Konflikt - Essay zur Politik der Freiheit, p. 91.

${ }^{9}$ DAHRENDORF, Ralf. Der moderne soziale Konflikt - Essay zur Politik der Freiheit, p. 97-109.

${ }^{10}$ HUF, Stefan. Sozialstaat und moderne - Modernisierungseffekte staatlicher sozialpolitik. Berlin: Duncker \& Humblot, 1997. p. 67.
} 


\subsection{TEORIA SOCIOJURÍDICA NACIONAL}

simbolicamente mediante uma religiosidade do poder perde espaço, valendo lembrar que no Período Moderno evidencia-se uma crise pela perspectiva individual graças ao considerável aumento da complexidade. O prisma social e o subjetivo demandam do Estado um papel securitário em ambos os cenários. ${ }^{11} \mathrm{O}$ resultado, sob esta outra perspectiva, qual seja, a social, também é o mesmo outrora expresso: O Estado e o Direito, apesar das infinitas possibilidades de interação, mantêm-se atrelados a uma única orientação racional: a individualidade.

\section{O MAU USO DO ESTADO}

Relacionar os problemas de legitimação e as eminentes transformações na mentalidade do Estado e do Direito na modernidade não é propriamente inédito. De fato, o pensamento da moderna ciência social sempre esbarra nessa temática, acidental ou deliberadamente. Ainda assim, uma das compreensões sobre esse fenômeno, que ainda é digna de nota, é aquele presente no pensamento de Max Weber. Weber pôde antecipar essa problemática quando escreveu todas as diferentes abordagens existentes entre direitos objetivos e direitos subjetivos. Essa diferença, na sua concepção, fora marcada desde suas distintas formas de concepção ao longo dos tempos.

Para compreender como essas diferenças funcionam e qual é o impacto delas na relação entre direito material e procedimental abordaremos rapidamente tal tema na perspectiva do pensamento de Weber. Começaremos pelo desenvolvimento do direito subjetivo.

A característica individualista que escrevemos a respeito na primeira parte deste trabalho possui uma forte relação com o processo de consolidação dos direitos subjetivos. Na obra de Weber essa relação se mostrou a partir da abordagem feita por ele sobre o conceito de contrato utilizado na Europa durante a Antiguidade e a Idade Média. $\mathrm{O}$ aumento do uso de contratos nas trocas comerciais reflete, vagarosamente, a preferência que vai dominar a Europa na Idade Moderna, qual seja a desejada dissociação do Estado da vida privada, individual. Esses aspectos mal conseguem apresentar o Estado como um trustee da liberdade e da autonomia privada, o que resulta na impossibilidade de o Estado deter poder efetivo para designar e estipular uma forte política social que consolide tais direitos e prerrogativas. Ao invés disso, o Estado acaba por reduzir as interações sociais em interações comerciais. ${ }^{12}$ Ao mesmo tempo, a liberdade, como o mais importante dos direitos materiais, visto em um sentido subjetivo, não possui um conteúdo material, mas sim formal, estando de acordo com sua origem. Isso significa que o objetivo primeiro da liberdade é manter-se como garante da autonomia contratual, anteriormente referido.

Os direitos objetivos, por seu turno, têm origem completamente distinta. De acordo com Weber, esses tipos de direitos têm suas bases consolidadas em uma transformação social com uma orientação externa, o que situa sua origem em uma ação social (Handeln) e destaca o conteúdo material dessas formas de direito.

Nesse sentido, é aceitável dizer que os direitos objetivos possuem suas fundações na percepção empírica da ação social. Essas transformações, novamente, têm-se estabelecido e transformado mediante o Direito, cujo objetivo é estipular limites de sociabilidade entre as pessoas que vivem em uma determinada sociedade. ${ }^{13}$

\section{CONCLUSÃO}

Se o Direito deve assegurar dois tipos diferentes de direitos, cada qual desenvolvido por formas completamente diferentes, podemos dizer, portanto, que o Direito possui tarefas dúbias e até mesmo conflitivas. Mais do que isso: o Direito, em sua origem, fora historicamente desenhado para consolidar e assegurar um determinado tipo de troca - aquelas legitimadas pelos direitos subjetivos que já mencionamos - mas quando o cenário jurídico é composto pelas transformações sociais, estas, por seu turno, exigem outro tipo de regulação, não com

\footnotetext{
${ }^{11}$ HUF, Stefan. Sozialstaat und moderne - Modernisierungseffekte staatlicher sozialpolitik, p. 86

${ }^{12}$ WEBER, Max. Wirtschaft und Gesellschaft. Paderborn: Voltmedia, 2000. p. 738.

${ }^{13}$ WEBER, Max. Wirtschaft und Gesellschaft, p. 651.
} 


\subsection{TEORIA SOCIOJURÍDICA NACIONAL}

o intuito de zelar pela boa transação comercial, mas sim para tentar dirimir seus efeitos colaterais. O resultado, contudo, é o inverso: a mesma estrutura é utilizada em ambos os tipos de direitos que, embora originários de padrões econômicos e seus impactos na sociedade, apresentam-se em contextos completamente distintos. Como podemos perceber, ambos os tipos de direitos aqui apresentados foram constituídos sobre os pilares da sociedade moderna e embora demandem formas distintas de regulação, a forma que o Estado atribui a eles é a mesma.

O diagnostico dado neste trabalho não é particularmente novo. Ele é compartilhado por muitas teorias modernas que, como escrito por Macpherson, "adotam a noção de processo democrático como um mercado competitivo" 14 . Tais teóricos sabem que o Estado Moderno que gravita sobre nós é inadequado e demanda uma severa mudança paradigmática. Esse novo ponto de vista a ser desenvolvido deve identificar teórica e empiricamente todos os problemas que se escoram nos pilares do Estado Moderno, aí incluída a percepção do Direito. Ambos os esforços podem ser empreendidos no sentido de aprimorar e transformar os padrões jurídicos e políticos, tarefa cujo papel fundamental incumbe ao Poder Legislativo como um todo, não como técnica, mas como reflexão. ${ }^{15}$

\section{REFERÊNCIAS}

BARRON, Anne. Colonization of the self in the Modern State. In: CARTY, Anthony (Ed.). PostModern law - Enlightenment, revolution and the death of the man. Edinburgh: University of Edinburgh Press, 2003. p. 108-134.

BÖCKENFÖRDE, E. W. Recht, Staat, Freiheit - Studien zur Rechtsphilosophie, Staatstheorie und Verfassungsgeschichte. Frankfurt a.M., Suhrkamp, 1991.

DAHRENDORF, Ralf. Der moderne soziale Konflikt - Essay zur Politik der Freiheit. Munique:
Deutscher Taschenbuch, 1994.

HUF, Stefan. Sozialstaat und moderne Modernisierungseffekte staatlicher sozialpolitik. Berlin: Duncker \& Humblot, 1997.

MACPHERSON, C. B. The rise and fall of economic justice - and other essays. Oxford: Oxford University Press, 1985.

WEBER, Max. Wirtschaft und Gesellschaft. Paderborn: Voltmedia, 2000.

\footnotetext{
${ }^{14}$ MACPHERSON, C. B. The rise and fall of economic justice - and other essays. Oxford: Oxford University Press, 1985. p. 60.

${ }^{15}$ MACPHERSON, C. B. The rise and fall of economic justice - and other essays, p. 74.
} 


\section{A JURIDICIZAÇÃO E A JUDICIARIZAÇÃO ENFOCADAS A PARTIR DA "SOCIOLOGIA POLÍTICA DO DIREITO" DE JACQUES COMMAILLE}

Orlando Villas Bôas Filho ${ }^{\text {ii }}$

Sumário: Introdução. 1 A abordagem sociológica como "ponto de vista externo" de enfoque do Direito. 2 A proposta de uma "sociologia política do direito". 3 A juridicização e a judiciarização enfocadas a partir da sociologia política do Direito. Conclusão. Referências.

\begin{abstract}
Resumo
O presente artigo pretende analisar os processos de juridicização e de judiciarização tal como ambos são tratados na "sociologia política do direito" proposta por Jacques Commaille. Para tanto, examina, em primeiro lugar, a especificidade da abordagem sociológica como "ponto de vista externo" de enfoque do direito. Em seguida, realiza uma apresentação geral, sem pretensão de distanciamento crítico, da "sociologia política do direito". Por fim, analisa os processos de juridicização e de judiciarização do campo político, da forma como ambos se delineiam no horizonte de tal proposta teórica.
\end{abstract}

${ }^{\mathrm{i}}$ Agradeço a Jacques Commaille pela oportunidade de uma interlocução sempre muito instrutiva.

ii Professor Doutor da Faculdade de Direito da Universidade de São Paulo e Professor Adjunto da Faculdade de Direito da Universidade Presbiteriana Mackenzie. 


\subsection{TEORIA SOCIOJURÍDICA NACIONAL}

Palavras-chave: Sociologia política do direito. Juridicização. Judiciarização. Regulação jurídica. Regulação judicial.

\begin{abstract}
This article aims to analyze both juridicalization and judicialization processes as they are treated in the "political sociology of law" proposed by Jacques Commaille. Thus, it analyzes, first, the specificity of the sociological approach as "external point of view" of law. Then it makes a general presentation, without critical distance, of the "political sociology of law". Finally, it analyzes juridicalization and judicialization processes of the political field as they are outlined in this theoretical proposal.
\end{abstract}

Keywords: Political sociology of law. Juridicalization. Judicialization. Juridical regulation. Judicial regulation.

\section{INTRODUÇÃO}

abordagem sociológica do direito, ${ }_{\text {como disciplina universitária }}$ recente no Brasil. ${ }^{1}$ Contudo, apesar das vicissitudes que marcaram sua instituição e seu desenvolvimento, ela progressivamente se difundiu e se institucionalizou nas principais faculdades de direito do país, tanto no ensino de graduação como no de pós-graduação ${ }^{2}$. O volume de publicações e a densidade das discussões apontam para uma efetiva consolidação dessa abordagem nas universidades brasileiras e o progressivo reconhecimento de sua importância na formação dos juristas. $\mathrm{O}$ número de pesquisadores tem aumentado significativamente, assim como a variedade de temas e a densidade das análises. ${ }^{3}$

No contexto das discussões, que no Brasil se desenvolvem acerca do direito pelo ângulo sociológico, há uma destacada atenção para questões relativas às mutações da regulação jurídica no âmbito das sociedades ocidentais modernas. Questões como o impacto da globalização econômica sobre a regulação jurídica; o policentrismo decisório e o pluralismo jurídico; os problemas do Estado-Nação diante de processos de desregulação e de deslegalização; os novos regimes de interação entre os âmbitos político e jurídico (geralmente enfocados em termos de politização da justiça e de judicialização da política) etc., têm ganhado cada vez mais destaque nas análises aqui realizadas. Para todas essas questões, a "sociologia política do direito", proposta por Jacques Commaille, pode oferecer aportes importantes que, de modo geral, não receberam entre nós a devida ressonância. Evidentemente que não se trata de simplesmente "importar" mais uma teoria europeia para alimentar a discussão sociológica do direito no

\footnotetext{
Cf. SOUTO, Cláudio; FALCÃO, Joaquim. Introdução. In: ed. São Paulo: Pioneira, 1999. p. IX.

2 Para uma análise das dificuldades enfrentadas pela institucionalização da sociologia jurídica na academia brasileira, ver, por exemplo: FARIA, José Eduardo. Estado, sociedade e direito. In: ___ _ KUNTZ, Rolf. Qual o futuro dos direitos? Estado, mercado e justiça na reestruturação capitalista. São Paulo: Max Limonad, 2002. p. 120-123; FARIA, José Eduardo. Sociologia jurídica: direito e conjuntura. São Paulo: Saraiva, 2010. p. 116-121; FARIA, José Eduardo; CAMPILONGO, Celso Fernandes. A sociologia jurídica no Brasil. Porto Alegre: Sergio Antonio Fabris, 1991. p. 7 e ss.

${ }^{3}$ Para uma excelente análise relativa ao desenvolvimento da sociologia jurídica no Brasil, ver: LOPES, José Reinaldo de Lima; FREITAS FILHO, Roberto. Law and society in Brazil at the crossroads: a review. Annual Review of Law and Social Science. v. 10, p. 91-103, 2014.
} 


\subsection{TEORIA SOCIOJURÍDICA NACIONAL}

Brasil, e sim de apropriar o que ela, a partir de indispensáveis mediações, pode proficuamente fornecer para a discussão sobre certas temáticas no Brasil. ${ }^{4}$

Entre as questões discutidas no Brasil, pela abordagem sociológica, que podem receber aportes da "sociologia política do direito" está a que se refere à relação entre direito e política, especialmente no horizonte complexo que caracteriza a sociedade hodierna. Conforme ressalta Jacques Commaille, essa questão é tradicionalmente tratada pelos juristas e pelos cientistas políticos a partir de perspectivas díspares que, não poucas vezes, fundam-se menos em aspectos cognitivos e epistemológicos do que em estratégias institucionais de autonomia, o que engendra, como consequência evidente, um empobrecimento do diálogo entre essas perspectivas que, fechadas em si mesmas, acabam por criar o que o autor designa, de um lado, de vision "juridiste" du politique e, de outro, de vision "politiste" du juridique. ${ }^{5}$

Rejeitando clivagens artificiais no âmbito das ciências sociais, a "sociologia política do direito", proposta por Jacques Commaille, assume uma clara perspectiva interdisciplinar. Remetendo a autores como Fernand Braudel e Immanuel Wallerstein, com os quais mantém clara relação de afinidade, Commaille enfatiza que a manutenção de fronteiras entre as ciências sociais hoje decorreria mais de razões institucionais ou coorporativas do que propriamente de razões cognitivas. ${ }^{6}$ Assim, assumindo uma pretensão interdisciplinar, a "sociologia política do direito" elege a questão do poder como objeto privilegiado de estudo e, fazendo-o, identifica no direito um instrumento fundamental de "revelação" dos processos constitutivos e de funcionamento do poder, uma vez que, baseando-se em autores com Michel Troper e Pierre Bourdieu, identifica a "forma jurídica" como "a estrutura do discurso pelo qual se exprime o poder" e como instrumento que institucionalizaria a "manutenção da ordem social e política".

Assim, pela perspectiva de Jacques Commaille, o direito é concebido como elemento central das formas de expressão do poder e como indicador privilegiado dos modos pelos quais se constrói e se exerce o poder, ${ }^{8}$ o que, aliás, revela uma clara inspiração durkheimiana - explicitamente assumida pela "sociologia política do direito"." Enquanto indicador privilegiado, o direito (e processos que concretamente o manifestam no contexto da sociedade atual, tais como a juridicização e a judiciarização) seria fundamental para a compreensão das mutações

\footnotetext{
${ }^{4}$ Uma "importação" não mediada seria francamente artificial e potencialmente banalizadora da teoria, uma vez que ela, apesar de suas pretensões de generalização, assenta seus pressupostos empíricos em pesquisas realizadas no contexto francês. Isso ocorre especialmente no livro intitulado L'esprit sociologique des lois. Essai de sociologie politique du droit, cujo fundamento empírico é a produção legislativa francesa acerca da família entre os anos de 1972-1993. Cf. COMMAILLE, Jacques. L’esprit sociologique des lois. Essai de sociologie politique du droit. Paris: PUF, 1994. Para excelentes análises relativas a esta obra, ver: MOSOVICH PONT-LEZICA, Diana; ARNAUD, André-Jean. Commaille Jacques. Lesprit sociologique des lois. Essai de sociologie politique du droit, coll. "Droit, éthique, société", 1994. Droit et Société. n. 30-31, p. 473-483, 1995. Para uma problematização da "migração das ideias”, ver: BOURDIEU, Pierre. Sur le pouvoir symbolique. In: __. Langage et pouvoir symbolique. Paris: Éditions Fayard, 2001. p. 201.

${ }^{5}$ Nesse particular, em virtude da dificuldade de traduzir adequadamente o que o autor pretende exprimir com as expressões vision "juridiste" du politique e vision "politiste" du juridique, optou-se por mantê-las no original. Cf. COMMAILLE, Jacques. De la "sociologie juridique" à une sociologie politique du droit. In:___ _ DUMOULIN, Laurence; ROBERT, Cécile (Dir.). La juridicisation du politique. Paris: LGDJ, 2010. p. $29-35$.

${ }^{6}$ Cf. COMMAILLE, Jacques. De la "sociologie juridique" à une sociologie politique du droit, p. 38; COMMAILLE, Jacques; DURAN, Patrice. Pour une sociologie politique du droit: présentation. Lannée sociologique, n. 1, v. 59, p. 12-13, 2009.

${ }^{7}$ Cf. COMMAILlE, Jacques. De la "sociologie juridique" à une sociologie politique du droit, p. 36. No que concerne ao modo pelo qual Pierre Bourdieu analisa o direito, ver, especialmente: BOURDIEU, Pierre. Habitus, code et codification. Actes de la Recherche en Sciences Sociales, v. 64, p. 40-44, 1986; BOURDIEU, Pierre. La force du droit. Éléments pour une sociologie du champ juridique. Actes de la Recherche en Sciences Sociales, v. 64, p. 3-19, 1986; BOURDIEU, Pierre. Esprits d'État [Genèse et structure du champ bureaucratique]. Actes de la recherche en sciences sociales. Vol. $96-97$, mars. 1993, p. 49-62; BOURDIEU, Pierre. Les juristes, gardiens de l'hypocrisie collective. In: CHAZEL, François; COMMAILLE, Jacques (Dir.). Normes juridiques et régulation sociale. Paris: LGDJ, 1991. p. 95-99. (Collection Droit et Société.); BOURDIEU, Pierre. Sur l'État. Cours au Collège de France 1989-1992. Paris: Éditions Seuil, 2012. especialmente p. 330-333, 516, 534-543. Sobre o campo jurídico no pensamento de Pierre Bourdieu, ver: GARCÍA VILLEGAS, Mauricio. On Pierre Bourdieu's legal thought. Droit et Société, n. 56-57, p. 57-70, 2001; GUIBENTIF, Pierre. Foucault, Luhmann, Habermas, Bourdieu. Une génération repense le droit. Paris: LGDJ, 2010. p. 247 e ss.; ROUSSEL, Violaine. Le droit et ses formes. Éléments de discussion de la sociologie du droit de Pierre Bourdieu. Droit et Société, n. 56-57, p. 41-55, 2004; SUEUR, Jean-Jacques. Pierre Bourdieu, le droit et les juristes. La méprise. Droit et Société, n. 85, p. 725-753, 2013.

${ }^{8}$ Cf. COMMAILLE, Jacques. De la "sociologie juridique" à une sociologie politique du droit, p. 37.

${ }^{9}$ Cf. COMMAILLE, Jacques. La juridicisation du politique. Entre réalité et conaissance de la réalité. En guise de conclusion. In: DUMOULIN Laurence; ROBERT, Cécile (Dir). La juridicisation du politique Paris: LGDI, 2010 p. 210. A respeito, ver: DURKHEIM, Émile. De la division du travail social. 7. ed. Paris: PUF, 2007. Sobre esse papel do direito no pensamento de Durkheim, ver, por exemplo: SERVERIN, Évelyne. Sociologie du droit. Paris: La Découverte, 2000. p. 36-42; STEINER, Philippe. La sociologie de Durkheim. Paris: La Découverte, 2005. p. 18-21; VILLAS BÔAS FILHO, Orlando. A sociologia do direito: o contraste entre a obra de Émile Durkheim e a de Niklas Luhmann. Revista da Faculdade de Direito da USP, v. 105, p. 568-574, jan.-dez. 2010.
} 
da regulação política. ${ }^{10}$ Nesse particular, cumpre notar ainda que se trata de uma abordagem que se coloca nas antípodas de algumas perspectivas sociológicas com significativa influência na discussão do direito, dentre as quais se destaca, por exemplo, a teoria dos sistemas de Niklas Luhmann. ${ }^{11}$

Feitas essas observações, o presente artigo visa apresentar, em termos gerais e sem pretensão de problematização, a "sociologia política do direito" proposta por Jacques Commaille para, a partir dela, analisar as questões da juridicização e da judiciarização do campo político. Para tanto, na tentativa de fixar o locus de onde provém a abordagem sociológica do direito, com a finalidade de captar sua especificidade, será realizada uma breve digressão relativa à sua classificação como "ponto de vista externo" de enfoque do direito (I). Em seguida, uma vez explicitado de onde provém a abordagem sociológica, proceder-se-á a uma apresentação geral, sem pretensão de distanciamento crítico, da "sociologia política do direito" proposta por Jacques Commaille (II). Indicados os elementos gerais que caracterizam a "sociologia política do direito", serão então examinadas as questões da juridicização e da judiciarização do campo político e como ambas se delineiam no horizonte de tal proposta teórica (III). Por fim, será feita uma breve conclusão, com a finalidade de indicar a importância da "sociologia política do direito" para as discussões em curso no Brasil.

\section{A ABORDAGEM SOCIOLÓGICA COMO "PONTO DE VISTA EXTERNO" DE ENFOQUE DO DIREITO}

É relativamente consensual situar a sociologia jurídica como expressão de uma forma de descrição externa do direito. Referindo-se à especificidade da abordagem sociológica acerca do direito, André-Jean Arnaud e María José Fariñas Dulce ressaltam que ela se caracterizaria por expressar um ponto de vista científico externo à análise do direito. Seria, portanto, uma ciência social e não uma ciência jurídica em sentido estrito. ${ }^{12}$ Analogamente, Jean Carbonnier insistia que a especificidade da abordagem sociológica em relação ao direito não se relacionaria ao objeto, mas ao "ponto de vista", ao "ângulo de visão", por ela fornecido. ${ }^{13}$

Segundo Niklas Luhmann, a formação e o desenvolvimento da abordagem sociológica jurídica teriam fornecido um importante impulso à análise científica do direito, com contorno claramente distinto de tudo o que a tradição europeia anterior já havia pensado acerca da relação entre direito e sociedade. ${ }^{14}$ Entretanto, conforme ressalta o autor, somente seria possível aludir à abordagem sociológica do direito a partir do momento em que ocorre a constituição da própria sociologia, ou seja, a

\footnotetext{
${ }^{10}$ Referindo-se especificamente à questão da judiciarização, Jacques Commaille e Laurence Dumoulin ressaltam que "la judiciarisation et les façons dont ele est définie [...] constitueraient bien pour nous un révélateur privilégié de la place ocupée par la légalité, ou que certains auteurs et/ou acteurs sociaux aspirent désormais à lui faire occuper dans la régulation politique" (Heurs et malheurs de la légitimité dans les sociétés contemporaines. Une sociologie politique de la "judiciarisation". L’Année Sociologique, v. 59(1), p. 66, 2009.

${ }^{11}$ Nesse particular, é possível afirmar que a teoria dos sistemas de Niklas Luhmann, na perspectiva de Jacques Commaille, assumiria contorno semelhante à dimensão "escolástica" que Pierre Bourdieu lhe atribui ou as feições da "fantasmagoria" que Bruno Latour enxerga nela. A respeito, ver: BOURDIEU, Pierre. Science de la science et réflexivité: cours du Collège de France 2000-200. Paris: Éditions Raisons d’agir, 2001. p. 200; LATOUR, Bruno. La fabrique $d u$ droit. Une ethnographie du Conseil d'État. Paris: La Découverte, 2004. p. 282. Para uma utilização da perspectiva de Latour por Commaille, ver: COMMAILLE, Jacques. Nouvelle économie de la légalité, nouvelles formes de justice, nouveau régime de connaissance. Lanthropologie du droit avaitelle raison? In: EBERHARD, Christoph; VERNICOS, Geneviève (Ed.). La quête anthropologique du droit. Autour de la démarche d'Étienne Le Roy. Paris: Karthala, 2006. p. 360-361. Cumpre notar que, mesmo em sua obra teórica de maior envergadura, Jacques Commaille não cita Niklas Luhmann. Cf. COMMAILLE, Jacques. À quoi nous sert le droit? Paris: Gallimard, 2015.

${ }^{12}$ Cf. ARNAUD, André-Jean; FARIÑAS DULCE, María José. Introduction à l’analyse sociologique des systèmes juridiques. Bruxelles: Bruylant, 1998. p. 2.

${ }^{13}$ Cf. CARBONNIER, Jean. Sociologie juridique. 2. ed. Paris: PUF, 2008. p. 17.

${ }^{14}$ No que concerne à expressão "sociologia do direito", não se utiliza aqui a distinção feita por Roberto Lyra Filho entre "sociologia jurídica", entendida como "exame do direito em geral", e "sociologia do direito", considerada estudo da "base social de um direito específico", pois em diversas tradições os termos Rechtssoziologie, Sociologie du droit, Sociología del derecho e Sociology of law assumem também o sentido de abordagens gerais acerca do direito. Sobre a distinção proposta por Roberto Lyra Filho, ver: FARIA, José Eduardo; CAMPILONGO, Celso Fernandes. A sociologia jurídica no Brasil, p. 27, nota 11. A respeito, Jean Carbonnier, mesmo observando a tendência de se atribuir à expressão "sociologia jurídica" um sentido mais amplo do que "sociologia do direito", desconsidera essa distinção conceitual de modo a utilizar indistintamente os termos "sociologia jurídica" e "sociologia do direito". (Sociologie juridique, p. 13). Para uma excelente análise do pensamento de Jean Carbonnier, ver: ARNAUD, André-Jean. Critique de la raison juridique. 1. Où va la sociologie du droit? Paris: LGDJ, 1981. p. 211 e ss.;___. Jean Carbonnier. Un juriste dans la cité. Paris: LGDJ, 2012. p. 81 e ss. Por fim, cumpre notar que André-Jean Arnaud e María José Fariñas Dulce também utilizam indistintamente os termos "sociologia jurídica" e "sociologia do direito". (Introduction à lanalyse sociologique des systèmes juridiques, p. 1).

${ }^{15}$ Para uma análise da "construção da sociologia" que articula aspectos sociais e teóricos a ela relacionados, ver: BERTHELOT, Jean-Michel. La construction de la sociologie. 6. ed. Paris: PUF, 2006. p. 5 e ss.; BOUDON, Raymond. La sociologie comme science. Paris: La Découverte, 2010. p. 3-6. Para uma análise
} 


\subsection{TEORIA SOCIOJURÍDICA NACIONAL}

partir da segunda metade do século XIX.${ }^{15}$ Nesse sentido, Luhmann enfatiza o caráter inovador assumido pela abordagem sociológica em relação à "tradição doutrinária" (Lehrtradition) desenvolvida na Europa, que concebia o direito como um dado essencial e inerente às associações humanas, de modo a considerá-lo imanente à natureza e enredado indissoluvelmente a outros traços característicos da sociedade, como as relações de amizade, as relações de hierarquia e de dominação. ${ }^{16}$

Segundo Luhmann, para o pensamento jusnaturalista, o convívio na sociedade humana não delinearia apenas uma normatividade abstrata, engendrando, ademais, normas determináveis em sua substância e capazes de reivindicar para si um surgimento e uma verdade naturais. Nesse sentido, além de sustentar a ligação indissolúvel entre direito e sociedade, essa tradição postularia uma segunda tese consistente na existência de certas normas que seriam igualmente válidas a todas as sociedades. Entretanto, segundo Luhmann, as próprias comparações históricas e etnográficas realizadas a partir do século XIX teriam solapado essa pretensão de postular invariâncias normativas de modo a indicar o caráter contingente na formação do direito. ${ }^{17}$

A sociologia jurídica se afastaria dessa tradição de análise da relação entre o âmbito jurídico e o social, pois, apesar de poder aceitar a tese do liame indissolúvel entre direito e sociedade, rechaçaria a postulação que dela se segue, qual seja: a de que, em virtude desse liame, haveria certas normas jurídicas igualmente válidas para todas as sociedades. Nesse sentido, a sociologia do direito enfocaria o direito como um construto em princípio indispensável, porém formado a partir da contingência das relações humanas, sendo, portanto, também ele contingente $\mathrm{e}$ desprovido de normas com pretensão de validade geral. $^{18}$

Assim, para Luhmann, o distanciamento em relação à "visão interna" do direito com sua fundamentação moral caracterizaria os esforços do que ele denomina de "abordagens clássicas da sociologia do direito", que seriam compreendidas como sociológicas especialmente em virtude desse distanciamento. ${ }^{19}$ Nesse contexto, apesar das diferenças entre as diversas versões expressivas das "abordagens clássicas da sociologia do direito", é possível reconhecer algumas premissas que lhes seriam comuns, quais sejam: a) o direito passa a ser diferenciado, como estrutura normativa, da sociedade; b) direito e sociedade passariam a ser definidos como duas variáveis dependentes entre si, cuja correlação, no século XIX, seria concebida, em termos evolucionistas, como expressão de um progresso regular da civilização; c) em tais condições seriam estabelecidas hipóteses empiricamente controláveis e verificáveis sobre a relação entre direito e sociedade a partir de observações da correlação em suas variações. ${ }^{20}$

Com o intuito de elucidar os pressupostos e as limitações das "abordagens clássicas da sociologia do direito", Luhmann realiza uma breve compilação comparativa de algumas de suas mais expressivas variações. Para tanto, reconstrói, em linhas gerais, as perspectivas

\footnotetext{
da formação da sociologia enquanto um "trabalho de interpretação" que procurava empreender uma análise científica de uma sociedade nova sem aderir às suas representações mais imediatas, ver: LAVAL, Christian. L’ambition sociologique. Paris: Gallimard, 2012. p. 11-53, 663-671. Para uma discussão relativa ao surgimento da sociologia que contrapõe Raymond Aron e Michel Foucault, ver: ARON, Raymond; FOUCAULT, Michel. Dialogue. Paris: Nouvelles Éditions Lignes, 2007. A respeito, ver também: ARON, Raymond. As etapas do pensamento sociológico. Tradução de Sérgio Bath. 6. ed. São Paulo: Martins Fontes, 2003. Para uma análise acerca das matrizes sociológicas que enfocam a modernidade a partir do último decênio do século XIX, ver: MARTUCCELLI, Danilo. Sociologies de la modernité. Paris: Gallimard, 1999. No que tange especificamente ao desenvolvimento da sociologia jurídica, ver, por exemplo: ARNAUD, André-Jean. Critique de la raison juridique: 1. Où va la sociologie du droit? Paris: LGDJ, 1981. p. 53 e ss.; FARIÑAS DULCE, María José. Introduction à l’analyse sociologique des systèmes juridiques, p. 33 e ss.; SERVERIN, Évelyne. Sociologie du droit, p. 3 -12.

${ }^{16}$ Cf. LUHMANN, Niklas. Rechtssoziologie. 4. Aufl. Wiesbaden: VS Verlag für Sozialwissenschaften, 2008, p. 10.

${ }_{17}$ Cf. LUHMANN, Niklas. Rechtssoziologie, p. 11. No que concerne ao impacto das análises que poderiam ser denominadas, genericamente, de antropológicas acerca do direito e que recobrem o campo da etnografia, ver, por exemplo: ROULAND, Norbert. Anthropologie juridique. Paris: Presses Universitaires de France, 1988. p. 47 e ss.; ROULAND, Norbert. L’Anthropologie juridique. Paris: Presses Universitaires de France, 1995. p. 7 e ss.; VANDERLINDEN, Jacques. Anthropologie juridique. Paris: Dalloz, 1996. p. 14 e ss.

${ }^{18}$ Cf. LUHMANN, Niklas. Rechtssoziologie, p. 11.

${ }^{19}$ Em obras posteriores, Luhmann se referirá à especificidade da abordagem sociológica acerca do direito em termos de "descrição externa". Cf. LUHMANN, Niklas. Das Recht der Gesellschaft. Frankfurt am Main: Suhrkamp, 1993. p. 17 e ss.; 496 e ss. (trad. ingl., p. 59 e ss.; 423 e ss.; trad. esp., p. 70 e ss.; 567 e ss.)

${ }^{20}$ Cf. LUHMANN, Niklas. Rechtssoziologie, p. 12
} 


\subsection{TEORIA SOCIOJURÍDICA NACIONAL}

de Karl Marx, Henry Sumner Maine, Émile Durkheim e Max Weber, na qualidade de autores típicos dessa abordagem clássica, e as de Eugen Ehrlich e de Talcott Parsons como autores atípicos. ${ }^{21}$ Feita essa análise, o autor expõe, em termos conclusivos, algumas características que considera correntes em tais "abordagens clássicas": a) o fato de o direito não ser visto como determinado por si próprio ou a partir de normas ou princípios superiores, mas por sua referência à sociedade; b) essa referência não seria mais interpretada no sentido tradicional de uma hierarquia de fontes do direito o que induziria a que a referência à sociedade substituísse aquela feita ao direito natural), passando a ser compreendida como uma correlação suscetível a modificações evolutivas, passível de verificação empírica; c) a evolução passaria a ser concebida (ou pelo menos implicitamente suposta) como expressão de um implemento de complexidade social; d) o direito surge como um elemento codeterminante e codeterminado por esse processo de desenvolvimento, na medida em que ele o fomentaria a adaptar-se às suas necessidades, as quais, entretanto, apontariam para uma maior variabilidade e complexidade social, o que implica uma compatibilização estrutural do direito com o maior número de possíveis situações e eventos que a sociedade passa a comportar. ${ }^{22}$

Não cabe aqui aludir às limitações que Luhmann atribui às abordagens "clássicas da sociologia do direito", que, segundo ele, em virtude da carência de um instrumental conceitual adequado, não teriam sido capazes de esclarecer a totalidade do fenômeno jurídico contemporâneo e de apreender a positividade como fenômeno mais característico de tal direito. O que importa notar é a ênfase dada pelo autor ao caráter inaugural que a abordagem sociológica assume, a partir da segunda metade do século XIX, no que concerne à análise da relação entre direito e sociedade, fornecendo-lhe um impulso científico. ${ }^{23}$ Esse impulso decorre, sobretudo, do fato de que a sociologia do direito se configura como uma perspectiva externa de observação e de descrição do direito. ${ }^{24}$ Essa observação, proveniente do sistema da ciência, aborda o direito por outro ângulo, qual seja: o de sua facticidade.

Nesse sentido, Luhmann ressalta que, na "clássica divisão de trabalho" entre as ciências do direito (tomadas aqui em sentido genérico como algo que abrange as teorias reflexivas do sistema jurídico, ou seja, a dogmática jurídica e a teoria do direito ${ }^{25}$ ) e a sociologia do direito, as primeiras se ocupariam de normas e a segunda de fatos. Assim, a atividade do jurista estaria direcionada à interpretação e à aplicação de normas, enquanto a do sociólogo se voltaria à apreensão do contexto factual do direito, às suas condições e aos efeitos sociais. ${ }^{26}$ Essa clivagem tradicional entre o âmbito das ciências jurídicas e o da sociologia do direito seria particularmente reforçada pela distinção entre os planos do "ser" e do "dever-ser". ${ }^{27}$ Luhmann, aliás, alude a Kelsen como expressão da formulação mais explícita dessa concepção que sustenta a

\footnotetext{
${ }^{21}$ Luhmann realiza uma breve compilação comparativa de algumas das mais expressivas variações das "abordagens clássicas da sociologia do direito". Para tanto, reconstrói, em linhas gerais, as perspectivas de Karl Marx, Henry Sumner Maine, Émile Durkheim e Max Weber, na qualidade de autores típicos dessa abordagem clássica, e as de Eugen Ehrlich e de Talcott Parsons como autores atípicos. Cf. LUHMANN, Niklas. Rechtssoziologie, p. 12-23. A respeito, ver: VILLAS BÔAS FILHO, Orlando. Ancient law: um clássico revisitado 150 anos depois. Revista da Faculdade de Direito da USP, v. 106-107, p. 533-566, jan./dez. 2011/2012.

${ }^{22}$ Cf. LUHMANN, Niklas. Rechtssoziologie, p. 23.

${ }^{23}$ É nesse sentido que André-Jean Arnaud e María José Fariñas Dulce ressaltam que “'sociologie du droit' ou 'sociologie juridique’ sont des expressions courantes pour désigner une approche scientifique dont l’objet est l'étude des rapports entre le droit et la réalité sociale, ce que l'on désigne également comme létude de la 'réalité du droit', ou, dans un sens plus strict, la 'recherche sur les faits juridiques"' (Introduction à lanalyse sociologique des systèmes juridiques, p. 1).

${ }^{24}$ Cf. ARNAUD, André-Jean; FARIÑAS DULCE, María José. Introduction à l’analyse sociologique des systèmes juridiques, p. 4 . Aliás, essa é a maneira preponderante pela qual Luhmann se refere à sociologia do direito. A respeito, ver: LUHMANN, Niklas. Das Recht der Gesellschaft, p. 17 e ss.; 496 e ss. (trad. ingl., p. 59 e ss.; 423 e ss.; trad. esp., p. 70 e ss.; 567 e ss.); LUHMANN, Niklas. Le droit comme système social. Droit et Société, n. 11/12, p. 67, 1994; LUHMANN, Niklas. La restitution du douzième chameau: du sens d’une analyse sociologique du droit. Droit et Société, n. 47 , p. 17 e ss., 2001.

${ }^{25}$ A esse respeito, André-Jean Arnaud e María José Fariñas Dulce ressaltam que os termos "ciência jurídica" ou "ciência do direito" se refeririam ao estudo do direito realizado a partir de um ponto de vista interno. (Introduction à l'analyse sociologique des systèmes juridiques, p. 4).

${ }^{26}$ Cf. LUHMANN, Niklas. Le droit comme système social, p. 53.

${ }^{27}$ Cf. GIMÉNEZ ALCOVER, Pilar. El derecho en la teoría de la sociedad de Niklas Luhmann. Barcelona: Bosch, 1993. p. 317

${ }^{28}$ Cf. LUHMANN, Niklas. Le droit comme système social, p. 53. A respeito da distinção entre "ser" e "dever-ser" na obra de Kelsen, ver, por exemplo:

DIAS, Gabriel Nogueira. Positivismo jurídico e a teoria geral do direito na obra de Hans Kelsen. São Paulo: Revista dos Tribunais, 2010. p. $149-154$.
} 
clivagem entre o plano da ciência do direito e o da sociologia. ${ }^{28}$

Assim, nessa perspectiva, a dogmática jurídica e a teoria do direito seriam, ambas, formas internas de reflexão ou auto-observação do sistema jurídico, cumprindo, portanto, funções específicas. ${ }^{29}$ Segundo Luhmann, a dogmática jurídica consistiria em um modo de reflexão interna do sistema jurídico relacionada estreitamente aos problemas decisórios elimitada em seu grau de abstração em virtude de sua subordinação ao princípio da inegabilidade dos pontos de partida. A teoria do direito, também ela uma reflexão interna ao sistema jurídico, consistiria em uma "abstração da abstração" capaz de questionar a própria identidade do sistema jurídico e entabular uma mediação entre a observação interna e a observação externa a ele relativas. Por sua vez, a sociologia do direito expressaria uma observação e uma descrição externas do direito e, por esse motivo, não poderia substituir, sobrepor-se ou mesmo pretender ter alguma ingerência ou influência direta no sistema jurídico. ${ }^{30}$

Essa distinção é muito bem ilustrada pelo quadro sinótico (Quadro 1) proposto por Donald Black na obra Sociological Justice, reproduzido na nota 95 do capítulo 11 do livro Das Recht der Gesellschaft, no qual Luhmann analisa a autodescrição do sistema jurídico ${ }^{31}$ :

\begin{tabular}{|c|c|c|}
\hline & $\begin{array}{c}\text { Jurisprudential } \\
\text { Model }\end{array}$ & $\begin{array}{c}\text { Sociological } \\
\text { Model }\end{array}$ \\
\hline Focus & Rules & Rules \\
Process & Logic & Logic \\
Scope & Universal & Universal \\
Perspective & Participant & Participant \\
Purpose & Practical & Practical \\
Goal & Decision & Decision \\
\hline
\end{tabular}

Fonte: Donald Black ${ }^{32}$

\section{Quadro 1 - Dois modelos analíticos de abordagem do direito}

Para Luhmann, apesar dessa diferença em relação às teorias que expressam a autodescrição do sistema, a sociologia do direito, enquanto descrição externa, não poderia desconsiderar o modo pelo qual seu objeto de análise se autodescreve. Deve, portanto, descrevê-lo tal como os juristas o entendem..$^{33}$ Assim, embora a abordagem sociológica do direito, por ser expressão de uma observação externa, não esteja atrelada às normas internas do sistema jurídico, não deve equivocar-se em relação ao seu objeto de análise que, segundo Luhmann, consiste em um objeto que se auto-observa e autodescreve. Nesse sentido, o compromisso com a auto-observação e a autodescrição do objeto é condição indispensável para uma descrição científica realista e, inclusive, empiricamente adequada. $^{34}$

Em sentido análogo, Olivier Corten, com o intuito de analisar a especificidade da "sociologia política do direito", propõe o seguinte quadro analítico (Quadro 2), que, fazendo abstração

\footnotetext{
${ }^{29} \mathrm{Na}$ conclusão da segunda edição de Rechssoziologie, Luhmann se refere à dogmática jurídica e à teoria do direito como "formas de autodescrição do sistema jurídico". Cf. LUHMANN, Niklas. Rechtssoziologie, p. 360.

${ }^{30}$ Cf. LUHMANN, Niklas. La restitution du douzième chameau: du sens d’une analyse sociologique du droit, p. 30-31. Esse aspecto também é ressaltado por Carbonnier. Referindo-se à especificidade da abordagem do sociólogo em relação à do jurista dogmático (ou seja, aquele que analisa o direito pelo ângulo interno), Jean Carbonnier salienta que "le sociologue, au contraire, demeure en dehors du système qu'il observe, ce système fût-il le sien, et l'observation qu'il en fait ne saurait le moins du monde en influencier le fonctionnement” (Sociologie juridique, p. 17).

${ }^{31}$ Cf. BLACK, Donald. Sociological justice. New York: Oxford University Press, 1989, p. 3 e ss. Apud LUHMANN, Niklas. Das Recht der Gesellschaft, p. 540 (trad. ingl., p. 457; trad. esp., p. 615). A respeito, ver, por exemplo: CAMPILONGO, Celso Fernandes. Interpretação do direito e movimentos sociais. Rio de Janeiro: Elsevier, 2012. p. 152-153; GONÇALVES, Guilherme Leite; VILLAS BÔAS FILHO, Orlando. Teoria dos sistemas sociais: direito e sociedade na obra de Niklas Luhmann. São Paulo: Saraiva, 2013. p. 151.

${ }^{32}$ BLACK, Donald. Sociological justice. New York: Oxford University Press, 1989, p. 3 e ss.

${ }^{33}$ Nesse particular, Niklas Luhmann ressalta a insuficiência das análises empíricas convencionais da sociologia do direito em descrever adequadamente o sistema jurídico. (Das Recht der Gesellschaft, p. 542-543, trad. ingl., p. 458-459; trad. esp., p. 616-617).

${ }^{34}$ Cf. LUHMANN, Niklas. Das Recht der Gesellschaft, p. 18 (trad. ingl., p. 60; trad. esp., p. 70).
} 


\subsection{TEORIA SOCIOJURÍDICA NACIONAL}

das interações existentes entre as disciplinas vizinhas, procura captar, em termos típicoideais, as características da dogmática jurídica, da teoria do direito, da filosofia do direito e da sociologia do direito. ${ }^{35}$

Sem negar a existência ou a utilidade da distinção entre perspectiva interna e externa, André-Jean Arnaud problematiza os usos que

\begin{tabular}{|c|c|c|c|c|c|c|}
\hline & Definição & Modelos & $\begin{array}{l}\text { Critério de } \\
\text { validade }\end{array}$ & $\begin{array}{l}\text { Vocação } \\
\text { privilegiada }\end{array}$ & $\begin{array}{l}\text { Estatuto } \\
\text { privilegiado } \\
\text { do } \\
\text { enunciado } \\
\text { científico }\end{array}$ & $\begin{array}{l}\text { Análise dos } \\
\text { critérios de } \\
\text { interpretação }\end{array}$ \\
\hline $\begin{array}{l}\text { Dogmática } \\
\text { jurídica }\end{array}$ & $\begin{array}{l}\text { "interpretação } \\
\text { das normas } \\
\text { jurídicas" }\end{array}$ & $\begin{array}{l}\text { - positivismo } \\
\text { formalista } \\
\text { - teoria das } \\
\text { fontes formais }\end{array}$ & $\begin{array}{l}\text { - interior ao } \\
\text { direito (fato } \\
\text { jurídico) }\end{array}$ & $\begin{array}{l}\text { - prescritiva/ } \\
\text { normativa } \\
\text { (relativa) }\end{array}$ & $\begin{array}{l}\text { - } \\
\text { determinação } \\
\text { do conteúdo } \\
\text { do direito }\end{array}$ & $\begin{array}{l}\text { - texto de lei } \\
\text { (dedução) } \\
\text { - critérios } \\
\text { jurisprudenciais } \\
\text { (indução) }\end{array}$ \\
\hline $\begin{array}{l}\text { Teoria } \\
\text { (pura) do } \\
\text { direito }\end{array}$ & $\begin{array}{l}\text { "estudo dos } \\
\text { conceitos } \\
\text { fundamentais } \\
\text { da ordem } \\
\text { jurídica } \\
\text { e de sua } \\
\text { articulação" }\end{array}$ & $\begin{array}{l}\text { - sistema } \\
\text { jurídico } \\
\text { (coerência, } \\
\text { completude, } \\
\text { monismo) } \\
\text { - } \\
\text { normativismo }\end{array}$ & $\begin{array}{l}\text { - interior ao } \\
\text { direito } \\
\text { (conceitos } \\
\text { jurídicos) }\end{array}$ & $\begin{array}{l}\text { - descritiva/ } \\
\text { constatativa } \\
\text { (relativa) }\end{array}$ & $\begin{array}{l}\text { - } \\
\text { compreensão } \\
\text { do estado do } \\
\text { direito }\end{array}$ & $\begin{array}{l}\text { - "legislador } \\
\text { racional" }\end{array}$ \\
\hline $\begin{array}{l}\text { Filosofia do } \\
\text { direito }\end{array}$ & $\begin{array}{l}\text { "estudo das } \\
\text { condições } \\
\text { de validade } \\
\text { das normas } \\
\text { jurídicas } \\
\text { ou de um } \\
\text { sistema } \\
\text { jurídico em } \\
\text { relação a } \\
\text { um padrão } \\
\text { situado fora } \\
\text { (para além) } \\
\text { do direito } \\
\text { positivo }\end{array}$ & $\begin{array}{l}\text { - direitos } \\
\text { naturais } \\
\text { ("natureza", } \\
\text { "razão") } \\
\text { - ex. razão } \\
\text { comunicativa }\end{array}$ & $\begin{array}{l}\text { - exterior ao } \\
\text { direito } \\
\text { (conceitos } \\
\text { metafísicos) }\end{array}$ & $\begin{array}{l}\text { - prescritiva/ } \\
\text { normativa } \\
\text { (avaliação } \\
\text { fundamental) }\end{array}$ & $\begin{array}{l}\text { - avaliação } \\
\text { dos fins do } \\
\text { direito }\end{array}$ & $\begin{array}{l}\text { - ex. } \\
\text { conformidade à } \\
\text { "natureza das } \\
\text { coisas" } \\
\text { - ex. } \\
\text { conformidade } \\
\text { às condições } \\
\text { de uma "boa } \\
\text { discussão" }\end{array}$ \\
\hline $\begin{array}{l}\text { Sociologia } \\
\text { do direito }\end{array}$ & $\begin{array}{l}\text { "estudo das } \\
\text { relações } \\
\text { entre o } \\
\text { direito e a } \\
\text { sociedade" }\end{array}$ & $\begin{array}{l}\text { - pluralismo } \\
\text { jurídico } \\
\text { - } \\
\text { funcionalismo/ } \\
\text { sistemismo } \\
\text { - legitimação }\end{array}$ & $\begin{array}{l}\text { - exterior ao } \\
\text { direito } \\
\text { (realidade } \\
\text { social) }\end{array}$ & $\begin{array}{l}\text { - descritiva/ } \\
\text { constatativa } \\
\text { (explicação } \\
\text { fundamental) }\end{array}$ & $\begin{array}{l}\text { - explicação } \\
\text { das funções } \\
\text { do direito }\end{array}$ & $\begin{array}{l}\text { - ex. adaptação } \\
\text { do texto à } \\
\text { realidade social } \\
\text { - ex. } \\
\text { legitimação } \\
\text { de posições } \\
\text { políticas } \\
\text { variáveis sob } \\
\text { o amparo de } \\
\text { uma noção } \\
\text { jurídica }\end{array}$ \\
\hline
\end{tabular}

Fonte: Olivier Corten. ${ }^{36}$

${ }^{35}$ CORTEN, Olivier. Éléments de définition pour une sociologie politique du droit. Droit et Société, n. 39, p. $352,1998$.

${ }^{36}$ CORTEN, Olivier. Éléments de définition pour une sociologie politique du droit. Droit et Société, n. 39, p. $352,1998$.

${ }^{37}$ Cf. ARNAUD, André-Jean. La valeur heuristique de la distinction interne/externe comme grande dichotomie pour la connaissance du droit: éléments d'une démystification. Droit et Société, n. 2, p. 139-141, 1986. 
dela são feitos. ${ }^{37}$ Não há como dehsenvolver essa análise aqui. Para os propósitos deste artigo, cumpre notar que, segundo Jacques Commaille e Jean-François Perrin, a abordagem sociológica do direito, especialmente a desenvolvida pela "sociologia política do direito", não se pode situar nem no exterior nem no interior do direito. ${ }^{38}$ Conforme enfatiza Olivier Corten, a pretensão interdisciplinar da "sociologia política do direito" implicaria verificar em que medida a realidade social se reflete no interior do direito e (ou) em que medida o direito se recobre de normas, modelos ou valores que têm repercussão na realidade social. ${ }^{39}$

\section{A PROPOSTA DE UMA "SOCIOLOGIA POLÍTICA DO DIREITO"}

A proposta de uma "sociologia política do direito" foi introduzida por Jacques Commaille, em 1994, na obra "L'esprit sociologique des lois. Essai de sociologie politique du droit", na qual o autor desenvolve uma análise original e minuciosa da legislação de família na França. ${ }^{40}$ No ano seguinte, Jacques Commaille organizou, com o antropólogo Louis Assier-Andrieu, a publicação do livro "Politiques des lois en Europe. La filiation comme modèle de comparaison", que teve por base uma extensa pesquisa comparativa realizada em diversos países. A partir de então, a proposta de uma "sociologia política do direito" começou a receber ampla acolhida no meio acadêmico francófono. Para explicitar o impacto da proposta, Olivier Corten observa que, no ano de 1995, em clara afinidade com a proposta de Jacques Commaille, foi criado, em Bruxelas, o Centro de Sociologia Política do Direito. ${ }^{41}$

Aludindo a autores clássicos da sociologia jurídica - especialmente Renato Treves e Jean Carbonnier -, Olivier Corten enfatiza que o interesse pela política não seria novo no âmbito da sociologia jurídica. Entretanto, segundo ele, apesar desse interesse, até o final dos anos 1990 não teria sido proposta uma definição efetiva do que poderia ser entendido por uma "sociologia política do direito". Em artigo publicado em 1998, Olivier Corten observava que nem mesmo a obra "Lesprit sociologique des lois. Essai de sociologie politique du droit" conteria uma definição explícita da disciplina e mesmo as características que fixariam sua especificidade em relação a outras abordagens que tomam o direito por objeto. ${ }^{42}$ Conforme se verá a seguir, em textos posteriores, Jacques Commaille procurará explicitar, em termos mais precisos, a especificidade de sua "sociologia política do direito". 43

Em 2013, durante o colóquio intitulado Sociologie politique du droit. Quels acquis? Quelles perspectives? Journées en l'honneur de Jacques Commaille, ocorrido entre 9 e 10 de setembro de 2013, na École Normale Supérieure de Cachan, diversos autores analisaram a importância da obra de Jacques Commaille, sublinhando a riqueza de perspectivas dela derivadas. ${ }^{44}$ Por ocasião de tal colóquio, foi publicado o texto intitulado "Une sociologie politique du droit",

\footnotetext{
${ }^{38}$ Segundo Jacques Commaille e Jean-François Perrin, "la sociologie du droit ne peut pas être ni tout à fait à l'exterieur ni tout à fait à l'intérieur du droit" (Le modèle de Janus de la sociologie du droit. Droit et Société, n. 1, p. 97, 1985).

${ }^{39}$ Segundo Olivier Corten, "une sociologie (politique) du droit suppose de déterminer dans quelle mesure une réalité sociale se reflète à l'intérieur du droit, ou/et dans quelles mesure le droit recouvre des normes, des modèles ou des valeurs qui ont des répercussions dans la réalité sociale. L'interdisciplinarité, en particulier le passage par une étape qui relève de la dogmatique juridique et de la théorie du droit, s'avere dans ce contexte indispensable, pourvu que le droit reste bien l’objet de l'analyse" (Éléments de définition pour une sociologie politique du droit, p. 361).

${ }^{40}$ Cf. COMMAILLE, Jacques. L’esprit sociologique des lois. Essai de sociologie politique du droit. Paris: PUF, 1994. A respeito, ver também: COMMAILLE, Jacques; STROBEL, Pierre; VILLAC, Michel. La politique de la famille. Paris: La Découverte, 2002.

${ }^{41}$ Cf. CORTEN, Olivier. Éléments de définition pour une sociologie politique du droit, p. 348. Sobre a importância assumida pela "sociologia política do direito" na França, ver: CAPELLER, Wanda. Relire Giddens. Entre sociologie et politique. Paris: LGDJ, 2011. p. 197.

${ }^{42}$ Cf. CORTEN, Olivier. Éléments de définition pour une sociologie politique du droit, p. 348 . Em sentido análogo Jacques Caillosse, aludindo aos dois volumes da revista L’année sociologique, publicados em 2009 sob a coordenação de Jacques Commaille e Patrice Duran, também observava a ausência de uma definição da "sociologia política do direito". A respeito, ver: CAILLOSSE, Jacques. La sociologie politique du droit, le droit et les juristes. Droit et Société, n. 77, p. 189-190, 2011.

${ }^{43}$ A respeito, ver, por exemplo: COMMAILLE, Jacques; DURAN, Patrice. Pour une sociologie politique du droit: présentation, p. 11-28.

${ }^{44} \mathrm{O}$ colóquio contou com a participação de André-Jean Arnaud, Anne Boigeol, Anne Revillard, Anne-Marie Brocas, Aude Lejeune, Benoit Bastard, Bertrand Jouve, Catherine Marry, Cécile Vigour, Claire de Galembert, Claude Didry, Claude Martin, Elisa Chelle, Emmanuelle Bernheim, Étienne Le Roy, François Ost, Françoise Thibault, Frédéric Chauvaud, Georges Garioud, Gérôme Truc, Jacques Chevallier, Jean-François Perrin, Jean-Guy Belley, Jean-Paul Jean, Jérôme Pélisse, Laure Blevis, Laurence Dumoulin, Liora Israël, Marie-Claire Lavabre, Martine Bentaboulet, Martine Kaluszynski, Mauricio Garcia Villegas, Michel van de Kerchove, Olivier Bouin, Olivier Paye, Pascal Arnaud, Patrice Duran, Pierre Guibentif, Pierre Lascoumes, Pierre Noreau, Pierre-Paul Zalio, Romain Melot, Susan Silbey, Sylvie Thénault, Vincent-Arnaud Chappe, Violaine Roussel e Werner Gephart.

${ }^{45} \mathrm{O}$ texto intitulado Une sociologie politique du droit foi originalmente publicado na Newsletter de La Mission de Recherche Droit et Justice - septembre
} 
em que o autor, em termos sintéticos, procurou delinear o essencial de sua proposta. ${ }^{45}$ Para tanto, enfatiza, logo de início, que sua experiência de trabalho como sociólogo, nos anos 1970, com Jean Carbonnier ${ }^{46}$ lhe teria proporcionado a oportunidade de descobrir duas dimensões entrelaçadas do direito: a) a que diz respeito ao saber jurídico em sentido estrito; e b) a que se relaciona à inscrição do direito e sua produção no espaço político. A partir de tal experiência, o autor passou a considerar conveniente se afastar de uma visão estritamente jurídico-centrada e deslocar a questão do direito para um quadro mais amplo, anteriormente referido à "sociologia da decisão" e, em seguida, ao âmbito das políticas

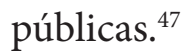

Assim, Jacques Commaille procura inscrever a análise da regulação jurídica no âmbito dos processos mais gerais que advêm do campo político. ${ }^{48} \mathrm{O}$ direito deixa então de ser enfocado como fenômeno específico e passa a ser entendido como portador de um forte potencial heurístico para o funcionamento do âmbito político do qual se torna, conforme já mencionado, um "revelador privilegiado". 49 Apoiando-se em autores como Paul Amselek, ressalta que o direito não pode ser concebido independente do exercício do poder público e de todo o contexto específico de atos e relações sociais de autoridade no qual ele se insere e que lhe fornece seu verdadeiro relevo. ${ }^{50}$ A sociologia política do direito se assume, portanto, como portadora da pretensão de uma interlocução estruturada com as demais ciências sociais. ${ }^{51}$ Aliás, conforme enfatiza Commaille, o direito é "reinstituído naquilo que ele foi para as grandes figuras fundadoras da sociologia: um elemento central na construção de teorias gerais das sociedades e de suas transformações". ${ }^{52}$ É com base em tais premissas que Jacques Commaille, rejeitando a inscrição de sua perspectiva teórica no horizonte de uma "sociologia dos campos", define a "sociologia política do direito" como "o estudo do âmbito político sob o prisma de uma sociologia do direito solidamente ancorada em uma sociologia geral e de uma ciência política que essa sociologia do direito entende proficuamente retroalimentar". ${ }^{53}$

Jacques Commaille sublinha que essa ampliação de perspectiva permite relacionar o estudo do direito às grandes mutações que ocorrem atualmente nas sociedades ocidentais e, simultaneamente, inscreverasanálisesproduzidas sobre as relações entre direito e política em uma corrente de pesquisa internacional atualmente

2013. Em seguida, foi traduzido e publicado na Revista da Faculdade de Direito da USP. Cf. COMMAILLE, Jacques. Uma sociologia política do direito. Revista da Faculdade de Direito da USP, v. 108, p. 929-933, jan.-dez. 2013.

${ }^{46}$ Como se sabe, Jean Carbonnier é considerado introdutor da sociologia jurídica nas faculdades de direito francesas. Suas principais obras de sociologia jurídica são: Flexible droit. Pour une sociologie du droit sans rigueur e Sociologie juridique. Sobre a obra de Cabonnier, ver, por exemplo: ARNAUD, AndréJean. Jean Carbonnier. Un juriste dans la cité (neste livro há, inclusive, um excelente prefácio de Jacques Commaille); ANDRINI, Simona; ARNAUD, André-Jean. Jean Carbonnier, Renato Treves et la sociologie du droit. Archéologie d’une discipline. Paris: LGDJ, 1995; COMMAILLE, Jacques. La construction d'une sociologie spécialisée. Le savoir sociologique et la sociologie juridique de Jean Carbonnier. L’Année Sociologique, v. 57(2), p. 275-299, 2007; VERDIER, Raymond (Dir.). Jean Carbonnier. L'homme et l'oeuvre. Nanterre: Presses Universitaires de Paris Ouest, 2011; PERRIN, Jean-François. Jean Carbonnier. La référence comme héritage. Droit et Société, n. 84, p. 477-486, 2013.

${ }^{47}$ Cf. COMMAILLE, Jacques. Uma sociologia política do direito, p. 929.

${ }^{48}$ Para uma definição de "regulação jurídica", ver, por exemplo: ARNAUD, André-Jean. Entre modernité et mondialisation. Leçons d'histoire de la philosophie du droit et de l'État. 2. ed. Paris: LGDJ, 2004. p. 122; ARNAUD, André-Jean. De la régulation par le droit à l'heure de la globalisation. Quelques observations critiques. Droit et société, v. 35, 1997. p. 11-35; ARNAUD, André-Jean. La gouvernance. Un outil de participation. Paris: LGDJ, 2014. p. 180-181; CHEVALLIER, Jacques. La régulation juridique en question. Droit et Société, n. 49, p. 827-846, 2001; CHEVALLIER, Jacques. L'État post-moderne. 3. ed. Paris: LGDJ, 2008. p. 61-62, 111-112.

${ }^{49}$ A respeito, Jacques Commaille ressalta que "une sociologie politique du droit est consacrée à l'analyse de léconomie des relations entre le juridique et le politique, de la place du juridique dans la construction du politique, du rôle du juridique comme révélateur du politique, ceci dans le cadre de démarches de recherche où le travail empirique est indissociable de l'investissement théorique" (De la "sociologie juridique" à une sociologie politique du droit, p. 38). A respeito, ver também: COMMAILLE, Jacques. Transformations du droit et de l'action publique. Économie Rurale, n. 260, p. 20-25, 2000; COMMAILLE, Jacques. Uma sociologia política do direito, p. 930; COMMAILLE, Jacques; DUMOULIN, Laurence. Heurs et malheurs de la légitimité dans les sociétés contemporaines. Une sociologie politique de la “judiciarisation”, p. 66.

${ }^{50}$ Cf. COMMAILLE, Jacques. Uma sociologia política do direito, p. 930.

${ }^{51}$ Cf. COMMAILLE, Jacques. De la "sociologie juridique" à une sociologie politique du droit, p. 38. A respeito, ver também: COMMAILLE, Jacques. $A$ quoi nous sert le droit? p. 13-14.

${ }_{52}$ Cf. COMMAILLE, Jacques. Uma sociologia política do direito, p. 930. Isso é particularmente evidente quando se considera a obra de Durkheim. Para uma análise que, ao contrastar Durkheim e Weber, sublinha as principais teses do primeiro acerca do direito, ver: SCHLUCHTER, Wolfgang. La sociologie du droit comme théorie empirique de la validité. In: HEURTIN, Jean-Philippe; MOLFESSIS, Nicolas (Dir.). La sociologie du droit de Max Weber. Paris: Dalloz, 2006. p. 7.

${ }^{53}$ COMMAILLE, Jacques. Uma sociologia política do direito, p. 930; COMMAILLE, Jacques; DURAN, Patrice. Pour une sociologie politique du droit: présentation, p. 13. Cumpre notar que os números 1 e 2 do volume 59, de 2009, da revista L’Année Sociologique foram inteiramente dedicados à "sociologia política do direito". Sobre a relação da "sociologia política do direito" com a "sociologia geral", ver: COMMAILLE, Jacques. Normes juridiques et régulation sociale. Retour à la sociologie générale. In: ; CHAZEL, François (Dir.). Normes juridiques et régulation sociale. Paris: LGDJ, 1991. p. 13-22. 
em curso. Nesse sentido, a sociologia política do direito procura estar atenta às metamorfoses da regulação política, identificando da seguinte maneira seus aspectos principais:

[...] substituição da noção de governança à de governo, relativização do peso do Estado-nação no contexto da globalização e da multiplicação das trocas transnacionais, transformações dos modos de intervenção do Estado marcados especialmente pela relativização dos processos de decisão top-down justificando em particular a substituição da noção de ação pública à de política pública, crise da democracia representativa, redefinição das relações entre legalidade e legitimidade correlativa à crise do modelo weberiano de dominação racional-legal, novas formas de mobilização da sociedade civil, no plano nacional mas também no supranacional (emergência de uma sociedade civil mundial) etc. ${ }^{54}$

\section{Conforme enfatiza Jacques Commaille,} essas mudanças ensejariam novas orientações de pesquisa, com forte acento interdisciplinar, para que se possa captar adequadamente o que o autor designa de "nova economia da legalidade em relação ao âmbito político" ${ }^{55}$ Segundo o autor, a "sociologia política do direito" teria ampliado consideravelmente seus horizontes de observação e de análise, notadamente no que concerne às mudanças de estatuto assumidas pelo direito quando este passa a ser visto como um recurso suscetível de aparecer em novos repertórios de ação coletiva implementados por alguns movimentos sociais ou ainda como um recurso instrumentalizado pela ação política. ${ }^{56}$

Jacques Commaille pontua, ainda, a afinidade da sociologia política do direito com perspectivas que enfocam o direito como constitutivo da realidade social e não mais como emanado de aparelhos institucionais destinados a intervir sobre essa realidade social. Assim, alinhandose a perspectivas como as de Susan Silbey e de Patricia Ewick (corrente do legal consciousness) ${ }^{57}$, à corrente internacional do cause lawyering ${ }^{58}$ e à dos activists lawyers ${ }^{59}$, Jacques Commaille pretende delinear uma nova representação do direito capaz de captar a redefinição das relações dos cidadãos com as normas jurídicas e a importância particular assumida pelos profissionais do direito enquanto atores do jogo político na medida em que dispõem da competência consistente em dominar o uso do recurso jurídico. ${ }^{60}$

Além disso, Jacques Commaille ressalta que uma "sociologia política do direito" não pode desconsiderar as transformações engendradas pelo fenômeno da globalização no estatuto do direito e às novas funções por ele assumidas, assim como as da justiça, especialmente em referência ao âmbito político. ${ }^{61}$ Aliás, enfatiza que, no bojo desse processo, a justiça, ao inscrever-se no âmbito supranacional, passa a ter

\footnotetext{
${ }^{54}$ COMMAILLE, Jacques. Uma sociologia política do direito, p. 930-931. No que tange a uma abordagem da democracia que a descentra da dimensão eleitoral-representativa, ver: ROSANVALLON, Pierre. La contre-démocratie: la politique à l'âge de la défiance. Paris: Éditions du Seuil, 2006; ROSANVALLON, Pierre. La légitimité démocratique: impartialité, réflexivité, proximité. Paris: Éditions du Seuil, 2008; ROSANVALLON, Pierre. La société des égaux. Paris: Éditions du Seuil, 2011. Para uma análise da polissemia do conceito de democracia, ver: VILLAS BÔAS FILHO, Orlando. Democracia: a polissemia de um conceito político fundamental. Revista da Faculdade de Direito da USP, v. 108, p. 651-696, jan.-dez. 2013.

${ }^{55}$ COMMAILLE, Jacques; DURAN, Patrice. Pour une sociologie politique du droit: présentation, p. 18; COMMAILLE, Jacques. Uma sociologia política do direito, p. 931.

${ }^{56}$ Cf. COMMAILLE, Jacques. Uma sociologia política do direito, p. 931. Para uma incontornável análise relativa aos movimentos sociais, ver: TOURAINE, Alain. Le retour de l'acteur: essai de sociologie. Paris: Fayard, 1984. p. 249 e ss. Na discussão brasileira, ver: CAMPILONGO, Celso Fernandes. Interpretação do direito e movimentos sociais, p. 9 e ss.

${ }^{57}$ Cf. EWICK, Patricia; SILBEY, Susan. The common place of law. Stories from everyday life. Chicago: The Chicago University Press, 1998. A respeito, ver: COMMAILLE, Jacques. Nouvelle économie de la légalité, nouvelles formes de justice, nouveau régime de connaissance. L'anthropologie du droit avait-elle raison? p. 361-362. Sobre as reverberações dessa perspectiva na discussão francesa, ver, por exemplo: COMMAILLE, Jacques; DURAN, Patrice. Pour une sociologie politique du droit: présentation, p. 15; COMMAILLE, Jacques. À quoi nous sert le droit? p. 70, 85, 346; PÉLISSE, Jérôme. A-ton conscience du droit? Autour des Legal Consciousness Studies. Genèses, n. 59, p. 114-130, 2005; KOURILSKY-AUGEVEN, Chantal. Socialisation, socialisation juridique et conscience du droit. In: RUDE-ANTOINE, Edwige; CHRÉTIEN-VERNICOS, Geneviève (Coord.). Anthropologies et droits. État des savoirs et orientations contemporaines. Paris: Dalloz, 2009. p. 245-269.

${ }^{58}$ Como referência fundamental a esse respeito, ver: SARAT, Austin; SCHEINGOLD, Stuart A. (Dir.). The worlds cause lawyers m Structure and agency in legal practice. Stanford, California: Stanford University Press, 2005. Jacques Commaille e Patrice Duran também aludem ao trabalho de Liora Israël. (Pour une sociologie politique du droit: présentation, p. 16); COMMAILLE, Jacques. Uma sociologia política do direito, p. 931; COMMAILLE, Jacques. À quoi nous sert le droit? p. 110-112, 427.

${ }^{59}$ Sobre essa questão, Jacques Commaille remete para as obras de Stuart Scheingold, Liora Israël, Alain Supiot e de Terence C. Halliday, Lucien Karpik e Malcolm M. Feeley. A respeito, ver: COMMAILLE, Jacques. Les vertus politiques du droit. Mythes et réalités. Droit et Sociét, n. 76, p. 695-713, 2010; COMMAILLE, Jacques. Uma sociologia política do direito, p. 932; COMMAILLE, Jacques. À quoi nous sert le droit? p. 427-428.

${ }^{60}$ Cf. COMMAILLE, Jacques. Uma sociologia política do direito, p. 931-932.

${ }^{61}$ Cf. COMMAILlE, Jacques. Uma sociologia política do direito, p. 932
} 


\subsection{TEORIA SOCIOJURÍDICA NACIONAL}

de redefinir suas funções no contexto das novas escalas territoriais que passa a abranger. ${ }^{62}$ Por fim, para ilustrar as ligações por ele sustentadas entre o direito e a justiça com o âmbito político, Jacques Commaille alude especialmente ao que denomina de "juridicização e judiciarização do político".

\section{A JURIDICIZAÇÃOE A JUDICIARIZAÇÃO ENFOCADAS A PARTIR DA SOCIOLOGIA POLÍTICA DO DIREITO}

Os processos de juridicização (juridicisation entre os autores francófonos e juridicalization entre os anglófonos) e de judiciarização (judiciarisation entre os autores francófonos e judicialization entre os anglófonos) são objeto de especial atenção da "sociologia política do direito" de Jacques Commaille que os associa às mudanças do "regime de legalidade" nas sociedades ocidentais contemporâneas. Conforme enfatizam Jacques Commaille e Laurence Dumoulin, embora esses dois fenômenos estejam frequentemente relacionados, não podem ser confundidos. ${ }^{63}$

Com o intuito de explicitar as especificidades desses dois processos, serão apresentadas a seguir, em linhas gerais, as características fundamentais que o autor atribui a um e a outro desses processos, a começar pelo de juridicização.

Jacques Commaille ressalta que a juridicização seria uma característica de nossas sociedades, observável nos mais diversos domínios. Segundo ele, essa juridicização tenderia a ser acompanhada de uma judiciarização das questões sociais e políticas, sendo, neste último caso, reveladora de um deslocamento do tratamento de certas questões da arena política para a judiciária, mediante a utilização cada vez mais frequente do direito, como recurso, pelos atores sociais. Além disso, questões relativas aos atores políticos, especialmente relativas à corrupção, passariam a ser deslocadas para o tratamento judiciário. ${ }^{64}$

Thierry Delpeuch, Laurence Dumoulin e Claire de Galembert ressaltam dois sentidos atribuíveis à noção de juridicização: a) o processo pelo qual as normas sociais partilhadas por um grupo são transformadas em regras e em dispositivos jurídicos explícitos. Logo, nesse primeiro sentido, juridicização remete para “a instauração de regras jurídicas destinadas a regular uma determinada relação ou atividade social", de modo a fazer com que seu respeito seja, inclusive, passível de ser imposto por uma instância judicial. Nesse sentido, a noção remeteria especialmente ao aumento da proporção das regras jurídicas na regulação da atividade social; b) o aumento progressivo dos mecanismos de imposição da regulação qualificada como jurídica, referindo-se, nesse caso, também ao fenômeno da judiciarização. Destarte, remeteria especialmente à ampliação da "força vinculativa" (force contraignante) das regras jurídicas, especialmente a partir da possibilidade de recurso a instâncias formais, com a decorrente de restrição da margem de autonomia deixada aos agentes no que tange à adoção de outras condutas que não aquelas prescritas juridicamente. ${ }^{65}$

Nesse particular, conforme ressaltam Thierry Delpeuch, Laurence Dumoulin e Claire de Galembert, as instâncias de produção do direito frequentemente tomam as normas sociais por referência quando definem o conteúdo de

\footnotetext{
${ }^{62}$ Cf. COMMAILLE, Jacques. Uma sociologia política do direito, p. 932; ARNAUD, André-Jean. Gouvernants sans frontières. Entre mondialisation et post-mondialisation. v. 2 de la Critique de la raison juridique. Paris: LGDJ, 2003. p. 183 e ss. A respeito, ver também: COMMAILLE, Jacques. Justice. In: ARNAUD, André-Jean (Dir.). Dictionnaire de la globalisation. Paris: LGDJ, 2010. p. 302-310.

${ }^{63}$ Conforme ressaltam Jacques Commaille e Laurence Dumoulin, "le phénomène de judiciarisation (judicialization) est souvent mis en relation avec un processus plus global d'expansion et de mutation de la légalité, celui de la 'juridicisation' ('juridicalization')” (Heurs et malheurs de la légitimité dans les sociétés contemporaines. Une sociologie politique de la “judiciarisation”, p. 70).

${ }^{64}$ Cf. COMMAILLE, Jacques. La juridicisation du politique. Entre réalité et conaissance de la réalité. En guise de conclusion. In: DUMOULIN, Laurence; ROBERT, Cécile (Dir.). La juridicisation du politique. Paris: LGDJ, 2010. p. 200. Em sentido análogo, Laurence Dumoulin e Cécile Robert ressaltam que "ce mouvement de juridicisation du social et du politique - dont témoignent la prolifération te la diversification de la règle de droit, la réglementation des pratiques de financement des partis politiques, l'essor du mouvement constitutionnaliste mais aussi l'émergence de 'la question du droit [...] comme l'un des axes fondamentaux d'un débat politique rénové - s'accompagne d'un processus parallèle de judiciarisation" (Autour des enjeux d'une ouverture des sciences du politique au droit. Quelques réflexions en guise d'introduction. In: ___ ; _ _ ; COMMAILLE, Jacques (Dir.). La juridicisation du politique. Paris: LGDJ, 2010. p. 9-10).

${ }^{65}$ Cf. DELPEUCH, Thierry; DUMOULIN, Laurence; GALEMBERT, Claire de. Sociologie du droit et de la justice. Paris: Armand Colin, 2014. p. 41-42. Sobre a juridicização, ver também: CHEVALLIER, Jacques. L'État post-moderne, p. 109-115.
} 


\subsection{TEORIA SOCIOJURÍDICA NACIONAL}

certas regras jurídicas. Contudo, essa operação de produção do direito não consiste em uma mera legislação calcada em regras sociais vigentes. Ela implica, por vezes, negociações e lutas entre os agentes sociais com concepções de mundo, interesses e valores diversos. Essa abordagem considera que o direito detém um alto grau de legitimidade social e que, portanto, a juridicização de uma norma social geraria como consequência um reforço à adesão por parte de seus destinatários. ${ }^{66}$ Haveria, assim, uma espécie de eficácia simbólica própria ao direito, tal como observa Maurício García Villegas. ${ }^{67}$

Baseando-se na análise de Pierre Bourdieu, ${ }^{68}$ Thierry Delpeuch, Laurence Dumoulin e Claire de Galembert, enfatizam que o efeito de legitimação engendrado pela juridicização de uma norma a destacaria simbolicamente de interesses particulares a ela relacionados, escamoteando, assim, tudo o que nela há de arbitrário e de contingente, apresentando-a como neutra e universal..$^{69}$ Remetendo às expressivas análises de Max Weber, Jürgen Habermas e Niklas Luhmann -, salientam que a juridicização de um número crescente de domínios da vida social constituiria um aspecto central da dinâmica de modernização das sociedades ocidentais, relacionando-se à emergência e à expansão do Estado moderno. ${ }^{70}$ Considera-se, assim, que a diferenciação e a complexificação, características das sociedades modernas, ensejariam uma crescente demanda de regulamentação jurídica relacionada, de um lado, à necessidade de organizar e regular as relações de interdependência entre domínios de atividade cada vez mais numerosos e, de outro, à necessidade delimitar as externalidades negativas que eles se impõem mutuamente. ${ }^{71}$

A pluralidade de perspectivas que se dirigem ao fenômeno de juridicização imprime ao conceito significativa polissemia. Isso implica que se estabeleça, em termos precisos, qual o sentido atribuído ao termo no âmbito da "sociologia política do direito". Jérôme Pelisse, por exemplo, sustenta que a juridicização expressaria um processo de formalização fundado sobre uma extensão do direito positivo para regulamentação das relações sociais, sobretudo fora dos tribunais, enquanto a judiciarização remeteria ao aumento do recurso à instituição judiciária e aos procedimentos formais para composição dos conflitos. ${ }^{72}$

Enfatizando a recorrente confusão entre os fenômenos referidos pelos termos juridicização e judiciarização, Thierry Delpeuch, Laurence Dumoulin e Claire de Galembert também procuram traçar uma fronteira entre eles. Nesse sentido, definem a juridicização (juridicisation/ juridicalization) como a proliferação do direito positivo, tal como observável por meio da inflação legislativa e regulamentar, e a multiplicação das formas jurídicas de regulação das relações sociais. Trata-se, assim, do que Jacques Commaille e Laurence Dumoulin descrevem em termos de um fenômeno global de expansão e

\footnotetext{
${ }^{66}$ Cf. DELPEUCH, Thierry; DUMOULIN, Laurence; GALEMBERT, Claire de. Sociologie du droit et de la justice, p. 42.

${ }^{67}$ Cf. GARCÍA VILLEGAS, Mauricio. La eficacia simbólica del derecho. 2. ed. Bogotá: IDEPRI; Debate, 2014, p. 233 e ss.

${ }^{68}$ Cf. BOURDIEU, Pierre. Habitus, code et codification, p. 40-44; BOURDIEU, Pierre.. La force du droit. Éléments pour une sociologie du champ juridique, p. 3-19.

${ }^{69}$ Cf. DELPEUCH, Thierry; DUMOULIN, Laurence; GALEMBERT, Claire de. Sociologie du droit et de la justice, p. 42.

${ }^{70}$ Cf. DELPEUCH, Thierry; DUMOULIN, Laurence; GALEMBERT, Claire de. Sociologie du droit et de la justice, p. 43.

${ }^{71}$ Referindo-se especificamente à teoria de Habermas, Thierry Delpeuch, Laurence Dumoulin e Claire de Galembert enfatizam a dinâmica paradoxal dos processos de juridicização das regulações sociais (Sociologie du droit et de la justice, p. 43). Nesse particular, cumpre notar que o termo Verrechtlichung é utilizado por Jürgen Habermas para ilustrar sua tese de uma colonização interna do "mundo da vida". Nesse con $\neg$ texto, a colonização aparece como "the juridification of communicatively structured action areas" (Law as medium and law as institution. In: TEUBNER, G. (Org.). Dilemmas of law in the welfare state. Berlin: Walter de Gruyther/European University Institute, 1989. p. 204). Acerca dessa questão, Stephen White ressalta que há uma evolução na posição sustentada por Habermas. Segundo ele, "in The Theory of Communicative Action, Habermas had certainly regarded the emergence of modern law, with its universalism and orientation to individual rights, as a significant evolutionary step in moral-practical learning. But this positive quality was seen largely as something that has kept us from recognizing the degree to which law in welfare state has in fact become a vehicle for expanding administrative power (a problem Habermas treated under the theme of 'juridification' Verrechtlichung). Thus, although modern law is understood in that book as deeply ambivalent, its negative side is what receives the most distinctive treatment. This one-sidedness is corrected in Facticity and Validity" (Reason, modernity, and democracy. In:___ (Ed.). The Cambridge Companion to Habermas. New York: Cambridge University Press, 1999. p. 11). A literatura especializada sobre essa questão é monumental, o que torna improfícuo capitulá-la aqui. Para uma análise da "juridificação" a partir de um viés sistêmico, ver: TEUBNER, Gunther. Juridification: concepts, aspects, limits, solutions. In: ___. (Ed.). Juridification of social spheres. A comparative analysis in the areas of labour, corporate, antitrust and social welfare law. Berlin: Walter de Gruyter, 1987. p. 3-48.

${ }^{72}$ Cf. PÉLISSE, Jèrôme. Les usages syndicaux du droit et de la justice. In: COMMAILLE, Jacques; KALUSZYNSKI, Martine. (Dir.). La fonction politique de la justice. Paris: La Découverte, 2007. p. 166.

${ }^{73}$ COMMAILLE, Jacques; DUMOULIN, Laurence. Heurs et malheurs de la légitimité dans les sociétés contemporaines. Une sociologie politique de la “judiciarisation", p. 70.
} 


\subsection{TEORIA SOCIOJURÍDICA NACIONAL}

mutação da legalidade. ${ }^{73}$ Por outro lado, definem a judiciarização (judiciarisation/judicialization) como o progressivo aumento de poder dos juízes e dos tribunais, sendo, desse modo, uma expressão do fenômeno geral de juridicização. ${ }^{74}$ É nesse sentido que Jacques Commaille ressalta que o termo judiciarização significaria, para alguns autores, "um deslocamento dos poderes Executivo e do Legislativo em direção ao Judiciário para assegurar a regulação do político no lugar do político" ${ }^{75}$

Contudo, conforme observam Jacques Commaille e Laurence Dumoulin, apesar de a judiciarização poder ser, em termos gerais, considerada uma forma de expressão da juridicização, a relação entre esses dois fenômenos não é linear, direta ou congruente. Ao contrário, como mostram os autores, é simplificador enfocar a judiciarização como uma expressão direta da juridicização, pois as relações que se estabelecem entre esses fenômenos são complexas e dependem de configurações históricas e nacionais, podendo, assim, assumir articulações concretas díspares. Mediante a alusão à análise de Barry Holmström acerca da experiência sueca, Jacques Commaille e Laurence Dumoulin procuram destacar concretamente o caráter não linear da relação entre juridicização e judiciarização. Conforme enfatizam os autores, no contexto sueco, a judiciarização crescente não teria decorrido da juridicização, e sim, ao contrário, de uma espécie de compensação decorrente do refluxo do papel dos juristas na vida política. Ou seja, seria o progressivo escasseamento da influência dos juristas no aparelho do Estado que teria ensejado, em termos compensatórios, um crescente reforço dos tribunais como "terceiro poder". Desse modo, a judiciarização teria, em última instância, decorrido de uma desjuridicização da vida política e do aparelho estatal sueco. ${ }^{76}$

A questão da judiciarização, concebida como um atributo característico das transformações experimentadas pelo âmbito político na contemporaneidade, é amplamente tratada por Jacques Commaille. Mobilizando uma expressiva literatura internacional sobre a questão da judiciarização, este autor e Laurence Dumoulin identificam três ordens de questões importantes que seriam ensejadas por tal fenômeno: constituiria a judiciarização uma expressão da evolução das formas de legalidade a ponto de significar uma transformação do princípio de legitimidade da dominação política? Representaria ela uma manifestação da relativização do monopólio do Estado moderno no tocante à produção do direito? Anunciaria ela uma transformação nos modos de governo? Partindo dessas questões, os autores desenvolvem uma tentativa de definição do que entendem por judiciarização, indicando, dentre as numerosas questões que emergem da discussão internacional sobre o tema, duas que lhes parecem fundamentais. Em primeiro lugar, o papel crescente e progressivamente crucial da justiça na produção das políticas públicas. Em segundo lugar, o caráter central da justiça no funcionamento das democracias. ${ }^{77}$ Segundo os autores, essas questões seriam reveladoras de uma mudança do estatuto e do regime da legalidade em relação às transformações experimentadas pelo exercício do poder político,

\footnotetext{
${ }^{74}$ Cf. DELPEUCH, Thierry; DUMOULIN, Laurence; GALEMBERT, Claire de. Sociologie du droit et de la justice, p. 44. Para uma análise que enfoca a judiciarização em termos de uma desestabilização dos tradicionais "territórios da justiça" no contexto francês, ver: COMMAILLE, Jacques. La déstabilisation des territoires de justice. Droit et Société, n. 42/43, p. 239-264, 1999. A respeito, ver também: COMMAILLE, Jacques. À quoi nous sert le droit? p. 320 e ss.

${ }^{75}$ COMMAILLE, Jacques. Uma sociologia política do direito, p. 932; COMMAILLE, Jacques. O modelo de Janus da regulação jurídica. O caráter revelador das transformações do estatuto político da justiça. Revista Crítica de Ciências Sociais, n. 87, p. 104, 2009. Cumpre notar que é especialmente a essa dimensão que a literatura sociológica brasileira se dirige. A respeito, ver, por exemplo: CAMPILONGO, Celso Fernandes. O direito na sociedade complexa. São Paulo: Max Limonad, 2000. p. 73-88; CAMPILONGO, Celso Fernandes. Política, sistema jurídico e decisão judicial. São Paulo: Max Limonad, 2002. p. 57-63; VIANNA, Luiz Werneck et al. A judicialização da política e das relações sociais no Brasil. Rio de Janeiro: Revan, 1999; BURGOS, Marcelo Baumann; SALLES, Paula Martins. Dezessete anos de judicialização da política. Tempo Social, v. 19, n. 2, p. 39-85, nov. 2007. Para uma análise crítica da judicialização da questão da saúde no Brasil, ver: LIMA, Fernando Rister de Sousa. Saúde e Supremo Tribunal Federal. Curitiba: Juruá, 2015. p. 221 e ss.

${ }^{76}$ Cf. COMMAILLE, Jacques; DUMOULIN, Laurence. Heurs et malheurs de la légitimité dans les sociétés contemporaines. Une sociologie politique de la “judiciarisation”, p. 70. Acerca dessa questão, no contexto da globalização, ver: FARIA, José Eduardo. Sociologia jurídica: direito e conjuntura, p. 51-64. ${ }^{77}$ Cf. COMMAILLE, Jacques. O modelo de Janus da regulação jurídica. O caráter revelador das transformações do estatuto político da justiça, p. 104107; COMMAILLE, Jacques; DUMOULIN, Laurence. Heurs et malheurs de la légitimité dans les sociétés contemporaines. Une sociologie politique de la "judiciarisation", p. 65 e ss.
} 


\subsection{TEORIA SOCIOJURÍDICA NACIONAL}

o que, em última instância, constitui o foco da "sociologia política do direito".

\section{CONCLUSÃO}

Mediante a reconstrução dos traços gerais da "sociologia política do direito" proposta por Jacques Commaille, este artigo procurou analisar os processos de juridicização e de judiciarização, inscrevendo-os nesse quadro teórico que os considera reveladores das transformações experimentadas pelo exercício do poder político nas sociedades ocidentais coetâneas. Evidentemente que um desenvolvimento mais detalhado desses processos demandaria uma digressão cujas proporções não seriam comportadas por um único artigo. Portanto, o propósito da presente análise consistiu apenas em explicitar, sem pretensão de problematização crítica, alguns aspectos fundamentais da "sociologia política do direito" para enfatizar o quanto sua incorporação ao debate sociológico do direito em curso no Brasil pode contribuir para a discussão de questões importantes, como as que foram aludidas neste artigo.

Ao sustentar que o direito se afirma, cada vez mais, como um recurso privilegiado no jogo político, a abordagem de Jacques Commaille pode fornecer aportes importantes para a análise do modo pelo qual os diversos atores que interagem nessa seara o utilizam para a obtenção de maior êxito em suas ações. Várias questões se colocam no horizonte de tal perspectiva teórica. Trata-se de uma abordagem atenta, por exemplo, aos usos feitos do "recurso jurídico" pelos movimentos sociais mediante a judiciarização de suas pautas e reivindicações ${ }^{78}$; às pesquisas que indicam 0 entrelaçamento do fenômeno da judiciarizaçao com o de democratização ${ }^{79}$; e à questão da gestão do direito como instrumento de governo para a obtenção de eficácia política para determinadas ações. ${ }^{80}$

Além disso, a atenção dispensada pela "sociologia política do direito" à complexa trama de relações que envolvem os processos de juridicização e judiciarização também pode fornecer um significativo aporte crítico para a discussão brasileira. Conforme indicado, o fenômeno da judiciarização é relacionado, por Jacques Commaille, ao de juridicização, porém não de maneira mecânica, o que também constitui uma virtude de sua análise. Ao insistir no fato de que a relação entre esses fenômenos não pode ser compreendida em termos de uma subsunção ou derivação recíproca automática, a "sociologia política do direito" pode contribuir para elidir simplismos analíticos que distorcem a compreensão dos fenômenos analisados. Essa observação é particularmente importante em um contexto social complexo como o brasileiro, pois não é improvável que no Brasil existam arranjos peculiares entre tais fenômenos e, ademais, que eles ocorram de modo variado conforme se trate de questões distintas, fazendo com que a judiciarização possa decorrer, em alguns casos, da juridicização e, em outros, enquanto compensação, da desjuridicização. ${ }^{81}$

\section{REFERÊNCIAS}

ANDRINI, Simona; ARNAUD, André-Jean. Jean Carbonnier, Renato Treves et la sociologie du droit. Archéologie d'une discipline. Paris: LGDJ, 1995.

ARNAUD, André-Jean. Critique de la raison juridique: 1. Où va la sociologie du droit? Paris: LGDJ, 1981.

La valeur heuristique de la distinction interne/externe comme grande dichotomie

\footnotetext{
${ }^{78}$ Cf. COMMAILLE, Jacques. Nouvelle économie de la légalité, nouvelles formes de justice, nouveau régime de connaissance. Lanthropologie du droit avait-elle raison?, p. 363 ; COMMAILLE, Jacques. Uma sociologia política do direito, p. 931. Sobre o direito como recurso no jogo político, ver também: COMMAILlE, Jacques. Le droit dans le politique. Actualité d'un projet (Postface). In: ___ _ DUMOULIN, Laurence; ROBERT, Cécile (Dir.). La juridicisation du politique. Paris: LGDJ, 2010. p. 212.

${ }^{79}$ Cf. COMMAILLE, Jacques. La justice entre détraditionnalisation, néolibéralisation et démocratisation: vers une théorie de sociologie politique de la justice. In: ___ _ KALUSZYNSKI, Martine. (Dir.). La fonction politique de la justice. Paris: La Découverte, 2007. p. 310 e ss.; COMMAILLE, Jacques. O modelo de Janus da regulação jurídica. O caráter revelador das transformações do estatuto político da justiça, p. 104-107; COMMAILLE, Jacques; DUMOULIN, Laurence. Heurs et malheurs de la légitimité dans les sociétés contemporaines. Une sociologie politique de la “judiciarisation”, p. 87-98.

${ }^{80}$ COMMAILLE, Jacques. Nouvelle économie de la légalité, nouvelles formes de justice, nouveau régime de connaissance. Lanthropologie du droit avaitelle raison? p. 366.

${ }^{81}$ Cf. COMMAILLE, Jacques; DUMOULIN, Laurence. Heurs et malheurs de la légitimité dans les sociétés contemporaines. Une sociologie politique de la "judiciarisation", p. 70.
} 


\subsection{TEORIA SOCIOJURÍDICA NACIONAL}

pour la connaissance du droit : éléments d'une démystification. Droit et Société, n. 2, p. 139-141, 1986.

De la régulation par le droit à l'heure de la globalisation. Quelques observations critiques. Droit et société, v. 35, p. 11-35, 1997.

Gouvernants sans frontières. Entre mondialisation et post-mondialisation. v. 2 de la Critique de la raison juridique. Paris: LGDJ, 2003.

- Entre modernité et mondialisation. Leçons d'histoire de la philosophie du droit et de l'État. 2. ed. Paris: LGDJ, 2004.

. Jean Carbonnier: Un juriste dans la cité. Paris: LGDJ, 2012.

La gouvernance. Un outil de participation. Paris: LGDJ, 2014.

; FARIÑAS DULCE, María José. Introduction à l'analyse sociologique des systèmes juridiques. Bruxelles: Bruylant, 1998.

ARON, Raymond. As etapas do pensamento sociológico. Tradução de Sérgio Bath. 6. ed. São Paulo: Martins Fontes, 2003.

; FOUCAULT, Michel. Dialogue. Paris: Nouvelles Éditions Lignes, 2007.

BERTHELOT, Jean-Michel. La construction de la sociologie. 6. ed. Paris: Presses Universitaires de France, 2006.

BOUDON, Raymond. La sociologie comme science. Paris: La Découverte, 2010.

BOURDIEU, Pierre. Habitus, code et codification. Actes de la recherche en sciences, v. 64, p. 40-44, 1986.

La force du droit. Éléments pour une sociologie du champ juridique. Actes de la Recherche en Sciences Sociales, v. 64, p. 3-19,
1986.

Les juristes, gardiens de l'hypocrisie collective. In: CHAZEL, François; COMMAILLE, Jacques (Dir.). Normes juridiques et régulation sociale. Paris: LGDJ, 1991. p. 95-99. (Collection Droit et Société.)

. Esprits d'État [Genèse et structure du champ bureaucratique]. Actes de la recherche en sciences sociales, v. 96-97, p. 49-62, mars. 1993.

. Science de la science et réflexivité: cours du Collège de France 2000-2001. Paris: Éditions Raisons d'agir, 2001.

Sur le pouvoir symbolique. In:

Langage et pouvoir symbolique. Paris: Éditions Fayard, 2001. p. 201-211.

Sur l'État. Cours au Collège de France 1989-1992. Paris: Éditions Seuil, 2012.

; CHARTIER, Roger. Le sociologue et l'historien. Paris: Agone \& Raisons d'Agir, 2010.

CAILLOSSE, Jacques. La sociologie politique du droit, le droit et les juristes. Droit et Société, n. 77, p. 189-206, 2011.

CAMPILONGO, Celso Fernandes. $O$ direito na sociedade complexa. São Paulo: Max Limonad, 2000.

- Política, sistema jurídico e decisão judicial. São Paulo: Max Limonad, 2002.

. Interpretação do direito e movimentos sociais. Rio de Janeiro: Elsevier, 2012.

CAPELLER, Wanda. Relire Giddens. Entre sociologie et politique. Paris: LGDJ, 2011.

CHEVALLIER, Jacques. La régulation juridique en question. Droit et Société, n. 49, p. 827-846, 2001. 


\subsection{TEORIA SOCIOJURÍDICA NACIONAL}

. L'État post-moderne. 3. ed. Paris: LGDJ, 2008.

COMMAILLE, Jacques. Normes juridiques et régulation sociale. Retour à la sociologie générale. In: ; CHAZEL, François (Dir.).

Normes juridiques et régulation sociale. Paris: LGDJ, 1991. p. 13-22.

La déstabilisation des territoires de justice. Droit et Société, n. 42/43, p. 239-264, 1999.

Transformations du droit et de l'action publique. Économie Rurale, n. 260, p. 20-25, 2000.

Nouvelle économie de la légalité, nouvelles formes de justice, nouveau régime de connaissance. Lanthropologie du droit avait-elle raison? In: EBERHARD, Christoph; VERNICOS, Geneviève (Ed.). La quête anthropologique du droit. Autour de la démarche d'Étienne Le Roy. Paris: Karthala, 2006. p. 351-368.

La construction d'une sociologie spécialisée. Le savoir sociologique et la sociologie juridique de Jean Carbonnier. L’Année sociologique, v. 57(2), p. 275-299, 2007.

La justice entre détraditionnalisation, néolibéralisation et démocratisation: vers une théorie de sociologie politique de la justice. In: ; KALUSZYNSKI, Martine. (Dir.). La fonction politique de la justice. Paris: La Découverte, 2007. p. 295-321.

O modelo de Janus da regulação jurídica. O caráter revelador das transformações do estatuto político da justiça. Revista Crítica de Ciências Sociais, n. 87, p. 95-119, 2009.

De la "sociologie juridique" à une sociologie politique du droit. In: DUMOULIN, Laurence; ROBERT, Cécile (Dir.). La juridicisation du politique. Paris: LGDJ, 2010. p. 29-51.
Justice. In: ARNAUD, André-Jean (Dir.). Dictionnaire de la globalisation. Paris: LGDJ, 2010. p. 302-310.

La juridicisation du politique. Entre réalité et conaissance de la réalité. En guise de conclusion. In: ; DUMOULIN, Laurence; ROBERT, Cécile (Dir.). La juridicisation $d u$ politique. Paris: LGDJ, 2010. p. 199-210.

Le droit dans le politique. Actualité d'un projet (Postface). In: __ ; DUMOULIN, Laurence; ROBERT, Cécile (Dir.). La juridicisation du politique. Paris: LGDJ, 2010. p. 211-226.

Les vertus politiques du droit. Mythes et réalités. Droit et Sociét, n. 76, p. 695-713, 2010.

Uma sociologia política do direito. Revista da Faculdade de Direito da USP, v. 108, p. 929-933, jan.-dez. 2013.

À quoi nous sert le droit? Paris: Gallimard, 2015.

; DUMOULIN, Laurence. Heurs et malheurs de la légitimité dans les sociétés contemporaines. Une sociologie politique de la “judiciarisation”. L'Année Sociologique, v. 59(1), p. 63-107, 2009.

; DURAN, Patrice. Pour une sociologie politique $\mathrm{du}$ droit: présentation. Lannée Sociologique, v. 59(1), p. 11-28, 2009.

; PERRIN, Jean-François. Le modèle de Janus de la sociologie du droit. Droit et Société, n. 1, p. 95-110, 1985.

; STROBEL, Pierre; VILLAC, Michel. La politique de la famille. Paris: La Découverte, 2002.

CORTEN, Olivier. Éléments de définition pour une sociologie politique du droit. Droit et Société, 


\subsection{TEORIA SOCIOJURÍDICA NACIONAL}

n. 39, p. 347-370, 1998.

DELPEUCH, Thierry; DUMOULIN, Laurence; GALEMBERT, Claire de. Sociologie du droit et de la justice. Paris: Armand Colin, 2014.

DIAS, Gabriel Nogueira. Positivismo jurídico e a teoria geral do direito na obra de Hans Kelsen. São Paulo: Revista dos Tribunais, 2010.

DUMOULIN, Laurence; ROBERT, Cécile. Autour des enjeux d'une ouverture des sciences $\mathrm{du}$ politique au droit. Quelques réflexions en guise d'introduction. In:

COMMAILLE, Jacques (Dir.). La juridicisation du politique. Paris: LGDJ, 2010. p. 9-26.

DURKHEIM, Émile. De la division du travail social. 7. ed. Paris: PUF, 2007.

EWICK, Patricia; SILBEY, Susan. The common place of law. Stories from everyday life. Chicago: The Chicago University Press, 1998.

FARIA, José Eduardo. Estado, sociedade e direito. In: _ KUNTZ, Rolf. Qual o futuro dos direitos? Estado, mercado e justiça na reestruturação capitalista. São Paulo: Max Limonad, 2002. p. 53-130.

. Sociologia jurídica: direito e conjuntura. São Paulo: Saraiva, 2010.

; CAMPILONGO, Celso Fernandes. A sociologia jurídica no Brasil. Porto Alegre: Sergio Antonio Fabris, 1991.

GARCÍA VILLEGAS, Mauricio. On Pierre Bourdieu's legal thought. Droit et Société, n. 56/57, p. 57-70, 2001.

La eficacia simbólica del derecho. 2. ed. Bogotá: IDEPRI; Debate, 2014.

GIMÉNEZ ALCOVER, Pilar. El derecho en la teoría de la sociedad de Niklas Luhmann. Barcelona: Bosch, 1993.
GONÇALVES, Guilherme Leite; VILLAS BÔAS FILHO, Orlando. Teoria dos sistemas sociais: direito e sociedade na obra de Niklas Luhmann. São Paulo: Saraiva, 2013.

GUIBENTIF, Pierre. Foucault, Luhmann, Habermas, Bourdieu. Une génération repense le droit. Paris: LGDJ, 2010.

HABERMAS, Jürgen. Law as medium and law as institution. In: TEUBNER, G. (Org.). Dilemmas of law in the welfare state. Berlin: Walter de Gruyther /European University Institute, 1989. p. 203-220.

KOURILSKY-AUGEVEN, Chantal. Socialisation, socialisation juridique et conscience du droit. In: RUDE-ANTOINE, Edwige; CHRÉTIEN-VERNICOS, Geneviève (Coord.). Anthropologies et droits. État des savoirs et orientations contemporaines. Paris: Dalloz, 2009. p. 245-269.

LATOUR, Bruno. La fabrique du droit. Une ethnographie du Conseil d'État. Paris: La Découverte, 2004.

LAVAL, Christian. Lambition sociologique. Paris: Gallimard, 2012.

LIMA, Fernando Rister de Sousa. Saúde e Supremo Tribunal Federal. Curitiba: Juruá, 2015.

LOPES, José Reinaldo de Lima; FREITAS FILHO, Roberto. Law and society in Brazil at the crossroads: a review. Annual Review of Law and Social Science, v. 10, p. 91-103, 2014.

LUHMANN, Niklas. Das Recht der Gesellschaft. Frankfurt am Main: Suhrkamp, 1993. [trad. esp.: El derecho de la sociedad. México: Herder/ Universidad Iberoamericana, 2005; trad. ingl. Law as a social system. Oxford: Oxford University Press, 2004.]

Le droit comme système social. Droit et Société, n. 11/12, p. 53-67, 1994. 


\subsection{TEORIA SOCIOJURÍDICA NACIONAL}

La restitution du douzième chameau: du sens d'une analyse sociologique du droit. Droit et Société, n. 47, p. 15-73, 2001.

. Rechtssoziologie. 4. Aufl. Wiesbaden: VS Verlag für Sozialwissenschaften, 2008.

MARTUCCELLI, Danilo. Sociologies de la modernité. Paris: Gallimard, 1999.

MOSOVICH PONT-LEZICA, Diana; ARNAUD, André-Jean. Commaille Jacques, Lesprit sociologique des lois. Essai de sociologie politique du droit, coll. "Droit, éthique, société, 1994. Droit et Société, n. 30-31, p. 473-483, 1995.

PÉLISSE, Jérôme. A-t-on conscience du droit? Autour des Legal Consciousness Studies. Genèses, n. 59, p. 114-130, 2005.

Les usages syndicaux du droit et de la justice. In: COMMAILLE, Jacques; KALUSZYNSKI, Martine (Dir.). La fonction politique de la justice. Paris: La Découverte, 2007. p. 165-189.

PERRIN, Jean-François. Jean Carbonnier. La référence comme héritage. Droit et Société, n. 84, p. 477-486, 2013.

ROSANVALLON, Pierre. La contre-démocratie: la politique à lâge de la défiance. Paris: Éditions du Seuil, 2006.

. La légitimité démocratique: impartialité, réflexivité, proximité. Paris: Éditions du Seuil, 2008.

. La société des égaux. Paris: Éditions du Seuil, 2011.

ROULAND, Norbert. Anthropologie juridique. Paris: PUF, 1988.

1995.
ROUSSEL, Violaine. Le droit et ses formes. Éléments de discussion de la sociologie du droit de Pierre Bourdieu. Droit et Société, n. 56-57, p. 41-55, 2004.

SARAT, Austin; SCHEINGOLD, Stuart A. (Dir.). The worlds cause lawyers make. Structure and agency in legal practice. Stanford, California: Stanford University Press, 2005.

SCHLUCHTER, Wolfgang. La sociologie du droit comme théorie empirique de la validité. In: HEURTIN, Jean-Philippe; MOLFESSIS, Nicolas (Dir.). La sociologie du droit de Max Weber. Paris: Dalloz, 2006. p. 3-26.

SERVERIN, Évelyne. Sociologie du droit. Paris: La Découverte, 2000.

SOUTO, Cláudio; FALCÃO, Joaquim. Introdução. In: (Org.). Sociologia \& direito: textos básicos para a disciplina de sociologia jurídica. 2. ed. São Paulo: Pioneira, 1999. p. IX-XIV.

STEINER, Philippe. La sociologie de Durkheim. Paris: La Découverte, 2005.

SUEUR, Jean-Jacques. Pierre Bourdieu, le droit et les juristes. La méprise. Droit et Société, n. 85, p. 725-753, 2013.

TEUBNER, Gunther. Juridification: concepts, aspects, limits, solutions. In: (Ed.). Juridification of social spheres. A comparative analysis in the areas of labour, corporate, antitrust and social welfare law. Berlin: Walter de Gruyter, 1987. p. 3-48.

TOURAINE, Alain. Le retour de l'acteur: essai de sociologie. Paris: Fayard, 1984.

VANDERLINDEN, Jacques. Anthropologie juridique. Paris: Dalloz, 1996.

VERDIER, Raymond (Dir.). Jean Carbonnier. 
L'homme et l'oeuvre. Nanterre: Presses Universitaires de Paris Ouest, 2011.

VIANNA, Luiz Werneck et al. A judicialização da política e das relações sociais no Brasil. Rio de Janeiro: Revan, 1999.

; BURGOS, Marcelo Baumann; SALLES, Paula Martins. Dezessete anos de judicialização da política. Tempo Social, v. 19, n. 2, p. 39-85, nov. 2007.

VILLAS BÔAS FILHO, Orlando. A sociologia do direito: o contraste entre a obra de Émile Durkheim e a de Niklas Luhmann. Revista da Faculdade de Direito da USP, v. 105, p. 561-593, jan./dez. 2010.

Ancient law: um clássico revisitado 150 anos depois. Revista da Faculdade de Direito da USP, v. 106/107, p. 533-566, jan./dez. 2011/2012.

- Democracia: a polissemia de um conceito político fundamental. Revista da Faculdade de Direito da USP, v. 108, p. 651-696, jan./dez. 2013.

WHITE, Stephen K. Reason, modernity, and democracy. In: (Ed.). The Cambridge Companion to Habermas. New York: Cambridge University Press, 1999. p. 3-16. 


\section{PESQUISAS SOCIOJURÍDICAS}




\title{
ENTRE POLÍTICOS, BACHARÉIS, CORONÉIS E JUÍZES DA REPÚBLICA VELHA:
}

\author{
AS PRÁTICAS JURÍDICAS E A TRADIÇÃO \\ PATRIMONIALISTA NA FORMAÇÃO \\ DO ESTADO BRASILEIRO
}

Daniel Barile da Silveira

Sumário: Introdução. 1 A República, os juízes e os bacharéis. $2 \mathrm{O}$ Judiciário e o patrimonialismo. Conclusão. Referências.

\section{Resumo}

O período da formação do Estado brasileiro, marcado pela fundação das nossas bases republicanas durante a República Velha, mostrou-se densamente rico para esclarecer como os magistrados foram fundamentais para a estruturação da vida social da época. Neste artigo, busca-se demonstrar a prática empírica da magistratura deste período, no sentido de elucidar suas relações mais intestinas com o mundo da política e das oligarquias existentes.

Palavras-chaves: Magistratura republicana. República Velha. Patrimonialismo. Formação do Estado brasileiro.

${ }^{\text {i }}$ Doutor e Mestre em Direito pelo Programa de Pós-Graduação da Faculdade de Direito da Universidade de Brasília (FD-UnB). Professor do Programa de Pós-Graduação e do Curso de Graduação em Direito do UniToledo (Centro Universitário Toledo - Araçatuba/SP). Professor do Programa de Mestrado em Direito da Unimar (Universidade de Marília). Procurador-Geral do Município de Araçatuba/SP. 


\begin{abstract}
The period of the formation of the Brazilian State, marked by the foundation of our republican basis during the Old Republic, proved to be rich to clarify how the magistrates were instrumental in structuring the social life of the time. In this article, we seek to demonstrate the empirical practice of the judiciary of this period in order to elucidate its most deep relations with the world of politics and existing oligarchies.
\end{abstract}

Keywords: Republican judiciary. Old republic. Patrimonialism. Brazilian state formation.

\section{INTRODUÇÃO}

A relações íntimas entre o Judiciário e a sociedade nunca foram objetos de $\mathcal{L}$ estudos aprofundados que pudessem aclarar o real entrelaçamento dos magistrados no tecido social. Na formação do Estado brasileiro, durante a República Velha, quando então se fundam as bases jurídico-republicanas que hoje conhecemos, importantes olhares se voltam para o modo como os juízes contribuíram para a solidificação do Estado nacional, porém com um custo social bastante acentuado, levando-se em conta o entranhamento que este grupo social adquiriu naquele período.

Conhecer melhor essas nuances é o objetivo deste artigo, na perspectiva de demonstrar as práticas sociais da magistratura no período da formação das instituições nacionais, como elemento partícipe da vida política e social do período da República Velha. Como centros de justiça da época, eivados das garantias de independência funcional e demais prerrogativas constitucionais, notadamente mantinham estreitas relações com os sistemas de manutenção do status quo vigente, advindos dos relacionamentos estreitos entre a elite cafeeira e a política corrente, no sentido de enquadraremse como legítimos reprodutores dos valores e dos modelos sociais de convivência até então estabelecidos.

\section{A REPÚBLICA, OS JUÍZES $\mathrm{E}$ OS BACHARÉIS}

O contraste histórico e repetitivo entre o formalismo retórico da Constituição e as práticas sociais da magistratura brasileira encontrava uma clivagem de difícil superação na República Velha. A veleidade republicana de solucionar os problemas nacionais por via da legalidade com a criação de uma nova Constituição acabou fenecendo em seus intuitos, posto que grande parte dos problemas historicamente vivenciados pelas instituições brasileiras acabou perpetuando-se no novel período que despontava dias a fio.

As práticas políticas culturalmente reproduzidas por séculos enveredaram pela 
torrente que se vinha consolidando no cenário estatal do Brasil desde a época da Colônia, embora revestidas de uma sofisticação inerente à complexidade da sociedade contemporânea. A explicação deste não reconhecimento de nossas realidades social e institucional, como complementa Oliveira Vianna, é que o problema legislativo no Brasil, especialmente em nível constitucional, situa-se no fato de que "nenhuma destas construcções se assentou sobre bases argamassadas com a argilla da nossa realidade viva, da nossa realidade social, da nossa realidade nacional"'. Até então, Constituição e sociedade se desvinculariam, na medida em que o caráter textual da norma não atingiria a complexidade das relações sociais tecidas no plano da realidade. Assim, tendo como ponto de toque a magistratura republicana, buscarse-á demonstrar doravante como essa cisão se efetivou, notadamente pela reconstrução da ação social de seus membros, marcada por múltiplas relações de poder.

O fato é que grande parte da magistratura republicana ainda convalidava as antigas problemáticas nacionais vivenciadas em seu seio profissional, a começar pela sua origem mais remota: o bacharelismo elitista. As transformações nascidas em 1889, se em grande parcela são tributárias do movimento militar que levou os republicanos ao poder, de fato serviram para recrudescer a influência dos bacharéis no cenário social, constituindo uma verdadeira elite presente nos mais altos escalões dos postos oficiais do período. Uma das características de toda a República Velha é a forte presença dos bacharéis na vida política nacional, em especial na magistratura, constituindo um verdadeiro grupo seleto que notadamente reivindicava privilégios para a manutenção de sua influência social.

Durante o Período Republicano, as faculdades de Pernambuco e de São Paulo continuavam produzindo, em grande escala, as levas de bacharéis que adentravam o cenário profissional da época. Uma boa monta de egressos dos cursos buscava galgar cargos públicos ("a burocracia como vocação de todos", na eterna lição de Joaquim Nabuco). Porém, como o contingente de formandos superava o número de postos à disposição, considerável parte desses indivíduos acabava guiando-se para as carreiras da advocacia, normalmente atrelada à vida política, literária e/ou jornalística. Assim, relevante parcela dos republicanistas revolucionários, inclusive, nasceu de grupos autônomos nas próprias faculdades de Direito, ganhando destaque posteriormente no contexto político nacional. $\mathrm{O}$ próprio Governo Provisório era composto por inúmeros bacharéis, tais como Campos Sales (Pasta da Justiça), Benjamin Constant (Guerra), Eduardo Wandenkolk (Marinha), Quintino Bocaiúva (Relações Exteriores), Aristides Lobo (Interior), Demétrio Ribeiro (Agricultura, Comércio e Obras Públicas) e, talvez o mais ilustre deles, Rui Barbosa (Fazenda). Não obstante, a mesma fórmula se repetiu na feitura da Constituição. Os membros da Comissão dos Cinco eram primordialmentejuristas, em especial advogados, havendo inclusive entre eles um professor da Faculdade de Direito do Largo São Francisco, Américo Brasiliense, fundador do Partido Republicano Paulista (PRP). ${ }^{2}$ Não bastasse, a revisão e a alteração do texto, determinantes para a finalização do projeto constitucional, foram incumbidas ao advogado Rui Barbosa, além de que os três governos civis da República foram também exercidos por bacharéis, quais sejam, Prudente de Morais (1894-1898), Campos Sales (1898-1902) e Rodrigues Alves (1902-1906) ${ }^{3}$.

Conforme alcunhava Taunay, a "bacharelocracia" ainda impunha um ritmo dinâmico ao discurso ideológico do período, grupo do qual decerto nasceu o vernaculismo das fórmulas constitucionais, bem como seria a

${ }^{1}$ VIANNA, Oliveira. O idealismo da constituição. 2. ed. Rio de Janeiro: Brasiliana, 1939. p. XIV.

${ }^{2}$ PAULO FILHO, Pedro. O bacharelismo brasileiro: da colônia à república. Campinas: Bookseller, 1997. p. 432.

${ }^{3}$ Proclamada a República, na lista dos 138 oradores que figuravam no índice dos Anais do Congresso, 66 deles eram bacharéis, um número notório em face dos vinte militares, dos oito médicos e dos dois engenheiros dos que discursaram no púlpito do parlamento. Além disso, dos 49 signatários dos projetos durante todo o período republicano, 25 eram advogados, seis militares, quatro médicos e quatro engenheiros. Cf. PAULO FILHO, Pedro. O bacharelismo brasileiro: da colônia à república, p. 434. Parecia ser latente a presença dos bacharéis na virada republicana, cujos ideais foram manifestamente propalados entre tais grupos, e com especial razão, no interior das academias de Direito. 


\subsection{SOCIOLOGIA CONSTITUCIONAL}

fonte dos políticos que movimentaria a máquina estatal e seu discurso parlamentar predominante.

Não obstante, o fato mais notório a se considerar é que o sistema judiciário da República Velha constituía um subsistema vinculado diretamente ao macrossistema político que regulava as situações da vida social citadina. A forma como o Judiciário se organizava e solucionava os conflitos a ele submetidos era condicionada a uma parte do mecanismo de dominação vigente, representado, na prática, pela "política dos governadores"4 e pelo fenômeno do "coronelismo", ambas engenharias políticas intimamente interligadas e de forte predominância na vida social do Brasil republicano.

Nesse sentido, durante a República Velha, os representantes políticos dos estados eram eleitos diretamente pelos cidadãos, situação que compelia a esfera pública a compactuar com as oligarquias dominantes na busca por apoio político, encontrando na figura do coronel o centro de gravitação de respaldo no âmbito municipal. Ao revés, como forma de recompensa à barganha estabelecida, serviam-se os coronéis da indolência do governo, permitindo-lhes o exercício do domínio dos municípios ${ }^{6}$. Esse mecanismo de cooptação política se reproduzia também na órbita federal, na medida em que as facções dominantes nos estados trocavam favores com o governo federal, reivindicando apoio político regional em troca da não intervenção federal no estado, de forma, assim, a manter sua autonomia política local a salvo de interferências externas.

Nesse pano de fundo, a engenharia social de troca de favores e apoio político se reproduzia também no seio do Poder Judiciário, posto que a magistraturadaépocaigualmenteserendia aojogo de forças presentes nessa relação de barganha, na medida em que se apresentava como consectária de uma perpetuação de relações simbióticas sedimentadas no cerne dessas alianças. Assim, o sistema de ingresso na magistratura republicana estava estritamente adstrito aos ensejos políticos dos grupos oligárquicos que detinham o poder em determinada localidade. Como se viu, os juízes seccionais (federais) eram nomeados pelo Presidente da República, a partir de lista tríplice elaborada pelo Supremo Tribunal. A grande

\footnotetext{
${ }^{4}$ A "política dos governadores" foi um sistema de alianças implementado por Campos Sales (1898), a fim de que se reestruturassem as relações até então estabelecidas entre o Governo Central e os Estados, institucionalizando-as. Tratava-se do estabelecimento de um compromisso em que o Governo Federal ratificava a predominância dos grupos políticos dominantes nos Estados, garantindo-lhes sua supremacia no poder local, tendo como lance de troca a formação de uma base política com estas facções, no afã de poder legitimar a governabilidade presidencial, especialmente adquirida com a construção de uma maioria parlamentar no Congresso Nacional. Com a ajuda dos "coronéis", os partidos políticos dominantes nos Estados garantiam a eleição de seus preferidos no controle de seus eleitores (o "curral eleitoral"). Neste esquema, o coronel controlava os votantes em sua área de influência, obtendo votos para seu candidato em troca de presentes, favores ou benefícios, ou mesmo com a promessa de cargos públicos. Por sua vez, o corone apoiava o poder político estadual, que oferecia suporte ao Governo Federal. Em troca, o governo, no nível federal, retribuía favores aos poderes estaduais, que faziam o mesmo aos coronéis, permitindo que estes bancassem a administração de seus currais eleitorais. Tal troca de favores era justamente o fundamento do pacto, envolvendo Presidente da República, Governadores Estaduais, Deputados, Senadores e outros cargos públicos, como a própria magistatura. O coronel exercia seu domínio no município, nomeando e arranjando empregos para seus aliados, ao passo que o Governador não sofria oposição na Assembleia Legislativa Estadual, da mesma maneira que o Presidente da República garantia sua governabilidade ao ter aprovados seus projetos propostos no Congresso Nacional. Essa lógica garantia o funcionamento da política na República Velha, firmando um grande sistema de compromissos amplamente reproduzido. Cf. PAULO FILHO, Pedro. O bacharelismo brasileiro: da colônia à república, p. 435.

${ }^{5} \mathrm{O}$ "coronelismo" era um sistema de alianças políticas que envolvia a presença dos chefes locais, os "coronéis", nomenclatura esta que, embora conservada no tempo, tinha por raízes as antigas nomeacões conferidas aos membros da Guarda Nacional, em especial aos grandes proprietários rurais com alta parcela de influência em sua localidade. Tratava-se de um sistema de barganha política, que na prática foi recrudescida com a rede de alianças fixadas com a política de governadores. Segundo José Murilo de Carvalho, o coronelismo é "um sistema político nacional, baseado em barganhas entre o governo e os coronéis. O governo estadual garante, para baixo, o poder do coronel sobre seus dependentes e seus rivais, sobretudo cedendo-lhe o controle dos cargos públicos, desde o delegado de polícia até a professora primária. O coronel hipoteca seu apoio ao governo, sobretudo na forma de votos. Para cima, os governadores dão seu apoio ao presidente da República em troca do reconhecimento deste de seu domínio no estado. O coronelismo é fase de processo mais longo de relacionamento entre os fazendeiros e o governo. O coronelismo não existiu antes dessa fase e não existe depois dela. Ele morreu simbolicamente quando se deu a prisão dos grandes coronéis baianos, em 1930. Foi definitivamente enterrado em 1937, em seguida à implantação do Estado Novo e à derrubada de Flores da Cunha, o último dos grandes caudilhos gaúchos" (Mandonismo, coronelismo e clientelismo: uma discussão conceitual. Dados - Revista de Ciências Sociais. Rio de Janeiro, UERJ, v. 40, n. 2, p. 229-250, 1997. p. 230). Como pioneiro no uso da expressão, podemos consultar a obra paradigmática de Victor Nunes Leal (Coronelismo, enxada e voto: o município e o regime representativo no Brasil. São Paulo: AlfaOmegaz, 1978).

${ }^{6}$ No livro clássico de Victor Nunes Leal, pode-se encontrar: "A essência, portanto, do compromisso 'coronelista' - salvo situações especiais que não constituem regra - consiste no seguinte: da parte dos chefes locais, incondicional apoio aos candidatos do oficialismo nas eleições estaduais e federais; da parte da situação estadual, carta-branca ao chefe local governista (de preferência o líder da facção local majoritária) em todos os assuntos relativos ao município, inclusive na nomeação de funcionários estaduais do lugar" (Coronelismo, enxada e voto: o município e o regime representativo no Brasil, p. 49-50). "E assim nos parece este aspecto importantíssimo do 'coronelismo', que é o sistema de reciprocidade: de um lado, os chefes municipais e os 'coronéis', que conduzem magotes de eleitores como quem toca tropa de burros; de outro lado, a situação política dominante no Estado, que dispõe do erário, dos empregos, dos favores e da força policial, que possui, em suma, o cofre das graças e o poder da desgraça." (Coronelismo, enxada e voto: o município e o regime representativo no Brasil, p. 42-43).
} 
questão suscitada nessa forma de nomeação é a de que, embora aparentemente o procedimento de ingresso se revestisse de certo grau de imparcialidade e isenção, na prática a indicação dos juízes seccionais estava submetida ao jugo da facção política dominante, a qual reclamava pela apresentação de seu candidato partidário no rol da malsinada lista de elegíveis.

Segundo nos esclarece Andrei Koerner, "as listas elaboradas pelo STF eram criticadas pela imprensa, porque eram colocados dois candidatos mais qualificados, mas também o candidato indicado pela oligarquia dominante no estado, o qual era nomeado"'.

Com igual força, tais grupos manifestavam sua forte influência quando tencionavam em se opor à nomeação de um juiz seccional. Contase que em 1898, no processo de seleção para o preenchimento do cargo de juiz seccional no Estado do Mato Grosso, o veto ao candidato havia se manifestado mesmo em momento posterior à nomeação com sua consequente entrega do diploma ao escolhido. Ao que se registra nos anais do Jornal do Comércio de 1905, o Ministro da Justiça Epitácio Pessoa enviou uma mensagem telefônica ao Presidente do Supremo Tribunal no intuito de que tal autoridade não desse posse ao recém-nomeado juiz seccional.

Quando o interessado chegou lá, exibiu seu título, já registrado. Pois bem, entre esse título que tinha a assinatura do presidente, que fora nomeado no Diário Oficial e o simples recado do ministro - recado verbal, pelo telefone - o recado prevaleceu! Não se deu a posse. O Presidente da República fez então outra nomeação. Este ato extravagantíssimo do Tribunal teve, porém, o mérito de firmar o princípio de que, até o momento da posse, basta um recado do ministro para retirar o direito de qualquer dos classificados por ele. ${ }^{8}$

Fato similar ocorrera com Otávio Kelly, classificado em terceiro lugar na lista tríplice, o qual, embora sequer tivesse experiência na magistratura, foi nomeado juiz seccional do Rio de Janeiro (1909), preterindo dois antigos desembargadores elencados nas melhores colocações (primeira e segunda) por seu conhecimento e títulos conquistados. Segundo se registra, tal nomeação teve por objetivo a preparação da eleição no mesmo ano para a assembleia legislativa do estado federado e para as câmaras municipais, no intuito de promover intervenção federal nessas localidades que não se compactuassem com a facção política comungada pelo magistrado, que, por sua vez, era a dominante no estado fluminense ${ }^{9}$.

Dessa forma, o controle dos cargos federais dependia da manipulação exercida pelas oligarquias presentes nos estados, abrindo um enorme campo de negociação político entre o Presidente, os membros do STF e as facções locais. Como as atribuições constitucionais dos juízes federais cercavam especialmente a solução de dissídios que envolviam a União e os estados, causas que afetassem violação direta à Constituição ou ainda os crimes de natureza política (art. 60, CF/91), o controle desses membros, que teriam por responsabilidade exercer tais jurisdições, era de fundamental importância aos grupos dominantes regionais. Isso ocorria, sobretudo porque, uma vez havendo violação de sentença ou leis federais, tal procedimento justificaria intervenção federal nos estados, fato absolutamente indesejado pelas oligarquias, posto que desejavam que seu poder local não fosse afetado pela presença de forças federais em sua área de dominação.

Com a mesma lógica de uso político de nomeação de cargos públicos, o partidarismo e o nepotismo foram intensos objetos de críticas dos contemporâneos da República, evidenciando esse misto de relações públicas e interesses privados que se reproduzia no

${ }^{7}$ KOERNER, Andrei. Judiciário e cidadania na Constituição da República brasileira. São Paulo: Hucitec/USP, 1998. p. 191.

${ }^{8}$ Apud KOERNER, Andrei. O Poder Judiciário no sistema político da primeira república. Revista Tempo Social. São Paulo, Dossiê Judiciário, n. 21, p. 58-69, 2000. p. 63

${ }^{9}$ Conta-se que no preenchimento da vaga desse juiz seccional, cujo critério seria analisar "a prática dos candidatos, especialmente na magistratura", dos 19 requerentes inscritos, dez foram desclassificados, juízes e desembargadores antigos, apenas por não terem apresentado o título de bacharel em Direito em sua documentação. Como no país o cargo de juiz de direito era preenchido somente por bacharéis, presume-se que a apresentação do título da colação de grau seria mais um formalismo utilizado, no caso, a fim de criar um subterfúgio material para a desclassificação dos candidatos não coadunados com a oligarquia predominante. KOERNER, Andrei. O Poder Judiciário no sistema político da primeira república. Revista Tempo Social. São Paulo, Dossiê Judiciário, n. 21, p. 58-69, 2000. p. 198-199. 
Judiciário do período. Tanto os Ministros do STF, na defesa de ensejos próprios, como a elite política coronelista, mesmo impulsionados pela satisfação de interesses de seus correligionários, submetiam-se a sucessivos episódios de nomeação de parentes para o exercício do mister público na magistratura oficial. Como o procedimento de nomeação dos juízes admitia certa margem de discricionariedade, não raro ocorria de a designação ser crivada pelo vício do personalismo, do favoritismo, do nepotismo político. Em 1897, Manoel D. de Aquino e Castro, filho do Presidente do STF, fora escolhido como juiz seccional em São Paulo; Venâncio Neiva, parente afastado de Epitácio Pessoa, foi designado em 1904 para o cargo de magistrado federal na Paraíba; um afilhado do Presidente Affonso Pena foi também nomeado para atuar no juízo do Acre, no ano de 1905; em 1906, José Clímaco, irmão de ministro do STF, foi lotado para seu estado natal o Espírito Santo. ${ }^{10}$ Todos estes casos, que não se resumem ao universo das práticas nepotistas da época, denotavam o grau de cumplicidade dos cargos do Judiciário para com os sistemas políticos da República Velha. Essas forças de poder, presentes no momento da nomeação, em muitas das vezes, acabavam por refletir os próprios ensejos privados dos membros da Corte Suprema, degenerando por conseguinte a função pública em prol da satisfação de interesses particularistas, procedimento paradoxalmente avesso à própria Constituição e a todo o arcabouço legal vigente. Não era à toa ter restado célebre a frase de João Mangabeira, de ser o Supremo "o poder que mais faltou à República"11, não apenas se constituindo um "arroubo oratório", porém, uma prática leitura cotidiana factual. Entretanto, caso não se constatasse que o nome do candidato preferido pelas oligarquias estivesse presente na lista tríplice elaborada, era comum o próprio Presidente da República solicitar a realocação de alguns juízes seccionais para os cargos vacantes, fazendo com que a vaga fosse então preenchida e, como conseqüência, gerasse o cancelamento da lista. Desta forma, com o preenchimento do cargo, eram abertas novas inscrições para a supressão da novel vaga que se abria, o que possibilitaria, neste caso, o controle maior dos membros que por sua vez participariam da próxima lista tríplice elaborada.

Segundo Koerner, em pesquisa nos arquivos do Jornal do Comércio:

Em 15/10/1995, o STF publicava a lista dos classificados para a vaga de juiz seccional de Pernambuco e dois dias depois o juiz seccional do Espírito Santo era removido para a vaga pelo Presidente da República. Essa remoção somente foi cogitada após a publicação da lista pelo STF, porque o candidato do governo não aparecia nela [Grifos nossos]. ${ }^{12}$

Na esfera estadual tais processos não mudavam muito em seu cenário de atuação. Seus membros (desembargadores dos tribunais estaduais, juízes de direito nas comarcas, tribunais do júri, juízes municipais e juízes de paz), por estarem mais próximos do poder exercido pelas oligarquias nos estados, a fortiori, perpetuavam o sistema de compromissos políticos de troca de favores entre as facções e a esfera governista.

Ocorre que entre os vários auxiliares da Justiça no âmbito estadual, apenas os juízes de direito e os desembargadores eram considerados membros efetivos do Judiciário, para os fins das garantias que a Constituição albergava. Em muitos estados, essas mesmas garantias eram sonegadas aos juízes estaduais, posto que a Carta Maior apenas trouxe textualmente a garantia de vitaliciedade, de inamovibilidade e de irredutibilidade dos vencimentos, além da prerrogativa de foro, somente para os juízes federais (art. 57). Alguns estados ainda se serviam de uma fórmula dogmática da interpretação restritiva da norma jurídica, a fim de afastar dessa incidência a magistratura estadual, deixando-a desprotegida das investidas de suas facções. As mudanças de localidade para acomodar situações políticas, ou ainda, o exercício arbitrário da

${ }^{10}$ KOERNER, Andrei. O Poder Judiciário no sistema político da primeira república. Revista Tempo Social. São Paulo, Dossiê Judiciário, n. 21, p. 58-69, 2000. p. 64.

${ }^{11}$ Apud BALEEIRO, Aliomar. Supremo Tribunal Federal, esse outro desconhecido. Rio de Janeiro: Forense, $1968 . p .69$.

${ }^{12}$ KOERNER, Andrei. Judiciário e cidadania na Constituição da República brasileira, p. 192. 
pressão mediante ameaça da perda do cargo eram constrangimentos bastante elevados que compeliam os magistrados ao servilismo na seara de influência das oligarquias predominantes. A denominada "remoção por conveniência pública" era uma prática oficial corrente, tendo sido inclusive criado em 1903, no Estado de Minas Gerais, um controvertido "Tribunal de Remoções”, encarregado exclusivamente da análise sobre a realocação dos magistrados estaduais ${ }^{13}$.

Assim, embora a Constituição não tenha expressamente elencado os magistrados estaduais como destinatários das garantias institucionais da judicatura, inconformismo de alguns juízes, inúmeras ações foram intentadas na Suprema Corte, que, consentâneo com os reclames de seus pares, tutelou alguns requerimentos, estendendo as mesmas prerrogativas a tal classe burocrática. No entanto, a jurisprudência do STF compreendia a reintegração de magistrado aos quadros institucionais um ato meramente administrativo $^{14}$; sua determinação judicial implicava na famosa fórmula da "violação dos poderes". Desta maneira, reintegrar um magistrado insolente expulso do cargo invadiria a esfera de competência do Executivo, fazendo com que na prática suas decisões ficassem sem efeito. Sem dúvida, parece ter sido verdadeira a primeira parte da afirmação do Ministro Aliomar Baleeiro, ao dizer que a cúpula do Poder Judiciário na República "vacilou. Errou. Tergiversou. Mas, dentro de pouco tempo, o Supremo Tribunal imbuiu-se de sua missão e aos poucos, tenazmente, constituiu-se realmente o guardião do templo das liberdades ameaçadas"15.

Sem embargo, conforme nos esclarece
Victor Nunes Leal, tais garantias obtidas, invariavelmente não alcançavam os magistrados temporários (que passavam por estágio probatório para se efetivarem como juízes de direito), tornando-os reféns dos arbítrios voluntariosos das oligarquias dominantes. "Ficava, pois, uma numerosa categoria de juízes à mercê das exigências e seduções dos governantes menos ciosos da independência e dignidade do Poder Judiciário"16. Nesta visão sobre esse processo, complementa adiante o autor, "foram, aliás, muito variados os meios postos em prática pelos governos estaduais para submeter a magistratura, como a disponibilidade, a alteração de limites ou a supressão de circunscrições judiciárias, a retenção de vencimentos etc." ${ }^{17}$

$\mathrm{Na}$ prática judicial forense, os juízes temporários substituíam os vitalícios em sua ausência ou impedimento legal. Caso a supressão pelos juízes temporários não fosse possível em determinadas localidades, restavam na escala de substituição, ainda, os juízes de paz, membros eleitos que acabavam assumindo subsidiariamente as funções do juiz de direito no cometimento de atos do processo e, em muitos casos, até mesmo na própria sentença. Desta forma, a contar pela presença desses elementos partidários por excelência, fazia-se com que a distribuição da justiça tomasse contornos diversos do julgamento imparcial e baseado na lisura da decisão, tal qual preconizado por qualquer das mais influentes teorias da justiça.

Segundo alarmava o Deputado Pedro Aleixo, já no final da República:

Os juízes de paz pertencem a partidos políticos, a facções políticas e muitos deles vivem preocupados com os interesses facciosos de seu grupo. Ora, entre

\footnotetext{
${ }^{13}$ NEQUETE, Lenine. O Poder Judiciário do Brasil a partir da Independência: Brasil República. Brasília: Supremo Tribunal Federal, 2000. p. 31. No Estado da Bahia, encontrava-se também uma comissão semelhante, denominada Tribunal de Conflitos. Esse processo de remoção poderia, nos estados, ser movido por representação de qualquer cidadão ou por iniciativa do Procurador-geral de Justiça, sendo julgado pelo Tribunal de Justiça estadual ou pelo Senado, com a aprovação do Executivo. Para maiores informações, ver Nequete, Lenine. O Poder Judiciário do Brasil a partir da Independência: Brasil República, p. 28

${ }^{14}$ KOERNER, Andrei. Judiciário e cidadania na Constituição da República brasileira, p. 217.

${ }^{15}$ BALEEIRO, Aliomar. Supremo Tribunal Federal, esse outro desconhecido, p. 25.

${ }^{16}$ LEAL, Victor Nunes. Coronelismo, enxada e voto: o município e o regime representativo no Brasil, p. 234.

${ }^{17}$ Dizia o Deputado Raul Fernandes na Constituinte de 1934, sobre a situação até então vivenciada pelo Poder Judiciário na Primeira República: "Aí, o clamor vinha da periferia para o centro: era a opinião pública dos Estados que se queixava de não ter o Poder Judiciário de um modo geral, salvo honrosíssimas exceções, o amparo prometido na Constituição, desde que aos magistrados estaduais faltavam as garantias elementares: os governos eram livres de pô-los em disponibilidade quando queriam, pela extinção de suas comarcas, ou os removiam, fraudando a lei, de uma para a outra comarca, mediante reforma em sua lei judiciária, e quando nada disso bastava, alguns levavam a opressão até o sadismo: privavam os magistrados de seus vencimentos" . In: LEAL, Victor Nunes. Coronelismo, enxada e voto: o município e o regime representativo no Brasil, p. 234.
} 


\subsection{SOCIOLOGIA CONSTITUCIONAL}

as funções que, comumente, se atribuem ao juiz de paz, está a de substituir o Juiz Municipal e, às vezes, o próprio Juiz de Direito. Partidárias, muitas vezes, são as autoridades policiais dos Municípios, quando a nomeação delas se faz por indicação dos chefes políticos locais. De conluio com o juiz partidário e o delegado faccioso, não haverá adversário que lhes resista (ANAIS, XI, p. 403 apud LEAL, 1978, p. 203).

Assim, a magistratura estadual enveredava pelas mesmas sendas que tanto assolavam os espíritos mais críticos a respeito da neutralidade das decisões judiciais. O mecanismo de funcionamento da judicatura nos estados já era um produto de tensão desde o ingresso de seus membros, posto que a falta de garantias mínimas ao exercício de seus misteres fazia com que tal corpo judicial estivesse pressionado pelos grupos dominantes, os quais reivindicavam o controle do aparato Judiciário como veículo de propalação de seu domínio socioeconômico regional. Como em muitas situações, a justiça estadual ficava à mercê dos juízes temporários, os quais não gozavam das garantias funcionais dadas aos juízes federais (posteriormente estendida aos juízes de direito), o lobby das facções estaduais, especialmente controladas pelos coronéis, coagia tais indivíduos, manipulando suas decisões e seus atos oficiais. Tal fenômeno acabava reproduzindo-se no tocante ao juiz de paz, última instância da escala de substituição dos magistrados na esfera estadual, que por serem eleitos e representarem o resultado material da facção política em uma determinada localidade, revelavam-se parciais e comprometidos com a manutenção do status quo predominante.

Já no que se refere ao recrutamento dos Ministros do STF para ingresso na Corte, as deslisuras envoltas no procedimento não se desviavam muito daquelas encontradas na nomeação dos juízes seccionais e estaduais. Segundo a Constituição, os Ministros eram nomeados pelo Presidente da República, com a seguida aprovação do Senado, entre aqueles cidadãos em pleno gozo de seus direitos políticos, com mais de 35 anos, e possuidores de "notável saber e reputação" (art. 56 da CF/1891). O que se revela empiricamente é que a nomeação de um Ministro do STF poderia simbolizar a retribuição do Chefe do Executivo por "favores" recebidos, bem como poderia estar convalidada pelos reclames da oligarquia política dominante, a qual reclamava por cargos para o agraciamento de seus membros congêneres. Desta forma, o alcance de maioria de seus membros no plenário do Tribunal Supremo era um recurso que envolvia fortes manobras políticas desenvoltas pelas facções dominantes nos estados, na medida em que o controle das nomeações importava diretamente a essa pequena elite dirigente. Como o Supremo Tribunal tinha por competência decidir sobre o Presidente e Ministros de Estado, além de conflitos de competência entre estados e União ou mesmo entre dois ou mais estados, bem como decidir sobre o controle dos atos normativos em face da Constituição e das leis federais, sem se falar na revisão de processos findos, a manipulação desses cargos era de especial importância ao governo federal e às facções que o apoiavam (art. $59 \mathrm{da} \mathrm{CF/1891).} \mathrm{Isto} \mathrm{se} \mathrm{deveu} \mathrm{principalmente} \mathrm{ao}$ fato de, com a elevada competência reservada ao Tribunal, cujas causas envolviam diretamente o julgamento dos destinos das maiores autoridades do país, além de dirimir conflitos entre as facções estaduais nas divergências de competência, a violação de suas decisões justificava no plano político a intervenção federal no estado (art. $6^{\circ}$, $\$ 4^{\circ}$, da CF/1891). Este recurso constitucional era indesejado a todo preço pelas oligarquias locais, visto que interfeririam em sua autonomia. Segundo se pode depreender da passagem a seguir colacionada, nomeações por agraciamento de cargos públicos a correligionários, manifestação mais típica do cartorialismo de Estado, além do clientelismo que beneficia com cargos públicos os aliados e pessoas próximas ao Presidente, davam a tônica da mistura fluida das relações públicas e das relações privadas vivenciadas por nosso Judiciário - nossa marca mais manifesta do patrimonialismo na magistratura.

Alberto Torres e Epitácio Pessoa tiveram preteridas suas pretensões de domínio dos seus estados, por causa da regra do reconhecimento das facções dominantes da Política dos Governadores. Sua nomeação para o STF foi uma forma pela qual Campos Sales assegurou 
a manutenção da sua aliança com eles. Esse também é o caso de Guimarães Natal, cunhado de Leopoldo de Bulhões, nomeado por Rodrigues Alves. Bulhões era ministro da Fazenda e dominava o Estado de Goiás, onde o seu cunhado era juiz federal. Em meados de 1905, o governador do estado rompeu com Bulhões, aliando-se à oposição. $\mathrm{Na}$ sucessão governamental ocorreram duplicatas de governo e assembléia. Rodrigues Alves, porém, não de-cretou intervenção no estado, encaminhando o caso ao Con $\neg$ gresso Nacional, o que resultou no controle do estado pela oposição. $\mathrm{O}$ ministro pediu demissão, mas Rodrigues Alves não acei $\neg$ tou. Em setembro de 1905, este ofereceu uma cadeira do STF a Bulhões, que indicou o seu cunhado. [...] Nomeações por aliança parecem ter sido também a de Pedro Lessa e de Canuto Saraiva, ligados aos paulistas, nomeados por Affonso Penna, mineiro.

Rodrigues Alves nomeou três chefes de polícia: Oliveira Ribeiro, desembargador de São Paulo, que fora chefe de polícia durante seu governo em São Paulo; Cardoso de Castro e Manuel Espínola, na Presidência da República. Nilo Peçanha nomeou Leôni Ramos, que fora deputado estadual no Rio de Janeiro e chefe de polícia do Distrito Federal durante seu governo, e seu aliado Godofredo Cunha, genro de Quintino Bocaiúva. Quando era juiz secional do Rio de Janeiro, Godofredo Cunha concedeu habeas-corpus para garantir as eleições de dezembro de 1896 em Campos, onde Nilo Peçanha era candidato. $\mathrm{O}$ juiz secional foi à Capital Federal e requisitou em pessoa força federal ao vice-presidente em exercício Manuel Victorino, que lhe foi concedida. O juiz secional comandou pessoalmente a distribuição das duzentas praças pelo município. A intervenção causou na época grande controvérsia sobre se o presidente da República poderia apreciar os motivos da requisição do juiz secional antes de conceder a força federal [...]. Segundo Leda B. Rodrigues [...], Nilo teria prometido a Godofredo Cunha nessa ocasião que o nomearia ministro do STF quando fosse presidente da República. ${ }^{18}$

Não bastasse todo o dito, veja-se ainda que o requisito de "notável saber e reputação", utilizado como avaliação para o ingresso dos Ministros, por ser conceito fruto de um artigo de elevada indeterminação e que poderia levar seus intérpretes a múltiplas compreensões, foi um dos recursos utilizados pela política governista para acomodar situações particularistas, alijando a seriedade do processo de seleção dos membros de nossa Corte Maior. Se na visão mais clássica aristotélica, a ideia de conceito significaria a simplex apprehensio rei, como sendo a simples descrição das coisas, da forma mais clara e coerente possível, não foi esse o escopo atingido pelo legislador constitucional. Desta forma, os requisitos de precisão prática indeterminada de "notável saber e reputação" acabaram por enveredar por uma interpretação incerta quanto ao sentido da norma constitucional republicana. Como a Constituição não trouxe expressamente a necessidade de que o notável saber que disciplinava compreendia o conhecimento do Direito a partir de suas legislações e conceitos pertinentes (um saber minimamente "jurídico"), por mais de uma vez a nomeação dos Ministros do Supremo Tribunal fugira a essa regra no processo de escolha de cidadãos para a ocupação do cargo. Segundo demonstra Lêda Boechat Rodrigues, vendo-se o STF desfalcado em seu quorum, buscou-se em uma medida emergencial designar para a vaga remanescente um "médico clínico", da confiança pessoal do Presidente, de nome Cândido Barata Ribeiro, o qual tomou posse e exerceu o cargo por mais de um ano (1893-1894). ${ }^{19}$ O mesmo fator amical mostrouse influente na indicação, por parte do Presidente Floriano Peixoto, de dois Generais do Exército, Inocêncio Galvão de Queirós e Raimundo Ewerton Quadros. ${ }^{20}$ Já outro dos Ministros, como Alberto Torres (1901-1909), por exemplo, de vocação governista, que já havia participado do governo como Ministro, nomeado com os 35 anos mínimos de que necessitaria para ingresso no cargo, sentindo-se acabrunhado com a função a desempenhar, solicitou a postergação de sua posse por meses, a fim de que pudesse estudar para o exercício de tais funções: "Não entro em exercício já; não me sinto preparado; preciso de ainda uns meses de estudo"21. Demonstrase, destarte, que nem sempre o requisito

\footnotetext{
${ }^{18}$ KOERNER, Andrei. Judiciário e cidadania na Constituição da República brasileira, p. 188-189.

${ }^{19}$ RODRIGUES, Lêda Boechat. História do Supremo Tribunal Federal: defesa das liberdades civis, 1891-1898. Rio de Janeiro: Civilização Brasileira, 1965.

t. I. p. 42.

${ }^{20}$ BALEEIRO, Aliomar. Supremo Tribunal Federal, esse outro desconhecido, p. 25.

${ }^{21}$ RODRIGUES, Lêda Boechat. História do Supremo Tribunal Federal: defesa das liberdades civis, 1891-1898, p. 38.
} 


\subsection{SOCIOLOGIA CONSTITUCIONAL}

constitucionalmente posto refletia sua prática cotidiana, comportando as múltiplas molduras da regra legal para a acomodação de situações particulares, que na sua maioria visavam atender aos interesses oficiais que se impunham ao acontecer dos fatos, moldando a abstração da norma à conveniência política ocasional.

Segundo se justificava na argumentação dos seus fiéis defensores, o procedimento de escolha dos magistrados e dos Ministros do Supremo Tribunal baseado na listagem de candidatos eleitos ou indicados era plenamente ajustável à aferição de todos os atributos que poderiam os candidatos servir ao Estado em seus elevados postos oficiais. O estabelecimento do processo de seleção dos Ministros por concurso, ou mesmo por antiguidade, como previam as primeiras ideias liberais, segundo se aduzia, embora fosse capaz de revelar as habilidades técnicas dos candidatos, não era um método adequado para avaliar "os atributos morais" de seus postulantes, o que poderia ser prejudicial ao novo regime. Embora se julgue tal fórmula arcaica, obsoleta, trata-se de um procedimento em maior ou menor grau reproduzido pelas ulteriores Constituições brasileiras, inclusive a atual. Como se viu, tal pensamento puritano acabou na República Velha revertendo-se, na medida em que foram justamente os atributos morais que mais pesaram em desfavor dos eleitos, desvirtuando os propósitos iniciais propugnados pelos feitores do projeto constitucional.

Verifica-se, assim, que o mecanismo de ascensão na carreira desses integrantes do corpo Judiciário, segundo pensamento majoritariamente acolhido na República, adotava a sistemática de nomeação por mérito. Neste procedimento, buscava-se, em tese, valorizar as habilidades científicas e técnicas de cada magistrado, agraciando-lhes com um posto maior como meio de reconhecimento da labuta e do empenho individual na dissolução dos litígios. Entretanto, o discurso político, embora de essência honesta, recebeu uma prática na República Velha que desvirtuou seus ideais mais sublimes: como o sistema de ingresso e mobilização dos cargos estava submetido ao controle dos grupos de poder dominantes, o desempenho de sua promoção na carreira oscilava livremente ao arbítrio das facções, por mais enérgico que fosse o emprego das faculdades por parte de um magistrado. Como relembrava Victor Nunes Leal, no caso de atrito de um juiz estadual e o grupo político em voga, por exemplo, resultava na remoção daquele, substituindo-o por outro magistrado, mais bem arregimentado com o pacto coronelista. ${ }^{22} \mathrm{O}$ sistema de compromissos do qual a magistratura fazia parte lançava à instituição uma rendição que gravitava conforme os caprichos do grupo político dominante, transformando a retórica nomeação meritocrática em uma escolha por conveniências, a qual hesitava em favor do grupo que detivesse a primazia política naquela situação histórica.

Assim se descrevia, na época, nos anais do Relatório do Ministério da Justiça:

Se por acaso o juiz, revestido de nobre coragem e altivez, ousa contrariar a vontade do governo, ou as conveniências do partido, para distribuir somente a justiça, ele sabe que não tardará o castigo da sua rebeldia meritória. A sua remoção ou a destituição do cargo não se farão muito esperar. E quando, porventura, tais atos não caibam nas atribuições do governo, este convocará o seu Congresso, o qual, como bom auxiliar da sua política, não deixará de armá-lo de todos os poderes para a satisfação completa de quanto convenha aos arranjos partidários (1897, p. 88-89) [Grifos do autor]. ${ }^{23}$

Um comentador do Período Republicano brasileiro, Manoel Ignácio de Carvalho Mendonça, assim se referia a respeito de suas elucubrações acerca do Poder Judiciário do primeiro quartel do século XX:

Transformados em empregados do governo que os nomeia, os juízes vêm-se [...] expostos a todas as maquinações dos ódios dos vencidos. A respeitabilidade do juiz, que uma suspeita macula, a imperturbável serenidade de ânimo que uma simples desconfiança

\footnotetext{
${ }^{22}$ LEAL, Vitor Nunes. Coronelismo, enxada e voto: o município e o regime representativo no Brasil, p. 44.

${ }^{23}$ Apud KOERNER, Andrei. Judiciário e cidadania na Constituição da República brasileira, p. 216.
} 
inutiliza, a imparcialidade que a menor dúvida abala são a cada momento francamente atacadas pelos adversários que só anseiam pela oportunidade de colocar os juízes de sua confiança (1899, p. 284). ${ }^{24}$

Por outro lado, caso um magistrado federal ou mesmoum Ministro doSupremo TribunalFederal decidisse de forma contrária às oligarquias, não obstante sofresse as reprimendas institucionais que alhures se citou, tal decisão se depararia com a precariedade do sistema judiciário para que efetivamente pudesse ser cumprida em sua plenitude. Como a violação das leis ou sentenças federais justificaria intervenção federal nos estados, essa operação só era cumprida se a oligarquia dominante fosse contrária à aliança federal. Embora a comunicação de violação partisse do Judiciário, a requisição de força pública para intervir nos estados dependeria da convocação, por parte do Presidente da República, a qual apenas era feita ao sabor das conveniências políticas reinantes. Não atendida a solicitação realizada pelo Judiciário, haveria a possibilidade de requisição de forças estaduais para fazer valer o cumprimento da sentença ou lei violada.

\section{Conforme o relato de Andrei Koerner:}

[...] o presidente da República respondia ao juiz seccional que requisitasse ao presidente do estado a força militar, quando era precisamente a este que se atribuía a desobediência à sentença. Outras vezes, era concedida força federal insuficiente, ou esta recebia ordens para dirigir-se lentamente ao local de conflitos. Quando o governo federal tinha por objetivo derrubar a oligarquia dominante, ocorria o inverso. ${ }^{25}$

Dessa maneira, acabava a magistratura servindo-se de refém do sistema político dominante, na medida em que tanto o controle do "ingresso" e "promoção" dos juízes como o domínio dos "efeitos da decisão judicial” eram proximamente controlados pela elite política dirigente. A magistratura, que por essência deveria ser imparcial, tornava-se partidária, reprodutora de vontades privadas no interior do espaço público estatal, sendo, portanto, comum a crítica à figura do "juiz politiqueiro", conforme se tecia nas galerias do parlamento brasileiro.

Nessa mesma esteira já identificava Oliveira Vianna ser a Justiça da época caracterizada pelo "juiz nosso", pelo "delegado nosso", isto é, uma administração judiciária que existia a serviço de grupos ou "clãs", os quais interferiam na ação legal desses funcionários públicos na recatada caça pela satisfação de seus ensejos particularistas. O efeito da cooptação, aliado ao clientelismo e ao cartorialismo de Estado, revelavam as múltiplas facetas assumidas pelo Estado brasileiro, cujo pano de fundo alberga a fonte do patrimonialismo estatal que há tempos assola nossa política, dando margem para que a barganha, o compromisso eleitoreiro, o “jeitinho" e a corrupção façam parte da legenda institucional pátria. ${ }^{26}$

A culpa da "leviandade da Justiça" com que era executada, segundo criticavam os jornais da época, não se operava em função da inépcia da lei, a partir assim do que predispunha a norma constitucional. Ao revés, o que se justificava era o fato de sua prática cotidiana perverter os ideais preconizados pela concepção mínima de justiça, posto que o aparato judicial encontravase submetido ao sistema político dominante. Segundo se afirmava, os Ministros do Supremo Tribunal, "mesmo que representantes supremos da lei e da justiça, não trepidam em sacrificar a justiça e a lei à influência nefasta dos interesses e dos empenhos". E complementava a notícia:

É da maior evidência, por exemplo, que o fato de ser o candidato um político militante no estado em que se abriu a vaga, ou parente e dependente da oligarca ali reinante, constitui uma circunstância que o desabona para exercer com isenção e independência as funções de juiz neste estado. ${ }^{27}$

Certamente. O Poder Judiciário da República encontrou na complexa malha de relações tecidas intrainstitucionalmente o reflexo da política que vivenciava fora das barras estatais.

\footnotetext{
${ }^{24}$ Apud KOERNER, Andrei. Judiciário e cidadania na Constituição da República brasileira, p. 216.

${ }^{25}$ KOERNER, Andrei. Judiciário e cidadania na Constituição da República brasileira, p. 193.

${ }^{26}$ VIANNA, Oliveira. Populações meridionais no Brasil e instituições políticas brasileiras. Brasília: Câmara dos Deputados, 1982.

${ }^{27}$ Jornal do Comércio de 15/7/1890. Apud KOERNER, Andrei. Judiciário e cidadania na Constituição da República brasileira, p. 192.
} 


\subsection{SOCIOLOGIA CONSTITUCIONAL}

\section{O JUDICIÁRIO E O PATRIMONIALISMO}

Comoo sistema político da época concentravase em torno da política dos governadores, recrudescida pelo fenômeno do coronelismo que dava base a toda essa engenharia social, o próprio Estado simbolizava analiticamente o respaldo institucional dessas forças dominantes, as quais se arregimentavam para controlar funções estratégicas do Governo, do Parlamento e, finalmente, do visado Judiciário. Os magistrados, tanto os estaduais como os federais, incluindose os membros do Supremo Tribunal, serviam inevitavelmente de massa de manobra desses grupos dominantes, que sob as mais variadas formas buscavam influir nos assuntos oficiais para reclamar para si privilégios socialmente significativos. $\mathrm{Na}$ linguagem weberiana, encontrava-se aí a linhagem mais concreta da demonstração típico-ideal de seu "estamento", considerado como um grupo que busca, por meio da reivindicação por "honra social", controlar a distribuição de privilégios de modo ao poder permanecer concentrado nas mãos de poucos de seus membros. ${ }^{28}$ Se tal conceito fora por vezes utilizado por Faoro de forma monolítica, como que considerando a presença de um único grupo estamental fechado e orgânico, de fato, trata-se de um embate conceitual que não nos cabe aqui enfrentar ${ }^{29}$.

O que se pode apontar, em verdade, é a tendência da magistratura nacional na República Velha em se coadunar com o poder político predominante, materializando-se na vida jurídica brasileira como um primus inter pares ("o primeiro entre seus iguais") em face de seus cidadãos. Embora o discurso legal pregasse a imparcialidade, a neutralidade e as inúmeras reservas constitucionais de garantia aos magistrados para sua atuação profissional, o marco mais considerável dessa leitura estrutural é o fato de a judicatura republicana ser um dos braços mais importantes para a perpetuação dos grupos politicamente influentes no poder, convalidando oficialmente sua predominância social.

Se por um lado tal constatação possa estar maculada por um véu de continuísmo que fez com que a magistratura viesse se caracterizando pela satisfação dos posicionamentos políticos dominantes, resta cediço que suas práticas consolidaram a eterna e singular confusão da coisa pública com a privada em nossos núcleos institucionais. Tal patrimonialismo, que aparentemente se arraigava na cultura estatal de nosso país, denotava o estado da Justiça que a República herdou, não obstante o fausto da Constituição e a transformação do regime político estabelecido. Se a crítica tecida durante $o$ antigo regime residia na crença de que a magistratura era partidária e comungava de interesses privados porque vivia submersa nas trevas do Período Colonial, ou ainda submetida ao encanto mágico exercido pelo prestígio imperial, tais tergiversações não poderiam ser justificáveis à luz da República. Legatários de um sistema político de forte presença do modelo concentrador em que a figura do chefe político traria mais admiração aos cidadãos do que as fórmulas frias da legislação, esse cenário cultural parecia não ter mudado muito no Período Republicano. Para o descontentamento dos idealistas, o irrefreamento das veleidades privadas permanecia em seu espaço indelevelmente circunscrito, não obstante as modificações da sociedade e de suas instituições impusessem uma velada sofisticação nas formas de dominação até então configuradas. Como outrora, o espaço público via-se constantemente dominado por vontades particularistas, as quais, moldando a lógica de ação de seus agentes, transformavam o caráter gregário do Estado em mais um veículo de reprodução da faceta privada dos grupos dominantes no país, cooptando população, partidos e funcionários oficiais à conclamação de tal causa.

\section{CONCLUSÃO}

Não obstante os inúmeros avanços trazidos

\footnotetext{
${ }^{28}$ WEBER, Max. Economia e sociedade: fundamentos de sociologia compreensiva. Brasília: Ed. da UnB, 1999. v. 2. p. 180 et seq.

${ }^{29}$ Inúmeros questionamentos podem ser encontrados em José Murilo de Carvalho (A construção da ordem: a elite política imperial. Brasília: Ed. da UnB, 1980), os quais, com principal enfoque neste último, buscam demonstrar a ausência de um único estamento, mas de vários grupos heterogêneos, embora comungassem de visões de mundo próximas.
} 


\subsection{SOCIOLOGIA CONSTITUCIONAL}

pela Constituição republicana, há de se repensar que os construtos culturais são muito mais complexos de se eliminar do seio das instituições, a julgar pelo contraste entre a rápida transformação dos textos legais que nos regem e a lenta modificação da consciência coletiva, dispersa na informe malha de relações pulverizadas pela tessitura social. Desta forma, por mais dinâmica as mudanças legislativas que se processem, o tempo social de acomodação às formas estabelecidas vale-se da morosidade inerente à metamorfose cultural humana, que nem sempre se processa a contento dos ideários em determinada época historicamente predominantes.

Assim, o curto período que a República Velha vivenciou pode ter servido como exemplo mais cabal desses paradoxos a que toda sociedade submetida a grandes transformações passa como que invariavelmente. Não obstante os propósitos convalidados pelos diplomas legais trouxessem consigo prenúncios de um novo modelo de organização política e social, grande parte dessas promessas não foram cumpridas, visto que as práticas cotidianas dos cidadãos, dos políticos e dos agentes públicos ainda estavam ancoradas em uma tradição que custava desentranhar-se da vida social brasileira. Quando pomos em tela o núcleo judicante desse funcionalismo oficial, representado por seus magistrados, temos a concretização mais notória dessas premissas. A República Velha, malgrado seu curto período, não foi responsável por expurgar do Judiciário nacional os antigos laços patrimoniais que tanto impediram que este país pudesse constituir-se como uma sociedade eminentemente moderna, em que as cláusulas constitucionais fossem minimamente cumpridas, resguardando a população de arbítrios, de subversões das funções públicas e do completo descaso para com a gravidade do papel dos magistrados na construção de uma sociedade livre, justa e segura.

Normalmente, grandes transformações exigem grandes lapsos temporais para se processarem historicamente em sua plenitude. Dessa maneira, o patrimonialismo, consubstanciado pela confusão da coisa pública com a privada, parecia inarredavelmente, época a época, arraigando-se mais em nossa história jurídico-política. Sem querer profetizar (procedimento que inclusive tornava irritante o discurso científico), mas a grande lição para a contemporaneidade seria talvez a manutenção de um substrato ao qual toda proposta de transformação institucional desse modelo deveria embebedar-se, a fim de que efetivamente pudesse atingir os seus objetivos colimados. A reverberação de tais problemáticas daria a tônica da República contemporânea, que muitos de nossos cidadãos ainda se desdobram a entender.

Corrupção, nepotismo, enriquecimentoilícito, barganhismo, políticas de suborno e cooptação, entre várias outras formas de malversação da coisa pública, acabariam por conduzir a vida política ao descrédito, à inexplicável sandice kafkaniana da compreensão do aparato estatal em seus mínimos detalhes; e esse próprio aparato oficial não possuiria em si uma razão de ser que lhe fosse digna de denotá-lo como pertencente à coletividade. De outro lado, com o tempo, a população acabaria compadecendo-se ao inadvertidamente reproduzir tais fenômenos, admitindo-os de forma tácita como um produto natural das coisas, um atavismo ou um castigo sem explicação, do qual nada se poderia fazer para alterá-lo, a não ser resignar-se docilmente.

\section{REFERÊNCIAS}

BALEEIRO, Aliomar. Supremo Tribunal Federal, esse outro desconhecido. Rio de Janeiro: Forense, 1968.

CARVALHO, José Murilo de. A construção da ordem: a elite política imperial. Brasília: Ed. da UnB, 1980.

. A formação das almas: o imaginário da República no Brasil. São Paulo: Companhia das Letras, 1995.

Mandonismo, coronelismo e clientelismo: uma discussão conceitual. Dados Revista de Ciências Sociais. Rio de Janeiro, UERJ, v. 40, n. 2, p. 229-250, 1997. 
KOERNER, Andrei. Judiciário e cidadania na Constituição da República brasileira. São Paulo: Hucitec/USP, 1998.

. O Poder Judiciário no sistema político da primeira república. Revista Tempo Social. São Paulo, Dossiê Judiciário, n. 21, p. 58-69, 2000.

. A tutela da liberdade na jurisprudência do Supremo Tribunal Federal. Anais... Seminário O Supremo Tribunal Federal na história republicana. Brasília: AJUFE, 2002. p. 452-486.

LEAL, Vitor Nunes. Coronelismo, enxada e voto: o município e o regime representativo no Brasil. São Paulo: Alfa-Omegaz, 1978.

NEQUETE, Lenine. O Poder Judiciário do Brasil a partir da Independência: Brasil República. Brasília: Supremo Tribunal Federal, 2000.

História do Supremo Tribunal Federal: defesa do federalismo, 1899-1910. Rio de Janeiro: Civilização Brasileira, 1968. t. II.

PAULO FILHO, Pedro. O bacharelismo brasileiro: da colônia à república. Campinas: Bookseller, 1997.

RODRIGUES, Lêda Boechat. História do Supremo Tribunal Federal: defesa das liberdades civis, 1891-1898. Rio de Janeiro: Civilização Brasileira, 1965. t. I.

SCHWARTZMAN, Simon. A atualidade de Raymundo Faoro. DADOS - Revista de Ciências Sociais. Rio de Janeiro, UERJ v. 46, n. 2, p. 207213, 2003. As bases do autoritarismo brasileiro. Rio de Janeiro: Campus, 1982.

VIANNA, Oliveira. Populações meridionais no Brasil e instituições políticas brasileiras. Brasília: Câmara dos Deputados, 1982.

O idealismo da constituição. 2. ed. Rio de Janeiro: Brasiliana, 1939.

WEBER, Max. Economia e sociedade: fundamentos de sociologia compreensiva.
Brasília: Ed. da UnB, 1999. v. 2. 


\section{AGRICULTURA FAMILIAR, HABITUS E ACESSO À TERRA}

Luís Felipe Perdigão de Castro ${ }^{\mathrm{i}}$

Sumário: Introdução. $1 \mathrm{O}$ Acesso à terra como direito humano e fundamental. 2 A ideia de desenvolvimento na agricultura brasileira: panorama histórico. 3 As formas de agir e viver do agricultor familiar como elementos valorativos para um "outro desenvolvimento". 4 Agricultura familiar, habitus e valorações sobre a terra. Conclusão. Referências.

\section{Resumo}

O presente artigo discute a dinâmica histórica e cultural do rural brasileiro, enfatizando as formas de agir e viver do agricultor familiar. Investigam-se fatores de caráter social e cultural altamente específicos dos agricultores familiares e suas relações com perspectivas de desenvolvimento agrícola alternativas às propostas originárias da Revolução Verde. O pano de fundo é o acesso à terra como direito constitucional fundamental.

Palavras-chave: Agricultura familiar. Habitus. Progresso. Modernização. Valores

\footnotetext{
${ }^{1}$ Doutorando em Ciências Sociais, pelo Centro de Estudos Comparados sobre as Américas, da Universidade de Brasília (CEPPAC/UnB). Mestre em Agronegócios (Universidade de Brasília). Bacharel em Direito (Universidade Federal de Ouro Preto). Advogado (OAB/DF). Professor de Direito no Centro Universitário de Desenvolvimento do Centro Oeste (UNIDESC) e nas Faculdades Integradas da União Educacional do Planalto Central (FACIPLAC). Ex-assessor de Juiz na Comarca de Luziânia/GO - lfperdigao@gmail.com.
} 


\begin{abstract}
This article discusses the historical and cultural dynamics of the brazilian rural. The ways of acting and living of the brazilian family farmer are investigated as highly specific social and cultural characters. These elements are analyzed as an alternative agricultural development. The backdrop is access to land as a fundamental constitutional right.
\end{abstract}

Keywords: Brazilian family farmer. Habitus. Progress. Modernization. Values.

\section{INTRODUÇÃO}

$\mathrm{O}$ presente trabalho parte da ideia de que a "modernização da agricultura" é, reflexivamente, produto da organização dos recursos agrícolas, do cálculo de racionalidade e planejamento econômico, mas, sobretudo, decorrência de elementos históricos altamente específicos, determinantes da construção social do uso e da apropriação de recursos privados e públicos.

No caso do Brasil, essa trajetória é marcada pelo período pós-1965, em que os anseios de "modernização da agricultura" foram profundamente vinculados à ideia de progresso.

A implantação da Revolução Verde, por meio de um amplo programa de crédito e outros incentivos governamentais, consolidou a concepção de progresso no campo como produção baseada na combinação intensiva de tecnologia, capitais e informações. Nesse contexto, a agricultura familiar foi associada à ideia de atraso, de passado e, mesmo, de pobreza.

Por esse viés, o presente artigo discute de que forma os valores inseridos na agricultura familiar possibilitam um desenvolvimento social e econômico divergente, ou pelo menos diferen- te, da proposta da Revolução Verde e seus atuais desdobramentos.

No tocante ao direito constitucional, essa discussão tem por pano de fundo a função social da propriedade e a dignidade da pessoa humana (artigo $1^{\circ}$, inciso III, da CF/88) que legitimam, do ponto de vista jurídico e social, o esforço para constituir a terra como "um lugar de vida e de trabalho, capaz de guardar a memória da família e de reproduzi-la para as gerações posteriores"1.

Para tanto, apresentamos um breve panorama sobre a ideia de desenvolvimento na agricultura brasileira para, em seguida, discutir questões valorativas ligadas às formas de agir e de viver do agricultor familiar. $\mathrm{O}$ objetivo é analisar como se manifesta o papel da agricultura familiar para a mudança nas relações humanas, econômicas e sociais do campo e da sociedade, enfatizando reflexamente a diversidade cultural e social preconizada na Constituição Federal de 1988.

\section{O ACESSO À TERRA COMO DIREITO HU- MANO E FUNDAMENTAL}

Os direitos fundamentais, enquanto conjunto institucionalizado de direitos e garantias do ser humano, têm por finalidade básica garantir o respeito à dignidade humana, por meio da proteção contra o arbítrio do poder estatal e o estabelecimento de condições mínimas de vida e desenvolvimento da personalidade. Assim, são direitos ligados à plena realização das "condições mínimas de vida e desenvolvimento da personalidade humana"2.

Nesse entendimento, ainda que de cunho predominantemente didático, a doutrina diferencia "direitos do homem", "direitos humanos" e "direitos fundamentais". Os direitos do homem são de cunho jusnaturalista, ainda não positivados. Direitos humanos, por sua vez, dizem respeito à positivação de preceitos no âmbito do direito internacional. Os direitos fundamentais são preceitos protegidos internamente pelo direito constitucional de cada Estado. ${ }^{3}$

\footnotetext{
${ }^{1}$ WANDERLEY, M. N. B. Raízes históricas do campesinato brasileiro. In: TEDESCO, João Carlos (Org.). Agricultura familiar: realidades e perspectivas. 1. ed. Passo Fundo, RS: Universidade de Passo Fundo, 1999. p. 11.

${ }^{2}$ MORAES, A. Direitos humanos fundamentais: teoria geral, comentários aos arts. $1^{\circ}$ a $5^{\circ}$ da Constituição da República Federativa do Brasil, doutrina e jurisprudência. 6. ed. São Paulo: Atlas, 2005. p. 21.

${ }^{3}$ SARLET, I. W. A eficácia dos direitos fundamentais. 7. ed. rev. atual. e ampl. Porto Alegre: Livraria do Advogado, 2007. p. 36.
} 
O acesso à terra rural é um direito humano que se destaca como necessário à realização plena de uma série de outros direitos. Nesse sentido, o acesso à terra é um direito humano aglutinador e viabilizador de outros preceitos constitucionais básicos, como a vida e a dignidade humana. Para melhor compreensão, tomemos por exemplo a relação entre os direitos de acesso à terra e de alimentação adequada.

Alimentar-se adequadamente é um direito humano com bases jurídicas na Declaração Universal dos Direitos Humanos e recepcionado na Constituição Federal de 1988. Detalhado no Comentário Geral 12, enfatiza-se que o direito de alimentar-se não ocorre somente por sistemas eficientes de distribuição, processamento e venda de alimentos, mas também pelo acesso à terra. Dentre os principais dispositivos constitucionais que colocam o acesso à terra rural como direito humano e fundamental está o princípio da função social da propriedade.

O artigo 186 da ordem constitucional em vigor especifica que a função social é cumprida quando a propriedade rural atende, simultaneamente, aos seguintes requisitos:

I - aproveitamento racional e adequado;

II - utilização adequada dos recursos naturais disponíveis e preservação do meio ambiente;

III - observância das disposições que regulam as relações de trabalho;

IV - exploração que favoreça o bem-estar dos proprietários e dos trabalhadores. ${ }^{4}$

Além disso, a Constituição Federal reconheceu o direito de acesso à terra quando se referiu a povos indígenas e outras comunidades tradicionais, mediante direitos especiais sobre territórios. Tais direitos estão assegurados em tratados internacionais como a Convenção 169 da Organização Internacional do Trabalho (OIT), aprovada pelo Decreto Legislativo n. 143, de junho de 2002, o qual determina que o Estado deverá reconhecer aos povos interessados os direitos de posse sobre as terras que tradicionalmente ocupam. Esses dispositivos preconizam medidas que garantam o direito dos povos interessados em utilizar terras que não estejam exclusivamente ocupadas por eles, mas as quais, tradicionalmente, tenham tido acesso para suas atividades de subsistência.

Por esse viés, a Constituição Federal, em seu artigo 231, assegura aos índios o direito sobre as terras que tradicionalmente ocupam. Ao garantir este direito fica estabelecido que a ocupação originária precede e prevalece sobre qualquer outra posse, porque é o direito ao território que traz também a marca da necessidade cultural, religiosa e política, vinculado ao direito de autodeterminação dos povos.

Além dos povos indígenas, as comunidades quilombolas também possuem o direito constitucionalmente garantido ao território, previsto na Constituição Federal no art. 68 das Disposições Transitórias, que define: "Aos remanescentes das comunidades dos quilombos que estejam ocupando suas terras é reconhecida a propriedade definitiva, devendo o Estado emitir-lhes os títulos definitivos". ${ }^{5}$

Embora a Constituição Federal não tenha dado à agricultura familiar um tratamento específico no tocante ao acesso à terra, este direito está profundamente relacionado à categoria social.

Nesse sentido, a agricultura familiar é o principal ator social para a garantia do direito humano à alimentação adequada, este previsto desde 2010 na Constituição da República. Os agricultores familiares produzem cerca de $70 \%$ dos alimentos que são consumidos no planeta. No Brasil, esse segmento produz $87 \%$ da mandioca, $70 \%$ do feijão, $46 \%$ do milho, $38 \%$ do café, $34 \%$ do arroz, $21 \%$ do trigo, $60 \%$ do leite, $59 \%$ do rebanho suíno, $50 \%$ das aves e $30 \%$ dos bovinos. Toda essa capacidade produtiva ocorre em meio a uma realidade social em que os agricultores possuem pouca ou nenhuma terra. ${ }^{6}$

\footnotetext{
${ }^{4}$ BRASIL. Constituição da República Federativa do Brasil de 1988. Disponível em: <http://www.planalto.gov.br/ccivil_03/constituicao/ConstituicaoCompilado.htm>. Acesso em: 19 de jan. 2016.

${ }^{5}$ BRASIL. Constituição da República Federativa do Brasil de 1988. Disponível em: <http://www.planalto.gov.br/ccivil_03/constituicao/ConstituicaoCompilado.htm>. Acesso em: 19 de jan. 2016.

${ }^{6}$ CASTRO, L. F. P.; SAUER, S. A problemática e as condicionantes dos arrendamentos rurais na agricultura familiar. Anais... 50 Congresso da SOBER, Espírito Santo, Vitória, 2012. p. 09.
} 
Contudo, a importância de se discutir o direito de acesso à terra como direito humano, no âmbito da agricultura familiar, não se liga apenas à segurança alimentar, mas a novas formas de se propor o desenvolvimento, na medida em que essa categoria social evidencia formas de viver e de agir peculiares, presentes na interação do homem com a produção agrícola e com o meio ambiente. A agricultura familiar acessa e difunde formas de saber, de organização do trabalho, de cultivo de sementes e de tecnologias não ligadas aos modelos homogeneizadores de produção. Dessa forma, o diálogo entre acesso à terra e agricultura familiar traz a lume a questão da luta por terra como espaço de reivindicação de direitos que transcendem a propriedade fundiária, mas se traduzem em demandas por infraestrutura, serviços públicos e autonomia, com desdobramentos práticos sobre a memória da família, emprego produtivo, geração de renda e combate à fome.

\section{A IDEIA DE DESENVOLVIMENTO NA AGRICULTURA BRASILEIRA: PANORAMA HISTÓRICO}

A combinação de mão de obra escrava, primeiramente indígena e depois africana, aplicada ao cultivo monocultor da cana-de-açúcar, constituiu o primeiro ciclo econômico do Brasil-Colônia e a origem de "uma estrutura agrária socialmente excludente, predatória de recursos naturais e concentradora do acesso à terra"'

A concepção de desenvolvimento mercantilista do Estado Moderno português - cuja lógica básica foi promover o exclusivo comercial $^{8}$ para garantir o equilíbrio da balança comercial lusa e a acumulação bulionista - iniciou o ciclo de aproveitamento econômico das terras brasilei- ras, que, ao longo de séculos, mantém-se dentro de pactos de poder político e social, nos quais "a grande propriedade, dominante em toda a sua História, se impôs como modelo socialmente reconhecido". ${ }^{9}$ Em tal cenário, a agricultura familiar ocupou um "lugar secundário e subalterno na sociedade brasileira. Quando comparado ao campesinato de outros países, foi historicamente um setor 'bloqueado', impossibilitado de desenvolver suas potencialidades" enquanto forma social específica. ${ }^{10}$

Partindo de tais precursores históricos, sem ignorar as peculiaridades de cada período, mas lançando um olhar panorâmico sobre o trajeto da institucionalidade estatal, o processo de "consolidação da tradição autoritária do Estado brasileiro" constituiu uma "barreira à construção da ação coletiva" na luta por direitos, inclusive o de acesso à terra. Em épocas mais recentes, ao findar da Ditadura Militar (anos 80 do século XX), a implementação desses direitos, conquistados por ocasião da Constituição de 1988, foi dificultada no início do período neoliberal em toda a América Latina, nos anos 1990. ${ }^{11}$

Em síntese, do Período Colonial à República contemporânea, o quadro de especificidades no campo brasileiro pode ser caracterizado pela incorporação de novas terras somada à concentração fundiária. Em termos numéricos, o índice de Gini em 1992, que era de 0,826, apresentou decréscimo de apenas 0,010 para o ano de $2003^{12}$, mostrando a persistência e a atualidade do caráter excludente do modelo brasileiro.

Esse modelo é fruto do desenvolvimento pensado a partir do atrelamento da estrutura econômica à organização político-social, em condições originalmente mercantil-coloniais, que se reatualizam e se mesclam a novos elementos. $\mathrm{Na}$

\footnotetext{
${ }^{7}$ WANDERLEY, M. N. B. Reencontro com o Nordeste: itinerários de pesquisa e construção do campo intelectual dos estudos rurais. Estudos de Sociologia, Recife, v. S, n. 1, p. 1-132, 1999. Disponível em: <http://www.revista.ufpe.br/revsocio/index.php/revista/article/view/306>. Acesso em: 19 jan. 2016. p. 52 .

${ }^{8}$ FURTADO, C. Formação econômica do Brasil. São Paulo: Companhia das Letras, 2007. p.11.

${ }^{9}$ WANDERLEY, M. N. B. Raízes históricas do campesinato brasileiro. In: MOTA, D. M. da; TAVARES, E. D.; IVO, W. M. P. de (Org.). Agricultura familiar em debate. Aracaju,SE: EMBRAPA-CPATC, 1997. p. 08.

${ }^{10}$ WANDERLEY, M. N. B. Raizes históricas do campesinato brasileiro. In: MOTA, D. M. da; TAVARES, E. D.; IVO, W. M. P. de (Org.). Agricultura familiar em debate, p. 08.

${ }^{11}$ BALESTRO, M. V.; MARINHO, D. N. C.; WALTER, M. I. Seguro-desemprego no Brasil: a possibilidade de combinar proteção social e melhor funcionamento do mercado de trabalho. Sociedade e Estado. Brasília: UnB. Impresso, 2011. p. 203.

${ }^{12}$ GIRARDI, E. P. Proposição teóricometodológica de uma cartografia geográfica crítica e sua aplicação no desenvolvimento do Atlas da Questão Agrária Brasileira. Tese (Doutorado em Geografia) - Faculdade de Ciências e Tecnologia, Universidade Estadual Paulista, Presidente Prudente. 2008. p. 204.
} 
reinvenção do velho, o uso da terra e seus recursos sob uma lógica fortemente capitalista (guardadas as devidas diferenças de tempo e espaço históricos) trazem consigo a essência do modelo mercantil-colonial que, de forma excludente e concentradora, está focada nas regras de como e o que produzir para exportar, compondo o conjunto de questões estruturais que barram outro modelo de desenvolvimento para o país ${ }^{13}$.

Exemplo dessa reatualização é a Revolução Verde, como projeto imposto ao conjunto da sociedade, sob o argumento de que seria a portadora do progresso para todos, subordinando a agricultura à indústria, pelo complexo agroindustrial. Sob a égide da Revolução Verde, a agricultura brasileira deveria cumprir algumas funções para o projeto de desenvolvimento industrial, tais como liberar mão de obra, fornecer alimentos e matérias-primas para aumento da oferta e diminuição dos preços na indústria, transferir capital e gerar divisas, aumentar o incremento tecnológico e a produtividade com apoio do arcabouço institucional do crédito rural, pesquisa agrícola, preços mínimos e extensão rural. ${ }^{14}$

Essa concepção, no fim da década de 1990, sofreu questionamentos. O modelo de desenvolvimento neoliberal, imposto por órgãos internacionais, como o Banco Mundial e o Fundo Monetário Internacional, buscou solucionar os problemas causados pelo capitalismo por meio das próprias regras capitalistas. Contudo, as críticas a tal paradigma de Estado passariam a indicar outra via, a do desenvolvimento intolerável aos olhos do capitalismo, já que este modelo contraria suas regras. ${ }^{15}$ Esse momento de questionamento também foi decisivo para que se evidenciasse que as democracias desenvolvidas não precisariam seguir um único modelo econômico - o modelo de mercado norte-americano, reforçando as peculiaridades de outros modelos: o modelo social europeu, o modelo desenvolvimentista asiático ou japonês e o modelo misto de capitalismo latino-americano. ${ }^{16}$

Esses modelos, porém, não se consolidaram pacificamente no Brasil, mas em meio a lutas de resistência de diversas categorias sociais, a exemplo dos "Agricultores Familiares". Esses agricultores lutam e resistem por meio de ocupações, mobilização e organização social em entidades e, principalmente, pela reprodução de suas formas de agir e de viver no campo. A criação de assentamentos rurais e a própria recriação do campesinato são manifestações de luta por terra, como lugar de vida e dignidade. ${ }^{17}$

Tais especificidades nos mostram a existência de diferentes capacidades de resistência e adaptação de categorias sociais, frente às condições do campo brasileiro. As formas de resistência da "Agricultura Familiar" trazem consigo respostas à imposição de modelos de desenvolvimento baseados nos valores da Revolução Verde e, como formas de agir e de viver, representam novas perspectivas de desenvolvimento para o rural e para o nacional.

Nesse contexto, como "resultado da capacidade de iniciativa, adaptação e resistência da própria população do campo"18 aos processos locais e mais gerais da sociedade, os agricultores familiares foram reconhecidos e vêm firmando-se como atores sociais responsáveis pela produção da maior parte dos alimentos consumidos no Brasil. ${ }^{19}$ Embora não se possa falar em um projeto de desenvolvimento "exclusivo" da

\footnotetext{
${ }^{13}$ GIRARDI, E. P. Proposição teóricometodológica de uma cartografia geográfica crítica e sua aplicação no desenvolvimento do Atlas da Questão Agrária Brasileira, p. 119.

${ }^{14}$ KAGEYAMA, A et al. O novo padrão agrícola brasileiro: do complexo rural aos complexos agroindustriais. In: DELGADO, G.C.; GASQUES, J.G.; VILLA VERDE, C.M. (Orgs.) Agricultura e politicas públicas. Brasília: IPEA, 1990. p. 113-223.

${ }^{15}$ GÓMEZ, J. R. M. Desenvolvimento em (des)construção: narrativas escalares sobre desenvolvimento territorial rural. Presidente Prudente, 2006. Tese (Doutorado em Geografia) - Faculdade de Ciências e Tecnologia, Universidade Estadual Paulista, 2006. p. 397-398.

${ }^{16}$.GIRARDI, E. P. Atlas da Questão Agrária Brasileira. Disponível em: <http://www2.fct.unesp.br/nera/atlas/questao_agraria.htm>. Acesso em: 19 jan. 2016.

${ }^{17}$ CASTRO, L. F. P.; SAUER, S. A problemática e as condicionantes dos arrendamentos rurais na agricultura familiar. Anais... 50 ${ }^{\circ}$ Congresso da SOBER, Espírito Santo: Vitória, 2012. p. 03.

${ }^{18}$ WANDERLEY, M. N. B. O mundo rural brasileiro: acesso a bens e serviços e integração campo-cidade. Estudos Sociedade e Agricultura e Sociedade. Rio de Janeiro, UFRJ, v.17, n. 1, 2009. p. 61.

${ }^{19}$ CASTRO, L. F. P. Dimensões e lógicas do arrendamento rural na agricultura familiar. 2013. Dissertação (Mestrado em Agronegócios) - Universidade de Brasília, Brasília, 2013. p. 11.
} 
"Agricultura Familiar", é possível identificar nas peculiaridades culturais do agricultor familiar, elementos implícitos à sua forma de agir e de viver, que apontam para formas sustentáveis de desenvolvimento social e econômico, tanto no rural, quanto no nacional.

Trata-se de um processo histórico reflexivo, pois a "agricultura familiar que se reproduz nas sociedades modernas deve adaptar-se a um contexto socioeconômico próprio destas sociedades, que a obriga a realizar modificações importantes em sua forma de produzir e em sua vida social tradicionais" ${ }^{20}$. A compreensão dessa dimensão de desenvolvimento diferenciado exige, contudo, que se avalie o ambiente institucional em que essa categoria se insere e a forma com que seu sistema de valores se relaciona com ele.

Calha frisar que o termo agricultura familiar, neste trabalho, recupera o pensamento de Wanderley $^{21}$, para quem a conceituação assume ares de novidade, designando conceitos já enraizados na sociedade brasileira, como o tradicional camponês, o agricultor de subsistência e o pequeno produtor rural, e incorpora, conceitualmente, os desafios da modernidade. A agricultura familiar, que se reproduz nas sociedades modernas, deve adaptar-se a um contexto socioeconômico próprio dessas sociedades, as quais levam a modificações importantes nas formas de vida social tradicionais.

Essas transformações não significam, contudo, uma ruptura total e definitiva com as formas anteriores, devendo o agricultor familiar moderno adaptar-se às novas exigências da sociedade, sem desvincular-se das tradições camponesas. ${ }^{22}$

Segundo Sauer ${ }^{23}$, na luta pela terra, enquanto resistência aos processos de dominação e exclusão, termos como agricultura familiar e agronegócio surgem enquanto conceitos-síntese ou mais que simples categorias empíricas, à medida que teriam uma construção, apropriação e uso voltados para a expressão de identidades sociais. Nesse contexto, a agricultura familiar pode ser caracterizada a partir dos seguintes elementos:

a) a gestão da unidade produtiva e os investimentos nela realizados são feitos por indivíduos que mantém entre si laços de sangue ou casamento; b) a maior parte do trabalho é igualmente fornecida pelos membros da família; c) a propriedade dos meios de produção (embora nem sempre da terra) pertence à família e é em seu interior que se realiza sua transmissão em caso de falecimento ou aposentadoria dos responsáveis pela unidade produtiva ${ }^{24}$.

Do ponto de vista legal, com um viés mais operacional, a Lei n. 11.326, de 24 de julho de 2006, definiu o agricultor familiar como aquele:

[...] que pratica atividades no meio rural, atendendo, simultaneamente, aos seguintes requisitos:

I - não detenha, a qualquer título, área maior do que 4 (quatro) módulos fiscais;

II - utilize predominantemente mão-de-obra da própria família nas atividades econômicas do seu estabelecimento ou empreendimento;

III - tenha renda familiar predominantemente originada de atividades econômicas vinculadas ao próprio estabelecimento ou empreendimento; IV - dirija seu estabelecimento ou empreendimento com sua família. ${ }^{25}$

Embora essas definições pareçam bem delimitadas, o termo agricultura familiar se consolida e se difunde nos diferentes setores da sociedade, como um "guarda-chuva conceitual que abriga grande número de situações", em contraposição à agricultura patronal, tendo como ponto focal da polarização os tipos de mão de obra e de gestão empregados. Assim, as unidades de produção familiar seriam "formas de conexão, de disjunção e de conjunção", sistemas de "procedimentos e de

\footnotetext{
${ }^{20}$ WANDERLEY, M. N. B. Agricultura familiar e campesinato: rupturas e continuidades. In: (Org.). O mundo rural como espaço de vida: reflexões sobre a propriedade da terra, agricultura familiar e ruralidade. Porto Alegre. Ed. da UFRGS, 2009. p. 43-44.

${ }^{21}$ WANDERLEY, M. N. B. O agricultor familiar no Brasil: um ator social da construção do futuro. Revista Agriculturas - Experiências em Agroecologia. Rio de Janeiro, AS-PTA, p. 33-45, 2009. p. 41-43.

${ }_{22}^{2}$ WANDERLEY, M. N. B. Raizes históricas do campesinato brasileiro. In: TEDESCO, João Carlos (Org.). Agricultura familiar: realidades e perspectivas, p. 02 .

${ }^{23}$ SAUER, S. Agricultura familiar versus agronegócio: a dinâmica sociopolítica do campo brasileiro. Brasília, DF: Embrapa Informação Tecnológica, 2008. p. 67.

${ }^{24}$ INSTITUTO NACIONAL DE COLONIZAÇ̃̃O E REFORMA AGRÁRIA/FOOD AND AGRICULTURE ORGANIZATION OF THE UNITED NATIONS. Perfil da Agricultura Familiar no Brasil: dossiê estatístico. MDA: Brasília, 1996. p. 04.

${ }^{25}$ BRASIL. Lei n. 11.326, de 24 de julho de 2006. Estabelece as diretrizes para a formulação da Política Nacional da Agricultura Familiar e Empreendimentos Familiares Rurais. Disponível em: <http://www.planalto.gov.br/ccivil_03/_ato2004-2006/2006/lei/l11326.htm>. Acesso em: 19 jan. 2016.
} 
estratégias e não uma estrutura dada, à qual aos indivíduos só cabe a própria modelação" 26 .

Para o objeto desta pesquisa, interessa investigar abordagens que dão espaço à reflexão sobre a complexidade da lógica intrínseca à agricultura familiar, "apontando para a importância das afiliações socioculturais dos grupos sociais, isto é, seu modo de ver as coisas" ${ }^{27}$.

\section{AS FORMAS DE AGIR E VIVER DO AGRI- CULTOR FAMILIAR COMO ELEMENTOS VALORATIVOS PARA UM “OUTRO DESEN- VOLVIMENTO"}

A modernização da agricultura brasileira foi uma imposição baseada no argumento de um projeto pretensamente portador do progresso ${ }^{28}$. Esse processo garantiu "à classe média a inserção no circuito global de consumo", reforçando o uso da terra e seus recursos sob uma lógica fortemente capitalista, à medida que se tornaram centrais "as regras de como e o que produzir para exportar" 29 .

Embora essa lógica pareça evidente, suas formas assumem, sob as condições modernas, aspectos diferentes de todas as versões anteriores e, portanto, há que se considerar variedades do capitalismo ao conceituar as diferenças entre os tipos modernos de capitalismo. ${ }^{30}$ Essa é uma importante especificidade para compreender, de forma mais global e comparativa, as forças que regeram e regem a dinâmica da modernização da agricultura.

Por esse viés, a modernização do campo no Brasil se desenvolveu no contexto de uma economia de mercado hierárquica, na qual o ambiente institucional foi determinado pela ausência de relações de emprego de longo prazo, baixos ní- veis de sindicalização, poucos investimentos em qualificação profissional e uma grande distância de poder entre os trabalhadores e suas representações. O elevado grau de hierarquia ocorre nas relações entre trabalhadores e empregadores, assim como nas relações entre os próprios empregados. Somam-se a essas características "o elevado grau de informalidade, a alta rotatividade e a alta taxa de desemprego aberto" 31 .

Em termos comparativos, se as economias de mercado liberais enfatizaram os processos de coordenação guiados pelos mecanismos de mercado (os EUA são o paradigma), as economias de mercado coordenado lograram o êxito da concertação entre seus agentes, como ocorreu na Alemanha. Porém, no caso do Brasil, vigoram estruturas conflitantes de capitalismo, como versões intermediárias dos tipos ideais ${ }^{32}$.

Essa variedade de capitalismo, com princípio alocativo nas hierarquias, foi, entre nós, um importante fator que reforçou o campo como o espaço em que as instituições geram mais assimetrias socioeconômicas que complementaridades funcionais. Ou seja, por um lado, foi capaz de viabilizar a inserção global nos mercados, aumento da produtividade e competitividade econômica por meio do agronegócio, mas, por outro, bloqueou a resolução de problemas históricos como as desigualdades sociais de acesso à terra, a insegurança alimentar, a insuficiência de serviços públicos no campo, a deficiência de infraestrutura física em áreas mais pobres, a baixa captação de crédito por agricultores familiares, confluindo, em última análise, para um processo crônico de concentração de riquezas. Dessa forma, "a ideia de desenvolvimento econômico é um simples mito", que possibilita desviar as aten-

\footnotetext{
${ }^{26}$ NEVES, D. P. Agricultura familiar: questões metodológicas. Revista Reforma Agrária. Campinas,SP, v. 25, n, 2, p. 21-37. 1995. p. 34.

${ }^{27}$ CHALITA, M. A. N. Agricultura familiar na citricultura paulista: a reconstituição da trajetória de um conceito. Anais... XLIII Congresso da Sociedade Brasileira de Economia e Sociologia Rural - Instituições, eficiência, gestão e contratos no sistema agroindustrial. São Paulo, Ribeirão Preto, 2005. p. 09. ${ }^{28}$ KAGEYAMA, A et al. O novo padrão agrícola brasileiro: do complexo rural aos complexos agroindustriais. In: DELGADO, G. C; GASQUES, J. G.; VILLA VERDE, C. M. (Org.). Agricultura e políticas públicas. Brasília: IPEA, 1990. p. 113-223.

${ }^{29}$ GIRARDI, E. P. Atlas da Questão Agrária Brasileira. Disponível em: <http://www2.fct.unesp.br/nera/atlas/questao_agraria.htm>. Acesso em: 19 jan. 2016.

${ }^{30}$ HALL, P. A.; GINGERICH, D. W. Varieties of capitalism and institutional complementarities in the macroeconomy: an empirical analysis. Cologne: Max Planck Institute for the Study of Societies MPIFG Discussion Paper, 2004. Disponível em: <http://www.mpifg.de/pu/mpifg_dp/dp04-5.pdf>. Acesso em: 20 jan. 2016. p. 08-10.

${ }^{31}$ CHAHAD, J. P. Z. Flexibilidade no mercado de trabalho, proteção aos trabalhadores e treinamento vocacional de força de trabalho: a experiência de América Latina e perspectivas (Análise do caso brasileiro). Documento de Proyecto da CEPAL. Santiago: Naciones Unidas, 2009. p. 212.

${ }^{32}$ BALESTRO, M. V.; MARINHO, D. N. C.; WALTER, M. I. Seguro-desemprego no Brasil: a possibilidade de combinar proteção social e melhor funcionamento do mercado de trabalho. Sociedade e Estado. Brasília: UnB. Impresso, 2011. p. 11.
} 


\subsection{SOCIOLOGIA CONSTITUCIONAL}

ções da tarefa básica de identificação das necessidades fundamentais da coletividade, para concentrá-las em objetivos abstratos como são os investimentos, as exportações e o crescimento" 33 .

A interação dessas condicionantes com fatores políticos e sociais favoreceu a associação entre progresso e escala da propriedade, segundo a qual apenas os grandes proprietários puderam beneficiar-se das somas consideráveis de recursos públicos a ele destinados, reforçando a tendência histórica de concentração da terra. Tais assimetrias condicionaram o apropriamento do termo agronegócio como conceito-síntese da eficiência, eficácia, tecnologia, capitais e informações do setor produtivo rural comprometido com a modernização conservadora, identificando a agricultura familiar como conceito-síntese do atraso, da força braçal e da ineficiência. Esse modelo de desenvolvimento dicotômico favoreceu a produtividade, sem distribuição de capital, tecnologia e informação, em desfavor da agricultura familiar.

Assim, considerando as mazelas de nossa variedade de capitalismo, as dificuldades de conciliar êxito econômico e social, bem como a fragilidade do "enforcement", temos que o ambiente institucional em que os agricultores familiares se inserem é o de uma modernidade que reproduziu formas tradicionais de dominação e de exclusão social. De um lado, restringiu-se aos trabalhadores não proprietários o acesso à terra, de outro, tornou-se o crédito e a tecnologia inalcançáveis aos pequenos proprietários descapitalizados ou em descapitalização. O resultado disso é que, em 2004, a população rural representava $17,1 \%$ do total, mas $31,5 \%$ do total dos pobres estavam na área rural, evidenciando "relações de força profundamente assimétricas que são assim reproduzidas" 34

Ao mesmo tempo em que propicia concentra- ção de terras, crédito e tecnologia, esse ambiente institucional retroalimenta formas de resistência e de luta através do "esforço para constituir um 'território' familiar, um lugar de vida e de trabalho, capaz de guardar a memória da família e de reproduzi-la para as gerações posteriores" 35 . Existem condições de pressão social intensas, haja vista que no campo brasileiro, onde vivem apenas $18,8 \%$ da população, foi registrado um êxodo rural de 4,2 milhões de pessoas no período 1991-2000 e a extinção de 1,5 milhões de postos de trabalho no campo no período 1996 $2006 .{ }^{36}$

Essas tensões provocam formas de resistência na forma de luta pela terra que se traduzem ora como movimentos de ocupação para acesso ao recurso produtivo, ora como forma de resistência cultural. A ideia de desenvolvimento da agricultura brasileira foi baseada em um projeto de modernização econômica e tecnológica, por meio da capitalização do latifúndio com recursos públicos. Isso representou a sistemática exclusão do agricultor familiar do acesso à terra e seus recursos, não somente pela construção de pactos políticos excludentes, direcionados a capitalistas urbanos, oligarquias e setores patronais capitalizados. Tais categorias, além de historicamente empoderadas, possuem valorações adequadas à "aliança entre o capital e a terra", ao passo que o agricultor familiar está culturalmente inserido em outra lógica de aproveitamento do capital e da terra, no qual a renda e o lucro são elementos componentes e não norteadores de suas decisões.

Nesse cenário, a Constituição Federal de 1988 é um importante marco para os discursos e as lutas das diversas categorias sociais relacionadas à disputa por terra. Com a Letra Magna de 1988, o princípio da função social assumiu novas significações. Ou seja, o debate sobre a questão agrária passou a considerar, do ponto de vista jurídico,

\footnotetext{
${ }^{33}$ FURTADO, C. O mito do desenvolvimento econômico. São Paulo: Círculo do Livro, 1974. p. 75.

${ }^{34}$ WANDERLEY, M. N. B. O mundo rural brasileiro: acesso a bens e serviços e integração campo-cidade. Estudos Sociedade e Agricultura. Rio de JaneiroRJ, UFRJ, v.17, n.1, 2009. p. 71.

${ }^{35}$ WANDERLEY, M. N. B. Raízes históricas do campesinato brasileiro. In: TEDESCO, João Carlos (Org.). Agricultura familiar: realidades e perspectivas, p. 11.

${ }^{36}$ INSTITUTO BRASILEIRO DE GEOGRAFIA E ESTATÍSTICA. Séries Estatísticas \& Séries Históricas. Censos Agropecuários (1920 a 1995/96). Rio de Janeiro, RJ: IBGE. 2013. Disponível em: <http:www.ibge.gov.br/series_estatisticas/subtema.php?idsubtema=100:. Acesso em: 15 set. 2014 ; INSTITUTO BRASILEIRO DE GEOGRAFIA E ESTATÍSTICA. Censo Agropecuário 2006: Brasil, Grandes Regiões e Unidades da Federação. Rio de Janeiro, RJ: IBGE. 2007. Disponível em: <http://ibge.gov.br/home/estatistica/economia/agropecuaria/censoagro/2006_segunda_apuracao/default.shtm>. Acesso em: 15 set. 2014
} 
que a função social da terra tem por fundamento a cidadania e a dignidade da pessoa humana.

A Constituição Federal de 1988 deu importante passo na institucionalização dos direitos fundamentais no campo na medida em que reconheceu que o acesso legítimo à terra ocorre nos estritos limites da utilização adequada e "não de modo cego e mecânico" ${ }^{37}$. Nessa linha, a posse agrária é que passou a legitimar a propriedade agrária em sede constitucional ${ }^{38}$.

Posto nesse ambiente institucional, o agricultor familiar avalia as condições de produção para além de instrumentais jurídicos ou econômicos, típicos da agricultura capitalista, incorporando "uma diversidade de situações específicas e particulares" 39 . É por essa especificidade que se manifesta o papel revolucionário da agricultura familiar para a mudança nas relações humanas, econômicas e sociais do campo e da sociedade. Isto é, sua forma de agir e de vivenciar representa uma alternativa ao desenvolvimento baseado no binômio capital-terra, voltando-se para uma via de desenvolvimento sustentável e instrumentalizado por uma reforma agrária de feição especialmente modernizadora, não somente do ponto de vista econômico, mas como superação de relações de dominação. ${ }^{40}$

Há, portanto, uma racionalidade intrínseca ao agricultor familiar, que ultrapassa o pacto capital-terra, criando novas visões sobre o que seja desenvolvimento econômico, social e político. A percepção das vantagens ou desvantagens do ambiente institucional está submetida a um arranjo de cosmovisões ${ }^{41}$ que se insere em uma unidade e que, do ponto de vista operacional e cultural, é ao mesmo tempo estrutura de produção, de consumo e de reprodução sociocultural. Ideias como progresso, desenvolvimento e modernização estão vinculadas à produção combinada de valores de uso e de mercadorias, objetivando, para além da renda, do lucro ou da comercialização, a reprodução social das cosmovisões. $^{42}$

Essa peculiaridade na forma de lidar com recursos e promover o desenvolvimento não passa ao largo da Constituição Federal de 1988. Elementos como artes, memória coletiva e repasse de saberes se relacionam ao conceito antropológico de cultura, à dignidade da pessoa humana e ao terreno comumente reverenciado como cultura pelo direito brasileiro, devendo ser considerado que: "cultura para o mundo jurídico é a produção humana juridicamente protegida, relacionada às artes, à memória coletiva e ao repasse de saberes, e vinculada ao ideal de aprimoramento, visando à dignidade da espécie como um todo, e de cada um dos indivíduos"43.

Nesse sentido, a orbe constitucional alcança a agricultura familiar como espaço de manifestação cultural peculiar e legitimamente protegida. A família, como proprietária dos meios de produção, trabalho na terra, valores e tradições (patrimônio sociocultural) em torno da e para a família ${ }^{44}$ cria valorações de base cultural acerca da relação de trabalho, do grupamento afetivo e da visão da terra como lar. Noutras palavras, todo processo de desenvolvimento do agricultor familiar se baseia na reflexão e no exercício de opções econômicas e políticas profundamente orientadas por fatores de caráter social e cultural altamente específicos. ${ }^{45}$

A renda ou o lucro seria aspecto componente das decisões, mas não orientadora delas, conforme atestam inúmeros estudos de caso. A "integração ao mercado e a garantia do consumo" - fundamental para a constituição do "pa-

\footnotetext{
${ }^{37}$ COMPARATO, F. K. Direito e deveres em matéria de propriedade. In: STROZAKE, J. J. (Org.). A questão agrária e a justiça. São Paulo: RT, 2000. p. 146. ${ }^{38}$ LIMA, R. A. M. Direito agrário. Rio de Janeiro: Renovar, 1994. p. 89. No mesmo sentido: MIRANDA, A. G. O instituto jurídico da posse agrária. Belém: Cejup, 1992. p. 51.

${ }^{39}$ WANDERLEY, M. N. B. Raízes históricas do campesinato brasileiro. In: TEDESCO, João Carlos (Org.). Agricultura familiar: realidade e perspectivas, p. 02 .

${ }^{40}$ SAUER, S. Terra e modernidade: a reinvenção do campo brasileiro. São Paulo: Expressão Popular, 2010. p. 35-50.

${ }^{41}$ Neste caso, é o modo pelo qual o agricultor familiar vê ou interpreta a realidade. A palavra alemã é weltanschau-ung, que significa um 'mundo e uma visão da vida', ou 'um paradigma'. É a estrutura por meio da qual a pessoa entende os dados da vida. (GEISLER, 2002).

${ }^{42}$ CASTRO, L. F. P. Dimensões e lógicas do arrendamento rural na agricultura familiar, p. 76.

${ }^{43}$ CUNHA FILHO, F. H. Direitos culturais como direitos fundamentais no ordenamento jurídico brasileiro. Brasília: Brasília Jurídica, 2000. p.28

${ }^{44}$ TEDESCO, J. C. Agricultura familiar: realidades e perspectivas. Passo Fundo, RS: Ed. da UPF, 2001, p. 149-155.

${ }^{45}$ CASTRO, L. F. P. Dimensões e lógicas do arrendamento rural na agricultura familiar, p. 135.
} 
trimônio sociocultural" da agricultura familiar - estão combinados em formas de saber específico, transmitido por gerações sucessivas e que serve de base para o enfrentamento - vitorioso ou não - da precariedade e da instabilidade da estrutura rural. É este saber que fundamenta a complementação e a articulação entre a atividade mercantil e a de subsistência, sobre a base de uma divisão do trabalho interna da família ou da prática do "princípio da alternatividade", formulado por Garcia ${ }^{46}$. Isso, na prática cria, por exemplo, a distribuição de glebas no seio da família fora de uma lógica rígida de venda ou troca de lotes. À medida que ocorrem reconfigurações na organização social da família, caso das uniões matrimoniais, o núcleo familiar redistribui recursos entre si, orientando-se por valores que partem da necessidade de produzir e sobreviver no mercado, mas centralmente orientados pela ligação afetiva com a terra, manifestos pela manutenção de vínculos comunitários e familiares na distribuição espacial das glebas, pela proximidade para cooperação de esforços no trabalho, convivência diária do núcleo, etc. ${ }^{47}$

\section{AGRICULTURA FAMILIAR, HABITUS E VALORAÇÕES SOBRE A TERRA}

Segundo Bourdieu ${ }^{48}$, a dinâmica no espaço social ocorre pela existência do habitus. O habitus é um conjunto de disposições gerais e transponíveis - socialmente construídas e incorporadas - que fazem com que o conjunto de práticas, uma vez produto de condições sociais semelhantes, adquira um caráter sistemático e, da mesma forma, seja sistematicamente distinto de outras condições sociais.

O habitus permite compreender que o agricultor familiar age racionalmente, realizando práticas que reproduzem e transformam as estruturas sociais do espaço social em que se inse- re. Sua racionalidade não é um simples produto de uma razão autoconsciente (capaz de pôr de forma unívoca seus fins e meios, com clara delimitação de valores só econômicos ou somente jurídicos), mas consiste na operação prática do habitus, isto é, de esquemas geradores de classificações e de práticas classificáveis que funcionam na prática sem chegar à representação explícita, e que são o produto da incorporação, sob a forma de disposições, de uma posição diferencial no espaço social. ${ }^{49}$

Assim, a partir de peculiaridades (em especial a racionalidade que ultrapassa o pacto capital-terra, criando novas visões sobre o que seja desenvolvimento econômico, social e político), a dinâmica da agricultura familiar pode ser compreendida à luz da concepção de "habitus", enquanto uma subjetividade socializada ${ }^{50}$, na qual:

[...] os agentes sociais determinam ativamente, por intermédio de categorias de percepção e de apreciação social e historicamente constituídas, a situação que os determina. Podemos dizer até que os agentes sociais são determinados somente e na medida em que eles se determinam; mas as categorias de percepção e de apreciação, que são o princípio desta (auto)determinação, são elas mesmas, em grande parte, determinadas pelas condições econômicas e sociais de sua constituiçãa ${ }^{51}$

Portanto, haveria práticas nas quais e pelas quais os agentes reagem e adaptam-se desencadeando "processos de construção de representações e identidades" 52 . Contudo, essa trajetória é multidirecional, pois não guarda total coerência com a racionalidade econômica ou jurídica. Nela estão inseridos elementos de percepção do agricultor familiar, oriundos do "processo de apropriação que não se deu em um vazio social e político, nem foi resultado de uma classificação estabelecida por setores ou teóricos" ${ }^{\prime 3}$.

Esse "apropriar e perceber" se dá por oposição e diálogo, convergência e divergência, entre

\footnotetext{
${ }^{46}$ GARCIA JR., A. Sul: O caminho do roçado: estratégias de reprodução camponesa e transformação social. Rio de Janeiro: Marco Zero, Brasília: CNPq, 1989. p. $42-50$.

${ }^{47}$ WANDERLEY, M. N. B. Raízes históricas do campesinato brasileiro. In: TEDESCO, João Carlos (Org.). Agricultura familiar: realidades e perspectivas, p. 02.

${ }^{48}$ BOURDIEU, P. Razões práticas: sobre a teoria da ação. Campinas: Papirus, 2008. p. 162-164.

${ }^{49}$ CATANI, A. M. Espaço social e espaço simbólico: introdução a uma topologia social. Perspectiva. Florianópolis, v. 20, p. 107-120, 2002, p. 111

${ }^{50}$ BOURDIEU, P. Pierre Bourdieu avec Löic Wacquant: réponses. Paris: Seuil, 1992. p. 101.

${ }^{51}$ BOURDIEU, P. Pierre Bourdieu avec Löic Wacquant: réponses, p. 111.

${ }^{52}$ SAUER, S. Agricultura familiar versus agronegócio: a dinâmica sociopolítica do campo brasileiro, p. 13.

${ }^{53}$ SAUER, S. Agricultura familiar versus agronegócio: a dinâmica sociopolítica do campo brasileiro, p. 15.
} 
realidade exterior e realidades individuais. Significa a troca recíproca entre o mundo objetivo (da demanda, da oferta e das específicas condições de formação de preço) e o mundo subjetivo da categoria social (visão de mundo). Os agricultores familiares, nesse contexto, são sujeitos e produtos da história, das lutas sociais e das experiências individuais acumuladas. ${ }^{54}$

Esses aspectos teóricos foram observados em alguns trabalhos de campo, a exemplo da formação dos arrendamentos rurais. ${ }^{55}$ Nesse sentido, a dinâmica do habitus na formação de contratos agrários foi investigada a partir das percepções da categoria social acerca da prática de arrendar. Os resultados obtidos, com base em casos do sudoeste goiano, reforçam a tese da heterogeneidade e regionalidade dos arrendamentos rurais na agricultura familiar. A prática contratual foi identificada como fruto de uma combinação reflexiva e multidirecional de fatores que culminam em estratégias que privilegiam o acesso direto à terra pelo direito de propriedade, em detrimento dos arrendamentos rurais. Porém, essas fronteiras não são rígidas, pois são recorrentes as formas alternativas de acesso: contratos atípicos, garantias extrajurídicas e concentração da prática no seio da própria categoria, além de referências discursivas à terra como algo além do comércio, mas identificada como lugar de vida, de trabalho e de interação da família. ${ }^{56}$

Portanto, manifestam-se decisões calcadas em formas de agir e de viver que evidenciam "uma manha", ou ainda, "uma infinidade de esquemas particulares diretamente aplicados a situações particulares" ${ }^{\prime 2}$. Daí a importância de se compreender a prática do arrendamento rural a partir de um contexto de percepção, isto é, inserida na realidade da agricultura familiar, onde as decisões se dão para e por formas de agir e de pensar norteadas pelas ligações afetivas com a terra e pelos vínculos familiares do trabalho. ${ }^{58}$

Opera-se, assim, um sistema constituído de disposições estruturadas no social e estruturantes nas mentes. Essa forma de interpretar o conceito remete a uma análise relacional que enfatiza o caráter de interdependência entre o indivíduo e sua categoria social, considerando um sistema continuamente aberto e constantemente sujeito a novas experiências. ${ }^{59}$

\section{CONCLUSÃO}

A conservação e a transmissão de um patrimônio sociocultural constitui um modelo original, constitucionalmente protegido, que exerce "um papel fundamental no modo de funcionamento da agricultura familiar"60. Da centralidade da família, como portadora do esforço de trabalho e detentora da propriedade, tanto quanto, definidora das necessidades de consumo, decorre a importância que assume a evolução de sua composição ${ }^{61}$ como elemento chave do próprio processo de transformação interna da unidade família/estabelecimento.

As valorações acerca da relação de trabalho, do grupamento afetivo e da visão da terra como lar são racionalidades adicionais, consideradas pelo agricultor familiar no momento de decidir, organizar e produzir. Ele centraliza sua decisão em elementos para além do lucro, da renda ou da segurança da propriedade - fatores que evidenciam visões diferentes do modelo de desenvolvimento (anterior à Constituição Federal de 1988) e proposto a partir da Revolução Verde (na década de 1960), focalizada na concentração de terras, no capital e na informação, de maneira excludente. $^{62}$

\footnotetext{
${ }^{54}$ CASTRO, L. F. P. Dimensões e lógicas do arrendamento rural na agricultura familiar, p. 75.

${ }^{55}$ CASTRO, L. F. P. Dimensões e lógicas do arrendamento rural na agricultura familiar, Capítulo 02. p. 62.

${ }^{56}$ CASTRO, L. F. P. Arrendamentos rurais na agricultura familiar: habitus, direito e acesso à terra. Revista Científica Semana Acadêmica, Fortaleza, CE, n. 77, v. 1, ano MMXV, dez. 2015, p. 01-15.

${ }^{57}$ BOURDIEU, P. A economia das trocas simbólicas. 6. ed. São Paulo: Perspectiva, 2009. p. 208-209.

${ }^{58}$ CASTRO, L. F. P.; SAUER, S. A problemática e as condicionantes dos arrendamentos rurais na agricultura familiar. Anais... $50^{\circ}$ Congresso da SOBER, Espírito Santo: Vitória, 2012. p. 13.

${ }^{59}$ SETTON, M. A teoria do habitus em Pierre Bourdieu: uma leitura contemporânea. Revista Brasileira de Educação. São Paulo, n. 20. maio/jun./jul./ago. 2002. p. 63.

${ }^{60}$ LAMARCHE, Hugues. (Coord.). L'agriculture familiale. 1. Une réalité polymorphe. Paris: L'Harmattan, 1993. p. 13.

${ }^{61}$ WANDERLEY, M. N. B. Raízes históricas do campesinato brasileiro. In: TEDESCO, João Carlos (Org.). Agricultura familiar: realidades e perspectivas, p. 05 .
} 
Por esse caminho, as concepções de mundo são produtos do sujeito, mas também de um agregado de situações provenientes de sua categoria social, ao longo de todo um trajeto histórico. Essas relações podem ser interpretadas a partir da dinâmica de um habitus no espaço social $^{63}$ em que estão inseridos os capitais de uma categoria social. Esse capital não é somente econômico, mas inclui o patrimônio simbólico, cultural e social dos grupos, que se define segundo o capital que possuem. ${ }^{64}$ Assim, argumentos puramente econômicos (renda da terra) ou argumentos somente jurídicos (segurança ou insegurança do direito de propriedade) não são suficientes para compreender os desafios do "desenvolvimento" rural se considerarmos as visões de mundo peculiares dos agricultores familiares - especialmente no que tange ao acesso à terra, valorada reflexamente como lugar de vida, de cidadania e de direitos fundamentais.

Esse "apropriar e perceber" se dá por oposição e diálogo entre realidade exterior e realidades individuais, que encontram na Constituição Federal de 1988 elementos de legitimação da diversidade cultural na relação do agricultor familiar com a terra. Os princípios da dignidade humana e da função social reafirmam, na atual ordem constitucional, os agricultores familiares como sujeitos e produtos da história, das lutas sociais e das experiências acumuladas.

\section{REFERÊNCIAS}

BALESTRO, M. V.; MARINHO, D. N. C.; WALTER, M. I. Seguro-desemprego no Brasil: a possibilidade de combinar proteção social e melhor funcionamento do mercado de trabalho. Sociedade e Estado. Brasília: UnB. Impresso, 2011.

BOURDIEU, P. Sociologia. (Organizador Renato Ortiz). São Paulo: Ática, 1983.

Espaço social e gênese de classes. In:
1989.

(Ed.). O poder simbólico. Lisboa: Difel,

. O poder simbólico. Lisboa: Difel, 1989.

. Pierre Bourdieu avec Löic Wacquant: réponses. Paris: Seuil, 1992.

- A distinção: crítica social do julgamento. São Paulo: Edusp, Zouk, 2008.

Razões práticas: sobre a teoria da ação.

Campinas: Papirus, 2008.

A economia das trocas simbólicas. 6. ed. São Paulo: Perspectiva, 2009.

BRASIL. Constituição da República Federativa do Brasil de 1988. Disponível em: <http://www.planalto.gov.br/ccivil_03/constituicao/ConstituicaoCompilado.htm>. Acesso em: 19 de jan. 2016.

BRASIL. Lei n. 11.326, de 24 de julho de 2006. Estabelece as diretrizes para a formulação da Política Nacional da Agricultura Familiar e Empreendimentos Familiares Rurais. Disponível em: <http://www.planalto.gov.br/ccivil_03/_ ato2004-2006/2006/lei/111326.htm>. Acesso em: 19 jan. 2016.

CASTRO, L. F. P. Dimensões e lógicas do arrendamento rural na agricultura familiar. 2013. Dissertação (Mestrado em Agronegócios) - Universidade de Brasília, Brasília, 2013.

Arrendamentos rurais na agricultura familiar: habitus, direito e acesso à terra. Revista Científica Semana Acadêmica, Fortaleza, CE, n. 77, v. 1, ano MMXV, p. 1-15, dez. 2015.

; SAUER, S. A problemática e as condicionantes dos arrendamentos rurais na agricultura familiar. Anais... 50 $0^{\circ}$ Congresso da SOBER, Espírito Santo, Vitória, 2012.

\footnotetext{
${ }^{62}$ CASTRO, L. F. P. Dimensões e lógicas do arrendamento rural na agricultura familiar, p. 29.

${ }^{63}$ SETTON, M. A teoria do habitus em Pierre Bourdieu: uma leitura contemporânea. Revista Brasileira de Educação. São Paulo, n. 20. maio/jun./jul./ ago. 2002. p. 66.

${ }^{64}$ BOURDIEU, P. Sociologia. (Organizador Renato Ortiz). São Paulo: Ática, 1983. p. 81-90.
} 
CATANI, A. M. Espaço social e espaço simbólico: introdução a uma topologia social. Perspectiva. Florianópolis, v. 20, p. 107-120, 2002, p. 111.

CHAHAD, J. P. Z. Flexibilidade no mercado de trabalho, proteção aos trabalhadores e treinamento vocacional de força de trabalho: a experiência de América Latina e perspectivas (Análise do caso brasileiro). Documento de Proyecto da CEPAL. Santiago: Naciones Unidas, 2009.

CHALITA, M. A. N. Agricultura familiar na citricultura paulista: a reconstituição da trajetória de um conceito. Anais... XLIII Congresso da Sociedade Brasileira de Economia e Sociologia Rural - Instituições, eficiência, gestão e contratos no sistema agroindustrial. São Paulo, Ribeirão Preto, 2005.

COMPARATO, F. K. Direito e deveres em matéria de propriedade. In: STROZAKE, J. J. (Org.). A questão agrária e a justiça. São Paulo: RT, 2000.

COSTABEBER, J.A.; CAPORAL, F.R. Possibilidades alternativas do desenvolvimento rural sustentável. In: VELA, Hugo et al. (Org.). Agricultura familiar. Santa Maria, RS: Ed. da UFSM, 2003.

CUNHA FILHO, F. H. Direitos culturais como direitos fundamentais no ordenamento jurídico brasileiro. Brasília: Brasília Jurídica, 2000.

FURTADO, C. O mito do desenvolvimento econômico. São Paulo: Círculo do Livro, 1974. FURTADO, C. Formação econômica do Brasil. São Paulo: Companhia das Letras, 2007.

GARCIA JR., A. Sul: O caminho do roçado: estratégias de reprodução camponesa e transformação social. Rio de Janeiro: Marco Zero, Brasília: CNPq, 1989.

GEISLER, N. L. Enciclopédia de apologética. São Paulo: Vida, 2002.

GIRARDI, E. P. Proposição teóricometodológica de uma cartografia geográfica crítica e sua aplicação no desenvolvimento do Atlas da Questão
Agrária Brasileira. Tese (Doutorado em Geografia) - Faculdade de Ciências e Tecnologia, Universidade Estadual Paulista, Presidente Prudente. 2008.

GIRARDI, E. P. Atlas da Questão Agrária Brasileira. Disponível em: <http://www2.fct.unesp.br/ nera/atlas/questao_agraria.htm>. Acesso em: 19 jan. 2016.

GÓMEZ, J. R. M. Desenvolvimento em (des) construção: narrativas escalares sobre desenvolvimento territorial rural. Presidente Prudente, 2006. Tese (Doutorado em Geografia) - Faculdade de Ciências e Tecnologia, Universidade Estadual Paulista, 2006.

HALL, P. A.; GINGERICH, D. W. Varieties of capitalism and institutional complementarities in the macroeconomy: an empirical analysis. Cologne: Max Planck Institute for the Study of Societies MPIFG Discussion Paper, 2004. Disponível em: <http://www.mpifg.de/pu/mpifg_dp/dp045.pdf $>$. Acesso em: 20 jan. 2016.

INSTITUTO BRASILEIRO DE GEOGRAFIA E ESTATÍsTICA. Censo Agropecuário 2006: Brasil, Grandes Regiões e Unidades da Federação. Rio de Janeiro, RJ: IBGE. 2007. Disponível em: <http://ibge.gov.br/home/estatistica/economia/ agropecuaria/censoagro/2006_segunda_apuracao/default.shtm>. Acesso em: 15 set. 2014.

INSTITUTO BRASILEIRO DE GEOGRAFIA E ESTATÍSTICA. Séries Estatísticas \& Séries Históricas. Censos Agropecuários (1920 a 1995/96). Rio de Janeiro, RJ: IBGE. 2013. Disponível em: $<$ http:www.ibge.gov.br/series_estatisticas/subtema.php?idsubtema $=100>$. Acesso em: 15 set. 2014.

INSTITUTO NACIONAL DE COLONIZAÇÃO E REFORMA AGRÁRIA/FOOD AND AGRICULTURE ORGANIZATION OF THE UNITED NATIONS. Perfil da Agricultura Familiar no Brasil: dossiê estatístico. MDA: Brasília, 1996.

KAGEYAMA, A et al. O novo padrão agríco- 
la brasileiro: do complexo rural aos complexos agroindustriais. In: DELGADO, G. C.; GASQUES, J. G.; VILLA VERDE, C. M. (Orgs.) Agricultura e políticas públicas. Brasília: IPEA, 1990. p. 113-223.

LAMARCHE, Hugues. (Coord.). Lagriculture familiale. 1. Une réalité polymorphe. Paris: L'Harmattan, 1993.

1994.

.Du mythe à la réalité. Paris: L'Harmattan,

LIMA, R. A. M. Direito agrário. Rio de Janeiro: Renovar, 1994.

MIRANDA, A. G. O instituto jurídico da posse agrária. Belém: Cejup, 1992.

MORAES, A. Direitos humanos fundamentais: teoria geral, comentários aos arts. $1^{\circ}$ a $5^{\circ}$ da Constituição da República Federativa do Brasil, doutrina e jurisprudência. 6. ed. São Paulo: Atlas, 2005.

NEVES, D. P. Agricultura familiar: questões metodológicas. Revista Reforma Agrária. Campinas,SP, v. 25, n, 2, p. 21-37. 1995.

PEREIRA, R. P. C. A teoria da função social da propriedade rural e seus reflexos na acepção clássica de propriedade. In: STROZAKE, Juvelino Hosé (Org.). A questão agrária e a justiça. São Paulo: RT, 2000.

SARLET, I. W. Dignidade da pessoa humana e direitos fundamentais na Constituição Federal de 1988. Porto Alegre: Livraria do Advogado, 2001.

A eficácia dos direitos fundamentais. 7. ed. rev. atual. e ampl. Porto Alegre: Livraria do Advogado, 2007.

SAUER, S. A luta pela terra e a reinvenção do rural. Anais... XI Congresso de Sociologia, São Paulo, Campinas. 2003.

Agricultura familiar versus agronegócio: a dinâmica sociopolítica do campo brasileiro. Brasília, DF: Embrapa Informação Tecnológica, 2008.

Terra e modernidade: a reinvenção do campo brasileiro. São Paulo: Expressão Popular, 2010.

SETTON, M. A teoria do habitus em Pierre Bourdieu: uma leitura contemporânea. Revista Brasileira de Educação. São Paulo, n. 20. maio/ jun./jul./ago. 2002.

TEDESCO, J. C. Agricultura familiar: realidades e perspectivas. Passo Fundo, RS: Ed. da UPF, 2001.

Raízes históricas do campesinato brasileiro. In: MOTA, D. M. da; TAVARES, E. D.; IVO, W. M. P. de M. (Org.). Agricultura familiar em debate. Sergipe: Aracaju, EMBRAPA-CPATC, 1997

WANDERLEY, M. N. B. Raízes históricas do campesinato brasileiro. In: TEDESCO, João Carlos (Org.). Agricultura familiar: realidades e perspectivas. 1. ed. Passo Fundo, RS: Universidade de Passo Fundo, 1999.

WANDERLEY, M. N. B. Reencontro com o Nordeste: Itinerários de pesquisa e construção do campo intelectual dos estudos rurais. Estudos de Sociologia, Recife, v. S, n. 1, p. 1-132, 1999. Disponível em: <http://www.revista.ufpe.br/revsocio/index.php/revista/article/view/306>. Acesso em: 19 jan. 2016.

A ruralidade no Brasil moderno: por um pacto social pelo desenvolvimento rural. In: GIARRACCA (Coord.). Una nueva ruralidad en América Latina? Buenos Aires: CLACSO, 2001.

Agricultura familiar e campesinato: rupturas e continuidades. In: (Org.). $O$ mundo rural como espaço de vida: reflexões sobre a propriedade da terra, agricultura familiar e ruralidade. Porto Alegre. Ed. da UFRGS, 2009. p. 185-200.

. O agricultor familiar no Brasil: um ator 
social da construção do futuro. Revista Agriculturas - Experiências em Agroecologia. Rio de Janeiro, AS-PTA, p. 33-45, 2009.

O mundo rural brasileiro: acesso a bens e serviços e integração campo-cidade. Estudos Sociedade e Agricultura e Sociedade. Rio de Janeiro, UFRJ, v.17, n. 1, 2009. 


\title{
ACESSO À JUSTIÇA E DIREITO À MORADIA:
}

\author{
UMA CRÍTICA À ATUAÇÃO DO JUDICIÁRIO \\ NOS PROCESSOS DE REINTEGRAÇÃO \\ DE POSSE NO CENTRO DA CIDADE \\ DE SÃO PAULO
}

Ana Carolina Cinoca Piovan ${ }^{\mathrm{i}}$

Sumário: Introdução. $1 \mathrm{~A}$ aplicação dos procedimentos de reintegração de posse em situações coletivas passivas: a coletividade no polo passivo da demanda. 2 Os mandados liminares. 2.1 As provas utilizadas para cumprimento dos requisitos do artigo 927 do Código de Processo Civil (CPC). 3 Os mandados de constatação. $4 \mathrm{~A}$ utilização de métodos consensuais de resolução de conflitos. 4.1 A participação de outros órgãos do poder público nos processos. 4.1.1 Ministério Público. 4.1.2 Órgãos do Poder Executivo municipal. 4.1.3 Polícias Militar e Civil. 4.2 Os movimentos sociais nos processos analisados. 5 A fundamentação das sentenças. Conclusão. Referências.

\section{Resumo}

No ano de 2014, os veículos de comunicação de massa apresentaram uma série de notícias sobre o cumprimento de mandados de reintegração de posse no centro da cidade de São Paulo. Essas notícias se justificam pelo forte impacto que a execução de uma ordem judicial pode promover no cotidiano da população local: fechamento de vias de tráfego intenso, utilização de bombas de gás e balas de borracha, ocupantes detidos, uma série de violações a direitos humanos, entre outras situações. Selecionamos 24 processos patrocinados pelo Centro Gaspar Garcia de Direitos Humanos a fim de analisar alguns aspectos do procedimento aplicado nas ações de reintegração de posse. A pesquisa constata que o Poder

${ }^{1}$ Bacharela em Direito pela Faculdade de Direito da Universidade de São Paulo (FDUSP). 
Judiciário não tem tratado o conflito de forma equitativa e, ademais, não aborda a complexidade dos interesses envolvidos, deixando de considerar a natureza distributiva dos conflitos. Dessa forma, entende-se que o tratamento dirigido às ações de reintegração de posse acaba por retroalimentar os conflitos fundiários urbanos, uma vez que não traz soluções para a falta de moradia dos réus, tampouco impõe sanções aos possuidores de imóveis que não cumprem sua função social.

Palavras-chave: Reintegração de Posse. Conflitos fundiários urbanos. Centro Gaspar Garcia de Direitos Humanos. Ação coletiva passiva. Função social da propriedade.

\section{Abstract}

In the year of 2014, mass media communication vehicles presented a series of news stories about the compliance of writs of repossession in downtown São Paulo. These news stories are justified by the great impact that can be caused by the execution of a court order in the daily lives of the local population: closing of intense traffic lanes, use of gas bombs and rubber bullets, detained occupants, a series of human rights violations, among other situations. We selected 24 legal proceedings led by the Gaspar Garcia Center for Human Rights (Centro Gaspar Garcia de Direitos Humanos) with the intent to analyze some aspects of the proceeding applied in the repossession lawsuits. The research concludes that the Judicial System have not treated the conflicts in an equal manner, and does not approach the problem the complexity of the involved interests, failing to consider the distributive nature of the conflicts. Therefore, it is understood that the treatment directed towards the repossession lawsuits is responsible for feeding the land conflicts in the city, because it does not bring a solution to the problem of homelessness faced by the defendants, neither impose penalties to the realty owners that do not fulfill its social function. ]

Keywords: Urban land conflicts. Gaspar Garcia Center for Human Rights (Centro Gaspar Garcia de Direitos Humanos). Defendant class action. Social function of property.

\section{INTRODUÇÃO}

$\mathrm{N}$ este trabalho, analisamos o procedimento aplicado nas ações de reintegração de posse com a finalidade de investigar de que modo o processo impacta nos conflitos fundiários urbanos ${ }^{1}$. Verificaremos se a condução do procedimento é realizada de maneira equitativa, que permita às partes expor os interesses envolvidos na resolução da controvérsia, possibilitando a adequada resolução do conflito. Por meio da análise documental de processos de reintegração de posse, investigaremos se o Poder Judiciário tem sido apto a reconhecer os interesses das partes envolvidas no conflito, principalmente no que diz respeito ao direito social à moradia dos réus, de difícil incorporação nos processos que tramitam na Justiça Comum.

Para o desenvolvimento da presente pesquisa, contamos com o auxílio do Centro Gaspar Garcia de Direitos Humanos, uma organização ecumênica, não governamental, sem fins lucrativos ou econômicos, que atua em favor de pessoas de baixa renda. ${ }^{2}$ Mais precisamente, contamos com o auxílio do Projeto Moradia Digna, segmento do Centro Gaspar Garcia que atua diretamente na defesa do direito à moradia digna por meio da assistência jurídica às famílias moradoras de habitações precárias em processos de despejos, reintegração de posse, usucapião urbano e outras situações em que os direitos humanos estejam sendo desrespeitados. Atualmente, o Projeto Moradia Digna atua em casos encaminhados pela Defensoria Pública do Estado de São Paulo, fruto de convênio entre as duas instituições. ${ }^{3}$

${ }^{1}$ BRASIL. Ministério das Cidades. Resolução Recomendada n. 87, de 8 de dezembro de 2009. Recomenda ao Ministério das Cidades instituir a Política Nacional de Prevenção e Mediação de Conflitos Fundiários Urbanos. Brasília, DOU de 25/05/2010, Seção 1, n. 98 p. 88. Disponível em: <http://www. concidades.pr.gov.br/arquivos/File/87_Resolucao_Conflitos_versao_final_ConCidadesNacional.pdf>. Acesso em: 12 jan. 2016.

${ }^{2}$ CENTRO GASPAR GARCIA DE DIREITOS HUMANOS. Quem somos. Disponível em: <http://www.gaspargarcia.org.br/quem-somos>. Acesso em: 12 jan. 2016. 
Analisamos um total de 24 ações de reintegração de posse patrocinadas pelo Centro Gaspar Garcia de Direitos Humanos. Aproximadamente oitenta ações/processos contaram com a atuação do Centro no ano de 2014, conforme relatório interno da entidade. Para a seleção dos casos, utilizamos os seguintes critérios: 1) presença de coletividades no polo passivo; 2) distribuição no ano de 2014; 3 ) tramitação no Foro Central João Mendes Junior, o qual é territorialmente competente para julgar as demandas de reintegração de posse no centro de São Paulo; 4) tramitação em varas cíveis, uma vez que o foro selecionado também possui Varas da Fazenda, responsáveis por julgar ações em que Fazendas Públicas municipais ou estaduais sejam partes do processo, as quais excluímos de nossa análise pois buscamos focar o nosso trabalho nos conflitos entre particulares; 5) tramitação no Foro João Mendes Junior, em decorrência de competência territorial, uma vez que somente o centro da cidade de São Paulo é objeto desta pesquisa ${ }^{4}$.

Nos processos selecionados, focamos nossa atenção em petições das partes, decisões judiciais, documentos produzidos por oficiais de justiça e manifestações de outros órgãos do Poder Público (bem como a presença de ofícios intimando tais órgãos a se manifestarem).

Com base no objeto apresentado, analisaremos a atuação do Poder Judiciário na resolução dos conflitos fundiários urbanos manifestados em ações de reintegração de posse, investigando se a atividade jurisdicional tem tratado o conflito de maneira equitativa e fornecido soluções adequadas.

\section{A APLICAÇÃO DOS PROCEDIMENTO DE REINTEGRAÇÃO DE POSSE EM SITUA- ÇÕES COLETIVAS PASSIVAS: A COLETIVI- DADE NO POLO PASSIVO DA DEMANDA}

Neste trabalho, um dos critérios utilizados para selecionar os casos que seriam objeto de análise foi a presença de coletividades no polo passivo da demanda. Tal escolha se justifica porque, ante o contexto em que ocorrem os conflitos fundiários no centro de São Paulo - imóveis urbanos, inseridos em uma região valorizada e que conta com o problema do déficit de moradia -, as ações de reintegração de posse com coletividades no polo passivo são manifestações marcantes dos conflitos fundiários. A ocorrência de ocupações irregulares realizadas por dezenas ou centenas de pessoas evidencia, por um lado, que a situação de déficit de moradia afeta uma parcela significativa da população e, por outro, o cenário de abandono dos imóveis da região que, além de numerosos, são vastos o suficiente para acomodar grandes grupos de pessoas. Além disso, tais ações tendem a apresentar maior impacto na vida cotidiana, posto que o cumprimento das decisões judiciais como as estudadas mobiliza grandes contingentes policiais, impacta no trânsito da região e, em alguns casos, apresenta confrontos entre ocupantes e autoridades, sendo frequentemente objeto de notícias nos meios de comunicação de massa. Por fim, não há previsão expressa em nossa legislação a respeito de qual deve ser o tratamento direcionado a coletividades que figurem no polo passivo de uma relação processual. A ausência de previsão legislativa para o tratamento de uma situação coletiva passiva coloca uma série de desafios para a resolução do conflito de maneira equitativa.

Dentro desse cenário de inexistência de previsão legislativa sobre situações coletivas passivas, a atuação do Poder Judiciário tem enfrentado uma série de desafios na resolução de conflitos diante da aparição crescente de demandas propostas em face de coletividades ${ }^{5}$. No caso das ações de reintegração de posse, a jurisprudência optou, por exemplo, por algumas práticas que não inviabilizem o acesso à justiça do autor, como no caso das decisões que determinam que a não identificação dos réus no momento de pro-

\footnotetext{
${ }^{3}$ CENTRO GASPAR GARCIA DE DIREITOS HUMANOS. Programa moradia digna. Disponível em: <http://www.gaspargarcia.org.br/projeto/programa-moradia-digna>. Acesso em: 12 jan. 2016.

${ }^{4}$ SÃO PAULO. Tribunal de Justiça. Resolução n. 148/2001. Altera o disposto no inciso I, do artigo 54, da Resolução no 2, de 15 de dezembro de 1976. O Foro Central João Mendes Jr é competente para julgar ações cujo valor da causa seja superior a 500 salários mínimos. Disponível em: <http://www2. oabsp.org.br/asp/clipping_jur/ClippingJurDetalhe.asp?id_noticias=11251\&AnoMes=20019>. Acesso em: 12 jan. 2016.

${ }^{5}$ VIANA, Flavia Batista. Os fundamentos da ação coletiva passiva no ordenamento jurídico brasileiro. 2009. 342f. Dissertação (Mestrado em Direito)-Pontifícia Universidade Católica de São Paulo. São Paulo, SP, 2009. p. 121-122.
} 
positura da demanda não impede o deferimento da petição inicial. ${ }^{6}$ No entanto, verifica-se que ainda são tímidos os esforços do Poder Judiciário em garantir o direito de defesa dos réus.

Nos processos analisados, verificaram-se alguns padrões no apontamento dos réus na petição inicial: em aproximadamente $46 \%$ dos casos estudados - em 11 dos 24 analisados -, temos os ocupantes indicados pelo movimento social do qual fazem parte, ou seja, apesar de não apresentar personalidade jurídica, o movimento social é colocado como substituto processual dos ocupantes; em aproximadamente 33\% dos casos estudados - oito casos -, os ocupantes eram apontados de maneira completamente genérica com o uso de termos como "os invasores do imóvel...", "os ocupantes do imóvel..."; em relação aos cinco casos restantes, em aproximadamente $21 \%$ dos casos estudados, percebeu-se a identificação, ainda que precária, de um ou alguns dos ocupantes, enquanto o restante era apontado de maneira genérica.

Ainda que a jurisprudência mencione expressamente que a identificação dos réus é dispensada para o autor no momento da propositura da demanda, uma série de obstáculos de ordem prática dificulta a identificação dos réus em momentos posteriores da marcha processual, de modo que a dispensa dada ao autor no momento de propositura da demanda se mantém ao longo do processo. De todos os casos estudados, somente em um (autos no 1021019-51.2014.8.26.0100), a identificação de um grande número de ocupantes foi trazida pelo oficial de justiça, permanecendo impossível saber se referida identificação correspondeu à totalidade dos ocupantes.

As dificuldades em superar tais desafios acabam por criar cenários que escapam da lógica da doutrina de direito processual ou mesmo dar ensejo à violação dos princípios constitucionais que delimitam o que seria o "devido processo legal". A título de exemplo, mencionamos dois dos processos estudados (autos $\mathrm{n}^{\circ}$ 1020508-53.2014.8.26.0100 e autos $n^{\circ} 1033280$ 48.2014.8.26.0100), os quais apresentaram o deferimento de dois pedidos liminares no mesmo processo, ou seja, após o cumprimento da liminar de reintegração de posse requerida na petição inicial, a manutenção do abandono do imóvel permitia que uma nova ocupação se instaurasse no mesmo imóvel, de modo que o(s) autor(es) fazia $(m)$ novo pedido de mandado liminar, valendo mencionar que em ambos os casos o pedido foi deferido e houve expedição de novo mandado de reintegração de posse. É possível que tal situação guarde relação com a forma como os réus são identificados na demanda. Mesmo nas peças dos advogados dos réus a qualificação era de apenas alguns dos ocupantes. ${ }^{7}$ Dessa forma, é possível questionar se a ausência da devida indicação daqueles que compõem o polo passivo não prejudica a identificação dos limites da demanda.

Seria possível vislumbrar a justificativa para tal postura do Poder Judiciário como medida que visa à economia processual. No entanto, tal argumento, além de colocar em segundo plano uma série de princípios e garantias processuais como o contraditório e a ampla defesa, propicia uma situação de insegurança no sistema processual, pois cria o cenário em que o réu não identificado passa a ser tratado como todo aquele que viola o direito do autor ao longo do processo, tornando incertos e imprevisíveis os limites das decisões proferidas naquele processo.

Ademais, esse tipo de medida é mais um ponto que evidencia a situação de abandono dos imóveis no centro da cidade de São Paulo e como

\footnotetext{
${ }^{6}$ RIO DE JANEIRO. Tribunal de Justiça. Apelação n. 0002462-61.2013.8.19.0068. Décima Segunda Câmara Cível. Relator Des. Cherubin Helcias Schwartz Junior. Apelante:

Marisa Marrrochi Imperial Gonzalez e outro. Apelado: Réu incerto e desconhecido. Rio de Janeiro, RJ, 18 de setembro de 2014, p. 1. Disponível em: <http:// www4.tjrj.jus.br/ejud/ConsultaProcesso.aspx?N=201400161897>. Acesso em: 6 jan. 2016; RIO GRANDE DO SUL. Tribunal de Justiça. Apelação Cível n. 70061600391. Apelante: Sucessão de Nery Estevan da Fonseca de Campos. Apelado: Ignorado. Relator Des. Marco Antonio Angelo. Porto Alegre, RS, 3 de março de 2015, p. 1. Disponível em: <http://www1.tjrs.jus.br/site_php/consulta/download/exibe_documento_att.php?ano=2015\&codigo=226781>. Acesso em: 6 jan. 2016; COSTA, Susana Henriques da; FRANCISCO, João Eberhardt. Uma hipótese de "defendant class action" no CPC, 2015. p. 13-16. (NO PRELO).

7 Acredita-se que a não identificação dos réus nas contestações seja fruto de uma série de obstáculos de natureza prática que impedem um contato aproximado dos advogados com todos os ocupantes, como a utilização do sistema de peticionamento eletrônico, a apresentação de procuração e de outros documentos necessários de dezenas, ou até mesmo centenas, de ocupantes, em um prazo processual que pode ser considerado exíguo quando se trata de uma coletividade no polo passivo.
} 
a aplicação das normas processuais tem sido pouco eficaz para promover a pacificação social, uma vez que, inserido no contexto dos conflitos fundiários urbanos, o Judiciário acaba por atuar como uma ferramenta de "proteção em massa" do direito à propriedade sem questionar a destinação dada a tais imóveis, tampouco considerar o déficit de moradia instaurado na mesma urbe. Assim, o Judiciário, ao proporcionar a saída dos ocupantes de maneira célere a ponto de violar garantias processuais sem questionar a destinação dada ao imóvel, acaba por retroalimentar as demandas decorrentes dos conflitos fundiários urbanos, uma vez que os ocupantes retirados de um imóvel permanecem sem moradia, enquanto proprietários têm a garantia de que, caso haja uma invasão, o Poder Judiciário atuará rapidamente para preservar sua posse, ainda que o imóvel não exerça sua função social.

\section{OS MANDADOS LIMINARES}

O procedimento especial das ações possessórias prevê a possibilidade da concessão da tutela jurisdicional em caráter antecipado, sem que haja participação do réu, mediante o cumprimento de determinados requisitos previstos em lei que tornem evidente o direito do autor na demanda proposta. $\mathrm{O}$ cumprimento do mandado de reintegração de posse é medida irreversível que pode finalizar o processo de maneira precoce, sufocando uma série de questões importantes envolvidas no conflito. Nesta seção, investigaremos alguns aspectos práticos do mandado liminar nos casos estudados.

2.1 As provas utilizadas para cumprimento dos requisitos do artigo 927 do Código de Processo Civil (CPC)

De acordo com o artigo 927 do CPC de 1973, para a reintegração de posse, os requisitos para a concessão do mandado liminar são: a comprovação da sua posse; a comprovação do esbulho praticado pelo réu; a comprovação da data do esbulho; a comprovação da perda da posse.

Em todos os 24 casos analisados, a petição inicial trazia o pedido de expedição de mandado liminar, nos termos dos artigos 927 e 928 do $\mathrm{CPC}$, entre os quais somente em quatro processos o pedido liminar foi indeferido. O conteúdo de tais decisões será avaliado posteriormente, por ora a preocupação é avaliar quais foram as provas trazidas pelo autor para demonstrar o cumprimento dos requisitos apontados linhas atrás.

Em relação à prova da posse, percebemos que alguns documentos possuem maior incidência nos processos. Em 96\%, ou seja, em 23 dos 24 casos estudados, o autor da demanda apresentava-se como proprietário do imóvel, ou seja, a comprovação do primeiro requisito do artigo 927 contou com comprovação da propriedade do imóvel em aproximadamente $92 \%$ dos casos - 22 casos -, a comprovação se deu pela apresentação de documentos como matrícula do imóvel, compromisso de compra e venda, formal de partilha, contrato de doação, entre outros. Em $37,5 \%$ dos casos estudados, a comprovação do primeiro requisito do artigo 927 deu-se somente com a apresentação de documento apto a provar a propriedade do imóvel, enquanto nos outros casos havia a comprovação da propriedade combinada com outros documentos. Assim, verificou-se que a incidência de documentos relativos à propriedade foi bem maior do que outros: comprovantes de quitação de contas do imóvel como água, luz e IPTU - instruíram a inicial em apenas 50\% dos casos; já comprovantes da realização de benfeitorias no imóvel - como recibos relativos a reformas -, somente em $12,5 \%$ dos casos estudados; mesma porcentagem encontrada em relação ao uso de comprovantes relativos ao serviço de segurança prestado no imóvel - escala de trabalho, comprovante de pagamento, entre outras formas.

Apesar da alta incidência de documentos relativos à propriedade do imóvel como cumprimento do requisito da prova da posse, é importante ressaltar que tanto o possuidor quanto o proprietário são partes legítimas para a propositura da ação. Ainda que se considere a reintegração de posse um mecanismo de tutela, mediatamente, do titular de domínio, fica bastante claro que o legislador busca valorizar o sujeito que de fato exerce os poderes inerentes ao domínio, protegendo aquele que explora economicamente a coisa, seja trabalhando, seja residindo no bem possuído. $^{8}$ 
Já os outros três requisitos (a comprovação do esbulho praticado pelo réu, da data do esbulho e da perda da posse) tratam da violação do direito do autor pelo réu. Verificando os documentos que instruíram as petições iniciais dos casos analisados e as decisões que tratavam do pedido liminar, percebeu-se que não há uma delimitação precisa de quais requisitos são cumpridos em cada um dos documentos ou que o mesmo documento é apto a comprovar mais de um requisito. Dessa forma, optamos por analisar as provas dos três requisitos conjuntamente. Nos casos analisados, verificamos a apresentação de seis tipos de documentos a fim de comprovar os requisitos dos incisos II a IV do CPC, elencados aqui do mais incidente ao menos incidente: boletim de ocorrência, fotos do imóvel, declaração escrita do autor, notícias de jornal, declaração de testemunhas e notificação extrajudicial.

O boletim de ocorrência foi a fonte de prova mais utilizada para comprovar o ato ilícito praticado pelos réus, aparecendo em $91,6 \%$ dos casos analisados. No entanto, é importante ressaltar que, em uma leitura mais atenta dos documentos, verificou-se a necessidade de distinguir dois tipos de boletim de ocorrência: aqueles em que consta a mera declaração do autor de que houve esbulho do imóvel; e aqueles em que a ocorrência do esbulho foi verificada por autoridade que compareceu ao imóvel ocupado e confirma a declaração do autor frente à autoridade policial. $\mathrm{O}$ primeiro tipo de boletim de ocorrência, em que há a mera declaração pelo autor, é verificado em $62,5 \%$ dos casos analisados. Já o segundo tipo foi constatado em aproximadamente $29,1 \%$ dos casos analisados.

É importante olhar com cautela a aptidão de comprovar fatos mediante apresentação de boletim de ocorrência, uma vez que pode influenciar no deferimento do pedido liminar ou na procedência da demanda. Pelos casos analisados, verificou-se ampla utilização deste documento. Considerando que o boletim de ocorrência, em regra, constitui a declaração unilateral do autor frente à autoridade policial, é uma fonte de prova que apresenta certa fragilidade, de modo que não pode o julgador considerar tal documento como suficiente para comprovar a evidência do direito do autor. Nos casos em que alguma autoridade vai até o imóvel e posteriormente comparece ao plantão policial para confirmar o alegado pelo autor, o boletim de ocorrência adquire maior credibilidade, entretanto, questiona-se se a apresentação deste documento seria suficiente. Dos casos analisados, em sete deles o boletim de ocorrência foi o único documento apresentado para comprovar a violação do direito do autor, dos quais apenas um teve o pedido liminar indeferido. ${ }^{9}$

Os outros documentos verificados para comprovar os requisitos do artigo 927 se apresentaram de maneira bem menos incidente: fotos do imóvel apareceram em 62,5\% dos casos; depoimentos escritos pelo autor, em 12,5\%; notícias de jornal, em 12,5\%; declarações de testemunhas, em 4,16\%; e notificação extrajudicial pedindo a saída dos ocupantes, em 4,16\%. Na maioria dos casos, tais documentos estavam acompanhados do boletim de ocorrência.

Considerando os dados retromencionados, apontamos que as provas apresentadas não abordavam a situação do imóvel até o momento do esbulho. Inclusive, em muitos dos documentos apresentados pelo próprio autor ou na petição inicial havia a informação de que o imóvel estava desocupado: muitas das contas apresentadas foram enviadas por correio e apresentavam carimbos que continham informações como "imóvel vago"; nos boletins de ocorrência que contaram com a averiguação de alguma autoridade, afirmava-se, em alguns casos, a situação de abandono do imóvel até o momento do esbulho; em outros, verificou-se que os proprietários exerciam a posse com a mera contratação de seguranças para guardar o imóvel, sem lhe dar qualquer utilização.

\footnotetext{
${ }^{8}$ DIDIER JUNIOR, Fredie. A função social da propriedade e a tutela processual da posse. Revista de Processo, São Paulo, RT, ano 33, n. 161. 2008 , p. 16. ${ }^{9}$ Dos sete casos em que o boletim de ocorrência foi o único documento apresentado na petição inicial para comprovar a violação do direito do autor pelos réus, destaca-se que em apenas dois foi expedido o mandado de constatação - que será mais bem explicado adiante. No primeiro caso, o oficial de justiça constatou a ocupação do imóvel, o que foi considerado pelo magistrado como situação suficiente para o deferimento do pedido liminar; no segundo caso, o cumprimento do mandado de constatação mencionou indícios de que a posse seria datada de período maior que um ano e dia, de modo que o juízo indeferiu o pedido liminar.
} 
Ainda que a definição de "posse" adotada pelo Código Civil parta da noção de propriedade, esta, além de um direito humano positivado na Constituição brasileira, também impõe deveres ao titular, cujo cumprimento justifica a tutela estatal desse direito. ${ }^{10}$

Com base nos dados trazidos até este ponto do trabalho, percebe-se que, mesmo sendo um dever decorrente da propriedade em nosso ordenamento, a destinação adequada a um imóvel não é levada em consideração quando se discute o exercício da posse, o que, apesar de não ser previsão legal expressa, seria uma decorrência lógica do princípio da função social da propriedade.

Compreende-se que o esbulho do imóvel que atende à sua função social afetaria não apenas os interesses do possuidor, mas da coletividade, justificando a concessão de tutela jurisdicional da forma mais célere possível. No entanto, questiona-se a necessidade da concessão de tutela jurisdicional de forma célere com base na mera comprovação do domínio do autor sobre o imóvel, sem qualquer investigação a respeito da forma como a posse era exercida. Seria realmente medida de pacificação social a tutela da posse que não cumpre sua função social? Se a concessão do mandado liminar fosse realizada com base na comprovação de requisito que sustentasse a necessidade da celeridade da medida, qual seria o impacto na resolução do conflito?

Outra questão verificada durante a análise dos casos é que, apesar da redação clara dos artigos 927 e 928 do CPC, em relação a quais devem ser os requisitos cumpridos para o deferimento do pedido liminar, em $15 \%$ dos casos em que foi utilizado o procedimento especial as decisões que determinavam a expedição do mandado liminar utilizaram como fundamento a presença do $f u$ mus boni iuris e do periculum in mora, previstos no artigo $273^{11}$ do mesmo código.

Ainda que o princípio da fundamentação das decisões não determine quais diplomas legais devem orientar o entendimento do magistrado em determinado caso concreto, de modo que não se exclui a possibilidade de antecipar a tutela jurisdicional que reintegra o autor na posse com base em critérios de urgência, esta hipótese não foi verificada nos casos analisados.

A tutela prevista no artigo 928 do CPC consiste em tutela de evidência ${ }^{12}$, que apresenta requisitos, características e finalidades diversos daquela prevista genericamente no artigo 273, que consiste em tutela de urgência. No entanto, em algumas das decisões analisadas, verificou-se o tratamento da tutela prevista no procedimento especial das possessórias como tutela de urgência, afirmando que o cumprimento dos requisitos do artigo 928 demonstrava a ocorrência do fumus boni iuris e do periculum in mora. Dito isso, questiona-se a familiaridade de alguns magistrados com o procedimento de reintegração de posse e, principalmente, com o tipo de conflito que pode estar envolvido nesse tipo de processo.

Outro ponto que merece atenção é o impacto da expedição do mandado liminar de reintegração de posse nos atos processuais posteriores. Com base nos casos analisados, foi possível perceber que o cumprimento do mandado liminar de reintegração de posse afeta os atos processuais posteriores em decorrência de dois fatores: tempo e utilidade.

Em relação ao fator tempo, verificou-se que a celeridade com que o mandado liminar de reintegração de posse é deferido, expedido e cum-

\footnotetext{
${ }^{10}$ Art. 1.228 do Código Civil de 2002: "O proprietário tem a faculdade de usar, gozar e dispor da coisa, e o direito de reavê-la do poder de quem quer que injustamente a possua ou detenha.

$\$ 1$ o O direito de propriedade deve ser exercido em consonância com as suas finalidades econômicas e sociais e de modo que sejam preservados, de conformidade com o estabelecido em lei especial, a flora, a fauna, as belezas naturais, o equilíbrio ecológico e o patrimônio histórico e artístico, bem como evitada a poluição do ar e das águas. [...]."

${ }^{11}$ Art. 273 do Código de Processo Civil de 1973: "O juiz poderá, a requerimento da parte, antecipar, total ou parcialmente, os efeitos da tutela pretendida no pedido inicial, desde que, existindo prova inequívoca, se convença da verossimilhança da alegação e:

I - haja fundado receio de dano irreparável ou de difícil reparação; ou

II - fique caracterizado o abuso de direito de defesa ou o manifesto propósito protelatório do réu."

${ }^{12}$ Essa modalidade de tutela ocorre nos casos em que o legislador se contenta com a probabilidade de o autor ter razão, ou seja, na evidência de que o direito afirmado existe. Como é o caso da liminar prevista no procedimento de reintegração de posse, tal modalidade só é admitida quando expressamente prevista em lei, de modo que, nos demais casos, devem ser cumpridos os requisitos do periculum in mora e do fumus boni iuris, presentes nas tutelas de urgência. Cf. FUX, Luiz. Tutela de segurança e tutela de evidência. São Paulo: Saraiva, 1996. p. 305-306.
} 
prido é tamanha que acaba por limitar a participação do réu no processo. Nos casos analisados, em que foi utilizado o procedimento especial, o tempo médio entre a distribuição da petição inicial e a data da reintegração adquirida liminarmente é de 116,8 dias $^{13}$, de modo que a reintegração efetuada em menor tempo ocorreu em 32 dias e a efetuada em maior tempo em 219 dias. Considerando a complexidade de interesses envolvidos nos conflitos fundiários urbanos e a grande quantidade de pessoas envolvidas, que, como visto anteriormente, enfrentam uma série de questões de ordem prática para serem representadas no processo, nota-se que a concessão de medidas irreversíveis de forma altamente célere em casos complexos como os que são objeto deste estudo interfere no exercício da defesa dos réus.

Em relação ao fator utilidade, verifica-se que o deferimento do pedido liminar não afeta os atos processuais posteriores somente em relação à celeridade com que é cumprida a determinação do juízo mas também por conta da natureza da tutela concedida liminarmente. Ocorre que, após a desocupação do imóvel, a manutenção da relação processual torna-se inútil. Isso porque, satisfeita a pretensão do autor, não há mais razão para o polo passivo expor seus interesses, sua necessidade de moradia, vez que os ocupantes foram retirados do imóvel e qualquer medida para evitar a situação de desabrigo dos réus perdeu espaço na ação possessória. Ademais, diante dos problemas provenientes da ausência de um tratamento adequado à coletividade no polo passivo dificulta a sua participação no processo após a desocupação do imóvel, vez que os ocupantes se "espalham" em busca de moradia. Dessa forma, diante da ausência de interesse das partes em movimentar o processo, muitas ações de reintegração de posse deixavam de receber sentença, ficando esquecidas pelos magistrados.

Sendo assim, pode-se dizer que o procedimento de reintegração de posse, principalmen- te no que diz respeito à concessão do mandado liminar, ainda é marcado por uma perspectiva imanentista do processo, que privilegia a situação do autor na relação jurídica processual em detrimento de uma resolução equitativa do conflito. Isso ocorre porque a tutela jurisdicional concedida por meio do mandado liminar, além de ser outorgada com base no critério de probabilidade do direito do autor, como apontado anteriormente, possui natureza satisfativa e irreversível.

A tutela de natureza satisfativa é, segundo entendimento doutrinário, aquela que se destina a resolver a crise de direito material, os litígios trazidos ao processo pelas partes, a fim de restabelecer o ordenamento jurídico e a paz social. ${ }^{14}$ No entanto, tal definição é passível de questionamentos. O cumprimento do mandado liminar tem apenas aptidão de satisfazer a pretensão do autor e resolve o conflito apenas no plano da relação jurídica processual. Questiona-se se a satisfação da pretensão do autor, nestes casos, é sinônimo de restabelecimento do ordenamento jurídico e da paz social, uma vez que violações de direitos como os direitos à moradia e à dignidade da pessoa humana, e o descumprimento de deveres do proprietário como o da função social da propriedade não são objeto de tutela jurisdicional e muitas vezes sequer chegam a ser considerados na resolução do conflito.

Diante dessa situação, ocorreram casos como a circunstância de tumulto processual analisada anteriormente: a pendência do processo permitia que, na ocorrência de nova ocupação do imóvel - que permaneceu abandonado -, o autor se utilizasse do mesmo processo para desalojar ocupantes diferentes daqueles que compõem a relação jurídica processual.

Bem se percebe que a previsão legal de expedição do mandado liminar do artigo 928 do CPC, com base na evidência do direito do autor, apresenta uma série de impactos na resolução do conflito. Portanto, são pertinentes os seguin-

\footnotetext{
${ }^{13}$ Nos dois casos em que houve duas ordens de reintegração no mesmo processo, consideramos apenas o período abrangido entre a distribuição e o cumprimento da primeira reintegração, para evitar que a situação de tumulto processual nesses dois processos comprometesse o número buscado: o tempo médio entre a distribuição e o cumprimento do mandado de reintegração de posse.

${ }^{14}$ BEDAQUE, José Roberto dos Santos. Tutela cautelar e tutela antecipada: tutelas sumárias e de urgência (tentativa de sistematização). 5. ed. São Paulo: Malheiros, 2009. p. 113
} 
tes questionamentos: seria possível a resolução equitativa dos conflitos que provocam as ações de reintegração de posse com a manutenção da tutela de evidência? Ainda, seria possível distinguir o procedimento especial de reintegração de posse sem a previsão do mandado liminar?

\section{OS MANDADOS DE CONSTATAÇÃO}

Em alguns dos casos estudados, o magistrado, ao constatar que o polo passivo era composto por uma coletividade, determinou que um oficial de justiça fosse até o imóvel cuja posse é objeto do conflito para constatar a situação da ocupação. Para isso, o juiz expede o mandado de constatação, em que são avaliados aspectos como o número de famílias no imóvel, as condições em que estão instaladas as famílias, a presença de pessoas idosas, deficientes ou crianças, entre outros pontos. Essa medida não está prevista em nenhum diploma legal, sendo criação dos juízes, na tentativa de adaptar o procedimento ao conflito.

O mandado de constatação representa uma oportunidade de trazer a realidade das ocupações aos autos, ampliando a possibilidade de reconhecimento de interesses e necessidades dos ocupantes no processo. No entanto, é um mecanismo que, isoladamente, não tem aptidão de proporcionar a resolução equitativa do conflito, uma vez que está sujeito à forma como os magistrados e oficiais de justiça valoram e descrevem a situação das ocupações. A propósito, o conteúdo dos mandados de constatação apresentou variações nos casos analisados: em alguns, o oficial de justiça descreveu características da ocupação com pouca subjetividade - relatava um número aproximado de ocupantes, o perfil socioeconômico dos ocupantes e a forma como estavam instalados -; em outros, percebeu-se que o oficial de justiça realizou a constatação imprimindo uma série de valores pessoais - mencionava hábitos e aparência dos ocupantes e, em alguns casos, chegava até mesmo a emitir opinião sobre a necessidade ou não da concessão do pedido liminar.

Dos processos analisados, foram emitidos mandados de constatação em 37,5\% dos casos. Além disso, também se constatou que em 100\% dos casos cujo processo tramitou pelo rito ordi- nário, o procedimento foi adotado após o cumprimento do mandado de constatação, que trouxe aos autos a informação de que a posse dos réus era de mais de um ano e um dia.

\section{A UTILIZAÇÃO DE MÉTODOS CONSEN- SUAIS DE RESOLUÇÃO DE CONFLITOS}

Apesar de a previsão legal da reunião de mediação nos procedimentos de reintegração de posse ser uma novidade do Código de Processo Civil de 2015, não há qualquer impedimento legal para a aplicação de métodos autocompositivos na resolução de conflitos sob a vigência do Código de 1973. Neste trabalho, percebemos que a utilização desses métodos nas ações de reintegração de posse analisadas é pouco expressiva: dos casos estudados, a única forma de autocomposição mencionada foi a conciliação, utilizada em apenas $12,5 \%$ dos processos.

Acreditamos que esse quadro guarde relação com a forma como Poder Judiciário e demais autoridades tratam o conflito. Como vimos anteriormente, os réus das ações de reintegração de posse apresentam uma série de dificuldades para expor seus interesses na relação processual. Além disso, considerando o perfil socioeconômico dos ocupantes e as dificuldades de natureza prática do advogado de contatar a totalidade dos réus, há que se considerar a possibilidade de que os réus apresentem uma noção imprecisa de seus direitos, dificultando a exposição de seus interesses no processo. Sendo assim, a situação de desvantagem dos réus em relação à participação no processo e ao reconhecimento de seus interesses prejudica a sua capacidade de negociação, de modo que o espaço de composição se torna pouco atrativo.

\subsection{A participação de outros órgãos do Po- der Público nos processos}

Um dos aspectos da complexidade dos conflitos envolvidos nas ações de reintegração de posse com coletividades no polo passivo é a miríade de direitos envolvidos e, por consequência, a quantidade de órgãos aptos a tutelar tais direitos. Dessa forma, o Poder Judiciário tem como desafio realizar a prestação jurisdicional em diálogo com outros Poderes, de modo que questões 
como orçamento e planejamento de políticas públicas emergem na discussão. Neste trabalho, constatamos que esse diálogo entre Poder Judiciário e demais órgãos do Poder Público não é visto facilmente nos processos de reintegração de posse. Diante da atuação distinta de cada um desses órgãos, analisaremos sua participação nas ações separadamente.

\subsubsection{Ministério Público}

O Ministério Público é a instituição que tem responsabilidade de zelar pelo interesse público no processo. Mais do que tutelar o interesse da sociedade no correto exercício da jurisdição, o parquet é responsável por garantir que certos conflitos e certos valores a ele inerentes recebam o tratamento adequado. ${ }^{15} \mathrm{O}$ cumprimento das funções estabelecidas nos artigos 127 e $129^{16}$ da Constituição Federal é realizado por meio de uma série de atribuições ao órgão, como a legitimidade para propor ação civil pública e ação declaratória de inconstitucionalidade, entre outras. No entanto, atentaremos aqui para a função de custos legis - fiscal da lei - do Ministério Público, em que intervém em algumas causas específicas visando tutelar o interesse público.

Nos processos analisados, a atuação do $\mathrm{Mi}$ nistério Público foi pouco incidente, de modo que se manifestou apenas em $33,3 \%$ dos casos; em alguns casos, suas manifestações eram para declarar o desinteresse do órgão na ação. A pouca incidência de intimações do Ministério Públi- co pode resultar do fato de que a obrigatoriedade de intervenção ${ }^{17}$ deste órgão nas ações de reintegração de posse é uma novidade do novo CPC, valendo anotar que, nos processos regidos pelo Código atual, a participação deste órgão ficava a cargo da iniciativa do magistrado. Ademais, em alguns casos, percebeu-se que a atuação do parquet foi solicitada não em função da questão do direito à moradia, mas devido à presença de interesse diverso, como o interesse de incapazes ou de questões de saúde pública, por exemplo.

Por fim, percebeu-se que a atuação do Ministério Público nas ações de reintegração de posse nem sempre era voltada para o reconhecimento dos direitos dos réus. Independentemente do tipo de direito envolvido que motivou a intervenção do parquet, as declarações são comumente marcadas por certa resistência em reconhecer direitos básicos dos réus, em alguns momentos carregadas por estigmas negativos em relação a ocupações e movimentos sociais.

\subsection{2 Órgãos do Poder Executivo municipal}

Conforme disposto na Constituição Federal, cabe aos municípios realizar políticas de desenvolvimento urbano. ${ }^{18}$ Ainda que a União seja responsável por estabelecer diretrizes em relação ao assunto, é função do Poder Público municipal a aplicação de políticas públicas que visem ao bem-estar dos habitantes da cidade. Dessa forma, a intimação de órgãos do Poder Executivo municipal é uma forma de reconhecimen-

\footnotetext{
${ }^{15}$ DINAMARCO, Cândido Rangel. Instituições do direito processual civil. 6. ed. São Paulo: Malheiros, 2009. v. 1. p. 697.

${ }^{16}$ Artigo 127 da Constituição Federal: "O Ministério Público é instituição permanente, essencial à função jurisdicional do Estado, incumbindo-lhe a defesa da ordem jurídica, do regime democrático e dos interesses sociais e individuais indisponíveis.”

Artigo 129 da Constituição Federal: "São funções institucionais do Ministério Público:

I - promover, privativamente, a ação penal pública, na forma da lei;

II - zelar pelo efetivo respeito dos Poderes Públicos e dos serviços de relevância pública aos direitos assegurados nesta Constituição, promovendo as medidas necessárias a sua garantia;

III - promover o inquérito civil e a ação civil pública, para a proteção do patrimônio público e social, do meio ambiente e de outros interesses difusos e coletivos;

IV - promover a ação de inconstitucionalidade ou representação para fins de intervenção da União e dos Estados, nos casos previstos nesta Constituição; $\mathrm{V}$ - defender judicialmente os direitos e interesses das populações indígenas;

VI - expedir notificações nos procedimentos administrativos de sua competência, requisitando informações e documentos para instruí-los, na forma da lei complementar respectiva;

VII - exercer o controle externo da atividade policial, na forma da lei complementar mencionada no artigo anterior;

VIII - requisitar diligências investigatórias e a instauração de inquérito policial, indicados os fundamentos jurídicos de suas manifestações processuais; IX - exercer outras funções que lhe forem conferidas, desde que compatíveis com sua finalidade, sendo-lhe vedada a representação judicial e a consultoria jurídica de entidades públicas."

${ }^{17} \mathrm{O}$ termo "intervenção" na legislação processual diz respeito à manifestação do Ministério Público. Dessa forma, a obrigatoriedade prevista no novo Código de Processo Civil não implica um dever do parquet de promover políticas públicas de acesso à moradia ou diálogo com demais órgãos do Poder Público, mas apenas de se manifestar nos autos, ainda que tal manifestação seja para declarar desinteresse do órgão.

${ }^{18}$ Art. 182 da Constituição Federal: "A política de desenvolvimento urbano, executada pelo Poder Público municipal, conforme diretrizes gerais fixadas em lei, tem por objetivo ordenar o pleno desenvolvimento das funções sociais da cidade e garantir o bem-estar de seus habitantes."
} 
to dos direitos sociais envolvidos nos conflitos fundiários urbanos que se manifestam nas ações de reintegração de posse, além de proporcionar uma via importante para uma resolução adequada do conflito, vez que, ainda que o autor retome a posse do imóvel, há possibilidade de garantir que os ocupantes não permaneçam privados de seu direito à moradia digna. No entanto, apesar da importância na atuação desses órgãos, sua intervenção foi pouco incidente nos casos analisados: em apenas 33,3\% dos casos foi realizada a intimação para participar no processo e em somente $8,3 \%$ do total dos casos houve manifestação.

\subsubsection{Polícias Militar e Civil}

Diferentemente do Ministério Público e dos órgãos do Poder Executivo municipal, a atuação da Polícia Militar nas ações de reintegração de posse não é voltada para fornecer meios para a resolução do conflito, mas sim para o cumprimento dos mandados de reintegração de posse emitidos ao longo dos processos. A forma como os mandados de reintegração de posse são cumpridos não é regulada pela legislação processual, de modo que a estratégia traçada para a atuação da polícia fica a cargo dos comandantes dos batalhões competentes para atuar na área em que se encontra o imóvel cujo esbulho é objeto da demanda.

Ao longo deste trabalho, percebemos que o método adotado para o cumprimento da ordem judicial pode variar significativamente, a depender do batalhão responsável, diferença esta que interfere diretamente nos impactos sofridos pelos ocupantes e pela população local no cumprimento do mandado. Também foi possível perceber que, nos casos mais graves, o desalojamento dos ocupantes feito sem o devido preparo pode impactar fortemente nos arredores do imóvel, com o fechamento de vias principais, utilização de bombas de gás e balas de borracha, agressões e uma série de violações a direitos humanos. Por outro lado, há situações em que as autoridades policiais terminam por exercer funções que deveriam ser exercidas por agentes do Poder Ju- diciário como, por exemplo, quando noticiam a propositura da demanda para a maioria dos ocupantes.

Dos casos analisados em que foi expedido o mandado de reintegração de posse $-87,5 \%$ do total de casos -, em 95\% deles o cumprimento da ordem judicial contou com a atuação da polícia. ${ }^{19}$ Dessa forma, fica claro que a atuação das polícias militar e civil é altamente frequente nas ações de reintegração de posse. No entanto, raramente esses órgãos contam com o auxílio de outros profissionais com o treinamento necessário para preservar a dignidade dos habitantes dessas ocupações, como assistentes sociais ou psicólogos. Constata-se, ainda, que as polícias não apresentam preparação para o atendimento adequado dessa população.

Outro traço marcante da atuação das polícias nas ações de reintegração de posse é a realização de reuniões com as autoridades responsáveis por conduzir o cumprimento do mandado de reintegração de posse, as quais nominaremos reuniões preliminares. Apesar de promover o encontro entre as partes envolvidas no conflito, essas reuniões são essencialmente diferentes das reuniões de mediação e conciliação, que buscam a resolução consensual do conflito. As reuniões preliminares não representam um espaço que visa pôr fim ao conflito, mas sim organizar a condução do cumprimento do mandado de reintegração de posse: analisar quais meios o autor deve fornecer para que as famílias sejam retiradas do local, estudar formas de minimizar o impacto no tráfego da região, entre outros pontos.

As reuniões costumam acontecer nos Batalhões de Polícia Militar ou Civil e contam com a presença das partes e seus advogados, o comandante do batalhão e autoridades do Poder Público - como representantes da subprefeitura, da Companhia de Saneamento Básico do Estado de São Paulo (SABESP), da Companhia de Engenharia de Tráfego (CET), entre outras.

Importante ressaltar que a realização das reuniões preliminares, apesar de frequente, não ocorre em todos os processos. Como não há qualquer previsão legal que regule a condução

${ }^{19} \mathrm{Em} 83,3 \%$ do total de casos analisados, houve atuação da polícia. 
do cumprimento do mandado de reintegração de posse, sua ocorrência e a forma como é conduzida ficam a critério do chefe do Batalhão Policial competente para realizar o cumprimento do mandado de reintegração de posse. No presente trabalho, é importante destacar, em razão do recorte realizado com base em critérios territoriais, nos casos analisados a ocorrência das reuniões preliminares foi limitada à atuação dos Batalhões de Polícia competentes para atuar em área de competência do Foro Regional Central.

Considerando a discrepância da atuação da polícia no cumprimento dos mandados de reintegração de posse e a importância da forma como é conduzida tal operação, é questionável a ausência de certo controle pelo Poder Judiciário no cumprimento de suas ordens, uma vez que impacta diretamente na resolução do conflito, nas pessoas que circulam no entorno dos imóveis em que o litígio foi instaurado e na forma como a atuação deste Poder é percebida pelas diferentes camadas da sociedade. Além disso, questiona-se a necessidade do uso tão frequente de força policial no cumprimento dos mandados de reintegração de posse enquanto outros profissionais, como assistentes sociais, são tão pouco utilizados para auxiliar o Poder Judiciário nesses casos.

\subsection{Os movimentos sociais nos processos analisados \\ Conforme visto anteriormente, em 46\% dos} casos estudados a demanda foi proposta em face do movimento social do qual os ocupantes faziam parte. Até o momento, verificamos que a ausência de previsão legal no tratamento de coletividades no polo passivo da demanda e as dificuldades enfrentadas pelo autor na identificação dos ocupantes trazem uma série de consequên- cias para os processos de reintegração de posse, como a dispensa do autor de qualificar os réus na petição inicial e as dificuldades de identificação da demanda.

Com isso, outra consequência que se observou neste trabalho é a forma como os movimentos sociais estão presentes nos processos. Considerando que tais movimentos representam para os ocupantes uma forma de organização política, apta a organizar a luta por moradia daqueles que sofrem pelo déficit habitacional, fomentando uma cultura de direitos e coordenando estratégias para pressionar os órgãos do Poder Público para promover a tutela de direitos sociais, tais movimentos não são dotados de personalidade jurídica ou qualquer outra forma de organização que seja voltada à atuação processual em ações de reintegração de posse.

Considerando que no Direito brasileiro a questão sobre a representação processual adequada de coletividades no processo ainda seja objeto de controvérsia ${ }^{20}$, e mesmo que a atuação dos movimentos sociais por meio da via processual fosse viabilizada ${ }^{21}$ - como pode ser visto nos amici curiae $^{22}$-, ressalta-se que a organização e a escolha da entidade apta a atuar como representante do polo passivo não podem partir do autor ao propor a ação em face de um movimento social sem qualquer previsão legal ou histórico de atuação processual daquele movimento, de modo a "impor" um representante a uma coletividade. No entanto, a descrição dos ocupantes enquanto membros de determinado movimento social na petição, que deveria ser considerado mero recurso para auxiliar na identificação dos réus, acaba sendo admitida como uma situação de substituição processual, ainda que sem previsão legal.

Apesar da irregularidade da situação, não

\footnotetext{
${ }^{20}$ GIDI, Antonio. A representação adequada nas ações coletivas brasileiras: uma proposta. Revista de Processo. São Paulo, RT, n. 108, 2002. p. 61-63.

${ }^{21}$ Nesse sentido: MAIA, Diogo Campos Medina. Fundamentos da ação coletiva passiva. 2006. 220f. Dissertação (Mestrado em Direito Processual)-Universidade do Estado do Rio de Janeiro. Rio de Janeiro, RJ, 2006. p. 158-173.

22 "A introdução da figura do Amicus Curiae no sistema legal nacional abriu espaço para as associações de magistrados, de advogados, de membros do Ministério Público, das entidades do movimento social, comunidades étnicas e raciais, comunidades e entidades religiosas, ONGs, Ministério Público, órgãos e entidades governamentais requererem ingresso nos processos em que se discute a constitucionalidade de leis e atos governamentais que ameacem ou violem os interesses e direitos coletivos dos grupos que representam, bem como os direitos difusos.(4) Esses novos atores do processo constitucional podem apresentar petições com documentos; pedidos de sustentação oral dos argumentos apresentados, podendo mesmo requerer a oitiva de testemunhas e de peritos, conforme o caso." SILVA, Luiz Fernando Martins da. Amicus curiae, direito e ação afirmativa. Revista Jurídica. Presidência da República. Brasília, v. 7, n. 76, dez. 2005/jan. 2006. p. 1. Disponível em: <https://www.planalto.gov.br/ccivil_03/revista/ revistajuridica/index.htm>. Acesso em: 15/01/2016.
} 


\subsection{PODER JUDICIÁRIO}

verificamos problemas enfrentados pelos ocupantes em decorrência exclusiva da substituição, fora aqueles inerentes à situação de coletividade no polo passivo da demanda, já apontados anteriormente. No entanto, é neste momento que precisamos destacar o recorte do presente trabalho: os casos analisados foram fornecidos pelo Centro Gaspar Garcia de Direitos Humanos, de modo que não estudamos casos em que os ocupantes não conseguiram o patrocínio de um advogado, suprindo a substituição processual irregular. Sendo assim, fogem da nossa investigação as consequências da identificação dos réus enquanto movimento social no polo passivo de uma ação de reintegração de posse.

O que se pôde verificar no presente trabalho foi o tratamento dispensado tanto pelo Poder Judiciário como pelo Ministério Público quando havia menção a algum movimento social de luta por moradia ao longo do processo, em que se constatou a presença de estigmas em relação à organização política.

Merece destaque o Processo n. 105866158.2014.8.26.0100, em que a organização dos ocupantes, mediante um movimento social de luta por moradia, foi utilizada como fundamento para indeferimento do pedido de justiça gratuita realizado na contestação. Tal postura do Poder Judiciário evidencia não apenas o pouco contato com movimentos sociais, mas também deslegitima a luta organizada que visa à ação estatal na garantia de direitos básicos.

Assim, nos procedimentos de reintegração de posse, não só verificamos que as discussões instauradas no processo deixam de reconhecer direitos básicos dos réus, como também foi possível perceber que a organização dessas camadas da população, enquanto movimentos legítimos que buscam a efetivação de direitos pela via política, não é reconhecida nas decisões judiciais ou cotas do Ministério Público, as quais são carregadas de estigmas negativos em relação a movimentos sociais.

\section{A FUNDAMENTAÇÃO DAS SENTENÇAS}

Como já apontado anteriormente, a prolação da sentença, ainda que decorrência lógica da marcha processual, não acontece em todas as ações de reintegração de posse, uma vez que a satisfação da pretensão do autor, de forma irreversível, esgota a necessidade de novos atos processuais. Nos casos analisados, $58,3 \%$ dos processos apresentaram sentença, e não podemos deixar de considerar que o Centro Gaspar Garcia de Direitos Humanos adotou como estratégia pedir a prolação da sentença após o cumprimento do mandado de reintegração de posse a fim de evitar tumultos processuais.

Apesar de $100 \%$ das peças de defesa apresentadas pelo Centro Gaspar Garcia trazerem argumentos levantando a questão do direito à moradia, nenhuma das sentenças proferidas mencionou dispositivos legais relacionados a este direito inerente à dignidade humana. Ainda que o entendimento predominante de que quaisquer pleitos relativos ao direito à moradia devam ser feitos em face do Poder Executivo, percebemos que o diálogo entre o Poder Judiciário e demais órgãos do Poder Público tem sido pouco incidente nas ações de reintegração de posse, o que pode indicar que os magistrados não considerem as ações de reintegração de posse como uma via adequada para a consideração do direito à moradia dos réus. No entanto, conforme vimos até o momento, percebe-se que os conflitos que perpassam as ações de reintegração de posse são bastante complexos, não se tratando apenas de uma questão de justiça comutativa, em que o réu suprime injustamente o autor de seus direitos. Sendo assim, evidencia-se que o Poder Judiciário não reconhece os conflitos fundiários urbanos como causa das demandas ajuizadas. Por isso, questiona-se: se não como pacificador do conflito, qual o papel exercido pelo Poder Judiciário nos conflitos fundiários urbanos?

\section{CONCLUSÃO}

Ao longo do trabalho, pudemos perceber uma série de questões na aplicação do procedimento de reintegração de posse que levam a um tratamento do conflito sob uma perspectiva meramente individual, que descola o conflito do contexto social em que ele se encontra. Por consequência, a resolução do conflito não passa pelo reconhecimento da violação de direitos sociais, nem, consequentemente, da problemática 
distribuição de recursos e direitos que tem sido promovida por órgãos do Executivo e do Legislativo.

A maneira com que o Poder Judiciário tem enfrentado os conflitos envolvidos nas ações de reintegração de posse tem potencial de retroalimentá-los, ou seja, um processo de reintegração de posse que é resolvido de modo a não considerar a violação do direito à moradia dos réus proporciona sua retirada do imóvel ocupado de maneira inconsequente, expondo os ocupantes à necessidade de realizar nova ocupação para escapar da iminente situação de rua, o que farão de maneira dispersa, disseminada. Além disso, como o Poder Judiciário também não se preocupa em incentivar os proprietários e possuidores a fazer com que seus imóveis cumpram sua função social, acaba permitindo que sejam realizadas estratégias de especulação imobiliária que aumentam o déficit de moradia. Desse modo, a forma como o Poder Judiciário tem resolvido os conflitos instaurados nas ações de reintegração de posse promove a manutenção do cenário em que pessoas precisam de moradia e preserva a existência de imóveis vazios, passíveis de serem irregularmente ocupados. Tal deficiência do Judiciário, em parte, tem raízes em uma cultura jurídica conservadora, avessa e despreparada para o tratamento dos conflitos sob a visão da justiça distributiva. ${ }^{23}$

Verificamos ainda que os grupos que utilizam ocupações irregulares como forma de acesso à moradia sofrem uma crise de reconhecimento pelo Poder Judiciário no procedimento aplicado às ações de reintegração de posse, que não reconhece a existência do direito à moradia e demais direitos humanos violados, com vocação para desconfirmar os valores sociais envolvidos em tais conflitos. Se por um lado os grupos vulneráveis atingidos pelo déficit habitacional não são efetivamente reconhecidos na esfera política, uma vez que não conseguem acionar os Poderes Legislativo e Executivo de maneira eficaz para a aquisição de moradia em tempo hábil; por outro, o Poder Judiciário negligencia tais grupos quando sequer consegue decifrar seus interesses na resolução do conflito, o que se traduz em um problema de acesso à justiça das vítimas do déficit de moradia.

É importante destacar que não consideramos que a ineficiência do procedimento de reintegração seja uma forma legítima de acesso à moradia. No entanto, entendemos que a resolução do conflito deva ser realizada de modo que, na hipótese de satisfação da pretensão do autor, os réus não sofram com o agravamento de sua situação de vulnerabilidade econômica e social, colocados em situação de rua mediante a violação de direitos humanos. Sendo assim, considera-se que a abordagem da questão dos conflitos fundiários urbanos é condição necessária para o equacionamento do conflito, exigindo dos juízes uma postura mais cautelosa, que não considere que o simples desalojamento dos ocupantes seja uma resolução aceitável do conflito.

\section{REFERÊNCIAS}

BEDAQUE, José Roberto dos Santos. Tutela cautelar e tutela antecipada: tutelas sumárias e de urgência (tentativa de sistematização). 5. ed. São Paulo: Malheiros, 2009.

BRASIL. Ministério das Cidades. Resolução Recomendada $n^{\circ} 87$, de 8 de dezembro de 2009. Recomenda ao Ministério das Cidades instituir a Política Nacional de Prevenção e Mediação de Conflitos Fundiários Urbanos. Diário da União, Brasília, 25 maio 2010.

CENTRO GASPAR GARCIA DE DIREITOS HUMANOS. Quem somos. Disponível em: $<$ http://www.gaspargarcia.org.br/quem-somos $>$. Acesso em: 12 jan. 2016.

CENTRO GASPAR GARCIA DE DIREITOS HUMANOS. Programa moradia digna. Disponível em: <http://www.gaspargarcia.org.br/projeto/programa-moradia-digna $>$. Acesso em: 12

${ }^{23}$ SANTOS, Boaventura de Sousa: MARQUES, Maria Manuel Leitão; PEDROSO, João. Os tribunais nas sociedades contemporâneas. Coimbra: Centro de Estudos Sociais, 1995. p. 33. 
jan. 2016.

COSTA, Susana Henriques da; FRANCISCO, João Eberhardt. Uma hipótese de "defendant class action" no CPC. 2015 (no prelo).

DIDIER JUNIOR, Fredie. A função social da propriedade e a tutela processual da posse. Revista de Processo. São Paulo, RT, vol. 33, n. 161, p. 9-20, 2008.

DINAMARCO, Cândido Rangel. Instituições do direito processual civil. 6. ed. São Paulo: Malheiros, 2009. v. 1.

FUX, Luiz. Tutela de segurança e tutela de evidência. São Paulo: Saraiva, 1996.

GIDI, Antonio. A representação adequada nas ações coletivas brasileiras: uma proposta. Revista de Processo. São Paulo, RT, n. 108, p. 61-70, 2002.

MAIA, Diogo Campos Medina. Fundamentos da ação coletiva passiva. 2006. 220f. Dissertação (Mestrado em Direito Processual)-Universidade do Estado do Rio de Janeiro, Rio de Janeiro, RJ, 2006.

RIO DE JANEIRO. Tribunal de Justiça. Apelação n. 0002462-61.2013.8.19.0068. Décima Segunda Câmara Cível. Relator Des. Cherubin Helcias Schwartz Junior. Apelante:

Marisa Marrrochi Imperial Gonzalez e outro. Apelado: Réu incerto e desconhecido. Rio de Janeiro, RJ, 18 de setembro de 2014, p. 1. Disponível em: <http://www4.tjrj.jus.br/ejud/ConsultaProcesso.aspx? $\mathrm{N}=201400161897>$. Acesso em: 6 jan. 2016.

RIO GRANDE DO SUL. Tribunal de Justiça. Apelação Cível n. 70061600391. Apelante: Sucessão de Nery Estevan da Fonseca de Campos. Apelado: Ignorado. Relator Des. Marco Antonio Angelo. Porto Alegre, RS, 3 de março de 2015, p. 1. Disponível em: <http://www1.tjrs.jus.br/ site_php/consulta/download/exibe_documento_att.php? $\mathrm{ano}=2015 \&$ codigo $=226781>$. Acesso em: 6 jan. 2016.
SANTOS, Boaventura de Sousa; MARQUES, Maria Manuel Leitão; PEDROSO, João. Os tribunais nas sociedades contemporâneas. Coimbra: Centro de Estudos Sociais, 1995.

SILVA, Luiz Fernando Martins da. Amicus curiae, direito e ação afirmativa. Revista Jurídica. Brasília, Editor, v. 7, n. 76, dez. 2005/jan. 2006.

VIANA, Flavia Batista. Os fundamentos da ação coletiva passiva no ordenamento jurídico brasileiro. 2009. 342f. (Mestrado em Direito)-Pontifícia Universidade Católica de São Paulo. São Paulo, SP, 2009. 


\section{A JUDICIALIZAÇÃO E A CRISE DE AUTORIDADE NAS DEMANDAS QUE VERSAM SOBRE O ABORTO PREVENTIVO NO TRIBUNAL DE JUSTIÇA DO RIO GRANDE DO SUL ${ }^{\mathrm{i}}$}

Paula Deconto ${ }^{\text {ii }}$

Sumário: 1 Introdução. 2 A perda da autoridade e a justiça. 2.1 O que não é autoridade. 2.2 Autoridade, religião e tradição. 2.3 A origem do conceito de autoridade e seu parâmetro teórico. 2.4 A noção de autoridade em Weber. 2.5 Comparação entre o ato médico e o ato judiciário. 3 Conclusão. Referências.

\section{Resumo}

A judicialização das demandas sociais e políticas acontece nas sociedades democráticas ocidentais a partir do segundo pós-guerra. Tal fenômeno encontra-se estampado nas causas submetidas ao julgamento dos desembargadores do Tribunal de Justiça do Estado do Rio Grande do Sul, que versam sobre o aborto preventivo. Os juízes, em face da perda de autoridade das magistraturas sociais, cumprem o papel de últimos guardiões da democracia em nossas sociedades contemporâneas. Neste artigo, explana-se de que forma

\footnotetext{
${ }^{1}$ Artigo apresentado no Congresso “A Sociologia do Direito em Movimento: Perspectivas da América Latina”, realizado na UNILASALLE, no período de 5 a 8 de maio de 2015 .

${ }^{11}$ Graduação em Direito pela Universidade de Caxias do Sul (1991). Especialização em Direito Material e Processual do Trabalho pelo Instituto de Desenvolvimento Cultural (IDC). Especialização em Educação a Distância pela PUC/RS. Mestrado em Sociologia pela Universidade Federal do Rio Grande do Sul (UFRGS). Integrante do Projeto de Pesquisa CNPQ-UFRGS, intitulado Magistratura, Sociedade e Política, desde o ano de 2013, com foco na área da Sociologia Jurídica. Experiência nas áreas de direito constitucional e educação corporativa, com ênfase em EAD. Atualmente, atua como técnica judiciária da Justiça Federal. E-mail: pauladeconto@terra.com.br.
} 
os desembargadores gaúchos, enquanto atores sociais, interpretam este papel e se, eventualmente, sentem algum desconforto em tomar tais decisões. Para tanto, utilizamos como método de pesquisa a análise documental e a análise de conteúdo, buscando um exame mais qualitativo que quantitativo das decisões proferidas pelos referidos desembargadores.

Palavras-chave: Judicialização. Crise de autoridade. Aborto preventivo

\section{INTRODUÇÃO}

$\mathrm{E}$ ste estudo pretende problematizar o fenômeno da judicialização no âmbito do Tribunal de Justiça do Estado do Rio Grande do Sul, a partir de demandas que versam sobre o aborto preventivo. Parte-se do conceito de "jurisdicionalização dos conflitos sociais", como processo que se manifesta quando atores sociais, reconhecendo-se como sujeitos de direitos, "tomam a decisão de submeter a definição de suas demandas ao procedimento dos tribunais, ou de um terceiro (proveniente do âmbito administrativo ou ainda da esfera privada) que aja seguindo formas adjudicatórias"'. A jurisdicionalização que aparece no contexto das sociedades ocidentais a partir do segundo pós-guerra tem como característica, ainda, a submissão de demandas aos tribunais, ou a terceiros, quanto a conflitos que, nas sociedades tradicionais, eram solucionados pelas magistraturas sociais. É com o advento da crise de autoridade em nossas sociedades, portanto, que muitos desses conflitos são direcionados ao Poder Judiciário.

O direito brasileiro ${ }^{2}$ prevê que "quando a lei for omissa, o juiz decidirá o caso de acordo com a analogia, os costumes e os princípios gerais do direito", além de ressaltar que "na aplicação da lei, o juiz atenderá aos fins sociais a que ela se dirige e às exigências do bem comum". Fica claro, na norma legal referida, o tênue liame que separa os fundamentos jurídicos daqueles sociológicos quando o magistrado, ao decidir, soluciona o conflito entre as partes no caso concreto, principalmente quando se depara com a omissão da lei, prestando, assim, a função jurisdicional que lhe é própria.

O que se objetiva, aqui, é esclarecer as razões que levam os juízes a tomar determinado tipo de decisão nos casos de aborto preventivo, quando chamados a agir como novos "magistrados sociais" ${ }^{3}$, com vistas a propiciar uma reflexão mais abrangente sobre o papel desempenhado pelo

${ }^{1}$ ROJO, Raúl Enrique. Jurisdição e civismo: a criação de instâncias para dirimir conflitos sociais no Brasil e no Quebec. In: (Org.). Sociedade e direito no Quebec e no Brasil. Porto Alegre: PPGDir/UFRGS, 2003. p. 24.

${ }^{2}$ Especificamente, no art. 4 da Lei de Introdução ao Código Civil: Decreto-Lei n. 4.657, de 4 de setembro de 1942.

${ }^{3}$ Entende-se como "magistratura social" a figura de autoridade a quem se demanda a solução de um conflito, para que, na qualidade de terceiro, diga o que é justo e pronuncie o direito (podendo, inclusive, ser privada). 
juiz na sociedade contemporânea, ao decidir sobre questões do corpo, que tradicionalmente eram encaminhadas a figuras de autoridade hoje em crise.

Também se parte do pressuposto de que os juízes assumem com frequência o papel de última figura de autoridade legítima em nossas democracias, e que o Direito, nesses casos, converte-se na última moral compartilhada pelos cidadãos de democracias secularizadas, como a nossa.

Quanto aos desembargadores do Tribunal de Justiça gaúcho como um todo, podemos dizer que: do total de 112 desembargadores ativos, 83 são homens e apenas 29 são mulheres; 67 nasceram no interior do Estado, 42 na Capital, e três nasceram em outros estados da federação; 64 se formaram em universidades públicas e 48 em universidades particulares; a idade dos desembargadores se situa entre 40 e 60 anos; todos iniciaram a sua carreira no interior do Estado e depois foram promovidos à Capital; 44 ingressaram diretamente na carreira de juiz de direito, 36 foram, inicialmente, pretores, 19 são representantes do quinto constitucional (nove da OAB e dez do Ministério Público), e três foram defensores públicos.

Utilizamos como método de pesquisa a análise documental, a partir de acórdãos constantes do banco de dados virtual do Tribunal de Justiça gaúcho, e a análise de conteúdo, mediante a realização de entrevistas semiestruturadas, com questões abertas, com o objetivo de realizar uma análise mais qualitativa que quantitativa das referidas decisões. Comparou-se o conteúdo dos acórdãos com o das entrevistas, a fim de identificar o fenômeno da jurisdicionalização no contexto especificado.

Dos cem acórdãos disponíveis no banco de dados do Tribunal de Justiça gaúcho sobre o tema "aborto", selecionaram-se para análise cinquenta deles (decisões proferidas no período de 2001 a 2012), que tratavam, efetivamente, do aborto preventivo e que também não versavam apenas sobre questões de competência do juízo. Estas decisões foram proferidas por aproximada- mente vinte e sete desembargadores, três deles já se encontram aposentados. As entrevistas foram efetuadas com um terço desta amostra (oito desembargadores), preferencialmente com os relatores dos acórdãos analisados (cinco dos oito entrevistados atuaram como relatores).

No que tange ao método, ao longo de todo o texto, procuramos facilitar o diálogo da teoria com a empiria, de forma que se fizessem escutar polifonicamente as vozes dos autores que têm fornecido as categorias sociológicas a partir das quais tratamos nosso material empírico, com as vozes dos nossos entrevistados e o resultado de seu labor jurisdicional. A fim de preservar o anonimato dos entrevistados, utilizamos nomes fictícios em língua inglesa para designar os desembargadores respectivos e dificultar a coincidência (mesmo por acaso) com pessoas reais.

A relevância social desta pesquisa é reforçada pelo espaço que a Bioética tem conquistado no mundo contemporâneo e pela valorização do direito à vida digna e do direito à saúde, consagrados na Constituição Federal de 1988. Por sua vez, o avanço tecnológico na área da Medicina tem permitido a realização de diagnósticos cada vez mais detalhados sobre a saúde da gestante e do nascituro, colocando em foco o tema do aborto preventivo.

Antoine Garapon tem abordado a questão acima explanada com a maestria de um bom sociólogo e a experiência que lhe oferece a sua prática de magistrado na sociedade atual. Discorrendo sobre o sistema judiciário francês, o qual é oriundo da família romano-germânica assim como o brasileiro ${ }^{4}$, Garapon comenta que esta expectativa da sociedade em relação ao juiz para decidir tais matérias de ordem simbólica, esperando uma solução quase que "milagrosa", decorre da origem latina de nossa cultura. Ao invés de buscar dentre várias soluções plausíveis a mais aplicável ao caso concreto - como ocorre nos países da Common Law -, espera-se que o "juiz-salvador" traga a solução pronta, e milagrosa, que faria cessar o desconforto do conflito instalado. ${ }^{5}$

${ }^{4}$ Embora na opinião de Luiz Wernneck Vianna (1997) tenhamos, hoje, um sistema híbrido em nosso país (Corpo e alma da magistratura brasileira. 3. ed. Rio de Janeiro: Revan, 1997).

${ }_{5}^{5}$ GARAPON, Antoine. O juiz e a democracia: o guardião de promessas. 2. ed. Rio de Janeiro: Revan, 2001. p. 74. 
Abordaremos, neste estudo, a perda da autoridade relacionada ao novo papel atribuído aos juízes, iniciando com o conceito desenvolvido pela filósofa Hannah Arendt, a partir do estudo dos filósofos gregos e da experiência romana. Em seguida, passaremos a uma breve análise da autoridade em Weber, tendo em vista que, para estudar a perda de autoridade em nossas sociedades contemporâneas, como propõe Arendt, é preciso compreender de que forma ela está estruturada. Pensa-se que a noção de burocracia trazida por Weber é fundamental para delinear os contornos da autoridade e o seu declínio na modernidade tardia, que ele não chegou a conhecer. Também será efetuada, neste trabalho, uma comparação entre a decisão médica e a decisão judicial, conforme proposto por um autor de nossos dias, Paul Ricoeur, que dialoga com as ideias de Arendt, Garapon e Weber.

\section{A PERDA DA AUTORIDADE E A JUSTIÇA}

Passaremos a discorrer sobre a perda da autoridade nas sociedades democráticas ocidentais contemporâneas, tendo em vista que ela é tida como uma das causas da jurisdicionalização das demandas sociais e políticas.

Não podemos esquecer que o magistrado exerce uma função política sem ter sido eleito pelo voto da maioria da população e controla a legalidade e a legitimidade dos atos dos demais Poderes do Estado. Há quem defenda um grande controle da atividade jurisdicional, enquanto outros pregam a independência dos juízes como fundamental à concepção de democracia. Sem querer aprofundar os discursos de Guarnieri ${ }^{6} \mathrm{e}$ demais autores sobre o assunto, Garapon afirma que, para muitos homens políticos (e não poucos juízes) não é concebível "nenhuma acomodação entre a sacralização do ofício do juiz e sua submissão ao poder executivo" 7 .

Nas sociedades dessacralizadas da atualidade, nas quais os ritos foram abolidos, a justiça recebe demandas anteriormente encaminhadas às magistraturas sociais: autoridades religiosas, mé- dicos de família, chefe da família, entre outras. Um grande desafio se impõe ao julgador de hoje: ser destinatário de demandas motivadas pela ausência de outros referenciais. Nas demandas que versam sobre o aborto preventivo, encaminhadas aos desembargadores do Tribunal de Justiça gaúcho, nota-se que a família ou o próprio médico submete ao juiz a decisão final sobre a vida ou a morte do feto, cujo julgamento, nas sociedades tradicionais, era submetido ao sacerdote ou ao médico da família. $\mathrm{O}$ aspecto religioso de tal decisão, aliado ao conhecimento médico, não pode ser negado, apesar de as demandas acontecerem no contexto contemporâneo. Como se sentirá o magistrado, ao decidir tais demandas? A academia o preparou para tanto? Estará isento de suas convicções filosóficas, religiosas, políticas, ao proferir tal decisão?

\subsection{O que não é autoridade}

A filósofa Hannah Arendt ao abordar com maestria a evolução do conceito de autoridade, afirmando que a autoridade que perdemos no mundo moderno não é a "autoridade em geral", mas aquela autoridade que vigorou no mundo ocidental durante um longo período de tempo, propõe o estudo do conceito partindo-se da delineação do que "não é" autoridade. ${ }^{8}$ Para a autora, uma das fontes dos aspectos de nosso conceito de autoridade é de origem platônica. Segundo ela, quando Platão tentou introduzir a autoridade nos assuntos políticos da polis, buscava uma alternativa diferente da persuasão (utilizada nos assuntos domésticos) e da força (utilizada nos assuntos estrangeiros).

Interessante trazer, aqui, a diferenciação entre obediência hierárquica (a qual sempre é pressuposta na autoridade) e violência ou utilização de meios de coerção, pois "onde a força é usada, a autoridade fracassou" . Tampouco se deve confundir autoridade com persuasão, pois esta última pressupõe uma relação de igualdade. A relação de autoridade, portanto, assenta-se na hierarquia, cujo direito e legitimidade são reco-

${ }^{6}$ GUARNIERI, Carlo. Magistratura e politica in Itália: pesi senza contrappesi. Bolonha: Società Editrice il Mulino, 1993.

${ }^{7}$ GUARNIERI, Carlo. Magistratura e politica in Itália: pesi senza contrappesi. Bolonha: Società Editrice il Mulino, 1993.

${ }^{8}$ GARAPON, Antoine. O juiz e a democracia: o guardião de promessas, p. 170.

${ }^{9}$ ARENDT, Hannah. Entre o passado e o futuro. 6. ed. São Paulo: Perspectiva, 2009. p.129. 
nhecidos por aquele que manda e por quem o obedece, ambos com um lugar estável predeterminado.

Cabe ressaltar, nesse sentido, que a figura da autoridade judicial tem um papel definido em nossas sociedades, cujo cargo, uma vez provido mediante concurso público, dá-lhe legitimidade para decidir sobre as questões que o Estado democrático de direito coloca à Justiça. A obediência às ordens judiciais, por outro lado, é garantida em última instância pelo poder de polícia do Estado, que apenas é utilizado nos casos em que a autoridade da decisão não é reconhecida espontaneamente pelos seus destinatários.

\subsection{Autoridade, religião e tradição}

Desde uma perspectiva histórica, a perda da autoridade é a fase final de um processo de séculos, antecedida pela perda da religião e da tradição: a autoridade jurisdicional foi a que se mostrou mais estável com a "dúvida geral" da época moderna que invadiu também o domínio político, de forma que a perda da tradição e da religião "se tornaram acontecimentos políticos de primeira ordem" 10 .

Também é interessante trazer à tona, quanto ao peso da religião e da autoridade, um caso concreto no qual interveio o desembargador Henry. Nesse caso, uma moradora do interior do estado gaúcho solicitava aborto de feto com má formação cerebral (diferente da anencefalia), alegando que viveria por pouco tempo. A decisão do juiz de primeira instância foi de procedência do pedido, autorizando o aborto preventivo. Entretanto, foi impetrado habeas corpus pela Cúria Metropolitana, a fim de defender a vida do nascituro. Este recurso foi impetrado tendo em vista reportagem em jornal da Capital, na qual aparecia o caso em questão. O desembargador entrevistado disse que leu, logo após impetrado o habeas corpus, reportagem no mesmo jornal, afirmando que "a mãe havia desistido de efetuar o aborto, pese a autorização judicial". No entender do desembargador, "a Igreja a convenceu". Este caso, em particular, mostra-se bastante interessante para ilustrar a relação entre a autoridade social da Igreja e a da própria mídia (antes referida por Garapon), contrapondo-se à autoridade judiciária. A decisão de primeiro grau, proferida pelo juiz singular, já havia sido tomada e autorizava o aborto. Entretanto, em face da atuação da mídia e da Igreja, ela se tornou sem efeito social algum: a mãe desistiu do pedido judicial e o recurso da Mitra Diocesana nem chegou a ser julgado pelo órgão colegiado de juízes (Tribunal de Justiça do Estado do Rio Grande do Sul).

Pensa-se, assim, que talvez não haja propriamente uma perda de autoridade, como refere Arendt, mas uma crise. Talvez ainda persistam grupos sociais com autoridade legitimada por seus integrantes, apesar de existir a crise da autoridade tradicional como um todo, conforme mencionado pela autora. Não se pode esquecer, entretanto, neste caso específico, o papel fundamental da mídia, que movimentou a autoridade da Igreja.

\subsection{A origem do conceito de autoridade e} seu parâmetro teórico

Com amparo em Arendt, podemos dizer que autoridade, como fator decisivo nas comunidades humanas, não existiu sempre e não se encontra, necessariamente, em todos os organismos políticos. A palavra e o conceito são de origem romana, não fazendo parte da língua nem da experiência política da história grega. Porém, a filosofia política de Platão e Aristóteles é, com certeza, o parâmetro teórico de análise necessária do conceito referido ${ }^{11}$ e duas são as razões para tal ocorrer: (i) os dois filósofos tentaram introduzir algo semelhante à autoridade na vida pública da polis (que não fosse o governo tirânico, que privava os cidadãos da faculdade política) e (ii) as ideias de ambos dominaram todo o pensamento subsequente, inclusive o dos romanos. Ressaltamos que as ideias de Platão e Aristóteles partiam de duas dimensões de governo vigentes, à época, na polis: uma público-política e outra da esfera privada (administração doméstica).

É importante lembrar, com Arendt, que Pla-

\footnotetext{
${ }^{10}$ ARENDT, Hannah. Entre o passado e o futuro, p. 130

${ }^{11}$ ARENDT, Hannah. Entre o passado e o futuro, p. 148
} 
tão sentia a sua vida ameaçada após o julgamento e a morte de Sócrates, e talvez por isto tenha proposto um governo de filósofos. Também, provavelmente em decorrência de tal momento histórico, Platão começou a descrer da persuasão para guiar os homens, já que o resultado da coerção pela razão é o de que somente a minoria se sujeita a ela. ${ }^{12}$ Partindo deste raciocínio é que o filósofo busca outro meio de coerção, que não a violência, para sustentar a vida política grega. Comungamos com a ideia de Arendt quando afirma que na alegoria da caverna o problema da coerção encontra uma solução nova, mas que está distante da maioria dos gregos, pois apenas uma minoria estaria à altura da verdade filosófica.

Apontamos, ainda, a solução encontrada por Platão, nas Leis, ao indicar estas como substitutas da persuasão como meio coercitivo, as quais deveriam ser explicadas aos cidadãos, conforme referido por Arendt. Na busca de um princípio legítimo de coerção, Platão se baseou nos modelos de seu tempo: a relação entre o pastor e suas ovelhas, entre o médico e o paciente, e outros. A confiança, nesses casos, ou vem do conhecimento especializado, ou da relação de implicação de um sujeito ao outro por pertencerem a categorias completamente diferentes. Todos os modelos foram extraídos da esfera privada da vida. A plausibilidade desses modelos residia na natural desigualdade entre o governante e o governado, pois somente na flagrante desigualdade o governo poderia ser exercido sem a tomada do poder e a posse dos meios de violência. ${ }^{13}$ Portanto, nessas relações, o elemento coercitivo repousava na relação mesma e era anterior à efetiva emissão de ordens: o paciente tornava-se sujeito à autoridade do médico quando se sentia doente.

O poder coercitivo demonstrado na alegoria da caverna, entretanto, não advém da desigualdade, conforme refere Arendt, mas das ideias que são percebidas apenas pelo rei-filósofo, e que podem ser utilizadas como normas de comportamento humano (o céu das ideias está acima da caverna da existência humana, e serve como padrão).

Aristóteles, por seu turno, em seu primeiro Diálogo, compara a lei o mais próximo possível da ideia de prumo, o compasso e a régua, os mais notáveis entre os instrumentos. Tal raciocínio seguiu a filosofia de Platão, na qual as ideias são apresentadas como guias das artes e ofícios, que as reproduzem na realidade por meio da imitação, ao mesmo tempo em que elas se tornam padrões constantes e absolutos para o comportamento e o juízo moral e político. ${ }^{14}$ Concluímos, assim, que a analogia às artes e aos ofícios, na filosofia de Platão, remete à noção, na esfera política, de que o estadista é o especialista, o perito competente para lidar com os assuntos humanos.

Ao delinear os contornos da ideia de autoridade nas sociedades ocidentais, trazemos à tona conceitos essenciais à compreensão da autoridade no mundo contemporâneo. Assinalamos a importância da noção de hierarquia como elemento caracterizador da autoridade (algo que está “acima”), bem como a relevância do papel do especialista, definições estas previstas por Weber ${ }^{15}$ na organização burocrática do Estado moderno.

\subsection{A noção de autoridade em Weber}

A noção de autoridade em Weber parte da ideia de hierarquia - termo utilizado por Arendt em sua argumentação - presente em um Estado racional, que valoriza os seus especialistas. A autoridade, para esse autor, fundamenta-se em razões internas e externas que explicam a dominação. Mas há outro elemento fundamental em sua teoria para compreender o Estado racional moderno: a sua burocratização crescente. E, como consequência desta, Weber já vislumbrava profeticamente, à época em que escreveu a obra então referida ${ }^{16}$, uma crise de autoridade, que poderia

\footnotetext{
${ }^{12}$ No Diálogo "Protágoras", segundo ressalta o historiador Werner Jaeger, Sócrates duvida da força da palavra utilizada pelos sofistas e pelos retóricos, como meio de ensinar a virtude política (Paideia: a formação do homem grego. 4. ed. São Paulo: Martins Fontes, 2003. p. 650).

${ }^{13}$ ARENDT, Hannah. Entre o passado e o futuro, p. 148.

${ }^{14}$ ARENDT, Hannah. Entre o passado e o futuro, p. 150.

${ }^{15}$ WEBER, Max. Economia e sociedade: fundamentos da sociologia compreensiva. 4. ed. Trad. de Regis Barbosa e Karen Elsade Barbosa; revisão técnica de Gabriel Cohn. Brasília: Ed. da Unb: São Paulo: Imprensa Oficial do Estado de São Paulo, 2009 (reimpressão). v. 2.

${ }^{16}$ Durante os anos de 1911 a 1913, conforme o prólogo à quarta edição alemã.
} 
dar lugar ao surgimento de um pretendido líder carismático "salvador".

Acreditamos ser importante ressaltar a crise de autoridade relatada pelo desembargador Henry, que não é aquela decorrente do âmbito social, mas sim uma crise de autoridade dentro do próprio Poder Judiciário, decorrente do sistema recursal implementado e das decisões contraditórias proferidas. Pela fala do desembargador, o sistema burocrático processual teria engessado a autoridade do magistrado singular e dos tribunais estaduais. Vale transcrever a sua afirmação:

Como o juiz é desdito pelos tribunais superiores, houve uma perda da autoridade das decisões inferiores. Às vezes me pergunto: para que estou aqui? Pois uma simples liminar de um tribunal superior derruba uma decisão muito bem fundamentada da instância inferior.

O processo de legitimação da autoridade é visto como um problema atual, pois paira hoje uma dúvida sobre o que é autoridade, devido a uma crise de legitimação. Concordamos com Ricoeur quando aponta que há um descrédito das autoridades, instituições e pessoas que se encontram investidas de um poder, de fato, de impor obediência. ${ }^{17}$ Tal ideia aparece reforçada pela percepção dos desembargadores do Tribunal de Justiça gaúcho, por exemplo, quando um dos entrevistados referiu que há um descrédito nas autoridades devido à corrupção de algumas delas (desembargador Adam).

Pensamos, como o faz Ricoeur, que o processo sobre o qual estamos tratando não seja, talvez, a "perda" da autoridade no mundo moderno, como pretendia Hannah Arendt ${ }^{18}$, mas sim de "transformação" da autoridade, pois são ainda mantidos alguns liames com o passado. É coerente com tal argumento a constatação efetuada pelo desembargador Adam, quando trabalhou em Varas interioranas do Estado do Rio Grande do Sul como magistrado, de que o médico do município detinha uma verdadeira autoridade em seus pareceres e decisões, pois estes não eram questionados judicialmente; ao contrário do que percebeu quando chegou à capital. Este fato nos remete à teoria weberiana segundo a qual nos grandes centros urbanos acontece um enfraquecimento das relações sociais, pois o indivíduo se dilui no anonimato da multidão. Talvez, como consequência disto, a crise de autoridade se demonstre com maior relevância neste contexto. Seguindo esta linha de raciocínio, poderíamos dizer que ocorreria, na atualidade, uma transformação da autoridade, que se apresenta de forma diferenciada em realidades mais ou menos urbanizadas. É nos grandes centros urbanos, portanto, que o juiz figuraria como o último guardião dos princípios democráticos, substituindo os magistrados sociais que nas sociedades tradicionais davam conta de determinadas demandas cidadãs.

\subsection{Comparação entre o ato médico e o ato} judiciário

Pensamos que contribuirá muito para o nosso estudo efetuar uma comparação entre o ato médico e o ato judiciário, com base nas ideias trazidas por Ricoeur, tendo em vista que a decisão judicial sobre o aborto preventivo tomada pelos desembargadores do Tribunal de Justiça gaúcho, na quase totalidade das vezes, baseia-se em pareceres médicos. Muitas dessas demandas se relacionam com a questão médica e o diagnóstico, seja no caso de risco de morte da mãe, ou de fetos com deformidades físicas, entre demais aspectos.

Apontamos, com Ricoeur, que nos dois tipos de decisão (médica e judicial) há uma primeira semelhança: passa-se de um saber de normas e conhecimentos teóricos para uma decisão concreta quanto a uma situação dada. Ou seja, submete-se um fato único, particular, de uma pessoa, à regra geral, mediante um julgamento: o juízo médico ou a sentença que pronuncia uma palavra de justiça.

No cerne da ética médica consta um "pacto de tratamento" entre o médico e o paciente ${ }^{19}$ baseado na confiança. A prescrição médica, ao final

\footnotetext{
${ }^{17}$ RICOEUR, Paul. O justo. São Paulo: Martins Fontes, 2008. v. 2. p. 104.

${ }^{18}$ RICOEUR, Paul. O justo, p. 105.

${ }^{19}$ RICOEUR, Paul. O justo, p. 240
} 
deste processo, tem o seu equivalente na sentença judicial. O desenvolvimento da medicina preditiva aumentou a pressão do aparato científico sobre o terapêutico e a ciência avança mais rapidamente que o diagnóstico médico efetuado "na cabeceira do doente" 20 . Alertamos que este é o caso do aborto preventivo por motivo de risco de morte da mãe ou deformidades no feto, que são detectados com o uso da tecnologia avançada, antes não disponíveis em nossas sociedades. Portanto, a nosso ver, o médico de família das sociedades tradicionais tinha uma relevância, uma autoridade em seu diagnóstico, que o médico da atualidade talvez tenha perdido, entre outros motivos, em decorrência do avanço tecnológico.

Antes de abordar o ato judiciário, especificamente, cabe referir algumas diferenças entre este e o ato médico, na linha de raciocínio seguida por Ricoeur. Enquanto o ato médico decorre do sofrimento seguido do pedido de tratamento, $o$ ato judiciário se origina do conflito. Além disso, ao final desses processos, as conclusões são opostas: enquanto o pacto de tratamento une na mesma luta médico e paciente, a sentença judicial separa os protagonistas, declarando um como vítima e outro como culpado. As semelhanças entre os dois atos em questão ocorre no entremeio de seus processos, que é o ato de decisão em si: que conduz do nível normativo ao nível concreto de resolução do estado inicial de incerteza.

Prosseguimos, então, nossa análise, lembrando que há uma semelhança entre a prescrição médica (modelo de decisão de uma figura de autoridade tradicional) e a sentença judiciária (modelo de decisão da nova figura de autoridade que, sem deixar de ser um magistrado de direito, aparece por esta mesma razão como o único magistrado socialmente legitimado), para além do processo de formação do juízo: para os aspectos formais presentes no momento em que a decisão é ditada à maneira de um evento, como propõe Ricoeur. Alerta-se para o fato de que a decisão judicial é passível de recurso para tri- bunais superiores, mas, de todo modo, mantém características de irredutibilidade em cada instância em que é pronunciada, até estabelecer-se, definitivamente, no julgamento de último grau. Lembramos, ainda, que o ato médico também pode ser objeto de revisão, seja na alçada médica, seja até em sede judicial, pois, conforme viemos argumentando, a autoridade está em crise, e a autoridade médica faz parte deste contexto. O magistrado, ao decidir sobre o ato médico, é instado a pronunciar-se sobre argumentos que não são da seara jurídica, mas sim da deontologia médica, dos saberes científicos e biológicos, e da saúde pública. Desta forma, a decisão política, de competência da autoridade médica, é transferida ao magistrado, para que este tenha a palavra final, irredutível, capaz de extinguir a dúvida, a incerteza, a falta de autoridade social.

Indagado sobre as decisões judiciais que versam sobre o aborto preventivo do anencéfalo, em decorrência do julgamento recentemente proferido pelo Supremo Tribunal Federal ${ }^{21}$, bem como se as demandas judiciais deste tipo decorrem de uma crise de autoridade do médico, o desembargador Adam afirmou ideia semelhante à mencionada por Ricoeur: "é um problema de educação e lealdade do paciente com o médico". A confiança da relação médico-paciente, portanto, parece ser fundamental para impedir a jurisdicionalização de tais demandas, segundo o magistrado, apesar de referir anteriormente que tal ocorreu, também, por influência do modelo norte-americano. Lembrou que tais demandas estão só em Porto Alegre e não no interior do Estado. Explicou que, no seu entender, é fruto da relação de confiança e imediação com o médico no interior; avisa que na Capital não ocorre, devido ao tamanho da população. Tal constatação prática do desembargador, aliada à sua interpretação do fato, de que a superpopulação diminui a relação de confiança e pessoalidade entre médico e paciente, ocasionando a jurisdicionalização de tais demandas, vem ao encontro da teoria weberiana,

\footnotetext{
${ }^{20}$ RICOEUR, Paul. O justo, p. 242.

${ }^{21}$ O Supremo Tribunal Federal proferiu decisão histórica quanto ao tema no dia 12 de abril de 2012, quando aprovou, por oito votos a favor e dois contra (de Ricardo Lewandowski e Cezar Peluso) o direito de as gestantes interromperem a gravidez nos casos de fetos anencéfalos (malformação do tubo neural). Frisa-se, entretanto, que conforme já referido neste trabalho, um dos desembargadores entrevistados mencionou que tal decisão se aplica apenas aos casos de anencefalia "total".
} 
conforme antes referido. Notamos, entretanto, que o magistrado não se refere à crise de autoridade como fator da jurisdicionalização, mas sim à crise da relação de confiança entre médico e paciente. Todavia, como antes dito, a legitimação da autoridade pressupõe um voto de confiança; talvez estejamos falando do mesmo fato, apenas com outras palavras.

Cabe referir, ainda, que, no entender do desembargador Jeremy, a autoridade social competente para julgar sobre o aborto preventivo deveria ser aquela do profissional da saúde e não a do magistrado social.

A respeito do esclarecimento da decisão judicial pelo juízo médico, propriamente dito, cumpre referir a afirmação do desembargador Henry, quando lembrou que "em nenhum caso julgou de forma contrária à área médica”. Prosseguindo na análise da autoridade médica, o desembargador referiu que, hoje, para ele, o critério definidor do que é morte está na Lei dos Transplantes, ou seja, "quem não tem cérebro nunca vai ter circulação cerebral, e está morto para a lei dos transplantes". Afirmou, assim, que, com base nisto, autoriza o aborto no caso de anencefalia total, pois o corpo só tem movimento reflexo. Afirmou que alguns colegas exigem atestado médico no processo, dizendo que "o aborto é o único meio de salvar a vida da mãe". Entretanto, ele procurou colocar-se no lugar da mulher: "como ela se sente quando as pessoas a parabenizam pela gravidez, perguntam qual será o nome da criança e ela sabe que nascerá um anencéfalo". Portanto, em que pese reconhecer a autoridade médica, o magistrado toma a decisão embasado, também, na liberdade de pensamento e crença da gestante. Não exige, assim, que a decisão última sobre o aborto preventivo conste do atestado médico, mas que apenas ateste o quadro de saúde da gestante quanto ao risco da gravidez.

No entendimento do desembargador John, entretanto, o aborto preventivo "é um assunto médico, e o juiz não tem habilitação para decidi-lo". Pensa que o Poder Executivo poderia ter um departamento social competente para chancelar o aborto e solucionar esses casos. Notamos, aqui, portanto, que para uma parte da magistratura de direito é importante que a tomada de decisão continue a cargo da autoridade social competente, como se dava nas sociedades tradicionais.

\section{CONCLUSÃO}

Podemos concluir, assim, que o entendimento dos desembargadores do Tribunal de Justiça gaúcho quanto à possibilidade de a crise de autoridade ser uma das causas da jurisdicionalização das demandas sociais e políticas, e quanto à autoridade que seria competente para a tomada de decisão nas causas de aborto preventivo (principalmente do anencéfalo), não é unânime. Enquanto alguns confirmam a crise de autoridade como causa da jurisdicionalização, outros afirmam que esta decorre da falta de confiança na relação médico-paciente (utilizando termo de Ricoeur), ou no avanço da tecnologia, ou ainda na dúvida social que paira quanto à aplicação da norma que prevê o crime de aborto. Neste sentido, inclusive, a opinião de alguns deles, quando afirmam que a crise de autoridade acontece, muitas vezes, devido às decisões contraditórias proferidas pelo próprio Poder Judiciário, que geram na cidadania um sentimento de insegurança jurídica, de não ter talvez suas decisões amparadas pela autoridade competente. Na mesma linha de raciocínio, outros desembargadores afirmam que o excesso de recursos aos tribunais superiores, aliado às decisões contraditórias, está na origem de uma crise de autoridade dentro do próprio Poder Judiciário, enfraquecendo o poder decisório do juiz singular, o qual, às vezes, não vê sentido em seu trabalho.

Em outra ordem de ideias, no que tange à autoridade competente para a tomada de decisão sobre o aborto preventivo, enquanto alguns dos desembargadores admitiram a sua competência para tanto, devido ao fato de o aborto ser um crime previsto em lei, outros reforçaram a competência da autoridade médica quanto ao assunto. Para alguns que seguem este entendimento, a autoridade médica é quem deveria decidir tais questões, como especialista na área; para outros, a decisão judicial seria uma homologação do parecer médico.

Sabemos que o trabalho não esgota as possibilidades de abordagem do tema, tendo em vista o seu amplo espectro e as constantes inovações 
sociais que exigem das autoridades judiciárias novas soluções para os casos concretos apresentados.

\section{REFERÊNCIAS}

ARENDT, Hannah. Entre o passado e o futuro. 6. ed. São Paulo: Perspectiva, 2009.

BADINTHER, Elisabeth. Rumo equivocado: o feminismo e alguns destinos. Rio de Janeiro: Civilização Brasileira, 2005.

BADINTHER, Elisabeth. O conflito: a mulher e a mãe. Rio de Janeiro: Record, 2011.

BUTLER, Judith. Cuerpos que importan: sobre los límites materiales y discursivos del sexo. Buenos Aires: Paidós, 2010.

CASTELAIN-MEUNIER, Christine. Os homens diante da mulher e dos filhos. Rio de Janeiro: Summus, 1993.

La paternité. Paris: Presses Universitaires de France, 1997.

CORRÊA, Walter Guilherme Hütten. Estudo sociológico das relações entre a formação de padrões morais e a aplicação da norma legal: o caso do aborto voluntário no Poder Judiciário do Rio Grande do Sul. 2001. Dissertação (Mestrado em Sociologia)-Universidade Federal do Rio Grande do Sul, Porto Alegre, RS, 2001.

GARAPON, Antoine. O juiz e a democracia: o guardião de promessas. 2. ed. Rio de Janeiro: Revan, 2001.

Bem julgar: ensaio sobre o ritual judiciário. Lisboa: Instituto Piaget, 2009.

; SALAS, Denis. La république pénalisé.

Paris: Hachette, 1996.

GUARNIERI, Carlo. Magistratura e politica in Itália: pesi senza contrappesi. Bolonha: Società Editrice il Mulino, 1993.
JAEGER, Werner. Paideia: a formação do homem grego. 4. ed. São Paulo: Martins Fontes, 2003.

KHOSROKHAVAR, Farhad. Les nouvelles formes de mobilisation social. In: TOURAINE, Alain Touraine et al. (Ed.). Le grand refus. Paris: Fayard, 1996. p. 195-246.

LUXEMBURGO, Rosa. La revolución rusa. Madri: Castellote, 1975.

MARTUCCELLI, Danilo. Vies de familie. In: (Org.). Forgé par l'épreuve: l'individu dans la France contemporaine. Paris: Armand Colin, 2006. p. 159-210.

QUIVY, Raymond. Manual de investigação em ciências sociais. 5. ed. Lisboa: Gradiva, 2008.

RICOEUR, Paul. O justo. São Paulo: Martins Fontes, 2008.

ROJO, Raúl Enrique. Jurisdição e civismo: a criação de instâncias para dirimir conflitos sociais no Brasil e no Quebec. In: (Org.). Sociedade e direito no Quebec e no Brasil. Porto Alegre: PPGDir/UFRGS, 2003. p. 21-41.

TOURAINE, Alain. Le retour de l'acteur: essai de sociologie. Paris: Fayard, 1985.

Palavra e sangue: política e sociedade na América Latina. São Paulo/Campinas: Trajetória Cultural/Universidade Estadual de Campinas, 1989.

Pensar outramente. Petrópolis: Vozes, 2009.

. O mundo das mulheres. Petrópolis: Vozes, 2010.

Um novo paradigma. Petrópolis: Vozes, 2011.

; KHOSROKHAVAR, Farhad. A procura de si. Lisboa: Instituto Piaget, 2001. 
VIANNA, Luiz Werneck et al. Corpo e alma da magistratura brasileira. 3. ed. Rio de Janeiro: Revan, 1997.

et al. A judicialização da política e das relações sociais no Brasil. Rio de Janeiro: Revan, 1999.

WEBER, Max. Economia e sociedade: fundamentos da sociologia compreensiva. 4. ed. Trad. de Regis Barbosa e Karen Elsade Barbosa; revisão técnica de Gabriel Cohn. Brasília: Ed. da Unb: São Paulo: Imprensa Oficial do Estado de São Paulo, 2009 (reimpressão). v. 2. 


\title{
DIREITO GLOBAL E RESPONSIVIDADE: UMA ABORDAGEM CRÍTICO-SISTÊMICA DO DIREITO EM FACE DOS NOVOS DESAFIOS DA SOCIEDADE MUNDIAL ${ }^{\mathrm{i}}$
}

\author{
GLOBAL LAW AND RESPONSIVENESS: \\ A CRITICAL-SYSTEMIC APPROACH OF THE \\ LAW FACE THE NEW CHALLENGES OF THE \\ WORLD SOCIETY
}

Douglas Elmauer ${ }^{\mathrm{ii}}$

Sumário: 1 Introdução. 2 Responsividade jurídica: da justiça autossubversiva à crítica imanente do Direito. 3 Direito global e sociedade mundial: diagnósticos, tendências e desafios. 4 Conclusão. Referências.

\begin{abstract}
Resumo
O presente artigo se propõe a dar mais um passo no sentido do desenvolvimento de uma teoria crítica dos sistemas aplicada ao Direito. Visa-se ampliar a teoria sistêmica no sentido de potencializar sua capacidade de diagnosticar os dilemas jurídicos contemporâneos e ao mesmo tempo apontar para o modo de enfrentamento dos desafios existentes numa sociedade mundial paradoxalmente marcada, por um lado, pela ameaça da hipertrofia sistêmica das ordens sociais reificadas e, por outro, pelos processos de constitucionalização que buscam limitar essas ordens.
\end{abstract}

\footnotetext{
${ }^{1}$ Este artigo foi desenvolvido com base em minha Dissertação de Mestrado, defendida na Faculdade de Direito da Universidade de São Paulo (USP) em outubro de 2015. Cf. ELMAUER, Douglas. O direito na teoria crítica dos sistemas: da justiça autossubversiva à crítica imanente do direito. 2015. $316 f$. Dissertação (Mestrado em Direito)-Departamento de Filosofia e Teoria Geral do Direito da Faculdade de Direito da Universidade de São Paulo. São Paulo, SP, 2015. p. 264-281.

${ }^{11}$ Doutorando na Universität Bremen, Alemanha. Bolsista DAAD (Deutsher Akademischer Austauschdienst).
} 
Desse modo, este texto se dividirá em duas partes centrais: a primeira parte trata da explanação da ideia de uma (i) responsividade jurídica obtida por meio da justiça autossubversiva e da crítica imanente do direito como formas de aberturas do sistema jurídico às demandas do ambiente; a segunda parte, debruça-se sobre diagnósticos, tendências e desafios que o (ii) direito global enfrenta na sociedade mundial. O escopo final do artigo se concentra no esforço de construir um direito mais sensível e aberto ao seu próprio ambiente.

Palavras-chave: Teoria crítica dos sistemas. Direito global. Justiça autossubversiva. Sociedade mundial. Responsividade jurídica

\section{Abstract}

This article proposes to take another step towards the development of critical systems theory applied to the law. Seeks to improve the systems theory in order to enhance its capacity to diagnose the contemporary legal dilemmas. At the same time, aiming to face the world society challenges paradoxically marked on the one hand, by the menace of systemic hypertrophy of the reified social orders and on the other, by a constitution processes that seek to limit these orders. Thus, this text will be divided into two main parts: the first part deals with the explanation of the idea of a (i) Legal responsiveness obtained through self-subversive justice and immanent law criticism as forms of the legal system openings to the demands for its environment. The second part, in turn, focuses on diagnostics, trends and challenges that (ii) the global law faces in world society. The final scope of the article focuses on the effort to build a more sensitive and open law to the environment.

Keywords: Critical systems theory. Global Law. Self-subversive justice. World society. Legal responsiveness.

\section{INTRODUÇÃO}

$\mathrm{U}$ ma abordagem crítica da teoria dos sistemas possibilita um estudo mais bem apurado e consequente dos sistemas sociais da sociedade mundial, onde se averigua a hiperexpansividade de racionalidades específicas pertencentes a determinadas ordens sociais. $O$ foco central de uma teoria crítico-sistêmica ${ }^{1}$ é a análise destas ordens sociais as quais se podem denominar "ordens sociais reificadas". Ao desmascarar as discrepâncias e as contradições reais da sociedade mundial, esta teoria crítico-sistêmica permite também trazer à tona a necessidade da regeneração das relações autônomas desta mesma sociedade. Esta demanda por regeneração é especialmente cara ao sistema jurídico quando se analisa a crescente carência de responsividade do direito diante da sociedade mundial, ou seja, de uma justiça ecológica não fetichizada pelo encanto de sua própria racionalidade. A ameaça de um "direito reificado", entendido como manifestação primordial de uma "racionalidade irracional" (Adorno), coloca em xeque (de modo paradoxal) seus próprios logros pela busca infindável e permanentemente variável por justiça. O escopo do presente artigo será precisamente desenvolver e aplicar com maior minúcia este arcabouço conceitual às novas demandas da sociedade mundial para o sistema jurídico.

Diante dos desafios impostos por esta nova realidade, um sistema jurídico mais responsivo e sensível às demandas sociais, capaz de se autotranscender, poderia auxiliar no combate das ordens sociais reificadas (hiperexpansivas) por meio dos processos de constitucionalização dos sistemas da sociedade mundial, hábeis a limitar as dinâmicas reificantes (hipertróficas). É nesses moldes teóricos que a presente argumentação se desenvolverá, com o escopo de utilizar os novos instrumentos oferecidos pela teoria crítica dos sistemas para a análise do sistema jurídico mais responsivo e autolimitado.

\footnotetext{
${ }^{1}$ PHILIPPOPOULOS-MIHALOPOULOS, Andreas. Critical autopoiesis and the materiality of Law. International Journal for Semiotics of Law. Berlin, Springer Science, p. 1-19, 2013; FISCHER-LESCANO, Andreas. Systemtheorie als kritische Gesellschaftstheorie. In: __ ; AMSTUTZ, M. (Hrsg.). Kritische systemtheorie: zur evolution einer normativen theorie. Bielefeld: Transcript Verlag, 2013. p. 13-37. [Versão em português: FISCHER-LESCANO, Andreas. A teoria crítica dos sistemas da Escola de Frankfurt. Revista Novos Estudos. São Paulo, v. 86, p. 163-177, março 2010].
} 


\section{RESPONSIVIDADE JURÍDICA: DA JUSTI- ÇA AUTOSSUBVERSIVA À CRÍTICA IMA- NENTE DO DIREITO}

Com o processo de diferenciação funcional da sociedade, os sistemas sociais não apenas adotaram formas de codificação e de programação próprias, mas também "racionalidades" determinadas, ou como prefere Luhmann, "fórmulas de contingência" específicas. As formas de racionalidades sistêmicas se manifestam, por exemplo, na economia com o problema da "escassez", na política com a questão da "legitimidade", na religião com "Deus", entre outros modos. No sistema jurídico, a "justiça" se coloca como a forma específica de racionalidade (ou fórmula de contingência) do direito.

A justiça dá consistência ao sistema jurídico na busca infindável pelo equilíbrio entre o fechamento operativo (consistência interna) e a abertura cognitiva (adequação social), o que motiva a continuidade das comunicações sistêmicas. ${ }^{2}$ Ao nos referirmos à questão da justiça, devemos esclarecer que se toma como foco a justiça jurídica, a qual não se confunde com a justiça política ou com a justiça moral, por exemplo.

$\mathrm{Na}$ esteira da teoria crítica dos sistemas, a caracterização da justiça jurídica como fórmula de contingência (racionalidade) do sistema jurídico não seria suficiente, antes, ela também seria uma fórmula de transcendência que parte da própria imanência sistêmica. ${ }^{3}$

Para Adorno, o direito é "a manifestação primordial da racionalidade irracional"4, ou seja, de uma racionalidade que pode ser totalitária e expropriante por paradoxalmente promover a injustiça ao mesmo tempo em que faz a justiça.
Sendo assim, ela seria sempre obrigada a se autotranscender com o objetivo de superar esse antagonismo insistente e circular. O direito precisa constantemente recorrer ao seu "arcano interno", a justiça capaz de subverter a si própria e transcender a imanência reificada do sistema jurídico. Todavia, para compreender esses processos sistêmicos é necessário proceder com algumas reconstruções do pensamento adorniano e seguidamente adentrar a ideia de justiça autossubversiva proposta por Teubner.

Adorno criticou insistentemente os conceitos de "consistência" (Strigenz) e de "totalidade" (Totalität) "como ideais burgueses de necessidade e universalidade". ${ }^{5}$ Considerando a totalidade como o não verdadeiro (ou o estado falso), e ao mesmo tempo tomando em consideração a ideia de sistema em seu complexo construto teórico, Adorno procedeu com os primeiros passos para o abandono da tradição do antigo pensamento europeu. Se, por um lado, a teoria dos sistemas se preocupa com as racionalidades autônomas da sociedade, com a diferença básica entre sistema e ambiente e com a coevolução sistêmica, por outro, a teoria adorniana, na linha da "filosofia da nova música" e da "teoria estética", estabelece conceitos que são curiosamente análogos com os da teoria dos sistemas.

"Tanto Adorno como a teoria crítica dos sistemas não concebem o sistema como uma hierarquia estrutural estática”' . Nessa esteira:

A problemática da autonomização foi resumida por Adorno em sua filosofia da música; ele faz a acusação de que a música solipsista, com sua textura rígida, que permite a ela se preservar contra a ubiquidade das operações, tornou-se tão severa que seu elemento trans-

${ }^{2}$ LUHMANN, N. Ausdifferenzierung des rechts: beiträge zur rechtssoziologie und rechtstheorie. Frankfurt: Suhrkamp, 1981. p. 374-418; LUHMANN, N. El derecho de la sociedad. Ciudad de México: Herder, 2005b. p. 275-299 [LUHMANN, N. Das Recht der Gesellschaft. Suhrkamp: Frankfurt am Main, 1993. p. 214-238]. Acerca do tema, ver também NEVES, Marcelo. Transconstitucionalismo. [Tese apresentada ao concurso de provas e títulos para provimento do cargo de professor titular na área de direito constitucional no Departamento de Direito do Estado da Faculdade de Direito da Universidade de São Paulo]. São Paulo, 2009. p 56-58; VILLAS BÔAS FILHO, Orlando. Da ilusão à fórmula de contingência: a justiça em Hans Kelsen e Niklas Luhmann. In: PISSARA, Maria Constança Peres; FABBRINI, Ricardo Nascimento (Coord.). Direito e filosofia: a noção de justiça na história da filosofia. São Paulo: Atlas, 2007. p. 129-150.

${ }^{3}$ TEUBNER, Gunther. Self-subversive justice: contingency or transcendence formula of Law? 2009. Disponível em: <www.uni-frankfurt.de/>. Acesso em: 20 out. 2010. p. 1-22.

4 "Recht ist das Urphänomen irrationaler Rationalität". (ADORNO, T. W. Introdução à sociologia. São Paulo: UNESP, 2007. p. 257 [ADORNO, T. W. Negative dialektik. In: ___ Gesammelte Schriften. Band 6. Frankfurt am Main: Suhrkamp, 1984. p. 304]).

${ }^{5}$ FISCHER-LESCANO, 2013, p. 272010, p. 171. Segundo Adorno: "Stringenz und Totalität, die bürgerlichen Denkideale von Notwendigkeit und Allgemeinheit, umschreiben in der Tat die Formel der Geschichte, aber eben darum schlägt in den festgehaltenen herrschaftlich großen Begriffen die Verfassung der Gesellschaft sich nieder, gegen welche dialektische Kritik und Praxis sich richten" (ADORNO, T. W. Minima moralia: reflexionen aus dem beschädigten Leben. In:__ Gesammelte Schriften. Band 4. Frankfurt am Main: Suhrkamp, 1984. p. 170).

${ }^{6}$ FISCHER-LESCANO, 2013, p. 27 [2010, p. 171] 


\subsection{TEORIA DOS SISTEMAS}

cendente e real - que chegou a dar-lhe o conteúdo que fez a música absoluta verdadeiramente absoluta - é inalcançável.?

Adorno adverte para o fato de que esse fechamento hermético, seja da música ou do sistema, poderia levar a uma espécie de autismo sistêmico capaz de acarretar deficiências, tais como o déficit ou a hipertrofia funcional sistêmica em face do ambiente.

A conclusão de Adorno acerca da arte coincide com o ponto de vista sistêmico do teorema da abertura por meio do fechamento autopoiético, que aqui se torna aplicável para todas as racionalidades sistemicamente diferenciadas, as quais podem apenas existir a partir de uma relação de comensurabilidade com seu ambiente. "Fechamento e abertura simultaneamente: quem está aberto para todas as coisas se torna vazado; ao mesmo tempo, o autismo sistêmico precisa ser evitado"8. "O ponto crucial, segundo argumenta Adorno em sua Teoria Estética, está no fato de a instituição social existir apenas em sua relação com aquilo que ela não é, com seu outro, assim como precisa se manter aberta às influências externas".

Nesse momento teórico, Adorno lança mão do conceito de "fisiognomia" (Physiognomie), a qual diz respeito à relação entre a arte e o seu "exterior" (ambiente). Ao invés de falar na diferença abertura/fechamento, Adorno prefere utilizar a diferença autonomia/heteronomia. Para ele, esse "caráter duplo" (Doppelcharakter) da arte, que na teoria crítica dos sistemas é aplicável a todos os âmbitos sociais sistêmicos, é algo, segundo Adorno:
[...] fisiognomicamente (physiognomisch) decifrável sempre que se ouve ou se contempla a arte exterior, indiferente ao fato de se ela como tal é ou não planificada e, naturalmente, a arte precisa sempre daquele 'do exterior' para ser protegida da fetichização (Fetischisierung) da sua autonomia. ${ }^{10}$

$\mathrm{O}$ excesso de centralidade na dimensão interna do sistema pode levar à fetichização sistêmica, ou seja, ao predomínio de uma imanência reificada que não possui responsividade para com o ambiente. Os âmbitos reificados de racionalidade podem aparecer em todo e qualquer sistema, seja ele a arte, a economia, a política e até mesmo o direito. As noções fetichizadas não são apenas aparências, segundo Adorno, "quando os seres humanos realmente se tornam viciados nessas objetividades opacas, as reificações (Verdinglichungen) não aparecem apenas como falsa consciência (falsches Bewusstsein), mas simultaneamente como realidade". ${ }^{11}$

Considerando essas condições, a teoria crítica dos sistemas busca "ligar novamente as esferas autônomas de racionalidade à realidade - sem a qual aquelas não poderiam existir". ${ }^{12}$ É exatamente essa a proposta de Teubner quando elaborou o conceito de "justiça autossubversiva", ou seja, o conceito de uma justiça com a capacidade de subverter a si mesma, a qual transcenda a imanência reificada do sistema jurídico.

Uma justiça como fórmula de contingência e transcendência - trata-se de "um conceito duplo de justiça, que, como fórmula contingente intrassistêmica, precisa preservar tanto sua consistência interna como sua permeabilidade em relação às demandas vindas da sociedade". ${ }^{13}$ Essa concepção, segundo Fischer-Lescano, tem rele-

\footnotetext{
${ }^{7}$ FISCHER-LESCANO, 2013, p. 27 [2010, p. 171-172]. Para mais detalhes, ver esp. ADORNO, T. W. Gesammelte Schriften. Philosophie der neuen Musik, Band 12. Frankfurt am Main: Suhrkamp, 1984. p. 27.

${ }^{8}$ FISCHER-LESCANO, 2013, p. 28 [2010, p. 172].

${ }^{9}$ FISCHER-LESCANO, 2013, p. 27-28 [2010, p. 172]

${ }^{10}$ ADORNO, 1982, p. 282 [ADORNO, T. W. Ästhetische Theorie. In:

Gesammelte Schriften. Band 7. Frankfurt am Main: Suhrkamp, 1984. p. 375]

No original e na íntegra: "Der Doppelcharakter der Kunst als eines von der empirischen Realität und damit dem gesellschaftlichen Wirkungszusammenhang sich Absondernden, das doch zugleich in die empirische Realität und die gesellschaftlichen Wirkungszusammenhänge hineinfällt, kommt unmittelbar an den ästhetischen Phänomenen zutage. Diese sind beides, ästhetisch und faits sociaux. Sie bedürfen einer gedoppelten Betrachtung, die so wenig unvermittelt in eins zu setzen ist, wie ästhetische Autonomie und Kunst als Gesellschaftliches. Der Doppelcharakter wird physiognomisch lesbar, wann immer man Kunst, gleichgültig, ob sie als solche geplant war oder nicht, von außen sich anhört oder ansieht, und allerdings bedarf sie stets wieder jenes Von außen, um vor der Fetischisierung ihrer Autonomie beschützt zu werden". (ADORNO, 1984, p. 374-375). Para mais detalhes, ver também ADORNO, T. W. Philosophie der neuen Musik. In:_Gesammelte Schriften. Band 12. Frankfurt am Main: Suhrkamp, 1984. p. 158.

${ }^{11}$ FISCHER-LESCANO, 2013, p. 28 [2010, p. 172].

${ }^{12}$ FISCHER-LESCANO, 2013, p. 28 [2010, p. 172]

${ }^{13}$ FISCHER-LESCANO, 2013, p. 28 [2010, p. 172].
} 
vantes implicações normativas, já que "obrigam o direito a buscar traduzir os conflitos estruturais da sociedade em quaestio iuris; a manter mutuamente compatíveis os espaços de autonomia, a garantir condições para a autoconstituição dos indivíduos" ${ }^{14}$

O imperialismo da racionalidade jurídica e sua justiça totalitária (universalizante) tornam o sistema cego para o ambiente, gerando aquilo que é o completamente oposto à justiça almejada: a injustiça. Como expresso no velho brocardo latino de Cícero, summum ius summa injuria ${ }^{15}$, ou seja, o excesso de justiça leva à injustiça, como no exemplo do personagem Michael Kohlhaas, do escritor alemão Kleist. A imanência reificada do direito deve ser combatida com a transcendência. Nesse sentido, "é necessária a abertura a uma referência adicional (Verweisungüberschusses) à ativação de energias utópicas sobre a precondição de injustiças realmente vividas". ${ }^{16}$

A justiça autossubversiva é uma força interna ao direito que se levanta em face do próprio direito; trata-se da "transposição normativa dos limites cognitivos do sistema jurídico na auto-observação (cognitiva)"17, na forma de um transbordamento do marco conceitual da teoria dos sistemas que nesse momento se volta para o "outro" (no sentido de Lévinas e Derrida), sendo por isso, também, uma justiça responsiva (ecológica).

O conceito de justiça em Luhmann está baseado na ideia de fórmula de contingência (interna e formal) fundada na proibição da negação, na canonização, que ao mesmo tempo traz consigo o paradoxo de sua constante busca pelo irrefutável, o que leva sempre à criação de novas contingências. ${ }^{18}$ Para Teubner, falta no conceito luhmanniano a ideia de justiça como transcendência, não apenas contingência, já que em torno dela sempre se abre um "espaço imaginário" no qual se podem criar "ficções sobre o mundo exterior"; são as "energias utópicas" presentes no sistema jurídico. ${ }^{19}$

\begin{abstract}
A justiça atua internamente ao direito como uma força subversiva, com a qual o direito protesta contra si mesmo. A justiça protesta contra as tendências naturais do direito de se vincular a precedentes, rotina, segurança, estabilidade, autoridade e tradição. Contra as tendências de autocontinuidade bem ordenada embutidas no direito, a justiça exibe sua preferência pela desordem, revolta, divergência, variabilidade e mudança. Ela protesta em nome da sociedade, dos homens e da natureza - entretanto, ela o faz a partir do arcano interno do direito. A justiça subversiva é o espinho na carne. 'Motim a bordo' (Mauterei auf der Bounty) - é este o recado da sociologia para a justiça jurídica. ${ }^{20}$
\end{abstract}

De modo pertinente, Brunkhorst observa que esse poder da justiça autossubversiva é o que também está presente nas grandes revoluções jurídicas e constitucionais da sociedade na forma de um "aprendizado normativo" - trata-se da transformação da injustiça em justiça pela autotranscendência revolucionária, a alteração do status quo pelo direito. ${ }^{21}$

As implicações que a mudança de compreensão da ideia de justiça traz ao sistema jurídico são profundas. O direito passa a ser responsabilizado pelas injustiças por ele mesmo criadas, ou seja, pela sua "racionalidade irracional" (Adorno). No momento em que se reconhece a incapacidade do direito em realizar a justiça, emerge também o "motim" em sua interioridade. Trata-se de uma espécie de resistência que deriva de seu próprio "arcano interno".22

\footnotetext{
${ }^{14}$ FISCHER-LESCANO, 2013, p. 29 [2010, p. 172].

${ }^{15}$ CÍCERO, Marcus Tullius. De Officiis. Translated by Walter Miller. Loeb edn. Cambridge: Harvard University Press, 1913. p. 33-34 (Livro I, X, 33).

${ }^{16}$ FISCHER-LESCANO, 2013, p. 29 [2010, p. 173]. Para mais detalhes acerca da ideia da "ativação de energias utópicas" por meio da justiça, ver TEUBNER, G. Dealing with paradoxes of law: Derrida, Luhmann, Wiethölter. In: Publishing, 2006a. p. 54.

${ }^{17}$ BRUNKHORST, H. Ilusões de factibilidade, declarações festivas e cantorias: sobre a relação entre evolução e revolução no Direito. Civitas. Porto Alegre, v. 9, n. 3, p. 440-458, 2009. p. 442.

${ }^{18}$ TEUBNER, Gunther. Justiça autosubversiva: fórmula de contingência ou de transcendência do Direito? Revista Eletrônica do Curso de Direito, PUC Minas Serro [Online], 0.4, p. 17-54, 2011b. p. 27 [TEUBNER, Gunther. Self-subversive justice: contingency or transcendence formula of law? 2009a. p. 1-22. Disponível em: <www.uni-frankfurt.de/>. Acesso em: 20 out. 2010. p. 8].

${ }^{19}$ TEUBNER, 2011b, p. 31 [2009a, p. 11].

${ }^{20}$ TEUBNER, 2011b, p. $32-33$ [2009a, p. 12].

${ }^{21}$ Cf. BRUNKHORST, 2009, p. 443, 455.

${ }^{22}$ Cf. TEUBNER, 2011b, p. 33 [2009a, p. 12]
} 


\subsection{TEORIA DOS SISTEMAS}

A autodescrição do sistema jurídico por meio da justiça é em si mesma paradoxal já que a continuidade da circularidade recursal das operações jurídicas sempre leva à geração de novas injustiças, como no trilema de Münchhausen, numa constante oscilação agonizante. Essa autossabotagem sistêmica conduz sempre à conclusão de que ao ser produzida a injustiça, "a justiça deve novamente protestar, para então se expor mais uma vez aos compelimentos do sistema jurídico". ${ }^{23}$ A dinâmica da autossubversão é uma forma de circularidade entre as decisões jurídicas positivas (imanência) e o protesto pela justiça (transcendência), ou seja, "a práxis realiza e impossibilita a justiça em uma transformação permanente da imanência à transcendência do direito e de volta à imanência" ${ }^{24} \mathrm{O}$ conceito de transcendência da justiça, importado por Teubner do pensamento de Derrida, ${ }^{25}$ não implica adjudicação de critérios externos ao sistema, ou seja:

Os critérios da justiça não são, então, encontrados em algum lugar fora do direito, antes, o direito só pode se autotranscender de forma tal que ele se diferencie de si mesmo, na reentrada autoproduzida, aqueles ambientes dos quais o conflito jurídico se origina - sociedade, natureza, homem, para, então, em relação a essas enacted ecologies, estabelecer critérios de justiça ambientalmente adequados. ${ }^{26}$

Se o direito é excludente em seu aspecto decisório, o papel da justiça é exatamente o de reclamar a inclusão daquilo que ficou excluído desse processo, o "inteiramente outro". Como colocaria Derrida em suas analogias rabínicas, essa experiência de transcendência pela justiça é a "travessia do deserto" feita pelos cativos injustiçados. Se em Luhmann a transcendência está presente apenas no sistema religioso, para Derrida essa experiência pode ser estendida a toda a sociedade, incluindo os mundos autônomos altamente racionalizados, tais como a economia, a ciência, a política e o direito. ${ }^{27}$

No sistema jurídico, a justiça desempenha essa função, que impele o direito para além da limitação de suas fronteiras - "o discurso da justiça começa onde o direito termina"28 - "a justiça deve ultrapassar o direito em cada sentido, realizar a experiência da transcendência específica do direito, sob cuja impressão ela deve retornar para a imanência do direito". ${ }^{29}$ A justiça como princípio dinâmico do sistema jurídico, possibilita a superação da fratura entre imanência e transcendência, num constante processo de transformação do ilícito em lícito. Nesse sentido, "a justiça apenas se torna possível com a passagem real pela injustiça", como ocorre nos processos sociais de colère publique (Durkheim) ou com os argumentos sustentados pelo terror em face dos "corpos torturáveis" (Adorno). ${ }^{30}$

A articulação das experiências de injustiça já havia sido abordada por Adorno ao tratar do fenômeno da "imediaticidade social" (gesellschaftlicher Unmittelbarkeit). ${ }^{31}$

A imediaticidade social existe somente em configurações que não transformam a justiça em organizações jurídicas. Ao mesmo tempo, e aqui se nota seu momento dialético, a condição para que a fórmula transcendente tenha efeito é que a operação estabelecida e praticada pelo direito exista no mundo. ${ }^{32}$

Portanto, trata-se da interdependência mútua entre imanência e transcendência, ou como diria Sonja Buckel, entre "proteção" (Schutz) e "farsa" (Maskerade). ${ }^{33}$

Adorno, na esteira da "dialética negativa" e da

\footnotetext{
${ }^{23}$ TEUBNER, 2011b, p. 35 [2009a, p. 13].

${ }^{24}$ TEUBNER, 2011b, p. 35 [2009a, p. 14]

${ }^{25}$ Cf. DERRIDA, Jacques. Força de lei: o fundamento místico da autoridade. São Paulo: Martins Fontes, 2007. p. 41 e ss.

${ }^{26}$ TEUBNER, 2011b, p. 39 [2009, p. 15-16].

${ }^{27}$ TEUBNER, 2011b, p. 40 [2009, p. 16].

${ }^{28}$ TEUBNER, 2011b, p. 41 [2009, p. 17].

${ }^{29}$ TEUBNER, 2011b, p. 42 [2009, p. 18].

${ }^{30}$ Cf. FISCHER-LESCANO, 2013, p. 29 [2010, p. 173]; TEUBNER, 2011b, p. 43 [2009, p. 18]. Para mais detalhes acerca da apropriação do conceito de colère publique na teoria dos sistemas, ver, esp. FISCHER-LESCANO, Andreas. Ex facto ius oritur: procesos de escándalo y el derecho mundial emergente. DOXA - Cadernos de Filosofia del Derecho, Alicante, v. 30, p. 435-450, 2007. Sobre a ideia de "corpos torturáveis", ver, esp. ADORNO, ADORNO, T. W. Negative Dialektik. In:___. Gesammelte Schriften. Band 6. Frankfurt am Main: Suhrkamp, 1984, 6, p. 281 [2009, p. 238].

${ }^{31}$ Cf. ADORNO, 1984, 6, p. 281 [2009, p. 238].

${ }^{32}$ FISCHER-LESCANO, 2013, p. 29 [2010, p. 173].
} 


\subsection{TEORIA DOS SISTEMAS}

“justiça restauradora” ${ }^{34}$, mostra que essa interdependência também está presente no "princípio da troca". Segundo ele, "o que a crítica ao princípio da troca deseja é que o ideal da troca livre e justa, até hoje um mero pretexto, se torne realidade. Apenas isso transcenderia a troca" ${ }^{35}$ Do mesmo modo, Teubner pensa essa mesma função para a justiça jurídica diante da imanência reificada do direito e suas injustiças.

Decorre dessa postura de pensamento uma espécie de crítica imanente do direito como uma atitude de transcendência. Pode-se definir a crítica, em poucas palavras, como uma atitude específica com relação ao mundo ${ }^{36}$ - a crítica do status quo (Horkheimer). ${ }^{37}$

Horkheimer e Adorno definem com mais precisão o que diferencia a "sociologia descritiva" da "teoria crítica da sociedade", considerando que "a sociologia se converte em crítica da sociedade no mesmo momento em que não se limita a descrever e ponderar as instituições e os processos sociais, mas sim quando os confronta com esse substrato", trazendo à tona os conflitos e os antagonismos que marcam as tensões reais das relações entre a vida e as instituições. ${ }^{38}$

Seguindo os moldes do teor imanente da teoria crítica da sociedade de Adorno e Horkheimer, "a teoria crítica dos sistemas não é uma mera tecnologia social, nem uma descrição sociológica extrínseca, nem autodescrição teórico-jurídica, mas um esforço eminentemente filosófico de crítica social”. ${ }^{39}$ Essa crítica se torna possível no marco sistêmico-teórico a partir do momento em que se considera a existência de um referencial transcendente que transborda da própria imanência. De acordo com Fischer-Lescano, seguindo Adorno nesse ponto, "é no arcanum da sociedade, na atitude, no ponto de vista da resistência que a faculdade de distinguir o reconhecível e o meramente convencional, ou o que está sob a coerção da autoridade vigente, surge como crítica, que é derivada do termo grego krino, decidir" ${ }^{40}$

Todavia, é um pressuposto fundamental da teoria crítica dos sistemas que a sociedade não possa ser descrita a partir de fora. Nesse sentido, toda e qualquer forma de crítica deve ser necessariamente imanente, ou seja, deve partir de dentro do próprio sistema. A crítica imanente é sempre baseada nas próprias discrepâncias produzidas na interioridade do sistema. ${ }^{41}$ Por isso a teoria crítica dos sistemas busca analisar o direito das sociedades reais, em seus antagonismos constitutivos, tematizando as contradições fundamentais da sociedade. Na esteira das análises de Menke, o direito se justifica por meio de seus próprios antagonismos. ${ }^{42}$ Segundo ele, a forma jurídica e a produção dessa forma guardam consigo um aspecto de normatividade, no qual "o poder ( Kraft), de cuja expansão emerge a forma, é ao mesmo tempo uma exigência que se volta contra a própria forma que emerge. Essa exigência requer que a forma corresponda ao seu outro, que lhe faça justiça" ${ }^{43}$ - ou seja, trata-se da co-

\footnotetext{
${ }^{33}$ BUCKEL, Sonja. Zwischen Schutz und Maskerade: Kritik(en) des Rechts. Informationsbrief. Aufgabe 102, p. 11-23, Rav Infobrief, august 2009. p. 11 e ss.

${ }^{34}$ Cf. HONNETH, Axel. Pathologies of reason: on the legacy of critical theory. New York: Columbia University Press, 2009. p. 87.

${ }^{35}$ Citado em FISCHER-LESCANO, 2013, p. 29 [2010, p. 173]. Para mais detalhes, ver ADORNO, 1984, 6, p. 150 [2009, p. 128]. No original e na íntegra: "Annullierte man simpel die Maßkategorie der Vergleichbarkeit, so träten anstelle der Rationalität, die ideologisch zwar, doch auch als Versprechen dem Tauschprinzip innewohnt, unmittelbare Aneignung, Gewalt, heutzutage: nacktes Privileg von Monopolen und Cliquen. Kritik am Tauschprinzip als dem identifizierenden des Denkens will, daß das Ideal freien und gerechten Tauschs, bis heute bloß Vorwand, verwirklicht werde. Das allein transzendierte den Tausch." (ADORNO, 1984, 6, p. 150).

${ }^{36}$ Cf. FISCHER-LESCANO, 2013, p. 31 [2010, p. 173]. Ver, esp, FOUCAULT, Michel. O que é a crítica? 1978. Disponível em: <www.filoesco.unb.br/ foucault>. Acesso em: 12 jan. 2011.p. 1-2; SANTOS, Boaventura Sousa. "Por que é tão difícil construir uma teoria crítica?" Revista Crítica das Ciências Sociais, Coimbra, n. 54, p. 197-215, jun. 1999.

${ }^{37}$ Cf. HORKHEIMER, Max. Teoría tradicional y teoría crítica. In: (Org.). Teoría crítica. Buenos Aires: Amorrortu, 2003. p. 259

${ }^{38}$ ADORNO T. W.; HORKHEIMER, M. La sociedad: lecciones de sociología. Buenos Aires: Proteo, 1969. p. 32.

${ }^{39}$ FISCHER-LESCANO, 2013, p. 31 [2010, p. 174].

${ }^{40}$ FISCHER-LESCANO, 2013, p. 31 [2010, p. 174]. Para mais detalhes, ver esp. ADORNO, ADORNO, T. W. Kritik. In: (Ed.) Gesammelte Schriften. Band 10. Frankfurt am Main: Suhrkamp, 1984, 10, p. 785-793. No original: "Solcher Widerstand, als Vermögen der Unterscheidung des Erkannten und des bloß konventionell oder unter Autoritätszwang Hingenommenen, ist eins mit Kritik, deren Begriff ja vom griechischen krino, Entscheiden, herrührt." (ADORNO, 1984, 10, p. 785).

${ }^{41}$ FISCHER-LESCANO, 2013, p. 31 [2010, p. 174].

${ }^{42}$ Cf. MENKE, Christoph. Subjektive rechte: zur paradoxie der form. Zeitschrift für Rechtssoziologie. Stuttgart, v. 29, 2008, p. 105.

${ }^{43}$ MENKE, 2008, p. 105. Reproduzindo e apropriando essa análise, ver FISCHER-LESCANO, 2013, p. 32 [2010, p. 174].
} 


\subsection{TEORIA DOS SISTEMAS}

produção da forma e de sua oposição, como no conceito teubneriano de justiça autossubversiva.

Retraduzindo o movimento descrito por Menke, Fischer-Lescano argumenta que:

\begin{abstract}
A teoria crítica dos sistemas integra em sua crítica do direito essas exigências normativas que no direito se voltam contra o próprio direito de forma paradoxal e o leva a transcender a si mesmo num permanente tornar-se justiça do outro. Em sua busca por justiça, a teoria crítica dos sistemas argumenta com e por meio do direito e se submete às constrições sistêmicas de sentido para logo livrar-se delas e contribuir para quebrar o encanto do fechamento sistêmico. ${ }^{44}$
\end{abstract}

A ideia de "quebrar o encanto" do fechamento, ou melhor, de desfetichizar o sistema autista de sua imanência reificada, justifica-se na medida em que o sistema é sempre um sistema na sociedade, coexistindo com outros sistemas. $\mathrm{O}$ sistema cegado por sua própria interioridade perde a capacidade de reagir adequadamente ao ambiente, ou seja, deixa de ser responsivo. Parafraseando Adorno, pode-se dizer que aquilo que o próprio sistema fetichizado "possui de total exerce um encanto, que apesar de toda afetação afirmativa, torna-se nulo ante a desgraça real" ${ }^{45}$, e no caso do sistema jurídico, isso se torna evidente diante das injustiças reais que se derivam de uma ordem jurídica reificada.

Partindo dessas averiguações, a teoria crítica dos sistemas busca promover uma ciência jurídica "socialmente adequada" e "sociologicamente informada", especialmente num cenário de surgimento de novas perspectivas jurídicas proporcionadas pela "colisão de regimes", redes transnacionais, conflitos de princípios organizacionais, entre outros modos possíveis de manifestação do direito neoespontâneo.

Nessas condições, Fischer-Lescano considera que dois pontos parecem significativos para o direito, sendo eles (i) a "crítica dos valores"
(Wertkritik) e (ii) a "crítica ao estatismo" (Etatismuskritik). ${ }^{46}$

$\mathrm{Na}$ via da "crítica dos valores" (Wertkritik), segundo Fischer-Lescano:

A reformulação jurídica dos conflitos sociais em torno da estrutura social e de questões distributivas em termos de construções sofisticadas de valores e princípios, sobre os quais se poderia chegar a um acordo prático, consiste na tentativa inadequada e de caráter autoritário de solucionar os conflitos sociais do século $\mathrm{XXI}^{47}$

Assim, o caminho mais adequado às configurações da sociedade moderna estaria na criação de precondições para a segurança mútua dos diversos espaços autônomos da sociedade, tais como as "esferas espontâneas" 48 , capazes de possibilitar a autorregulação social.

No mesmo sentido, a "crítica ao estatismo" (Etatismuskritik) busca demonstrar que a política deixou de ser a única esfera social que se usurpa dos espaços sociais de autonomia. Atualmente, as tendências expansionistas turboautopoiéticas estão presentes em muitos sistemas funcionais ${ }^{49}$, podendo manifestar-se da economicização, da juridificação, da midialização, da medicinização, entre outros modos, que implicam "riscos específicos, que precisam ser combatidos pela introdução da obrigação de se agir de modo responsivo em relação ao ambiente social (seres humanos, sistemas e ecossistema natural)". ${ }^{50}$ Nesse ponto, a teoria crítica dos sistemas se une à tese de Habermas acerca da "colonização do mundo da vida" (Kolonialisierung der Lebenswelt), a qual denuncia a nociva expansividade dos sistemas administrativo e econômico. ${ }^{51}$

A "crítica dos valores" (Wertkritik) e a "crítica ao estatismo" (Etatismuskritik) traduzem "a teoria crítica dos sistemas para contra-modelos concretos com os quais pode intervir nas lutas pela adequação social das leis existentes". ${ }^{22}$ Con-

\footnotetext{
${ }^{44}$ FISCHER-LESCANO, 2013, p. 32 [2010, p. 174].

${ }^{45}$ ADORNO, T. W. Dialética negativa. Rio de Janeiro: Zahar, 2009. p. 312 [1984, 6, p. 369]. No original: "Das Totale der Frage selbst übt einen Bann aus, der bei allem affirmativen Gehabe nichtig wird vorm realen Unheil." No mesmo sentido, ver FISCHER-LESCANO, 2013, p. 32 [2010, p. 174].

${ }^{46}$ Cf. FISCHER-LESCANO, 2013, p. 32-33 [2010, p. 175].

${ }^{47}$ FISCHER-LESCANO, 2013, p. 32-33 [2010, p. 175].

${ }^{48}$ Cf. TEUBNER, Gunther. Constitutional fragments: societal constitutionalism and globalization. Oxford: Oxford University Press, 2012 . p. 89 e ss.

${ }^{49}$ Cf. TEUBNER, 2012a, p. 79.

${ }^{50}$ FISCHER-LESCANO, 2013, p. 33 [2010, p. 175].

${ }^{51}$ Cf. HABERMAS, Jürgen. Teoría de la accion comunicativa. Buenos Aires: Taurus, 1999. v. II. p. 451 e ss.
} 


\subsection{TEORIA DOS SISTEMAS}

siderando, junto com Adorno, que "o todo é o não verdadeiro" (das Ganze ist das Unwahre) ( $^{53}$, "quem quer introduzir caos na ordem precisa forçar o sistema de dentro para fora para com isso jogar a faísca nessa lareira que pode fazê-la explodir"54 - é o "espinho na carne", o "motim a bordo" "55, a revolução ${ }^{56}$, ou seja, trata-se do movimento autotranscendente do sistema jurídico, o qual é ao mesmo tempo uma crítica imanente. Brunkhorst, inspirado no conceito de justiça autossubversiva de Teubner, afirma que esse direito "não cumpre apenas a função de estabilização de expectativas, ele não é apenas sistema imunológico da sociedade (Luhmann), mas é ao mesmo tempo medium da práxis transformadora do mundo" ${ }^{57}$ que clama em face das injustiças realmente vividas.

\section{DIREITO GLOBAL E SOCIEDADE MUN- DIAL: DIAGNÓSTICOS, TENDÊNCIAS E DESAFIOS}

\section{Relatam Fischer-Lescano e Teubner que:}

Em 1971, enquanto teorizava sobre o conceito de 'sociedade mundial' [Weltgesellschaft], Luhmann permitiu-se elaborar a hipótese especulativa de que o direito global iria experimentar uma radical fragmentação, não no âmbito territorial, mas conforme distinções setoriais da sociedade. ${ }^{58}$

Em seus escritos, que precedem o giro teórico autopoiético, Luhmann admite que no plano estrutural da sociedade mundial os sistemas primariamente orientados cognitivamente, como economia, ciência e técnica, ganhariam certa primazia no processo de mundialização, enquanto os sistemas orientados normativamente, como a política e o direito, encontrariam dificuldades e limitações para alçar um nível global. ${ }^{59}$ Esse descompasso entre a evolução das estruturas cognitivas e normativas é, em certa medida, um dos pontos mais sensíveis de uma análise da sociedade moderna e, por isso, traz consigo o desafio de como seria possível o estabelecimento de estruturas normativas no plano da sociedade mundial.

A teoria crítica dos sistemas surge no contexto da sociedade mundial, embebida nesses complexos antagonismos e nessas discrepâncias. Certamente, o século XXI é um período de complexos desafios para o sistema jurídico, bem como para uma teoria preocupada com as estruturas normativas da sociedade.

As tendências sistêmicas expansivas têm gerado uma cadeia infindável de externalidades negativas, que vão desde a perda da autonomia funcional de alguns subsistemas, até a exclusão massiva de pessoas ao acesso às prestações sistêmicas básicas. ${ }^{60}$ Nesse processo tendenciosamente autodestrutivo da sociedade global, Brunkhorst destaca três mazelas: (1) a hipertrofia do sistema econômico e o excesso de pró-ciclici-

\footnotetext{
${ }^{52}$ FISCHER-LESCANO, 2013, p. 33 [2010, p. 175].

${ }^{53}$ ADORNO, T. W. Minima moralia: reflexões a partir da vida lesada. Rio de Janeiro: Azougue, 2008. p. 46 [ADORNO, T. W. Minima Moralia: Reflexionen aus dem beschädigten Leben. In: ___ Gesammelte Schriften. Band 4. Frankfurt am Main: Suhrkamp, 1984, 4, p. 55]. Também, ver ADORNO, T. W. Hegel: three studies. Cambridge: MIT, 1993. p. 87 [ADORNO, T. W. Drei Studien zu Hegel. In:___. Gesammelte Schriften. Band 5. Frankfurt am Main: Suhrkamp, 1984, 5, p. 324].

${ }^{54}$ FISCHER-LESCANO, 2013, p. 33 [2010, p. 175]. Ver também TEUBNER, 2011, p. 36 [2009a, p.14].

${ }^{55}$ Cf. TEUBNER, 2011b, p. 32-33 [2009a, p. 12].

${ }^{56}$ Cf. BRUNKHORST, 2009, p. 443.

${ }^{57}$ BRUNKHORST, 2009, p. 447. Sobre a ideia do Direito como sistema imunológico da sociedade, ver esp. LUHMANN, 2005 , p. 642 e ss. [1993, p. 565 e ss.]. Para uma análise crítica acerca do conceito de direito como sistema imunológico, ver esp. GUERRA FILHO, Willis Santiago. Luhmann and Derrida: immunology and autopoiesis. In: LA COUR, Anders; PHILIPPOPOULOS-MIHALOPOULOS, Andreas (Org.). Luhmann observed: radical theoretical encounters. Londres: Palgrave Macmillan, 2013. p. 227 e ss.

${ }^{58}$ FISCHER-LESCANO, Andreas; TEUBNER, Gunther. Colisões de regimes - a busca vã por unidade jurídica na fragmentação do direito global. Revista Brasileira de Estudos Constitucionais - RBEC. Belo Horizonte, ano 6, n. 21, p.105-155, jan./mar. 2012, p. 105 [TEUBNER; FISCHER-LESCANO. Regimme-collision. The vain search for legal unity in the fragmentation of global law. Michigan Journal of International Law. Michigan, v. 25, 2004. p. 1.000]. Ainda sobre o tema da hodierna estrutura do Direito Global, Larry Catá Backer fala em quatro características inerentes a essa nova configuração do sistema jurídico: fragmentação, fluidez, permeabilidade e policentricidade. Cf. BACKER, Larry Catá. The structure of global law: fracture, fluidity, permeability and polycentricity. CPE Working Papers n. 2012-7, Carlisle, Penn State Law, Research Paper n. 15-2012, p. 102-122 (esp. p. 106). Para mais detalhes sobre a hipótese especulativa de Luhmann, ver esp. LUHMANN, N. Sociologia do direito. Rio de Janeiro: Tempo Brasileiro, 1983. v. II. p. 154 e ss. Sobre a emergência da "sociedade mundial", ver esp. STICHWEH, Rudolf. On the genesis of world society: innovations and mechanisms. 2000. Disponível em: <http://www.uni-bielefeld.de/(en)/soz/iw/pdf/stichweh_2.pdf>. Acesso em: 20 ago. 2012. Sobre a emergência de um Direito Transnacional, ver ZUMBANSEN, Peer. Transnational law. In: SMITS, Jan (Ed.). Encyclopedia of comparative law. Northampton: Edward Elgar Publishing, 2006. p. 738-754. ${ }^{59}$ LUHMANN, N. Die Weltgesellschaft. Soziologische Aufklärung 2: Aufsätze zur theorie der Gesellschaft. Opladen: Westdeutscher Verlag, p. 51-71, 1975. p. 55; LUHMANN, N. Evolution und Geschichte. Soziologische Aufklärung 2: Aufsätze zur theorie der Gesellschaft. Opladen: Westdeutscher Verlag, p. 150-69, 1976. p. 154; LUHMANN, 1981, p. 150.
} 


\subsection{TEORIA DOS SISTEMAS}

dade financeira, que desembocaram na recente crise de $2008^{61}$, derivada da livre e incontrolável dinâmica do capitalismo internacional, o qual vem desmantelando progressivamente as fronteiras nacionais, bem como o direito vinculado aos Estados, inclusive os direitos fundamentais. Em suas palavras, "o capitalismo é global, um sistema altamente produtivo, mas internamente catastrófico, que de modo algum precisa da democracia e para o qual, infelizmente, não existe atualmente qualquer alternativa". ${ }^{2}$ Outra mazela seria o (2) "fundamentalismo religioso", que se transnacionalizou e hoje ameaça conquistas fundamentais da modernidade ${ }^{63}$, inclusive os espaços sociais de liberdade em diversas partes do mundo - o exemplo mais evidente dessa realidade é o "Estado Islâmico" (ISIS), com sua megalomaníaca pretensão de reestabelecer os califados do medievo -; por fim, também (3) a expansividade dos processos de poder e do direito hegemônico ${ }^{64}$ no plano mundial, que ameaça igualmente a manutenção da sociedade moderna e de sua diferenciação funcional, pois corrompe a autonomia dos múltiplos âmbitos sociais. ${ }^{65}$

Revela-se desse modo o "lado sombrio" (dark side) da sociedade moderna ${ }^{66}$ - trata-se do paradoxo da diferenciação funcional. A diferenciação da sociedade em subsistemas funcionais (dentro de suas dinâmicas hiperexpansivas) passou a ameaçar paradoxalmente a própria manutenção da sociedade que ela mesma possibilitou outrora. Tem-se então aquilo que Brunkhorst identificou como o retorno da dialética do esclarecimento na sociedade mundial. ${ }^{67}$ Em consonância com Brunkhorst, Neves destaca que a "autonomia operacional dos sistemas sociais parciais, embora constitua uma exigência funcional, não se realiza em grande parte do globo terrestre e, portanto, prejudica a diferenciação funcional no plano global". 68 Trata-se aqui do problema da "corrupção sistêmica" que leva à "sabotagem de códigos" ${ }^{69}$ Neves identifica essa condição da sociedade mundial como uma verdadeira "patologia da normalidade" (pathology normalcy) ${ }^{70}$, recuperando neste ponto um termo do pensador frankfurtiano Erich Fromm, para expres-

\footnotetext{
${ }^{60}$ Acerca da questão da exclusão na ótica sistêmica, e seus desdobramentos, ver esp. LUHMANN, N. Inklusion und exklusion. Soziologische Aufklärung 6: Die soziologie und der Menschen. Opladen: Westdeutscher Verlag, p. 237-264, 1994. p. 237-264 [1998, p. 167-195] e LUHMANN, N. Gesellschaftsstruktur und semantik. Studien zur wissenssoziologie der modernen Gesellschaft. Frankfurt: Suhrkamp, v. 4. p. 138-150, 1995. p. 138-150. Para ver a definição de inclusão em Luhmann, ver esp. LUHMANN, N. La sociedad de la sociedad. Ciudad de México: Herder, 2007. p. 48. Seguindo, em grande medida Rudolf Stichweh, Teubner se questiona sobre a possibilidade de a diferença inclusão/exclusão se converter no metacódigo do século XXI, que mediatizaria todos os demais códigos binários dos subsistemas sociais na sociedade moderna funcionalmente diferenciada. Sobre as "cadeias de exclusão", ver esp. LUHMANN, N. Die politik der Gesellschaft. Frankfurt am Main: Suhrkamp, 2000. p. 427. Para mais detalhes, ver esp. TEUBNER, G. La constitucionalización de la sociedad global. In: Carlos Gómez-Jara Díez (Ed.) El derecho como sistema autopoiético de la sociedad global. Lima: ARA Editores. p. 69-111, 2005b. p. 72-73. Para um estudo específico sobre a diferença inclusão/exclusão na teoria dos sistemas, ver STICHWEH, Rudolf. Inklusion/exklusion, funk tionale differenzierung und die theorie der Weltgesellschaft. Soziale Systeme Heft 3. p. 123-136, 1997. p. 244 e ss.; BACHUR, João Paulo. Inclusão e exclusão na teoria dos sistemas sociais: um balanço crítico. BIB. São Paulo, n. 73, p. 55-83, $1^{\circ}$ semestre de 2012. p. 55-83.

${ }^{61}$ Sobre o conceito de "crise" como "curto circuito" na reprodução autopoiética, ver esp. KJÆR, Poul. Law and order within and beyond national configurations. 2010. Disponível em: <papers.ssrn.com/sol3/papers.cfm?abstract_id=1687013>. Acesso em: 12 jan. 2013.p. 4.

${ }^{62}$ BRUNKHORST, H. Rumo a uma nova ordem global: vinte anos após 1989 e além. RBCS. São Paulo, v. 26, n. 77, p. 25-30, outubro 2011. p. 28. Acerca do tema, ver também, TEUBNER Gunther; GRABER, Christoph B. Art and money: constitutional rights in the private sphere? Oxford Journal of Legal Studies. Oxford, v. 18, n. 1, p. 61-73, 1998.; TEUBNER, 2011, p. 9-51. Sobre a ideia de bloqueios e corrupção sistêmica, ver NEVES, Marcelo. Niklas Luhmann: eu vejo o que tu não vês. In: ALMEIDA, Jorge de; BADER, Wolfgang (Org.). Pensamento alemão no século XX: grandes protagonistas e recepção da obra no Brasil. São Paulo: Cosac Naify; Instituto Goethe de São Paulo, 2013. p. 341. Sobre a expansividade da economia, também no âmbito da dogmática jurídica e teoria do direito, ver esp. NEVES, Marcelo. Pesquisa interdisciplinar no Brasil: o paradoxo da interdisciplinariedade. In: Crítica à dogmática: dos bancos acadêmicos à prática dos tribunais. Porto Alegre: Instituto de hermenêutica Jurídica, 2005. p. 207 e ss. Ver também, CAMPILONGO, Celso F. O direito na sociedade complexa. São Paulo: Max Limonad, 2000. p. 118

${ }^{63}$ Cf. ŽIŽEK, Slavoj Unsere Trägheit ist die größte Gefahr“. Der Spiegel, Heft 12, 14, p. 130-134, märz 2015.

${ }^{64}$ Sobre a ideia de "direito hegemônico", ver BRUNKHORST, H. Solidarity: from civic friendship to a global level community. Cambridge: MIT Press, 2005. p. 127 e ss. e BUCKEL, Sonja; FISCHER-LESCANO, Andreas. Reconsiderando Gramsci: hegemonia no direito global. Revista Direito GV, São Paulo, 5(2), p. 471-490, jul.-dez. 2009. p. 482-483. Na tradição da interpretação marxista do direito burguês, Paschukanis fala no "direito do mais forte" (Faustrecht). Cf. PASCHUKANIS, Evgeni. A teoria geral do direito e o marxismo. Coimbra: Centelha, 1977, p. 169 e ss.

${ }^{65}$ Cf. BRUNKHORST, H. Democracy under pressure: the return of the Dialectics of Enlightenment in the world society. Civitas. Porto Alegre, v. 10, n. 1, p. 153-171, jan.-abr. 2010. p. 164 e ss.

${ }^{66}$ Cf. BRUNKHORST, 2005, p. 113.

${ }^{67}$ Cf. BRUNKHORST, 2010, p. 154 e ss. Neves chega a uma conclusão semelhante, mas enfatiza a questão da metadiferença inclusão/exclusão como fator que leva ao desmantelamento da diferenciação funcional. Para tanto ver, NEVES, 2013, p. 348; LUHMANN, N. Das Recht der Gesellschaft. Suhrkamp: Frankfurt am Main, 1993. p. 583 [2005, p. 661].

${ }^{68}$ NEVES, 2013, p. 342.

${ }^{69}$ Cf. NEVES, 2009, p. 39, 262.

${ }^{70}$ Cf. FROMM, Erich. The sane society. London: Routledge, 2008. p. 12 e ss.
} 
sar a forma danosa e autodestrutiva com que os sistemas sociais se relacionam entre si e com a sociedade (como um sistema mais abrangente), impossibilitando a realização de uma série de acoplamentos estruturais, prestações e execução da própria função sistêmica específica de modo "saudável" (autônomo e autolimitado).

Nesse cenário, a teoria crítica dos sistemas busca meios para combater essas ordens sociais reificadas, fetichizadas, hipertróficas, que ameaçam a diferenciação funcional da sociedade moderna e seus espaços de liberdade. Ela não logra isso por meio de um sistema político mundial, como se tudo pudesse ser resolvido por meio de um mundo republicanizado. Em face dessa postura, para a teoria crítica dos sistemas, "a política como sistema, esse fetiche da coletivização, é ópio para o povo, e equivale à institucionalização de uma fantasmagoria e uma declaração irrealizável de autossuficiência. Em vez disso, a utopia é uma sociedade civil (jurídica) mundial sem o Estado" 71 , como a nova Pax bukowina de Teubner ${ }^{72}$, em analogia com a "associação de homens livres" (Verein freier Menschen) de Marx. ${ }^{73}$

Um sistema jurídico responsivo, em sua crítica imanente, lidaria com a nova realidade da sociedade mundial por meio de uma perspectiva crítico-emancipatória capaz de revelar a existência de um núcleo normativo nas instituições e nas práticas realmente existentes. Ela intervém "na luta em torno da magnae chartae [constituição] em relação às matrizes transnacionais" $\mathrm{e}$ busca "desenvolver em cada caso direitos humanos e organizacionais específicos" ${ }^{\text {" }}$

Os direitos fundamentais ${ }^{75}$ (e aqui podemos compreender os direitos humanos) protegem o primado da diferenciação funcional da sociedade em face das tendências desdiferenciantes ${ }^{76}$, não mais apenas da política, mas agora, especificamente, dos sistemas sociais globais.

Com a emergência do direito global na sociedade moderna, marcada pela primazia da diferenciação funcional, as questões relativas a direitos humanos se tornaram especialmente sensíveis à afirmação do novo primado. A proteção aos direitos humanos tornou-se imprescindível para a manutenção da diferenciação funcional e da inclusão de toda a população mundial no sistema jurídico. ${ }^{77}$ Todavia, a diferenciação segmentária entre Estados nacionais no âmbito do sistema político da sociedade mundial inviabiliza o surgimento de uma "constituição mundial"78 capaz de proteger os direitos fundamentais para além do alcance estatal. Esse complexo desafio de uma sociedade profundamente fragmentada e reificada pela hipertrofia de determinadas racionalidades sistêmicas é enfrentado pela teoria crítica dos sistemas por meio daquilo que aqui se denomina de "resistência normativa" in praxis (de cunho crítico-emancipatório).

Essa resistência normativa da teoria crítica dos sistemas não está ligada a modelos procedimentais que priorizam o consenso universal ou a justificação racional, antes, ela se pauta nos "processos sociais de constitucionalização" (gesellschaftliche Konstitutionalisierungsprozesse) e na formação de "instituições permeáveis às demandas sociais" ${ }^{79}$ - trata-se aqui da socialização dos processos de criação do direito. Primeiramente os "processos sociais de constitucionalização", os quais precisam ser assegurados, estabilizados e tornados permanentes para que se façam efeti-

\footnotetext{
${ }^{71}$ FISCHER-LESCANO, 2013, p. 33 [2010, p. 176]. Acerca disso, ver também, LUHMANN, N. Die Politik der Gesellschaft. Frankfurt am Main: Suhrkamp, 2000. p. 215.

${ }^{72}$ Cf. TEUBNER, 2003, p. 9 e ss.

${ }^{73}$ MARX, K. El Capital: crítica de la economía política. México: Fondo de Cultura Económica, 1973. v. I. p. 43. Ver também FISCHER-LESCANO, 2013, p. 34 [2010, p. 175].

${ }^{74}$ FISCHER-LESCANO, 2013,'p. 34 [2010, p. 176]. Acerca disso, ver TEUBNER, 2012; NEVES, 2009. Para um estudo específico da constitucionalização no âmbito corporativo, ver esp. AMATO, Lucas F. Constitucionalização corporativa: direitos humanos fundamentais, economia e empresa. Curitiba: Juruá, 2014.

${ }^{75}$ Cf. TEUBNER, G. “The anonymous matrix: human rights violations by 'private' transnational actors”. The Modern Law Review. Malden, v. 69, n. 3, p. 327-346, 2006b. p. 342.

${ }^{76}$ Cf. LUHMANN, LUHMANN, N. Los derechos fundamentales como institución. México D.F.: Iteso/Universidad Iberoamericana, 2010 . p. 321.

${ }^{77}$ Cf. LUHMANN, 1993, p. 573 [2005, p. 651].

${ }^{78}$ Cf. LUHMANN, 1993, p. 582 [2005, p. 660].

${ }^{79}$ FISCHER-LESCANO, 2013, p. 35 [2010, p. 176]. Ver também TEUBNER, G. "Die Erblast". Zeitschrift für Rechtssoziologie, 29, Heft 1, p. 3-7, 2008. p. 3; TEUBNER, 2012; TEUBNER, G. The Project of Constitutional Sociology”. Transnational Legal Theory, Cambridge, 4, p. 44-58, 2013.
} 
vos. As constituições protegem os direitos fundamentais. Nesse sentido, no caso de dilatarmos seu alcance para todos os âmbitos sociais quanto possíveis, na forma de uma capilarização constitucional $^{80}$, tornar-se-ia possível blindar as esferas autônomas da sociedade dos impulsos hipertróficos e desdiferenciantes de determinadas racionalidades sociais e ao mesmo tempo autolimitar as esferas sociais constitucionalizadas.

Segundo Wiethölter, levar o conceito de autonomia sistêmica a sério significa compreender que a autodeterminação implica ao mesmo tempo a inevitabilidade de externalizações. As externalizações (nem sempre negativas) não se confundem com "determinações externas" (Fremd-Bestimmung), antes, podem ser consideradas como potenciais suportes em momentos nos quais a autoajuda (Selbsthilfe) sistêmica já não é mais possível. ${ }^{81}$ "Isso pode ser comparado com a assistência terapêutica ou suporte estrutural além do direito" ${ }^{82}$, ou seja, a ajuda externa é possível não como determinação jurídica de outras esferas sociais, mas sim como uma espécie de prestação jurídica à sociedade por meio de processos de constitucionalização que auxiliam na manutenção da diferenciação funcional da sociedade, combatendo a nova dialética do esclarecimento.

Os processos de constitucionalização seriam capazes de assegurar a existência de "espaços sociais de liberdade", tais como as "esferas espontâneas". As esferas espontâneas atuam em face das "esferas organizadas" presentes numa diversidade de sistemas sociais. ${ }^{83} \mathrm{~A}$ diferença entre esfera espontânea e esfera organizada, além de ser uma diferenciação interna dos próprios sistemas, é também, segundo Teubner, essencial para a diferenciação funcional da sociedade. A atuação da esfera espontânea barra as tendências reificantes da esfera organizada e da racionalidade sistêmica específica. Na economia, a diferença entre esfera espontânea e esfera organizada se manifesta na oposição entre os consumidores e as grandes corporações; na política essa diferença também aparece, mas na forma de contraposição entre governo e opinião pública. ${ }^{84}$

O equilíbrio entre o espontâneo e o organizado deve ser recalibrado, especialmente no sentido de impedir a dominação do último sobre o primeiro. A presença de uma esfera espontânea nos sistemas é essencial para a existência de maior responsividade sistêmica e abertura ecológica. Esse equilíbrio se torna possível graças à criação de mecanismos democráticos internos a cada âmbito sistêmico, capazes de potencializar a participação, a deliberação, a descentralização, entre outros modos de abertura.

A inovação dessa proposta está em sua abrangência, que não mais se limita ao âmbito territorial dos Estados nacionais, alçando agora a possibilidade de atingir setores sociais autônomos e transnacionalizados. Esses avanços já estavam presentes nos marcos das "constituições civis globais" de Teubner 85 e do "constitucionalismo societal" de Sciulli. ${ }^{86}$ Quando a teoria crítica dos sistemas fala em processos de constitucionalização da sociedade, ela está indo muito além do mero acoplamento estrutural entre sistema jurídico e sistema político. Ela busca demonstrar que os processos de constitucionalização podem emergir do contato do sistema jurídico com outros sistemas sociais, tais como a economia, a ciência, a saúde, dentre outros.

Os processos sociais de constitucionalização permitem ao sistema jurídico compensar o déficit do estabelecimento de estruturas normativas

\footnotetext{
${ }^{80}$ TEUBNER, 2012, p. 83-86.

${ }^{81}$ Cf. WIETHÖLTER, Rudolf. Zum Fortbildungsrecht der (richterlichen) Rechtsfortbildung: Fragen eines lesenden Recht-Fertigungslehrers. 3 Kritische Vierteljahreszeitschrift für Gesetzgebung und Rechtswissenschaft, Baden-Baden, p. 1-28, 1988. p. 27-28. Para conferir mais acerca do desenvolvimento desse programa por Wiethölter, ver esp. WIETHÖLTER, Rudolf. Justifications of a law of society. In: PEREZ, Oren; TEUBNER, Gunther (Ed.). Paradoxes and inconsistencies in the law. Oxford: Hart, 2005. p. 65 e ss. Fazendo uso da ideia de "assistência terapêutica" e "constitucionalização" em Wiethölter, ver esp. TEUBNER, 2012, p. 35.

${ }^{82}$ WIETHÖLTER, 1988, p. 28.

${ }^{83}$ Cf. TEUBNER, 2012, p. 88 e ss.

${ }^{84}$ Cf. TEUBNER, 2012, p. 89.

${ }^{85}$ Cf. TEUBNER, 2003. Ver também TEUBNER, Gunther. Regimes privados: direito neoespontâneo e constituições dualistas na sociedade mundial. In: RÜDIGER, Dorothee; MENDES, Rodrigo (Org.). Direito, sistema e policontexturalidade. Piracicaba: Unimep, 2005a; TEUBNER, 2005b.

${ }^{86}$ Cf. SCIULLI, David. Theory of societal constitutionalism: fundations of a non-marxist critical theory. New York: Cambridge University Press, 1992. p. 67.
} 
na sociedade moderna, na forma de um caminho que possibilita remediar os efeitos negativos do predomínio hipertrófico de racionalidades de sistemas prioritariamente compostos por estruturas cognitivas (economia, ciência, técnica). Ao mesmo tempo, esses processos buscam também repelir toda espécie de regresso desdiferenciante da sociedade, seja de ordem política ou religiosa, e ao mesmo tempo se levantam em face da expansividade dos processos de poder na sociedade mundial.

Complementarmente aos processos de constitucionalização, a resistência normativa proposta pela teoria crítica dos sistemas está baseada, também, na legislação da sociedade civil via processos de escandalização como a "colère publique mundial". ${ }^{87}$ Do mesmo modo, considera-se a possibilidade da tomada de decisões em situações deliberativas por meio da articulação entre as esferas espontânea e organizada. ${ }^{88} \mathrm{Em}$ suma, isso representaria o estabelecimento de processos de autorregulação social. Nas palavras de Fischer-Lescano, "trata-se da abertura das decisões estruturais da sociedade sobre processos democráticos por meio do desenvolvimento de direitos constitucionais da sociedade mundial que liberta o potencial da sociedade civil global para salvaguarda da autonomia". ${ }^{9}$ A grande pre- ocupação da teoria crítica dos sistemas é com a possibilidade da "regeneração das relações autônomas na sociedade mundial"; trata-se de procurar "romper com os padrões de estratificação das instituições sociais". ${ }^{90}$

Tiradas essas conclusões, ainda na esteira da teoria crítica dos sistemas, Fischer-Lescano observa a possibilidade de um paralelo entre o conceito de "responsividade social" (soziale Responsivität) dos sistemas e o conceito de mimesis da teoria crítica. ${ }^{91}$ Porém, diferentemente da teoria crítica da primeira geração da Escola de Frankfurt, a teoria crítica dos sistemas postula que não é apenas o sistema da arte que pode trabalhar como um "órgão da mimesis" (Organ der Mimesis). ${ }^{92}$ Segundo Fischer-Lescano:

As ordens mundiais dos sistemas sociais precisam adotar uma relação mimética com a realidade externa ao sistema. Deixar a transcendência aparecer na realidade, ou seja, a negação do existente na mimese do existente não é assim apenas tarefa da arte, mas de todos os sistemas sociais que têm de ser orientados de modo que 'o sujeito, em diferentes níveis de sua autonomia, possa colocar-se no outro, separado, mas também sem separar-se. ${ }^{93}$

Essa relação mimética "é uma reação à má irracionalidade do mundo racional enquanto administrado" 94 , em outras palavras, a mimesis é

\footnotetext{
${ }^{87}$ Cf. FISCHER-LESCANO, 2007, p. 443.

${ }^{88}$ Cf. FISCHER-LESCANO, 2013, p. 36 [2010, p. 176-177].

${ }^{89}$ Cf. FISCHER-LESCANO, 2013, p. 36 [2010, p. 177]. Ver também TEUBNER, Gunther. Fragmented foundations. In: DOBNER P.; LOUGHLIN, M. (Ed.). The twilight of constitutional law. Oxford: Hart, 2010. p. 327-341.

${ }^{90}$ FISCHER-LESCANO, 2013, p. 36 [2010, p. 177].

${ }_{91}$ Cf. FISCHER-LESCANO, 2013, p. 36 [2010, p. 177].

${ }^{92}$ Cf. FISCHER-LESCANO, 2013, p. 36 [2010, p. 177]. Na concepção de Adorno: "O comportamento mimético, posição perante a realidade aquém da oposição fixa de sujeito e objeto, é, graças à arte, órgão da mimese desde o tabu mimético, açambarcado pela aparência e, complementarmente à autonomia da forma, quase seu suporte. [...] se o comportamento mimético não imita alguma coisa, mas se faz semelhante a si mesmo, as obras de arte tomam a seu cargo o seu cumprimento. Na expressão, não imitam as emoções de indivíduos humanos, e sobretudo não as dos seus autores; ao definirem-se essencialmente deste modo são vítimas, justamente enquanto cópias, da objectivação, contra a qual resiste o impulso mimético. Na expressão artística, leva-se simultaneamente a cabo o juízo histórico sobre a mimese enquanto comportamento arcaico: a saber, praticada imediatamente, ela não é um conhecimento; o que se faz semelhante não se torna semelhante; a intervenção da malsucedida - tudo isso a exila para a arte que se comporta mimeticamente, da mesma maneira que ela absorve na objectivação desse impulso a crítica que lhe é feita. [Tradução nossa]".

No original: "Die mimetische Verhaltensweise, eine Stellung zur Realität diesseits der fixen Gegenübersetzung von Subjekt und Objekt, wird durch die Kunst, das Organ der Mimesis seit dem mimetischen Tabu, vom Schein ergriffen und, komplementär zur Autonomie der Form, geradezu dessen Träger. [...] Ahmt das mimetische Verhalten nicht etwas nach, sondern macht sich selbst gleich, so nehmen die Kunstwerke es auf sich, eben das zu vollziehen. Nicht imitieren sie im Ausdruck einzelmenschliche Regungen, vollends nicht die ihrer Autoren; wo sie dadurch wesentlich sich bestimmen, verfallen sie als Abbilder eben der Vergegenständlichung, gegen die der mimetische Impuls sich sträubt. Zugleich vollstreckt sich im künstlerischen Ausdruck das geschichtliche Urteil über Mimesis als ein archaisches Verhalten: daß diese, unmittelbar praktiziert, keine Erkenntnis ist; daß, was sich gleichmacht, nicht gleich wird; daß der Eingriff durch Mimesis mißlang - das verbannt sie ebenso in die Kunst, die mimetisch sich verhält, wie diese in der Objektivation jenes Impulses die Kritik an ihm absorbiert." (ADORNO, T. W. Teoria estética. Lisboa: Edições 70, 1982. p. 130-131 [Ästhetische Theorie. In: furt am Main: Suhrkamp, 1984, 7. p. 169-170]).

${ }_{93}$ FISCHER-LESCANO, 2013, p. 36 [2010, p. 177]. Nesse ponto, Fischer-Lescano cita diretamente Adorno no trecho final, cf. a versão original: "In ihr stellt das Subjekt, auf wechselnden Stufen seiner Autonomie, sich zu seinem Anderen, davon getrennt und doch nicht durchaus getrennt" (ADORNO, 1982, p. $68[1984,7$, p. 86]).

${ }_{94}$ ADORNO, 1982, p. $68[1984,7$, p. 86].
} 
uma forma de reação interna à imanência reificada dos sistemas sociais fetichizados por suas próprias racionalidades.

Ao retirar a exclusividade da estética para a prática da resistência, a teoria crítica dos sistemas assegura essa possibilidade a todas as esferas sociais normativas, "preservando espaços de liberdade e espontaneidade e garantindo que prevaleçam sempre noções democráticas de organizações, instituições, grupos e redes sociais". ${ }^{95}$ Esse é o teor crítico-emancipatório da teoria, a resposta normativa da sociedade à hipertrofia de determinadas formas de racionalidades sistêmicas. Isso, ao mesmo tempo, representa a possibilidade de desreificação do sistema jurídico a partir da ideia de justiça, que dá ao sistema uma abertura ecológica, impelindo-o à transcendência e à constante dinâmica inovativa de suas próprias estruturas.

O direito, na teoria crítica dos sistemas, na forma de direito mimético, reage contra si (em face de sua própria racionalidade irracional) em favor de uma justiça autossubversiva (ecológica) e em oposição às tendências patológicas da sociedade mundial, lesivas aos espaços sociais de liberdade e às esferas espontâneas, buscando o auxílio da autolimitação dos sistemas sociais a partir dos constantes processos sociais de constitucionalização.

\section{CONCLUSÃO}

No âmbito jurídico, uma justiça que se autossubverte seria o ponto central da crítica imanente do direito. O sistema jurídico, quando reificado por sua própria imanência, torna-se autista e por isso cego ao ambiente, refletindo unicamente sua própria racionalidade universalizante, ou seja, sua própria "racionalidade irracional", na fórmula adorniana. $\mathrm{O}$ imperialismo da racionalidade jurídica cria novas formas de injustiças, as quais podem ser combatidas apenas pelo elemento transcendente do sistema jurídico: a justiça autossubversiva. A justiça autossubversiva é "a justiça do outro" (Lévinas/Derrida), da alteridade, do ambiente, que quebra o encanto do fechamento sistêmico e permite ao sistema trans- cender os limites internos de sua racionalidade. Trata-se aqui da justiça ecológica, tão próxima da problemática dos direitos fundamentais no sentido amplo descrito por Teubner em sua crítica às matrizes da sociedade global.

A crítica imanente do direito representa a libertação de seu "arcano" interno, capaz de identificar as discrepâncias internas do sistema e seus paradoxos, ou seja, não se trata mais de uma mera atitude conformista de um sistema jurídico sem "justiciabilidade"; agora é adicionado no sistema jurídico o "olhar maligno" e o ímpeto crítico-emancipatório diante do status quo, mediante a justiça autossubversiva.

$\mathrm{Na}$ teoria crítica dos sistemas o direito deixa de ser apenas o sistema imunológico da sociedade e passa a atuar como instrumento de práxis revolucionária (justiça autossubversiva), como apontado por Brunkhorst. Nesse sentido, os processos sociais de constitucionalização e a preservação dos espaços sociais de liberdade, tais como as esferas espontâneas, surgem como demandas essenciais que requerem o apoio do sistema jurídico.

Em suma, o principal escopo da teoria crítica dos sistemas é a "regeneração das relações autônomas da sociedade mundial". Nesse sentido, o papel desempenhado pelo sistema jurídico está em auxiliar na democratização dos sistemas sociais e na garantia da responsividade do sistema jurídico, de um modo terapêutico (Wiethölter). Como destacado por Fischer-Lescano, essa regeneração das "relações autônomas da sociedade mundial" só pode aperfeiçoar-se com os crescentes processos de constitucionalização das esferas sociais em conjunto com uma justiça autossubversiva, frutos de um sistema jurídico mais responsivo e com capacidade de transcendência. Formulando com o auxílio de um conceito adorniano, o direito concebido pela teoria crítica dos sistemas é um direito mimético que reage em face da imanência reificada e da fetichização provocada pela hipertrofia de sua racionalidade específica - assim, o direito na teoria crítica dos sistemas é um direito mais sensível ao ambiente, que dele se reaproxima através de um novo cará-

${ }^{95}$ FISCHER-LESCANO, 2013, p. 37 [2010, p. 177]. 
ter responsivo (ecológico).

\section{REFERÊNCIAS}

ADORNO, T. W. Ästhetische Theorie. In:

Gesammelte Schriften. Band 7. Frankfurt am Main: Suhrkamp, 1984, 7. [Versão em português: ADORNO, T. W. Teoria estética. Lisboa: Edições 70, 1982].

.Kritik. In: Gesammelte Schriften. Band 10. Frankfurt am Main: Suhrkamp, 1984. p. $785-793.10$

- Philosophie der neuen Musik. In: . Gesammelte Schriften. Band 12. Frankfurt am Main: Suhrkamp, 1984. 12

Hegel: three studies. Cambridge: MIT, 1993. [ADORNO, T. W. Drei Studien zu Hegel. In: . Gesammelte Schriften. Band 5. Frankfurt am Main: Suhrkamp, 1984. 5]

Introdução à sociologia. São Paulo: UNESP, 2007.

Minima Moralia: reflexões a partir da vida lesada. Rio de Janeiro: Azougue, 2008. [ADORNO, T. W. Minima Moralia: Reflexionen aus dem beschädigten Leben. In: . Gesammelte Schriften. Band 4. Frankfurt am Main: Suhrkamp, 1984. 4]

Dialética Negativa. Rio de Janeiro: Zahar, 2009. [ADORNO, T. W. Negative Dialektik. In: Gesammelte Schriften. Band 6. Frankfurt am Main: Suhrkamp, 1984. 6] Versão alternativa: ADORNO, T. W. Negative Dialektik. Frankfurt am Main: Suhrkamp, 1975.

; HORKHEIMER, M. La sociedad: lecciones de sociología. Buenos Aires: Proteo, 1969.

AMATO, Lucas F. Constitucionalização Corporativa: direitos humanos fundamentais, economia e empresa. Curitiba: Juruá, 2014.

BACHUR, João Paulo. Inclusão e exclusão na teoria dos sistemas sociais: um balanço crítico.
BIB. São Paulo, n. 73 , p. $55-83,1^{\circ}$ semestre de 2012.

BACKER, Larry Catá. The structure of global law: fracture, fluidity, permeability and polycentricity. CPE Working Papers, n. 2012-7, Carlisle, Penn State Law, Research Paper n. 15, p. 102122, 2012.

BRUNKHORST, H. Solidarity: from civic friendship to a global level community. Cambridge: MIT Press, 2005.

Ilusões de factibilidade, declarações festivas e cantorias: sobre a relação entre evolução e revolução no Direito. Civitas. Porto Alegre, v. 9, n. 3, p. 440-458, 2009.

. Democracy under pressure: the return of the Dialectics of Enlightenment in the world society. Civitas. Porto Alegre, v. 10, n. 1, p. 153171, jan.-abr. 2010.

Rumo a uma nova ordem global: vinte anos após 1989 e além. RBCS, v. 26, n. 77, p. 2530 outubro 2011.

BUCKEL, Sonja . Zwischen Schutz und Maskerade: Kritik(en) des Rechts. Informationsbrief \# 102, Aufgabe 102, p. 11-23, august 2009. Rav Infobrief.

; FISCHER-LESCANO, Andreas. Reconsiderando Gramsci: hegemonia no direito global. Revista Direito GV, São Paulo, 5(2), p. 471-490, jul.-dez. 2009.

CAMPILONGO, Celso F. O direito na sociedade complexa. São Paulo: Max Limonad, 2000.

CÍCERO, Marcus Tullius. De Officiis. Translated by Walter Miller. Loeb edn. Cambridge: Harvard University Press, 1913.

DERRIDA, Jacques. Força de Lei: o fundamento místico da autoridade. São Paulo: Martins Fontes, 2007. 
ELMAUER, Douglas. O Direito na teoria crítica dos sistemas: da justiça autossubversiva à crítica imanente do direito. 2015. 316f. Dissertação (Mestrado em Direito) - Departamento de Filosofia e Teoria Geral do Direito da Faculdade de Direito da Universidade de São Paulo. São Paulo, SP, 2015.

FISCHER-LESCANO, Andreas. Ex facto ius oritur: procesos de escándalo y el Derecho Mundial emergente. DOXA - Cadernos de Filosofia del Derecho, v. 30. p. 435-450, 2007.

Systemtheorie als kritische Gesellschaftstheorie. In: AMSTUTZ, M.; FISCHER-LESCANO, A. (hrsg.). Kritische Systemtheorie: Zur Evolution einer normativen Theorie. Bielefeld: Transcript Verlag, 2013. p. 13-37. [Versão em português: FISCHER-LESCANO, Andreas. A teoria crítica dos sistemas da Escola de Frankfurt. Revista Novos Estudos, São Paulo, v. 86, p. 163-177, março 2010].

; TEUBNER, Gunther. Colisões de regimes - a busca vã por unidade jurídica na fragmentação do direito global. Revista Brasileira de Estudos Constitucionais - RBEC. Belo Horizonte, ano 6, n. 21, p.105-155, jan./mar. 2012. [Versão em inglês: TEUBNER; FISCHER-LESCANO. Regimme-collision. The vain search for legal unity in the fragmentation of global law. Michigan Journal of International Law. Michigan, v. 25, 2004].

FOUCAULT, Michel. O que é a crítica? 1978. p. 1-29. Disponível em: <www.filoesco.unb.br/foucault $>$. Acesso em: 12 jan. 2011.

FROMM, Erich. The sane society. London: Routledge, 2008.

GUERRA FILHO, Willis Santiago. Luhmann and Derrida: Immunology and Autopoiesis. In: LA COUR, Anders; PHILIPPOPOULOS-MIHALOPOULOS, Andreas. (Org.). Luhmann Observed: Radical Theoretical Encounters. Londres, 2013. p. 227-242.
HABERMAS, Jürgen. Teoría de la accion comunicativa. Buenos Aires: Taurus, 1999. 2. v.

HONNETH, Axel. Pathologies of reason: on the legacy of critical theory. New York: Columbia University Press, 2009.

HORKHEIMER, Max. Teoría tradicional y teoría crítica. In: (Org.). Teoría crítica. Buenos Aires: Amorrortu, 2003.

KJÆR, Poul. Law and Order within and Beyond National Configurations. 2010. Disponível em: <papers.ssrn.com/sol3/papers.cfm?abstract_ $\mathrm{id}=1687013>$. Acesso em: 12 jan. 2013.

LUHMANN, N. Die Weltgesellschaft. Soziologische Aufklärung 2: Aufsätze zur Theorie der Gesellschaft. Opladen:Westdeutscher Verlag, p. 51-71, 1975.

.Evolution und Geschichte.Soziologische Aufklärung 2: Aufsätze zur Theorie der Gesellschaft. Opladen: Westdeutscher Verlag, p. 150-69, 1976.

Ausdifferenzierung des Rechts: Beiträge zur Rechtssoziologie und Rechtstheorie. Frankfurt: Suhrkamp, 1981.

- Sociologia do direito. Rio de Janeiro: Tempo Brasileiro, 1983. 2. v.

Das Recht der Gesellschaft. Suhrkamp: Frankfurt am Main, 1993.

Inklusion und Exklusion. Soziologische Aufklärung 6: Die Soziologie und der Menschen. Opladen: Westdeutscher Verlag, p. 237-264, 1994.

Jenseits von Barbarei. Gesellschaftsstruktur und Semantik. Studien zur Wissenssoziologie der modernen Gesellschaft. Frankfurt: Suhrkamp, v. 4, p. 138-150, 1995.

Inclusion y exclusion. Complejidad y Modernidad: de la unidad a la diferencia. Madri: Trotta. 1998. p. 167-195. 
Die Politik der Gesellschaft. Frankfurt am Main: Suhrkamp, 2000.

El derecho de la sociedad. Ciudad de México: Herder, 2005.

La sociedad de la sociedad. Ciudad de México: Herder, 2007.

Los derechos fundamentales como institución. México D.F.: Iteso/Universidad Iberoamericana, 2010.

MARX, K. (1973) El Capital: crítica de la economía política. México: Fondo de Cultura Económica, $1973.3 \mathrm{v}$.

MENKE, Christoph.Subjektive Rechte: Zur Paradoxie der Form. Zeitschrift für Rechtssoziologie, Berlin, v. 29, 2008.

NEVES, Marcelo. "Pesquisa interdisciplinar no Brasil: o paradoxo da interdisciplinariedade." In: Crítica à dogmática: dos bancos acadêmicos à prática dos tribunais. Porto Alegre: Instituto de hermenêutica Jurídica, 2005. p. 207-214.

Transconstitucionalismo. [Tese apresentada ao concurso de provas e títulos para provimento do cargo de Professor Titular na área de direito constitucional, junto ao Departamento de Direito do Estado da Faculdade de Direito da Universidade de São Paulo]. São Paulo, 2009.

. Niklas Luhmann: Eu vejo o que tu não vês. In: ALMEIDA, Jorge de; BADER, Wolfgang (Org.). Pensamento alemão no século XX: grandes protagonistas e recepção da obra no Brasil. São Paulo: Cosac Naify; Instituto Goethe de São Paulo, 2013. p. 257-273.

PASCHUKANIS, Evgeni. A teoria geral do direito e o marxismo. Coimbra: Centelha, 1977.

PHILIPPOPOULOS-MIHALOPOULOS, Andreas. Critical autopoiesis and the materiality of Law. International Journal for Semiotics of Law. Berlin, Springer Science, p. 1-19, 2013.
SANTOS, Boaventura Sousa. Por que é tão difícil construir uma teoria crítica? Revista crítica das ciências sociais, Coimbra, n. 54, jun. 1999.

SCIULLI, David. Theory of societal constitutionalism: fundations of a non-marxist critical theory. New York: Cambridge University Press, 1992.

STICHWEH, Rudolf. Inklusion/Exklusion, funktionale Differenzierung und die Theorie der Weltgesellschaft. Soziale Systeme, Stuttgart, (1997) Heft 3. p. 123-136.

On the genesis of world society: innovations and mechanisms. 2000. Disponível em: <http://www.uni-bielefeld.de/(en)/soz/iw/pdf/ stichweh_2.pdf $>$. Acesso em: 20 ago. 2012.

TEUBNER, Gunther. A Bukowina Global sobre a emergência de um pluralismo jurídico transnacional. Impulso, Piracicaba, v. 14, n. 33, p. 9-31, 2003.

. Regimes privados: direito neoespontâneo e constituições dualistas na sociedade mundial. In: RÜDIGER, Dorothee; MENDES, Rodrigo (Org.). Direito, sistema e policontexturalidade. Piracicaba: Unimep, 2005a.

La constitucionalización de la sociedad global. In: Carlos Gómez-Jara Díez (Ed.) El derecho como sistema autopoiético de la sociedad global. Lima: ARA Editores, 2005b. p. 69-111.

. Dealing with paradoxes of law: Derrida, Luhmann, Wiethölter. In: ; PEREZ, O. Paradoxes and inconsistencies in the law. Portland: Hart Publishing, 2006a. p. 41-64.

The anonymous matrix: human rights violations by 'private' transnational actors. The Modern Law Review. Malden, vol. 69, n. 3, p. 327-346, $2006 \mathrm{~b}$.

. Die Erblast. Zeitschrift für Rechtssoziologie, Stuttgart, 29, Heft 1, 2008, p. 3-7.

Self-subversive justice: contingency or 
transcendence formula of Law? 2009. p. 1-22. Disponível em: <www.uni-frankfurt.de/>. Acesso em: 20 out. 2010. [Versão em português: TEUBNER, Gunther. Justiça autosubversiva: fórmula de contingência ou de transcendência do Direito? Revista Eletrônica do Curso de Direito - PUC Minas Serro [Online], 0.4, 17-54, 2011b.].

. Fragmented foundations. In: DOBNER P.; LOUGHLIN, M. (Ed.) The twilight of constitutional law. Oxford: Hart, 2010. p. 327-341.

A constitutional moment? The logics of 'hitting bottom'. In: KJÆR, Poul, TEUBNER, Gunther, FEBBRAJO, Alberto (Ed.). Financial crisis in constitutional perspective: the dark side of functional differentiation. Oxford: Hart, 2011a. p. 9-51.

. Constitutional fragments: societal constitutionalism and globalization. Oxford: Oxford University Press, 2012.

The Project of Constitutional Sociology Transnational Legal Theory, Cambridige, 4, p. 44-58, 2013.

; GRABER, Christoph B. Art and money: constitutional rights in the private sphere? Oxford Journal of Legal Studies. Oxford, v. 18, n. 1, p. 61-73, 1998.

VILLAS BÔAS FILHO, Orlando. Da ilusão à fórmula de contingência: a justiça em Hans Kelsen e Niklas Luhmann. In: PISSARA, Maria Constança Peres; FABBRINI, Ricardo Nascimento (Coord.). Direito e filosofia: a noção de justiça na história da filosofia. São Paulo: Atlas, 2007. p. 129-150.

WIETHÖLTER, Rudolf. Zum Fortbildungsrecht der (richterlichen) Rechtsfortbildung: Fragen eines lesenden Recht-Fertigungslehrers". 3 Kritische Vierteljahreszeitschrift für Gesetzgebung und Rechtswissenschaft, Baden-Baden, p. 1-28, 1988.

Just-ifications of a Law of Society. In:

PEREZ, Oren; TEUBNER, Gunther (Ed.). $\mathrm{Pa}$ - radoxes and inconsistencies in the law. Oxford: Hart, 2005. p. 65-77.

ŽIŽEK, Slavoj. Unsere Trägheit ist die größte Gefahr“. Der Spiegel, Heft 12, 14. p. 130-134, März 2015.

ZUMBANSEN, Peer. Transnational law. In: SMITS, Jan (Ed.). Encyclopedia of comparative law. Northampton: Edward Elgar Publishing, 2006. p. $738-754$. 


\title{
DIREITOS HUMANOS E SISTEMA ECONÔMICO:
}

\author{
ESTRUTURA E SEMÂNTICA DE UM \\ FRAGMENTO CONSTITUCIONAL GLOBAL ${ }^{\mathrm{i}}$
}

Lucas Fucci Amato

Sumário: 1 Introdução. 2 A (trans)constitucionalização do sistema econômico. 3 As estruturas do "fragmento constitucional" do sistema econômico: mercado como esfera pública? 4 A semântica do "fragmento constitucional" do sistema econômico: sustentabilidade e governança. 5 Conclusão: o problema da legitimidade. Referências.

\begin{abstract}
Resumo
Partindo do referencial da teoria dos sistemas, estudos de sociologia da constituição têm discutido as perspectivas do constitucionalismo na sociedade mundial. Os direitos fundamentais, instituição típica das constituições nacionais, não apenas galgam o plano do direito internacional na forma de direitos humanos, mas também se reproduzem em ordens privadas, à margem do Estado e do sistema político. A economia, como um sistema funcional global que reproduz sobretudo expectativas cognitivas, é o foco principal desse constitucionalismo mundial. Criticando a tese dos fragmentos constitucionais globais de Gunther Teubner, este artigo mostra que as es-
\end{abstract}




\subsection{TEORIA DOS SISTEMAS}

truturas jurídicas envolvidas na conformação da constitucionalização privada da economia precisariam enfrentar o desafio de institucionalizar reivindicações de direitos apenas pelo mercado, sem depender do apelo à opinião pública (esfera pública da política). A semântica desse constitucionalismo mundial econômico - os discursos da governança e da sustentabilidade - parece insuficiente para, conjugada ao mercado, garantir legitimidade a essas pretensas constituições privadas.

Palavras-chave: Sociologia da constituição. Sociedade mundial. Sistema econômico. Gunther Teubner.

\section{Abstract}

Starting with references to systems theory, studies on the sociology of constitutions have been discussing the perspectives of constitutionalism in the world society. Fundamental rights, a typical institution of national constitutions, not only reach international law as human rights, but also are reproduced in private orders, outside the State and the political system. Economy, as a global functional system that reproduces mainly cognitive expectations, is the main focus of this global constitutionalism. By criticizing Gunther Teubner thesis on the global constitutional fragments, this paper shows that the legal structures involved in the conformation of the private constitutionalization of economy need to face the challenge to institutionalize rights claims only through the market, without dependence on the appeal to public opinion (the public sphere of politics). The semantics of this world economic constitutionalism - the discourses on governance and sustainability - seems insufficient to, alongside the market, ensure legitimacy to these alleged private constitutions.

Keywords: Sociology of constitution. World society. Economic system. Gunther Teubner.

\section{INTRODUÇÃO}

$\mathrm{D}$ iversas ordens jurídicas estão envolvidas no tratamento de um problema constitucional da sociedade mundial: as violações de direitos humanos por parte de empresas. Nas ordens nacionais e internacionais, há possibilidades de tratá-las a partir da eficácia privada dos direitos fundamentais, mas marcos normativos específicos vêm sendo desenhados por instituições como ONU, OIT, União Europeia, UNCTAD e OCDE. Já nas ordens jurídicas privadas (notadamente transnacionais), tal tema é expresso em diretrizes de ética empresarial, códigos de conduta e declarações de responsabilidade social corporativa. O objetivo do artigo é analisar o processo de vinculação de empresas a direitos humanos, vislumbrando o alcance e as limitações das mudanças semânticas e estruturais em que tal processo se insere ${ }^{1}$.

Após um breve panorama das ordens jurídicas envolvidas nesse problema "transconstitucional", o trabalho parte para analisar duas questões que são realçadas quando se analisa a tese ou hipótese de Teubner ${ }^{2}$ de que o próprio sistema econômico e suas organizações estariam se "autoconstitucionalizando", à margem do sistema político e do Estado. Do ponto de vista das estruturas, o problema analisado diz respeito ao potencial do mercado para sustentar uma "esfera pública" tão complexa e adequada quanto a esfera pública político-democrática. Do ponto de vista da semântica diante da qual ganha sentido tal discurso de constitucionalismo econômico para além do Estado, faz-se breve referência às noções de governança e sustentabilidade. Na interseção entre semânticas e estruturas, surge o problema da legitimidade postulada pelas "constituições" que as empresas e o sistema econômico estariam desenvolvendo para lidar com dois temas típicos das constituições nacionais: o controle do poder e a garantia dos direitos.

\footnotetext{
' Para mais detalhes, ver AMATO, Lucas Fucci. Constitucionalização corporativa: direitos humanos fundamentais, economia e empresa. Curitiba: Juruá, 2014.

${ }^{2}$ TEUBNER, Gunther. Constitutional fragments: societal constitutionalism and globalization. Oxford: Oxford University Press, 2012.
} 


\section{A (TRANS)CONSTITUCIONALIZAÇÃO DO SISTEMA ECONÔMICO}

Em complementação, colaboração, concorrência ou conflito aberto ou velado com a ordem estatal-nacional surgem múltiplas regulações nos planos internacional, supranacional e transnacional. Enquanto o plano internacional permanece basicamente interestatal, o exemplo de ordem supranacional é a União Europeia, cujas normas já têm aplicabilidade direta aos cidadãos dos Estados-membros. Já as ordens transnacionais ou setoriais obedecem antes a uma diferenciação funcional do que a uma segmentação territorial: em outros termos, são ordens produzidas a partir de organizações especializadas que integram sistemas funcionais globais, como a economia e os meios de comunicação de massa. Essas ordens são privadas ou quase-públicas, como aquelas formadas por ONGs transnacionais.

Mas em que medida tal pluralismo jurídico ganha caráter "constitucional"? Embora não caiba indicar a existência de constituições nesses diversos níveis, muito menos em um plano supranacional global - pois o conceito de constituição tem uma localização histórica e uma função social determinada em referência a essa realidade espacial e temporal específica -, os problemas constitucionais (controle do poder e direitos humanos) permeiam todos esses planos. É o que propõe a teoria do "transconstitucionalismo" de Marcelo Neves ${ }^{3}$. No campo dos direitos humanos, é especialmente notável sua inserção, para além do direito internacional (ONU e sistemas regionais de direitos humanos), em autorregulações de corporações transnacionais e de organizações não governamentais.

No âmbito das constituições nacionais, ganha destaque o debate acerca da eficácia privada dos direitos fundamentais (ou vinculação de privados, ou efeitos diante de terceiros - Drittwirkung $)^{4}$. Contudo, a liderança na tematização das violações de direitos humanos por empresas localiza-se no direito internacional. As iniciativas de regulação internacional das corporações transnacionais remontam à década de 1970, no contexto da descolonização, em grande medida por pressão dos novos Estados que surgiam e que haviam sofrido violações de direitos humanos perpetradas com o envolvimento daqueles atores, em regra com sede nos países do Norte. Esse contexto foi refletido na Resolução 3201 (S-VI) da Assembleia Geral da ONU, de 1974, "sobre o estabelecimento de uma Nova Ordem Econômica Internacional". Antes mesmo daquela década, a atividade corporativa já fora tangenciada por diversas resoluções da Assembleia Geral da ONU que afirmaram a soberania dos Estados sobre os recursos naturais de seus territórios. No mesmo ano de 1974, porém, a ONU criou o Centre on Transnational Corporations (UNCTC), seguindo o relatório de um grupo criado pela Resolução 1721 do Conselho Econômico e Social para estudar o impacto das corporações no desenvolvimento e nas relações internacionais. Fora expressiva uma manifestação do representante do Chile na ONU, em 1972, sobre a interferência da corporação americana ITT no processo que culminaria com a deposição de Allende no ano seguinte. Outro episódio marcante na regulação internacional das corporações deu-se em 1981, com a adoção, pela Assembleia Mundial da Saúde, de um Código Internacional de Comercialização de Substitutos do Leite Materno, após protestos sobre a produção e publicidade desses produtos (fórmula infantil) pela Nestlé .

Por diversas vezes foram produzidas no âmbito da ONU propostas de instrumentos vinculatórios às corporações, esboços que não tiveram sucesso - enquanto os países do "primeiro mundo" defendiam como foco principal do Código de Conduta para Corporações Transnacionais a proteção ao investimento estrangeiro direto, os países do "terceiro mundo" entendiam que o Código deveria vincular apenas as corporações, para não interferir em sua soberania, enquanto

\footnotetext{
${ }^{3}$ NEVES, Marcelo. Transconstitucionalismo. São Paulo: WMF Martins Fontes, 2009.

${ }^{4}$ GRABER, Christoph Beat; TEUBNER, Gunther. Art and money: constitutional rights in the private sphere? Oxford Journal of Legal Studies, Oxford, v. 18, n. 1, 1998. p. 69-79.

${ }^{5}$ ČERNIČ, Jernej Letnar. Human rights law and business: corporate responsibility for fundamental human rights. Groningen: Europa Law, 2010. p. 183; JÄGERS, Nicola M. C. P. Corporate human rights obligations: in search of accountability. Antwerpen: Intersentia, 2002. p. 119-121.
} 


\subsection{TEORIA DOS SISTEMAS}

os países socialistas defendiam que seu sistema socioeconômico já controlava suficientemente as atividades corporativas, pelo que o Código seria uma interferência indevida ${ }^{6}$. As negociações sobre o Código de Conduta foram abortadas em 1992 e, no ano seguinte, o Centro para Corporações Transnacionais foi transformado em uma agência subordinada à Conferência das Nações Unidas sobre Comércio e Desenvolvimento (UNCTAD). Outras iniciativas continuaram no âmbito da ONU, como o estabelecimento, pela Subcomissão sobre a Promoção e Proteção dos Direitos Humanos, de uma subcomissão para examinar as corporações transnacionais, o que culminou em um Esboço de Diretrizes de Direitos Humanos para as Corporações, em $2000^{7}$.

Em 2003, a Subcomissão da ONU sobre Promoção e Proteção dos Direitos Humanos aprovou as Normas da ONU sobre Responsabilidades das Corporações Transnacionais e Outras Empresas com Relação a Direitos Humanos, que se mantêm como referência, isto é, como proposta de regulação (draft proposal). As Normas, de caráter não vinculante, cobrem diversos campos do direito (internacional criminal e humanitário, direitos humanos civis, políticos, sociais, econômicos e culturais, direito do consumidor e do meio ambiente) e aplicam-se não só às corporações multinacionais, como também a seus fornecedores, subcontratados, licenciados, distribuidores e demais parceiros de negócio (seção 21 das Normas). As Normas deslocam-se do campo da autorregulação, por si só das corporações, impondo ora obrigações, como as relacionadas à transparência da implementação de suas diretrizes, ora encorajando condutas por meio de recomendações, como a de as corporações "aplicarem e incorporarem normas [nessa temática, seguindo as Normas da ONU] nos seus contratos com parceiros de negócio e assegurarem que só fazem negócios com quem segue padrões similares aos das Normas" (seção 15), o que ampliaria enormemente o enforcement das Normas, integrando-as a disputas contratuais judiciais e arbitrais $^{8}$.
De outro lado, em 2005 foi nomeado um Representante Especial do Secretário-Geral da ONU para o tema dos Direitos Humanos e Corporações Transnacionais e Outras Empresas, que veio a ser John Ruggie. Com essa iniciativa, a crítica de Ruggie às Normas de 2003 e a apresentação, por parte deste professor de Harvard, de um marco regulatório (conhecido como Marco Ruggie ou Marco "Proteger, Respeitar e Reparar [remedy]"), as Normas foram praticamente substituídas pelas iniciativas do mandato de Ruggie. Em junho de 2011, o Conselho de Direitos Humanos da ONU endossou os princípios propostos por Ruggie (Guiding Principles on Business and Human Rights: Implementing the United $\mathrm{Na}$ tions 'Protect, Respect and Remedy' Framework).

Ainda na ordem internacional, destacam-se iniciativas da Organização Internacional do Trabalho (OIT) e da Organização para a Cooperação e Desenvolvimento Econômico (OCDE). Em 2000, a OCDE criou as Linhas Diretrizes para Empresas Multinacionais, como parte da Declaração sobre Investimento Internacional e Empresas Multinacionais. No âmbito da OIT, a Declaração Tripartite de Princípios sobre Empresas Multinacionais e Política Social (adotada em 1977 e revisada em 2000), de caráter recomendatório, aplica-se a corporações, Estados, empregados e suas organizações, compondo-se de princípios gerais (em vez de direitos específicos) e instando tais sujeitos a contribuírem para a realização da Declaração da OIT sobre os Princípios e Direitos Fundamentais no Trabalho (1998) e a implementarem a Constituição da OIT, as legislações nacionais e os instrumentos internacionais de direitos humanos no âmbito da ONU, notadamente a Declaração Universal dos Direitos Humanos.

Uma ilustração da regulação supranacional europeia em matéria de corporações e direitos humanos pode ser dada por referência ao green paper da Comissão Europeia sobre responsabilidade social corporativa (2001). O paper apresenta algumas considerações especificamente sobre os direitos humanos. Reconhece, por exemplo,

${ }^{6}$ JÄGERS, Nicola M. C. P. Corporate human rights obligations, p. 121-122.

${ }^{7}$ JÄGERS, Nicola M. C. P. Corporate human rights obligations, p. 123-128.

${ }^{8}$ ČERNIČ, Jernej Letnar. Human rights law and business, p. 226. 
que o impacto das atividades das companhias sobre os direitos humanos de seus trabalhadores e comunidades locais vai além dos direitos trabalhistas. Assim, afirma a necessidade de mecanismos efetivos de implementação e fiscalização continuada do cumprimento das obrigações, com ampla abertura de informações da empresa.

Como exemplo de regulação transnacional abrangendo matéria de direitos humanos, vale mencionar as normas técnicas e sistemas de certificação como a SA 8000 (da Social Accountability International), que prevê a vedação do trabalho infantil ou forçado, de discriminação e de práticas disciplinares, a garantia de saúde e segurança no trabalho, de liberdade de associação e negociação coletiva, limites de carga horária de trabalho e suficiência de remuneração. Os direitos humanos também se integram nas ordens jurídicas transnacionais por meio de códigos de ética, diretrizes de responsabilidade social corporativa e conflitos arbitrais. Resta a dúvida, porém, se tais instrumentos jurídicos constituem, eles mesmos, um tipo de "constituição", como propõe Teubner?.

Isso porque a constatação de que há conflitos entre diferentes ordens jurídicas na temática dos direitos humanos não implica uma identificação imediata de constituições isomórficas às nacionais-estatais nas diversas ordens jurídicas $^{10}$ : pense-se na Carta da ONU como constituição do direito internacional ${ }^{11}$ ou nos códigos de conduta ou de ética empresarial como "autoconstitucionalizações" das "autorregulações" de abrangência "corporativa" ou setorial - local, nacional ou transnacional -; na verdade, de âmbito de vigência referido a toda uma organização ou rede de organizações, ligadas societariamente ou não, abrangendo "parceiros" de suas cadeias de suprimento e distribuição, ao longo de uma ou várias cadeias produtivas. Podem esses "equivalentes (proto)constitucionais" ser reconhecidos como constituições, tais como as nacionais? O que isso significa para o sistema jurídico?

\section{AS ESTRUTURAS DO "FRAGMENTO CONSTITUCIONAL" DO SISTEMA ECONÔ- MICO: MERCADO COMO ESFERA PÚBLI- $\mathrm{CA}$ ?}

A defesa de que o sistema econômico e suas organizações estariam desenvolvendo não meras juridificações, mas verdadeiras constituições "civis" está no centro da tese do "constitucionalismo societal", de Teubner ${ }^{12}$. Tal tese remonta à elaboração de Sciull $^{13}$, que propunha como principal mecanismo institucional de expansão de uma racionalidade normativa para além do Estado as "formações colegiais". Esses órgãos implementariam certos padrões de interpretação e realizariam uma "ação voluntarística" nas diversas organizações da sociedade, construindo nelas uma "esfera pública" que moderaria o exercício de poderes e promoveria possibilidades de integração social.

Para Sciulli ${ }^{14}$ :

[...] a mera presença de formações colegiais em qualquer sociedade civil moderna institucionaliza uma específica infraestrutura social que sublinha tanto uma direção não autoritária da mudança social quanto possibilidades para a integração social de atores heterogêneos e grupos concorrentes [Grifos do autor].

Em uma aplicação de sua teoria do constitucionalismo societal à realidade judicial estadunidense, Sciulli ${ }^{15}$ preocupou-se em entender as expectativas do Judiciário e os deveres por este impostos às corporações no que concerne à relação da economia com a sociedade civil. Em outros termos, colocou a questão de em que medida o Judiciário compreende que, para além da geração de emprego e lucro, haveria padrões sociais de conduta a serem seguidos pelas organizações econômicas, não apenas impostos pelo autocontrole da competição (como na tese puramente contratualista), mas também normativamente

\footnotetext{
${ }^{9}$ TEUBNER, Gunther. Constitutional fragments.

${ }^{10}$ NEVES, Marcelo. Transconstitucionalismo, p. 1-6.

${ }^{11}$ FASSBENDER, Bardo. The United Nations Charter as the constitution of the international community. Leiden: Martinus Nijhoff, 2009.

${ }^{12}$ TEUBNER, Gunther. Constitutional fragments.

${ }^{13}$ SCIULLI, David. Theory of societal constitutionalism: foundations of a non-Marxist critical theory. Cambridge, MA: Cambridge University Press, 1992.

${ }^{14}$ SCIULLI, David. Theory of societal constitutionalism, p. 77

${ }^{15}$ SCIULLI, David. Corporate power in civil society: an application of societal constitutionalism. New York: New York University Press, 2001 . p. 1-5.
} 


\subsection{TEORIA DOS SISTEMAS}

executados pela jurisdição. Essa executoriedade pela jurisdição vem defendida como uma "vigilância republicana", contraposta à "complacência liberal" que resulta da crença de que o exercício do poder privado na empresa não poderia colocar em risco a institucionalidade democrática e a sociedade civil (famílias, comunidades, associações voluntárias "intermediárias" entre o indivíduo e o Estado). Tal risco à manutenção de uma ordem social democrática seria de fato uma externalidade institucional derivada do poder corporativo não submetido a restrições normativas (no sentido de restrições à lógica meramente instrumental da competição econômica ${ }^{16}$. No seio das corporações, órgãos ou organizações colegiais - não burocráticos, nem clientelistas nem apenas formalmente democráticos - garantiriam a autocontenção normativa e a aderência a padrões procedimentais por parte de organizações como as empresariais ${ }^{17}$. Assim, o desenho institucional de uma sociedade democrática precisaria estender "mediações normativas de poder" (como obrigações fiduciárias que impeçam o exercício abusivo de poder) para as principais coletividades "intermediárias" da "sociedade civil"18. Isso implicaria tratar a "governança corporativa" como mais do que um mecanismo de proteção de investimentos e investidores, mas também como uma "importante janela no desenho institucional da sociedade civil"19.

Inspirado no estudo de Sciulli ${ }^{20}$, Teubner ${ }^{21}$ buscou desenvolver sua própria observação de um constitucionalismo societal, visto como global e fragmentado. Teubner ${ }^{22}$ procura realizar uma generalização do conceito de constituição para toda a sociedade, partindo da ideia da constituição estatal, mas reespecificando-a para a sociedade civil, ou melhor, para os diversos siste- mas funcionais. Cabe notar este ponto: a (hipó) tese de Teubner $^{23}$ primeiramente se apresenta como uma espécie de isomorfismo entre a constituição estatal (que permanece fundada nacionalmente, i.e. segmentariamente) e as "constituições civis transnacionais" (fundadas na diferenciação funcional de sistemas globais). Permanece aqui a dualidade moderna clássica Estado/sociedade civil. Posteriormente, Teubner ${ }^{24}$ parece ter levado mais a sério a colocação luhmanniana sobre a crise dessa dicotomia para a descrição da sociedade "policontextural" e multiplamente codificada ${ }^{25}$, que não mais se biparte em uma relação autoritária (Estado determinando a sociedade civil) ou democrática simples (sociedade civil constituindo o Estado), mas se multiparte de forma a levar o Estado apenas à posição de centro organizacional de um dos vários sistemas autopoiéticos (a política), que apenas pode irritar os outros e com eles aprender se os reconstruir por dentro de suas próprias (políticas) operações (hetero-observação).

Inicialmente, Teubner ${ }^{26}$ identificava quatro traços caracterizadores do constitucionalismo societal: 1) o acoplamento estrutural entre o direito e um subsistema que não o político (locus da constituição estatal/nacional clássica); 2) uma hierarquização, no respectivo acoplamento (constituição sistêmico-funcional), entre as normas constitucionais (igualadas às normas secundárias no sentido de Hart) e as normas ordinárias em sentido amplo (normas primárias no sentido de Hart); 3) normas secundárias e procedimentos de revisão judicial da constitucionalidade (segundo a constituição do sistema funcional em questão) das normas "ordinárias" do sistema; 4) constituição dual de setores espontâneos e organizados.

\footnotetext{
${ }^{16}$ SCIULLI, David. Corporate power in civil society, p. 8-30.

${ }^{17}$ SCIULLI, David. Corporate power in civil society, p. 6.

${ }^{18}$ SCIULLI, David. Corporate power in civil society, p. 14-25.

${ }^{19}$ SCIULLI, David. Corporate power in civil society, p. 61.

${ }^{20}$ SCIULLI, David. Theory of societal constitutionalism.

${ }^{21}$ TEUBNER, Gunther. Constitutional fragments.

${ }^{22}$ TEUBNER, Gunther. Societal constitutionalism: alternatives to State-centered constitutional theory. In: JOERGES, Christian; SAND, Inger-Johanne; TEUBNER, Gunther (Ed.). Transnational governance and constitutionalism. Oxford: Hart, 2004. p. 19.

${ }^{23}$ TEUBNER, Gunther. Societal constitutionalism, p. 18-28.

${ }^{24}$ TEUBNER, Gunther. Constitutional fragments.

${ }^{25}$ LUHMANN, Niklas. La sociedad de la sociedad. México: Herder, 2007. p. 21-22, 63, 707; LUHMANN. I diritti fondamentali come instituzione. Bari: Dedalo, 2002. p. 62-69; LUHMANN. Sociologia do direito I. Rio de Janeiro: Tempo Brasileiro, 1983. p. 33.

${ }^{26}$ TEUBNER, Gunther. Societal constitutionalism, p. 20-28.
} 
A revisão judicial de contratos comerciais padronizados, de standards privados de due diligence, de normatização [standardisation] por associações privadas, de decisões de cortes arbitrais tanto na esfera nacional quanto na internacional são exemplos de um controle de constitucionalidade de fato do direito não legislado. Ninguém deveria se iludir pelas fórmulas antiquadas de direito privado dos 'bons costumes' e da 'boa-fé', que as cortes ordinárias usam, como pelo fato de que aqui, substantivamente, é a 'ordre public', i.e., o ajuste entre normas 'privadas' e constitucionais, especialmente de direitos humanos, que está sendo decidida. Ainda, um olhar mais próximo mostra que elas estão sendo mensuradas não pela constituição política do Estado, mas por sua própria constituição. ${ }^{27}$

É fundamental a dualidade que Teubner ${ }^{28}$ identifica em cada sistema funcional entre a "esfera profissional-organizada" e a "esfera espontânea” - por exemplo, na economia (empresas/ consumidores), na política (governo/opinião pública), nas artes (artistas/público), no direito (tribunais/cidadãos). Assim é que o sistema pode não só ser “irritado" por seu ambiente, mas também promover sua "autoirritação" por meio dessas distinções internas, subsumíveis a alguns papéis sociais complementares. A partir dessa distinção de esferas é que se pode equacionar a tarefa sempre imperfeita no funcionamento de um sistema de balancear fechamento operacional (vinculável tendencialmente à "esfera profissional-organizada") e abertura cognitiva (vinculável tendencialmente à "esfera espontânea"). Dessa forma, por exemplo, as demandas de consumidores conscientes, por um comportamento socioambientalmente responsável das empresas, reconstroem, em termos do sistema econômico, as exigências ecológicas (no sentido amplo, do ambiente natural e social da economia), colocando uma exigência na forma de demanda à qual as empresas precisam responder com a oferta de produtos e processos sustentáveis. É nesses termos que Teubner ${ }^{29}$ coloca a questão da "politização 'interna' da economia”.

Mas se a democracia abarcada no projeto constitucional dos "fragmentos constitucionais globais" diz respeito à dualidade esfera pública- esfera organizada e se, no sistema econômico, a esfera pública é o mercado (e não a opinião pública, que é o correspondente no sistema político), caberia perguntar sobre o potencial do mercado em estruturar as expectativas e processar o dissenso social.

A partir de Dirk Baecker, Luhmann ${ }^{30}$ define esfera pública "como a reflexão sobre cada fronteira sistêmica interna à sociedade, ou, dito de outra forma, como o ambiente social interno dos subsistemas sociais", o que inclui as organizações e as interações que se processam no marco de determinado sistema funcional, bem como os movimentos sociais. Assim, por exemplo, o mercado seria a esfera pública da economia, o âmbito de reflexão desse sistema, que é centralizado em organizações e interações específicas para as quais o mercado não é senão o ambiente que re-entra o sistema econômico e potencializa sua autoirritação. A opinião pública nada mais seria que o correspondente ao mercado no âmbito político, ou seja, uma expressão interna do ambiente, uma auto-observação do sistema por meio da construção interna reflexiva de sua hetero-observação; assim "internalizado", o ambiente pode apresentar ao sistema postulações pouco estruturadas, que lhe incrementam a complexidade, forçando (irritando) o processamento e a estruturação de novos sentidos pelas organizações e interações que compõem o núcleo duro do sistema funcional. "A esfera pública, assim, é um medium social geral de reflexão que registra a intransponibilidade das fronteiras e, inspirado nisso, o observar das observações" ${ }^{31}$.

Luhmann $^{32}$ registra a historicidade do conceito de esfera pública, cuja gênese se situa no século XVIII, quando o ideário constitucionalista o expressou como "meio de imposição da razão" e "marcado por exigências como a liberdade de opinião, de imprensa, de abolição

\footnotetext{
${ }^{27}$ TEUBNER, Gunther. Societal constitutionalism, p. 24-25.

${ }^{28}$ TEUBNER, Gunther. Constitutional fragments, p. 88-96.

${ }^{29}$ TEUBNER, Gunther. Constitutional fragments, p. 119.

${ }^{30}$ LUHMANN, Niklas. A realidade dos meios de comunicação. São Paulo: Paulus, 2005. p. 168-170.

${ }^{31}$ LUHMANN, Niklas. A realidade dos meios de comunicação, p. 170.

${ }^{32}$ LUHMANN, Niklas. La sociedad de la sociedad, p. 870.
} 


\subsection{TEORIA DOS SISTEMAS}

da censura". Data desse cenário histórico, portanto, a utilização da imprensa para a obtenção de "ressonância pública para as comunicações politicamente ambiciosas", que pretendiam reconstruir avaliativamente diagnósticos (cognitivos) e projetos (normativos) sobre a sociedade em geral, politizando-a. Já que a esfera pública não decide politicamente e está fora do sistema político em seu fechamento institucional, apela-se ao ambiente para que produza irritações passíveis de serem duplicadas no sistema político quando este reflete internamente (sob a menção à opinião pública) sua face "espontânea", "civil". Os meios de comunicação de massa funcionam então na representação, na coagulação e na generalização simbólica das comunicações produzidas flutuantemente por aqueles que ocupam os papéis não organizados nos diversos sistemas funcionais (i.e., os clientes "unidos" no mercado, e não os trabalhadores e organizações econômicas; os cidadãos que conformam a opinião pública, e não os políticos). A opinião pública constitui-se, portanto, pela reflexão de sentidos mais ou menos espontaneamente conformados (pois podem ser produzidos extrainstitucionalmente) neste medium (a própria opinião pública) que promove a abertura cognitiva do sistema político ao seu ambiente.

Do ponto de vista das estruturas da constitucionalização do sistema econômico, a grande questão, portanto, diz respeito aos limites do mercado para estruturar a autoirritação do sistema econômico. Luhmann reduz a "esfera pública" à "opinião pública" e ao "mercado". Dentro da teoria dos sistemas, porém, há autores que concebem a "esfera pública" de modo diferente.

Eu restrinjo o conceito de esfera pública à chamada esfera pública 'informal' ou 'não organizada', localizada no entorno dos sistemas jurídico e político [...], reduzindo o conceito de povo constitucional a uma dimensão procedimental interna do sistema jurídico [...]. A esfera pública é forte quando influencia de maneira abrangente e relevante os procedimentos constitucio- nais; frágil, quando só tiver influência eventual e pouco relevante sobre esses procedimentos, não contribuindo satisfatoriamente para sua heterolegitimação. ${ }^{33}$

Com o conceito de Neves, por exemplo, seria possível pensar uma esfera pública econômica não redutível ao mercado: tal esfera estaria estruturada quando de "um boicote 'público' a determinado produto ou empresa, não atribuível a um determinado sistema funcional ou organizacional" e não direcionado à institucionalidade estatal-constitucional ${ }^{34}$. Mas como institucionalizar essa irritação vinda do ambiente social do próprio sistema econômico?

Reconhecendo ou não que o sistema econômico possa estruturar uma esfera pública para além dos mecanismos de mercado, ressaltam-se os pressupostos deliberativos que a institucionalização da "esfera pública" reclama. Esses pressupostos - sobretudo a ampla inclusão dos potenciais afetados - são realçados pela crítica da "democracia deliberativa" à visão do "pluralismo de grupos organizados", que tende a interpretar os processos políticos democráticos como equivalentes à maximização de interesses buscada por atores racionais no mercado; esse modelo "agregativo" toma as preferências como dados exógenos ao processo político, carecendo de uma ideia de formação pública da vontade ${ }^{35}$.

Young $^{36}$ nota os pressupostos exigidos para a inclusão na deliberação política, inclusão sem a qual o processo decisório tem sua legitimidade corroída. Obstáculos maiores à inclusão deliberativa apresentam-se conforme diferentes graus de privilégio material ou simbólico de indivíduos e grupos e conforme os padrões culturais dominantes sobre a forma e o conteúdo adequados de expressão política, o que inclui desvalorização de propostas que não sejam apresentadas sob certa linguagem e forma de expressão e em nome de dadas filiações institucionais dos representantes. Assim, permanece uma questão em aberto: saber se o sistema econômico poderá construir

\footnotetext{
${ }^{33}$ NEVES, Marcelo. Transconstitucionalismo, p. 96.

${ }^{34}$ NEVES, Marcelo. A constituição e a esfera pública: entre diferenciação sistêmica, inclusão e reconhecimento. In: BENEVIDES, Maria Victoria de Mesquita; BERCOVICI, Gilberto (Org.). Direitos humanos, democracia e república: homenagem a Fábio Konder Comparato. São Paulo: Quartier Latin, 2009. p. 671.

${ }^{35}$ YOUNG, Iris Marion. Inclusion and democracy. Oxford: Oxford University Press, 2000. p. 20-21.

${ }^{36}$ YOUNG, Iris Marion. Inclusion and democracy, p. 36-44.
} 


\subsection{TEORIA DOS SISTEMAS}

uma esfera pública complexa a ponto de (auto) legitimá-lo.

\section{A SEMÂNTICA DO "FRAGMENTO CONS- TITUCIONAL" DO SISTEMA ECONÔMICO: SUSTENTABILIDADE E GOVERNANÇA}

A dimensão de abertura ao ambiente e adequação social da economia e das empresas é o núcleo comum representado nas fórmulas de responsabilidade social, governança e sustentabilidade. No sentido de uma nova forma jurídica que decodifica as irritações produzidas pelo ambiente dos sistemas sociais é que se instala a proposta ou teoria do constitucionalismo societal fragmentado de Teubner. Ao visualizar múltiplas ordens constitucionais (basicamente normas secundárias que "constitucionalizam" não só o sistema político, mas também outros sistemas, com variáveis abrangências dentro de sua lógica setorial), Teubner ergue ${ }^{37}$ a sustentabilidade a um "princípio de justiça requerido em tais normas constitucionais descentralizadamente produzidas". Se originalmente se impôs como princípio limitador do crescimento econômico diante da proteção do meio ambiente em vista das futuras condições de vida, a sustentabilidade não pode, todavia, ser reduzida à interface economia/natureza. E argumenta: precisa antes ser considerada como princípio geral aplicável aos vários regimes (constitucionais) funcionais; "deve ao mesmo tempo incluir não apenas o meio ambiente natural, mas todos os ambientes relevantes. Meio ambiente deve ser entendido aqui no seu sentido mais amplo, como os meios naturais, sociais e humanos dos regimes transnacionais" ${ }^{38}$.

A sustentabilidade específica de cada regime é uma fórmula a demandar do sistema autocontenção, prevenção de "tendências destrutivas" (expansionistas) sobre seu(s) ambiente(s), mas tal função limitativa pode ser incrementada com uma versão mais "intensificada" de sustentabilidade constitucional, abrangendo o suporte e a promoção dos respectivos ambientes por parte de cada sistema constitucionalizado. "A base é sempre a covariação de formas societais de organização e princípios de direito constitucional" 39 . Saltando da "solidariedade orgânica" ainda demandável em condições de divisão do trabalho social (em termos durkheimianos) para a limitação dos efeitos da complexa diferenciação funcional global, com a respectiva demanda por maior sensibilização dos sistemas aos seus ambientes (em termos luhmannianos), Teubner ${ }^{40}$ postula a dupla reflexividade que as constituições produzem (no sistema jurídico e nos outros sistemas que ela acople a este - agora não mais apenas a política), incrementando a irritabilidade dos sistemas funcionais em relação aos seus ambientes sociais, naturais e humanos e colocando-os mais equidistantes em relação à racionalidade discursiva, à escolha racional e à competitividade; a "tarefa genuína" seria "criar as precondições normativas" para a "politização interna" de cada sistema, o que significaria "argumentar e decidir" sobre o "papel" destes na sociedade.

A relativa distância à política internacional e ao direito internacional não preservará o 'direito mundial sem Estado’ de uma repolitização. Muito pelo contrário: justamente a reconstrução de (trans)ações sociais e econômicas como atos jurídicos globais solapa o caráter apolítico do direito global e fornece dessarte o fundamento da sua repolitização. Ela, porém, ocorrerá previsivelmente sob novas formas, pouco conhecidas até agora. Suspeito que o direito mundial não será repolitizado por instituições políticas tradicionais, e.g. de natureza por assim dizer parlamentar, mas justamente pela via daqueles processos nos quais o direito mundial se 'acopla estruturalmente' a discursos altamente especializados, isolado. ${ }^{41}$

Ao lado da sustentabilidade e da responsabilidade social corporativa, a semântica que permeia as estruturas de constitucionalismo transnacional das empresas é aquela da governança. Segundo Teubner, a governança é um discurso do direito mundial que se diferencia:

\footnotetext{
${ }^{37}$ TEUBNER, Gunther. Constitutional fragments, p. 172.

${ }^{38}$ TEUBNER, Gunther. Constitutional fragments, p. 173.

${ }^{39}$ TEUBNER, Gunther. Constitutional fragments, p. 173.

${ }^{40}$ TEUBNER, Gunther. Constitutional fragments, p. 173.

${ }^{41}$ TEUBNER, Gunther. A Bukowina global sobre a emergência de um pluralismo jurídico transnacional. Impulso, Piracicaba, v. 14, n. 33, 2003 . p. 11.
} 


\subsection{TEORIA DOS SISTEMAS}

[...] internamente em 'colégios invisíveis', 'mercados e ramos de negócios invisíveis', 'comunidades profissionais invisíveis' e 'redes sociais invisíveis', estendendo-se por cima de fronteiras territoriais, mas, apesar disso, buscando insistentemente a formação de formas jurídicas autônomas. ${ }^{42}$

Tal semântica apresenta-se, de fato, como um "absolutismo da verdade disciplinar declarada por instituições que pretendem validade universal, um absolutismo da razão especulativa" ${ }^{33}$. As formas jurídicas da governança, empoderadas pelo medium do dinheiro, podem atuar no sentido da privatização da política, do espaço público, do direito - tanto pela tomada de espaço do direito público pelo direito privado, nas ordens estatais, quanto pela geração não estatal de normatividades jurídicas.

\section{CONCLUSÃO: O PROBLEMA DA LEGITI- MIDADE}

A emergência de obrigações de direitos humanos para as empresas e o sistema econômico envolve diversas ordens jurídicas, mas traz as questões mais prementes quando se avalia a hipótese ou tese de que as organizações empresariais e o sistema econômico estariam em condições de estruturar suas próprias "constituições", independentemente do sistema político e do Estado. São várias e permanecem não respondidas as indagações suscitadas na interpretação desse cenário.

O direito constitucional privado autorregulado é capaz de conjugar adequação social e complexidade ou traz apenas juízos arbitrais casuísticos com um reforço ao fechamento autointeressado particularmente do sistema econômico, sem consideração de variáveis ambientais? Nesse caso, nem se trataria de um fechamento operacional adensado, que produza condições para a abertura cognitiva, mas de um bloqueio mesmo a tal abertura.

As constituições transnacionais e os códigos de conduta e de ética das corporações buscam afirmar-se contra a expansividade desdiferen- ciante do Estado, ao mesmo tempo em que, sob o pretexto de autolimitar seus sistemas (organizacionais ou funcionais), na verdade instrumentalizam formas jurídicas para reforçar a expansividade destes? As organizações estariam dispostas a adotar "autoconstituições" que fossem efetivas para terceiros, que incrementassem a própria irritação destas e de seus sistemas funcionais? Em que medida pretende tal direito corporativo constitucional abrir-se a conflitos com outras ordens envolvidas em "problemas constitucionais" como limitação de poderes e direitos fundamentais? Como constituições do sistema funcional da economia (cuja "esfera pública" é o mercado) poderão subordinar-se às irritações da "opinião pública" ("esfera pública" da política, sistema que não participa do acoplamento)? O "poder constituinte" do povo pode ser substituído pelo "ter" constituinte do consumidor, expresso em termos de precificação, oferta e procura? Os colegiados administrativos das corporações constituem-se como verdadeiras e eficientes comunidades de discurso ou "formações colegiais", no sentido de Sciulli? Como se dará a "irritação" pela concretização de direitos humanos diante das corporações, quem serão seus titulares em potencial, quem, por outro lado, não terá "cidadania" diante das empresas?

As regulações transnacionais no sistema econômico parecem ter por amparo, sobretudo, o código deste sistema (as ameaças de retaliação, de perda de reputação e mercado), que tende a se superpor até mesmo aos mecanismos jurídicos autogerados e auto-organizados. O direito transnacional é forte (vinculante juridicamente, com mecanismos jurisdicionais eficazes, como a arbitragem) em um sistema forte (o econômico) para os agentes fortes (as corporações transnacionais). Nessa medida, a suficiência da autolimitação autopoiética é mais um reforço ao expansionismo que se pretende limitar do que o próprio "regime hegemônico"44, por exemplo, do direito internacional econômico (OMC), ainda vinculado a bases (inter)estatais.

\footnotetext{
${ }^{42}$ TEUBNER, Gunther. A Bukowina global sobre a emergência de um pluralismo jurídico transnacional, p. 14.

${ }^{43}$ KOSKENNIEMI, Martti. The politics of international law. Cambridge: Hart, 2011. p. 358.

${ }^{44}$ KOSKENNIEMI, Martti. Hegemonic regimes. In: YOUNG, Margaret A. (Ed.). Regime interaction in international law: facing fragmentation. Cambridge: Cambridge University Press, 2012. p. 305-324.
} 
A constituição, como "acoplamento estrutural" entre política e direito ${ }^{45}$, envolve uma vinculação íntima e procedimental entre as "fórmulas de contingência" desses dois sistemas: legitimidade e justiça ${ }^{46}$. Como as "autoconstituições" do sistema econômico poderiam perseguir sua legitimidade, estando fora do sistema político? Há autores que entendem que a legitimidade das "constituições privadas" estaria baseada na expertise, na reputação e na capacidade de solução de problemas que as organizações privadas altamente especializadas e globalizadas teriam, reconhecidamente ${ }^{47}$.

Mas o discurso da constitucionalização inevitavelmente traz não apenas o isomorfismo estrutural com as constituições nacionais, mas também a herança semântica do constitucionalismo. Por isso, "é improvável que o estatismo democrático vá, nesta ou mesmo na próxima geração, perder sua credibilidade como um sério paradigma para o estudo do direito constitucional" ${ }^{48}$. De outro lado, a pluralidade de experiências institucionais e culturais do constitucionalismo nacional permanece como lastro epistêmico e ideológico, cuja autoridade o transforma em paradigma de todas as experiências de constitucionalismo descentrado do Estado ${ }^{49}$. Em contraponto ao paradigma nacional, pergunta-se: em que medida as constituições para além do Estado podem ser constituições sem um povo procedimentalizado e uma esfera pública democrática?

No juízo de Koskenniemi ${ }^{50}$, a semântica constitucional e a tentativa de isomorfismos estruturais protoconstitucionais não se demonstram $a$ priori preferíveis aos vocabulários da economia, da tecnologia, do socialismo, do nacionalismo, do cristianismo, cada qual com seus especialistas, valores e preferências intrincadas. Assim, corroborando essa constatação, é evidente que, sem um projeto político aberto à deliberação e sem estruturas efetivamente institucionalizadas, o constitucionalismo além do Estado pode ser apenas mais uma nova ideologia.

\section{REFERÊNCIAS}

AMATO, Lucas Fucci. Constitucionalização corporativa: direitos humanos fundamentais, economia e empresa. Curitiba: Juruá, 2014.

ČERNIČ, Jernej Letnar. Human rights law and business: corporate responsibility for fundamental human rights. Groningen: Europa Law, 2010.

FASSBENDER, Bardo. The United Nations Charter as the constitution of the international community. Leiden: Martinus Nijhoff, 2009.

GRABER, Christoph Beat; TEUBNER, Gunther. Art and money: constitutional rights in the private sphere? Oxford Journal of Legal Studies, Oxford, v. 18, n. 1, p. 61-73, 1998.

JÄGERS, Nicola M. C. P. Corporate human rights obligations: in search of accountability. Antwerpen: Intersentia, 2002.

KOSKENNIEMI, Martti. The politics of international law. Cambridge: Hart, 2011.

Hegemonic regimes. In: YOUNG, Margaret A. (Ed.). Regime interaction in international law: facing fragmentation. Cambridge: Cambridge University Press, 2012. p. 305-324.

KUMM, Mattias. The best of times and the worst of times: between constitutional triumphalism and nostalgia. In: DOBNER, Petra; LOUGHLIN, Martin. (Ed.). The twilight of constitutionalism? Oxford: Oxford University Press, 2010. p. 201219.

LUHMANN, Niklas. Sociologia do direito I. Rio

\footnotetext{
${ }^{45}$ LUHMANN, Niklas. La sociedad de la sociedad, p. 620.

${ }^{46}$ LUHMANN, Niklas. La sociedad de la sociedad, p. 371.

${ }^{47}$ PRANDINI, Riccardo. The morphogenesis of constitutionalism. In: DOBNER, Petra; LOUGHLIN, Martin. (Ed.). The twilight of constitutionalism? Oxford: Oxford University Press, 2010. p. 316.

${ }^{48}$ KUMM, Mattias. The best of times and the worst of times: between constitutional triumphalism and nostalgia. In: DOBNER, Petra; LOUGHLIN, Martin. (Ed.). The twilight of constitutionalism? Oxford: Oxford University Press, 2010. p. 219.

${ }^{49}$ WALKER, Neil. Taking constitutionalism beyond the State. Political Studies, London, v. 56, n. 3, 2008. p. 540.

${ }^{50}$ KOSKENNIEMI, Martti. The politics of international law, p. 349.
} 


\subsection{TEORIA DOS SISTEMAS}

de Janeiro: Tempo Brasileiro, 1983.

. I diritti fondamentali come instituzione. Bari: Dedalo, 2002.

A realidade dos meios de comunicação. São Paulo: Paulus, 2005.

. La sociedad de la sociedad. México: Herder, 2007.

NEVES, Marcelo. Transconstitucionalismo. São Paulo: WMF Martins Fontes, 2009a.

A constituição e a esfera pública: entre diferenciação sistêmica, inclusão e reconhecimento. In: BENEVIDES, Maria Victoria de Mesquita; BERCOVICI, Gilberto (Org.). Direitos humanos, democracia e república: homenagem a Fábio Konder Comparato. São Paulo: Quartier Latin, 2009b. p. 653-688.

PRANDINI, Riccardo. The morphogenesis of constitutionalism. In: DOBNER, Petra; LOUGHLIN, Martin. (Ed.). The twilight of constitutionalism? Oxford: Oxford University Press, 2010. p. 309-326.

SCIULLI, David. Theory of societal constitutionalism: foundations of a non-Marxist critical theory. Cambridge: Cambridge University Press, 1992.

Corporate power in civil society: an application of societal constitutionalism. New York: New York University Press, 2001.

TEUBNER, Gunther. A Bukowina global sobre a emergência de um pluralismo jurídico transnacional. Impulso, Piracicaba, v. 14, n. 33, p. 9-31, 2003.

Societal constitutionalism: alternatives to State-centered constitutional theory. In: JOERGES, Christian; SAND, Inger-Johanne; TEUBNER, Gunther (Ed.). Transnational governance and constitutionalism. Oxford: Hart, 2004. p. 3-28.
Constitutional fragments: societal constitutionalism and globalization. Oxford: Oxford University Press, 2012.

WALKER, Neil. Taking constitutionalism beyond the State. Political Studies, London, v. 56, n. 3, p. 519-543, 2008.

YOUNG, Iris Marion. Inclusion and democracy. Oxford: Oxford University Press, 2000. 